\title{
A Guide to the Selection, Training, and Licensing or Certification of Reprocessing Plant Operators
}

\author{
Volume II
}

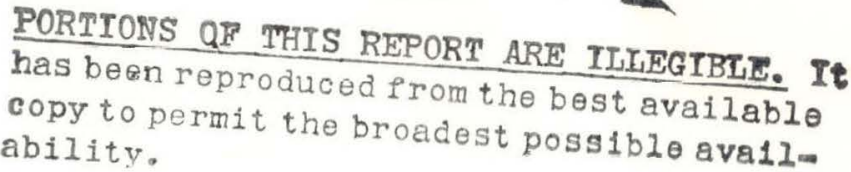

\section{OAK RIDGE NATIONAL LABORATORY}

OPERATED BY UNION CARBIDE IORPORATINN FOR THF FNFRGY RFSFARCH AND DEVELOPMENI AUMINISIKAIIUN 


\section{DISCLAIMER}

This report was prepared as an account of work sponsored by an agency of the United States Government. Neither the United States Government nor any agency Thereof, nor any of their employees, makes any warranty, express or implied, or assumes any legal liability or responsibility for the accuracy, completeness, or usefulness of any information, apparatus, product, or process disclosed, or represents that its use would not infringe privately owned rights. Reference herein to any specific commercial product, process, or service by trade name, trademark, manufacturer, or otherwise does not necessarily constitute or imply its endorsement, recommendation, or favoring by the United States Government or any agency thereof. The views and opinions of authors expressed herein do not necessarily state or reflect those of the United States Government or any agency thereof. 


\section{DISCLAIMER}

Portions of this document may be illegible in electronic image products. Images are produced from the best available original document. 
Printed in the United States of America. Available from

National Technical Information Service

U.S. Department of Commerce

5285 Port Royal Road, Springfield, Virginia 22161

Price: Printed Copy \$9.00; Microfiche $\$ 2.25$

This report was prepared as an account of work sponsored by the United States Government. Neither the United States nor the Energy Research and Development Administration/United States Nuclear Regulatory Commission, nor any of their employees, nor any of their contractors, subcontractors, or their employees, makes any warranty, express or implied, or assumes any legal liability or responsibility for the accuracy, completeness or usefulness of any information, apparatus, product or process disclosed, or represents that its use would not infringe privately owned rights.

Volume I of this manual, which contains Sect. 1

through Sect. 6, including Appendix A, is published

as ORNL/TM-5323. 
ORNL/TM-5324

(Second Volume of ORNL/TM-5323)

Contract No. 7405-eng-26

CHEMICAI TECHNOLOGY DIVISION

A GUIDE TO THE SELECTION, TRAINING, AND LICENSING OR CERTIFICATION OF REPROCESSING PLANT OPERATORS

Volume II

Compiled by :

The Staff of the Pilot Plant Section

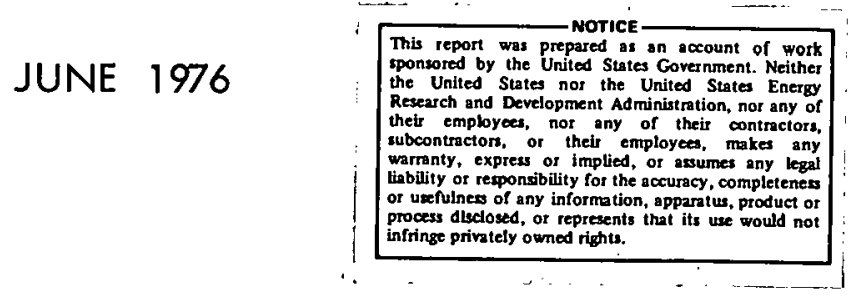

OAK RIDGE NATIONAL LABORATORY

Oak Ridge, Tennessee 37830

operated by

UNION CARBIDE CORPORATION

for the

ENERGY RESEARCH AND DEVELOPMENT ADMINISTRATION 


\section{THIS PAGE}

\section{WAS INTENTIONALLY}

LEFT BLANK 
TABLE OF CONTENTS

VOLUME I (ORNL/TM-5323)

Page

FOREWORD . . . . . . . . . . . . . . . . . . . . . . ix

1. INTRODUCTION . . . . . . . . . . . . . . . . . 1-1

2. SELECTION OF CANDIDATES . . . . . . . . . . . . . . 2-1

2.1 INITIAL SCREENING OF CANDIDATES . . . . . . . . . . 2-1

2.2 TESTING . . . . . . . . . . . . . . . . . . . 2-2

2.3 EDUCATIONAL BACKGROUND REQUIREMENTS . . . . . . . . 2-2

2.4 HUMAN FACTORS .................... 2-3

REFERENCES FOR SECTION 2 ................ 2-3

3. LICENSING . . . . . . . . . . . . . . . . . 3-1

3.1. REQIITRFMFNTS . . . . . . . . . . . : . . . . . . . . . . 3-1

3.2 CATEGORIES OF OPERATORS . . . . . . . . . . . . . 3-5

3. 3 EXAMINATION AND CERTIFICATION OF OPERATORS . . . . . . 3-6

3.3.1 Written Examination of Candidates . . . . . . . 3-6

3.3.2 Sample Examination Questions . . . . . . . 3-7

3.3.3 Operator Certification . . . . . . . . 3-7

4. THE TRAINING PROGRAM . . . . . . . . . . . . . . . 4-1

4.1 MANAGEMENT FUNCTIONS . . . . . . . . . . . . . . 4-1

4.1.1 Planning the Training Program........ . . . 4-1

4.1.2 Organizing the Training Program . . . . . . . 4-2

4.1.3 Directing the Training Program .. . . . . . . . . 4-3

4.1.4 Coordinating the Training Program . . . . . . . 4-3

4.1.5 Controlling the Training Program . . . . . . . 4-4

4.2 DETERMINING TRAINING REQUIREMENTS .......... . 4-4

4.2.1 Determining Performance Requirements . . . . . 4-5

4.2.2 Determining Skills of Employees . . . . . . . 4-5

4.3 DEVELOPMENT OF THE TRAINING PROGRAM . . . . . . . . 4-5

4.3.1 Typical Training Course at National

Laboratory ............. . 4-6

4.3.2 Typical Training Course at a Commercial

Reprocessing Plant ... . . . . . . 4-8

4.4 EVALUATION OF THE TRAINING PROGRAM ........ . . . 4-11

4.5 SUMMARY . . . . . . . . . . . . . . . . . . 4-11

REFERENCES FOR SECTION 4 . . . . . . . . . . . . . . 4-12

5. ACCOUNTABILITY . . . . . . . . . . . . . . . 5-1

REFERENCES FOR SECTION 5............... . 5-10 
6. PLANT SAFETY ..................... 6- 6-1

6.1 HEALTH PHYSICS .................. 6-2

6.1.1 Radiation in a Reprocessing Facility . . . . . 6-2

6.1.2 Radiation Detection and Monitoring

6.1 Equipment . . . . . . . . . . . . 6-7

Radiation Exposure Limits for Personnel. . . . 6-37

6.1.4 Radiation Exposure Control Procedures . . . . . 6-41

6.1.5 Contamination Control . . . . . . . . . 6-52

6.1.6 Decontamination Procedures . . . . . . . 6-69

REFERENCES FOR SECTION 6.1 .............. 6-74

6.2 CRITICALITY . . . . . . . . . . . . . . 6-77

6.2.1 Administration of Nuclear Criticality

Safety ............... . 6-77

6.2.2 Atomıc structure ............. . $6=79$

6.2.3 Nuclear Reactions . . . . . . . . . . 6-82

6.2.4 Methods of Control . . . . . . . . . . 6-88

6.2.5 Monitoring Equipment .......... . 6-95

REFERENCES FOR SECTION 6.2 ............... 6-96

6.3 STANDARD OPERATING FROCEDURES ........... . 6-97

6.3.1 Purpose and Description . . . . . . . . . 6-97

6.3.2 Typical Example of a Standard Operating

Procedure . . . . . . . . . . . . 6-97

6.4 CHEMICAL SAFETY AND SAFETY EQUIPMENT . . . . . . . . 6-103

6.5 FIRE PREVENTION AND CONTROL . . . . . . . . . . . 6-104

6.5.1 Fires and Explosions . . . . . . . . . . 6-105

6.5.2 Fire Prevention .. . . . . . . . . . 6-106

6.5.3 Extinguishing Methods and Agents . . . . . 6-1.07

6.5.4 Summary and General Rules . . . . . . . . . . 6-109

6.6 EMERGENCY PROCEDURES .............. . . . b-110

APPENDIX . . . . . . . . . . . . . . . . . . . A-1

VOLUME II

7. PROCESS UYERALLUNS . . . . . . . . . . . . . . . . 7-1

7.1 TRANSPORTATION OF FUEL AND WASTES . . . . . . . . 7-2

7.1.1 Typical Shipping-Cask Design . . . . . . . . 7-2

7.1 .2 Material to be Shipped . . . . . . . . . 7-8

7.1.3 Shipping Requirements . . . . . . . . 7-9

7.1.4 Control of Radiation and Contamination

During Unloading . . . . . . . . . 7-12

7.1.5 Decontamination Procedure . . . . . . . . . 7-13

7.1.6 Criticality Control During Unluading and

Shipping .............. . 7-14

7.1.7 Accountability Control During Shipping and

Unloading . . . . . . . . . . . . 7-15

REFERENCES FOR SECTION 7.1 . . . . . . . . . . . 7-17 
7.2 SPENT-FUEL RECEIVING AND STORAGE FACILITY . . . . . 7-18

7.2.1 General Description . . . . . . . . . . . 7-18

7.2.2 Shipping-Cask Decontamination . . . . . . . 7-19

7.2.3 Cask Unloading Pool . . . . . . . . . . . . 7-19

7.2.4 Fuel Storage Basin . . . . . . . . . . 7-24

7.2.5 Criticality and Accountability . . . . . . . 7-26

7.3 FUEL DISASSEMBLY AND SIZE REDUCTION . . . . . . . . 7-27

7.3.1 Description of Typical Fuel Assemblies . . . . . 7-29

7.3.2 Description of a Typical Mechanical

Processing Cell . . . . . . . . . 7-29

7.3.3 Description of Typical Mechanical

Processing Cel1 Operating Equipment... . . . 7-34

7.3.4 Description of Some Mechanical Processing

Cell Process Equipment .. . ... . . . . 7-38

7.3.5 Fire Control ... . . . . . . . . . . . 7-44

7.3.6 Criticality Control and Accountability . . . . 7-47

REFERENCES FOR SECTION 7.3 . . . . . . . . . . 7-48

7.4 CHEMICAL MAKEUP . . . . . . . . . . . . . . 7 7-49

7.4.1 General .. . . . . . . . . . . . . . 7-49

7.4.2 Typical Methods of Making up Solutions

from Solids . . . . . . . . . . . . 7-49

7.4.3 Dilution of Liquids . . . . . . . . . . . 7-49

7.4.4 Continuous Methods . . . . . . . . . . . 7-49

7.5 FUEL DISSOLUTION ... . . . . . . . . . . . 7-50

7.5.1 Chemistry of Fuel Dissolution . . . . . . . 7-50

7.5.2 Fuel Dissolution Equipment . . . . . . . . 7-52

7.5.3 Typical Dissolution of Chopped Fuel . . . . . 7-55

7.5.4 Control of Gaseous Effluent During

REFERENCES FOR SECTION 7.5 .............. . 7-60

7.6 SOLVENT EXTRACTION . . . . . . . . . . . . . . . 7-61

7.6.1 Definition of Terms . . . . . . . .. . . 7-61

7.6.2 Chemistry of Solvent Extraction . . . . . . . 7-64

7.6 .3 Feed-Adjustment Step . . . . . . . . . 7-68

7.6 .4 Extraction Step ................ 7-68

7.6 .5 Partitioning Step ............. . 7-69

7.6 .6 Stripping Step ............... . 7-69

7.6.7 Solvent Recovery .............. 7-69

7.6.8 Solvent-Extraction Contactors . . . . . . . 7-70

REFERENCES FOR SECTION 7.6 . . . . . . . . . . . . 7-81

7.7 EVAPORATION .................... 7-82

7.7.1 Definition of Terms . . . . . . . . . . 7-82

7.7.2 Purpose (Uses in the Process). . . . . . . . 7-82

7.7.3 Description of Equiprient . . . . . . . . 7-83

7.7.4 Modes of Evaporator Operation . . . . . . . . 7-87

7.7.5 Control of Operating Variables . . . . . . . 7-89

7.7 .6 Instrumentation .. . . . . . . . . . 7-90 
$\underline{\text { Page }}$

7.7.7 Recovery of Nitric Acid from SolventExtraction Wastes . . . . . . . . . 7-93

REFERENCES FOR SECTION 7.7 . . . .......... $7-94$

7.8 ION EXCHANGE .................... . . . $7-95$

7.8.1 Definition of Terms . . . . . . . . . . 7-95

7.8.2 Basic Chemistry .. . . . . . . . . . . 7-96

7.8.3 Plutonium Purification by Ion Exchange . . . . 7-97

7.8.4 Ion-Exchange Equipment .. . . . . . . . . 7-98

7.8.5 Operating Variables and Restrictions . . . . . 7-100

7.8.6 Safety Precautions Required . . . . . . . 7-100

REFERENCES FOR SECTION 7.8 . . . . . . . . . . . . 7-101

7.9 CONVERSION OF URANYL NITRATE TO URANIUM

IIEXAPLUORIDE . . . . . . . . . . . . . . . . . 7=102

7.9.1 Conversion of Urany 1 Nicrace to Uranium

Trioxide .. . . . . . . . . . . . 7-104

7.9.2 Reduction of Uranium Trioxide to Uranium

7.9 Dioxide • • • • • • • • • • • . . 7-104

7.9.4 Fluorination of Uranium Tetrafluoride and

Uranium Trioxide . . . . . . . . . . 7-108

REFERENCES FOR SECTION 7.9 . . . . . . . . . . . . . . 7-121

7.10 PRODUCT WITHDRAWAL, STORAGE, AND PACKAGING . . . . . . 7-122

7.10.1 Product Packaging and Storage . . . . . . . . 7-122

7.10.2 Product Preparation . . . . . . . . . . 7-123

7.10.3 Contamination Control Methods . . . . . . . 7-123

7.10.4 Criticality Control Methods . . . . . . . . 7-124

7.10.5 Accountability Methods .......... . 7-125

REFERENCE FOR SECTION 7.10 .............. 7-125

7.11 SOLUTION TRANSFER . . . . . . . . . . . 7-126

7.11 .1 Pumps . . . . . . . . . . . . . . 7-126

7.11 .2 Jets .................. . 7-138

7.11.3 Air Lifts . . . . . . . . . . . . . . 7-141

REFERENCES FOR SECTION 7.11 . . . . . . . . . . . . 7-146

7.12 GAS HANDLING EQUIPMENT . . . . . . . . . . . . . 7-147

7.12.1 Fans . . . . . . . . . . . . . . . 7-147

7.12.2 Rotary Blowers . . . . . . . . . . 7-150

7.12 .3 Jets . . . . . . . . . . . . . . 7-161

7.12 .4 Compressors ................ . 7-164

REFERENCES FOR SECTION 7.12 . . . . . . . . . . . 7-168

7.13 FLUIDIZED BEDS . . . . . . . . . . . . . . . . . 7-169

7.13.1 Purpóse and Usés in Fuel Reprocessing . . . . . 7-169

7.13.2 Description ................ . 7-169

7.13.3 Instrumentation .. . . . . . . . . . . 7-171

7.13.4 Operating Variables and Method of Control . . . 7-173

REFERENCES FOR SECTION 7.13 .............. . 7-177

7.14 CALCINERS ................... . . . . . . . . . . . . . . .

7.14.1 Use in Fuel Reprocessing . . . . . . . . . 7-178

7.14.2 Description of a Fluidized-Bed Calciner . . . . 7-178 
Page

7.14.3 Instrumentation ............. 7-181

7.14.4 Operating Variables and Common Difficulties . . . 7-183

REFERENCES FOR SECTION 7.14................ 7-184

7.15 WASTE HANDLING SYSTEMS . . . . . . . . . . . . 7-185

7.15.1 Liquid Waste Systems . . . . . . . . . . 7-190

7.15 .2 Gaseous Waste Systems . . . . . . . . . 7-197

7.15.3 Solid Wastes .. . . . . . . . . . . . 7-198

REFERENCES FOR SECTION 7.15 ............... 7-200

7.16 VENTILATION SYSTEMS ................. 7-201

7.16.1 Building Ventilation Systems ......... . 7-201

7.16.2 Cell Ventilation .............. 7-203

7.16.3 Process Off-Gas and High-Level and

Intermediate-Level Waste off-Gas . . . . . 7-203

7.16.4 High-Level and Intermediate-Level Waste

Building Ventilation ... . . . . . . 7-203

7.16.5 Iodine and Acid Recovery Building

Ventilation . . . . . . . . . . . . 7-204

7.16.6 Miscellaneous Ventilation Systems....... 7-204

8. PROCESS CONTROL . . . . . . . . . . . . . . 8-1

8.1 BASIC INSTRUMENTATION . . . . . . . . . . . 8-1

8.1.1 Definition of Terms ............. . 8-3

8.1.2 Temperature Measurement ... . . . . . . . 8-3

8.1.3 Pressure Measurement . . . . . . . . . . 8-7

8.1.4 Liquid Level Measurement . . . . . . . . . 8-8

8.1.5 Flow Measurement . . . . . . . . . . 8-13

8.1.6 Density and Specific Gravity Measurement . . . 8-14

8.1.7 Interface Location . . . . . . . . . . . 8-18

8.1.8 Instruments for Measuring Chemical

Composition .. . .. . . . . . . . 8-18

8.1.9 Motor Speed Control .. . . . . . . . . 8-19

8.1.10 Radiation Detection Instruments . . . . . . 8-20

8.1.11 Interpretation of Data . . . . . . . . 8-20

8.2 SAMPLING . . . . . . . . . . . . . . . 8-21

8.2.1 Basic Requirements of Sampling .. . . . . . 8-23

8.2.2 Methods of Sampling and Sampling Devices . . . 8-23

8.2.3 Records of Sampling ............. 8-27

8.2.4 Transportation of Samples. . . . . . . 8-28

8.2.5 Replicates ................ 8-29

REFERENCES FOR SECTION 8 . . . . . . . . . . . . 8-29

9. UTILITY SYSTEMS . . . . . . . . . . . . . . . 9-1

9.1 WATER SYSTEMS .................. 9-1

9.1.1 Process Water . . . . . . . . . . . . . 9-2

9.1.2 Potable Water .. . . . . . . . . . . . 9-2

9.1.3 Demineralized (Deionized) Water . . . . . . 9-3

9.1.4 Nuclear Safety Aspects . . . . . . . . 9-5 
9.2 STEAM . . . . . . . . . . . . . . . 9-5

9.3 COMPRESSED AIR . . . . . . . . . . . . . . 9-6

9.4 VACUUM ......... . . . . . . . . . . . 9-7

9.5 ELECTRICAL SYSTEMS ... . . . . . . . . . . . 9-7

9.6 COMMUNICATIONS SYSTEMS . . . . . . . . . . . . 9-8

REFERENCES FOR SECTION 9 . . . . . . . . . . . 9-8 
A GUIDE TO THE SELECTION, TRAINING, AND LICENSING OR CERTIFICATION OF REPROCESSING PLANT OPERATORS

FOREWORD

The Code of Federal Regulations, Title 10, Part 55, commonly referred to as $10 \mathrm{CFR}$ 55, establishes procedures and criteria for the licensing of operators, including senior operators, in "Production and Utilization Facilities" that are themselves licensed under 10 CFR.50. Since production facilities are defined to include plants for reprocessing irradiated nuclear fuel and since several commercial fuel reprocessing plants are scheduled to go into operation during the next few years, considerable interest has been expressed in the nuclear industry concerning the need for guidance in training operators. The ERDA Division of Operational Safety, therefore, has supported a program at Oak Ridge National Laboratory (ORNL) to develop personnel guides that will assist the ERDA and the nuclear induetry in thio roopoet.

This first training guide proposes to facilitate the licensing of operators for nuclear reprocessing plants by offering generlized descriptions of the basic principles (theory) and the unit operations (mechanics) employed in reprocessing spent fuel. Hopefully, this generalized approach will assist in the writing of training manuals for operators in specific reprocessing plants and in preparing these individuals for their licensing examinations. The guide is written in two parts: Volume I supplies details about the portions of a training program that are of major interest to management, and Volume 2 presents a step-bystep description of typical fuel reprocessing operations together with controls and utility systems that support these operations. When the final draft for the present guide is complete, similar guides will be undertaken for fuel fabrication and other facets of nuclear fuel production.

The contributors to this training manual have all had long careers in their respective areas of radiochemical operations, and each brings a special expertise to this effort. Several have actively participated in the training of radiochemical operators at ORNL and in licensing operators at other facilities. It is appropriate here to acknowledge the most valuable contributions of $\mathrm{R}$. E. Brooksbank, W. D. Box, F. N. Browder, J. M. Chandler, H. E. Cochran, M. F. Fair, R. W. Horton, Elizabeth B. Johnson, L. J. King, J. L. Matherne, W. T. McDuffee, C. H. Miller, R. G. Nicol, J. R. Parrott, R. H. Rainey, A. D. Ryon, L. B. Shappert, R. B. Waters, C. D. Watson, W. R. Whitson, 0. 0. Yarbro, and E. L. Youngblood of ORNL: A. J. Hill, Jr. of Savannah River Laboratory; and $\mathrm{H}$. J. Moe of Argonne National Laboratory. 


\section{PROCESS OPERATIONS}

Nuclear fuels undergo partial fissioning during the operation of a light water power reactor. This fissioning produces highly radioactive neutron absorbers that inhibit or poison the fission chain reaction. The fuel must therefore be periodically removed from the reactor and the valuable components recovered for recycling. Recycling the fuel includes its removal, storage, packaging, shipping, unloading, disassembly, and reprocessing. Each step in this series of operations requires the utmost care in order to restrict the release of hazardous liquid and gaseous effluents to the biosphere as well as to limit the exposure of employees in the nuclear industry to radioactive levels as low as practicable. After reprocessing, the fuel is sent to a refabrication plant or to an enrichment facility for further use. The radioactive waste will then be transferred to a properly licensed site for safe disposal and surveillance at a later date.

Section 7 of this gulde describes the methods used in the handling and reprocessing of irradiated (spent) fuel from the time it arrives at the nuclear fuel reprocessing plant until the valuable fuel components are purified and packaged for transport to a fuel refabrication plant or until the uranium is converted to a fluoride suitable for feed to a uranium isotopic enrichment plant.

The spent nuclear reactor fuel arrives at the reprocessing plant inside heavily shielded shipping packages designed to contain the nuclear fuel and to shield the public from radioactivity under both normal and accident conditions. At the reprocessing facility, the shipping package is inspected and unloaded from the transport vehicle; and the fuel in the form of individual fuel assemblies is unloaded from the shipping package and stored. Both unloading and storage are generally conducted under water. Fuel assemblies are withdrawn from the underwater storage area to supply feed to the reprocessing facility. After disassembly and segmenting, the valuable fuel-element pieces are charged to a feed preparation system, where the nitric acid-soluble components are leached from the insoluble fuel-element cladding and the cladding is disposed of as waste.

The leachate or dissolver solution is usually clarified, its chemical properties are adjusted, and it is fed to solvent-extraction and other types of purification systems, where the valuable fuel is isolated and purified from the highly radioactive fission products and other metallic and chemical impurities. These radioactive wastes are treated (usually made alkaline and/or their volume reduced) and stored. The purified product is packaged for transport to a nuclear fuel refabrication plant where recycle fuel is prepared for reuse in the nuclear reactor, or the uranium product is converted to a fluoride form and packaged for shipment to a uranium isotopic enrichment plant. The plutonium product is packaged and delivered to a plutonium fabrication factlity or to a mixed uraniumplutonium reactor fuel refabrication facility. 
The chemical flowsheets employed for the purification process utilize the PUREX solvent-extraction process in its entirety or a combination of the PUREX and volatile-fluoride processes.

\subsection{TRANSPORTATION OF FUEL AND WASTES}

Three different operations in a chemical reprocessing plant are concerned with transportation of radioactive material: (1) receiving of the spent fuel, (2) shipment of decontaminated uranium and plutonium, and (3) shipment of wastes.

\subsubsection{Typica1 Shipping-Cask Design}

Shipping-cask packages are designed to provide safè ànd economicàl means of containing radioactivity present in the materials being transported. All radioactive materials must be packaged in contalners designed to provide adequate shielding against penetrating radiation, criticality control, and containment of the materials.

Since these packages, before use, must first be evaluated for the job they are designed to do, a Safety Analysis Report on the Package (SARP) is written and submitted to the NRC for their concurrence and approval. The SARP describes in some detail how the package is expected to behave under normal and some very severe accident conditions. Occasionally, scale models or a prototype package will be destructively tested to "prove" its invulnerability under the test conditions.

Many packages built both by the government and by private industry are described in the Directory of Shipping Containers for Radioactive Materials published in 1973.1 This directory will be periodically updated by the Waste Management and Transportation Division of the NRC.

Probably the heaviest package that must be handled is the spent-fuel cask. (The high-level waste cask should be similar in design, if not in weight.) Spent fuel is highly radioactive and produces substantial amounts of heat. The spent-fuel cask must have both gamma and neutron shields. The gamma shield is a dense material such as lead, steel, or depleted uranium. The neutron shield must have large amounts of hydrogen in it to be effective; a frequent choice for this shield is water (sometimes borated water) contained in a steel jacket immediately outside of the gamma shield. Solid materials with a high hydrogen content can also be used for neutron shielding.

Spent-fuel casks come in two sizes: small and large. Small casks are limited to about 25 tons gross weight and can be transported by truck. The payload of such a cask is normally one spent-fuel assembly from a pressurized-water reactor (PWR) or two assemblies from a boiling-water reactor (BWR). The decay heat load, which is not very great, can be easily dissipated from the cask surface by natural convection to the 
surroundings. Frequently a sunshade is used to cover the cask and minimize the solar heat load on the cask. The primary coolant, that which comes in contact with the fuel cladding, can be water or helium.

Small casks may be similar to one built recently for Nuclear Fuel Services, Inc. (NFS). The cask, designated NFS-4, can safely transport two BWR fuel assemblies or one PWR assembly. The principal means of transportation will be by specially designed truck-trailer under soleuse assignment. Rail or other modes of transportation may also be utilized. The weight of the cask is $50,000 \mathrm{1b}$, and the combined maximum weight of the truck-trailer-cask system is $73,000 \mathrm{lb}$, which permits operation in most states without special restrictions. An overhezd crane and a specially designed lifting yoke which attaches to the cask are utilized for trailer loading and unloading. Figure 7.1.1 shows the NFS-4 cask being checked for contamination.

Large casks can weigh 100 tons and above, limited generally by the capacity of the cranes at the reactor or reprocessing plants. These casks can be shipped by rail or barge and can have a payload of possibly 20 BWR or 10 PWR assemblies. Since the decay heat load is around 50 to $100 \mathrm{~kW}$, some form of forced cooling is necessary to keep internal temperatures down to reasonable levels. The primary coolant is usually water. Most casks are equipped with valves which permit sampling of the primary coolant before the cask is opened. High contamination levels in the coolant could indicate that some fuel cladding may have ruptured in transit.

Typical of large casks designed to carry current-generation high-burnup fuel from light water reactors (LWRs) is the General Electric IF- 300 cask, weighing about 70 tons, which is capable of carrying 7 PWR or 18 BWR spent-fuel assemblies and is transported by rail (Figs. 7.1.2 and 7.1.3). Interchangeable heads and internals are utilized to accommodate either BWR or PWR fuel bundles, which have different lengths and cross sections. The rail car is equipped with blowers that can maintain the outer surface (and consequently the inner cavity) at reasonable operating temperatures during shipment. Capacity, weight, and dimensional parameters are as follows:

$\underline{\text { BWR Fuel }} \quad$ PWR Fue1

Capacity Assemblies

Approximate loaded weight

Cask $n n 1 y, 1 \mathrm{~h}$

Skid, enclosure, and cooling system, 1b

Total system, 1b

$\begin{array}{rr}140,000 & 136,000 \\ 35,000 & 35,000 \\ 175,000 & 171,000\end{array}$

Cavity

Length, in.

Diameter, in.

180

37.5

169

37.5 


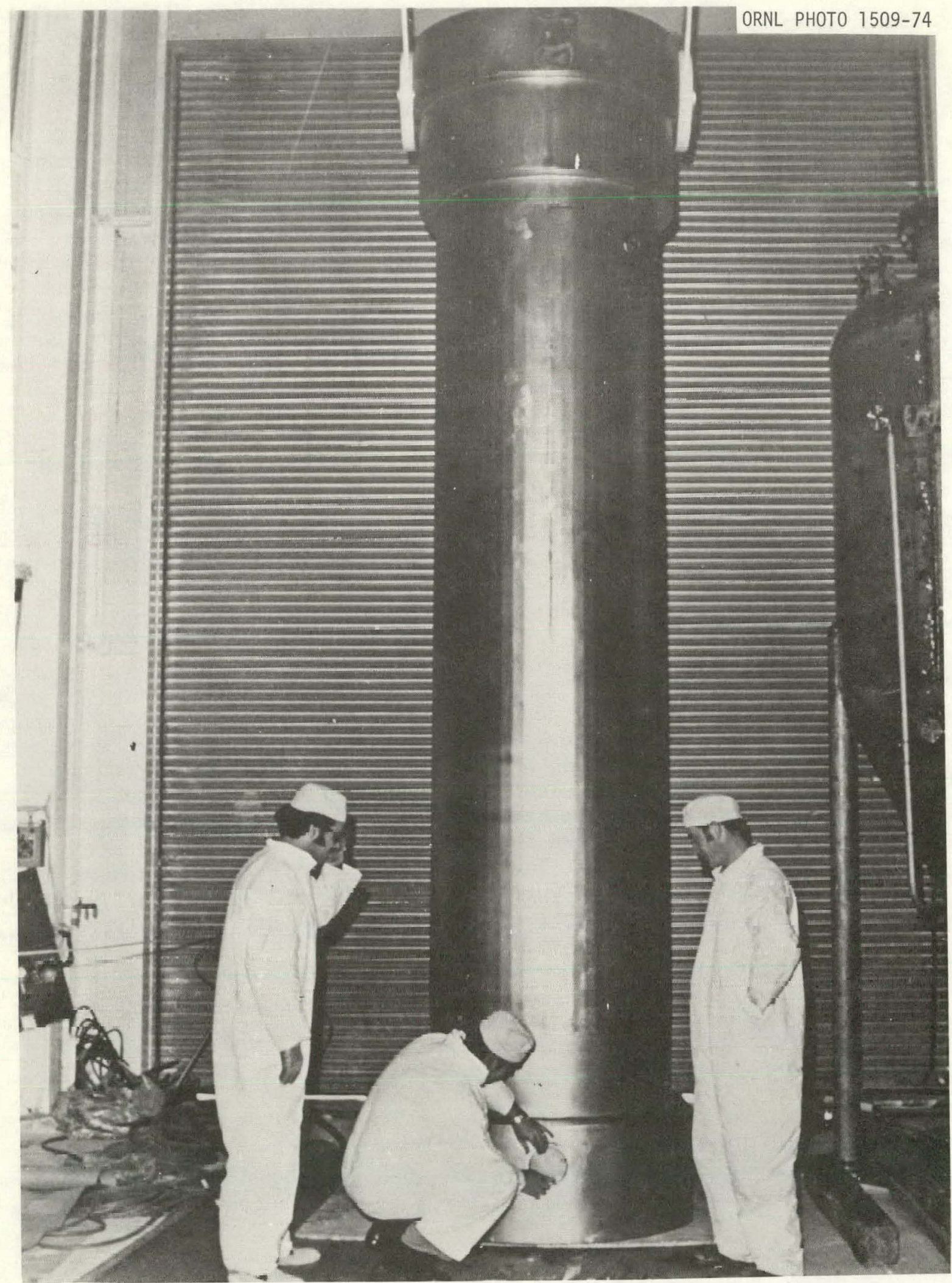

Fig. 7.1.1. NFS-4 Spent Fuel Shipping Cask Undergoing Receiving Inspection 
ORNL DWG 71-10819

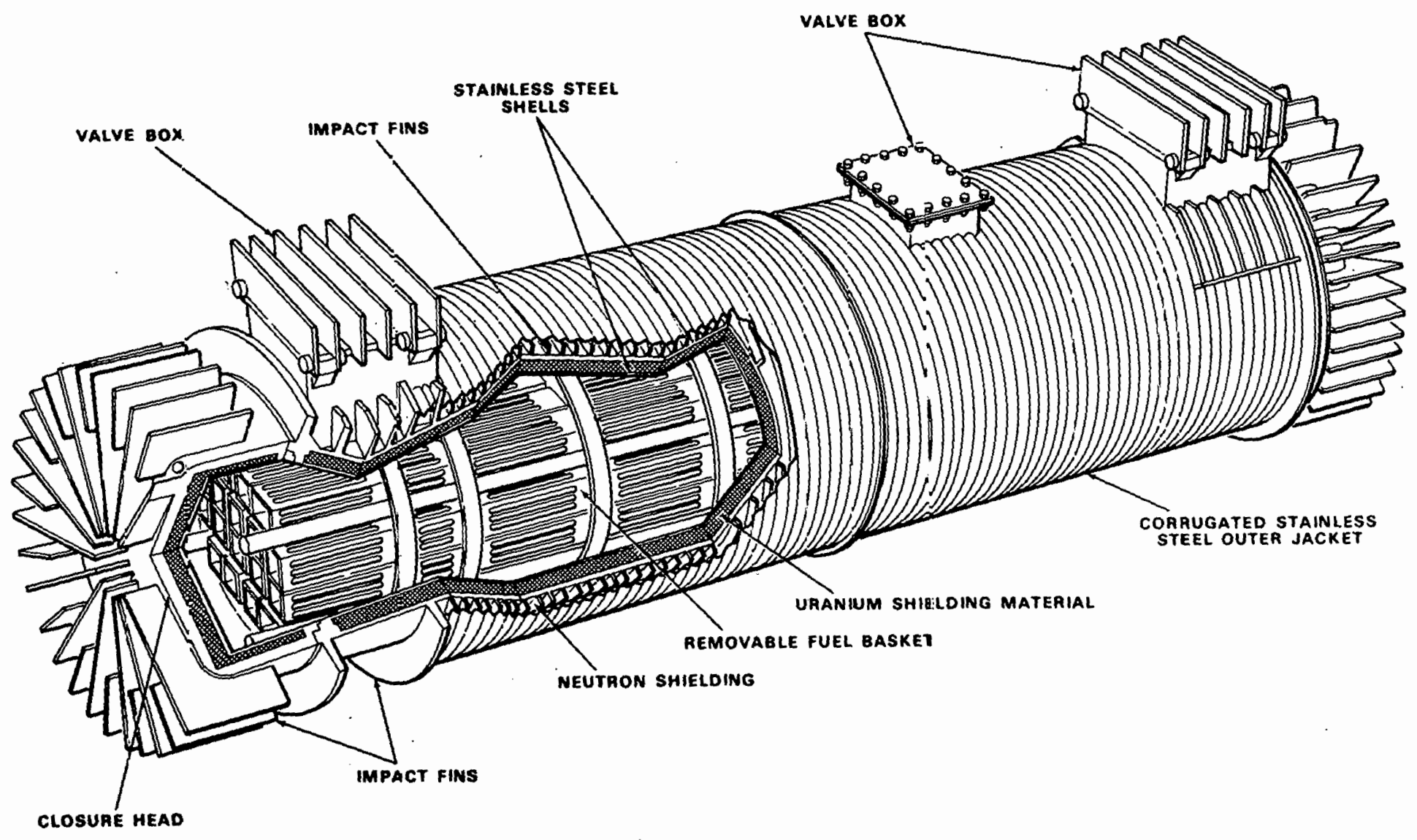

Fig. 7.1.2. IF 300 Spent Fuel Shipping Cask 
C.RNL DWG 71-10818

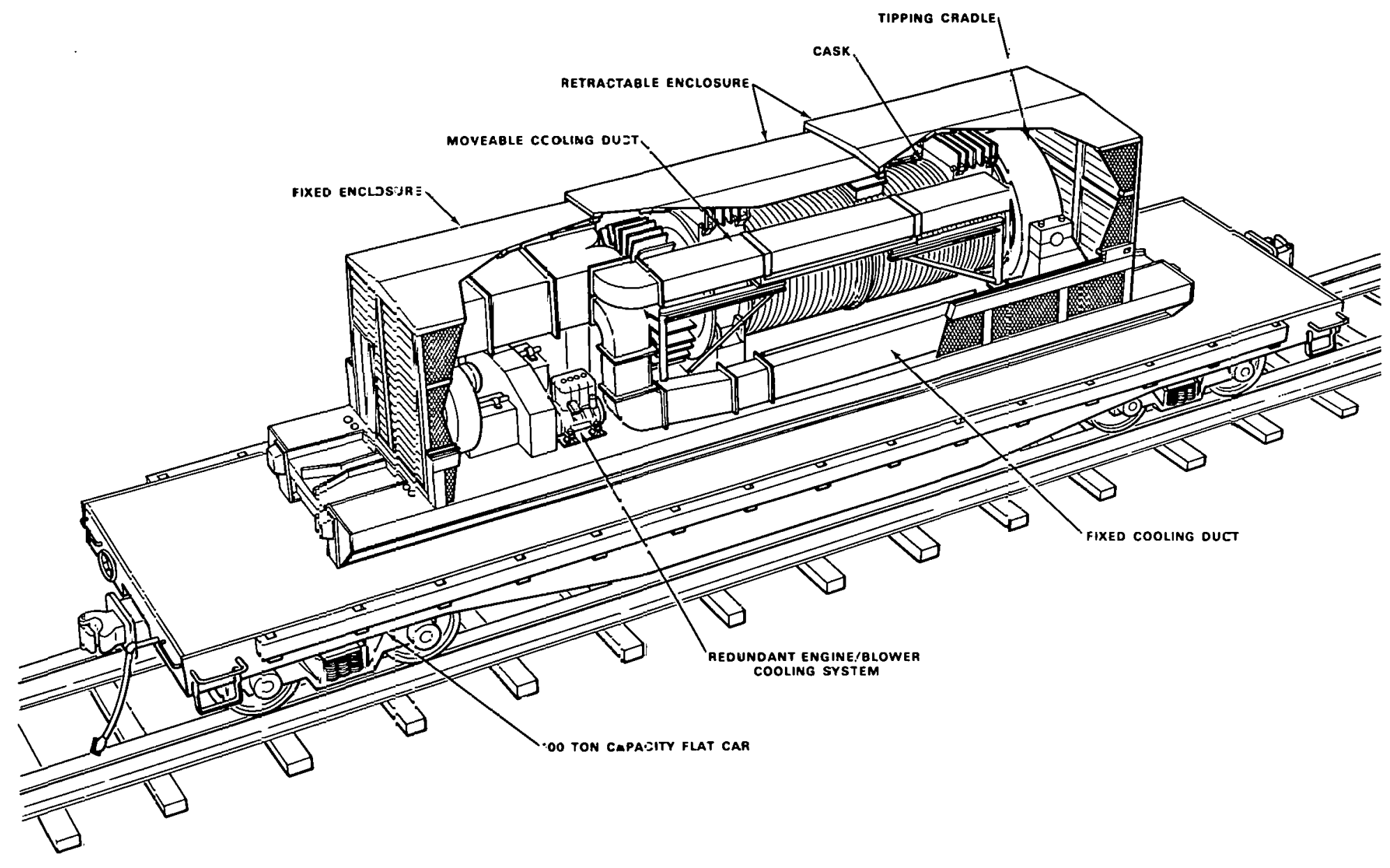

Iig. :.1.3. IF 300 Spent Fuel Shipping Cask in Normal Rail Transport Configuration 
BWR Fue1 PWR Fue1

Cask body

Length, in.

208

Nominal diameter, in.

64

198

Skid

Length, ft

Width, ft

37.5

8

37.5

8

The fuel baskets and all external and internal surfaces of the cask are stainless steel. This will aid in maintaining clean surfaces.

Shielding is provided by water in the cask cavity, depleted-uranium metal within the cask shell, and an exterior water-filled enclosure. The exterior shielding-water enclosure is fabricated from thin-walled stainless steel, corrugated to maximize the heat transfer area. The corrugations also significantly increase the strength of the outer jacket and its resistance to damágé.

The closure head is sealed with a replaceable metallic gasket. The maximum normal operating pressure for the cask cavity is 200 psig. However, the design working pressure is 400 psig at a material temperature of $815^{\circ}$. Overpressure protection is provided by a pressure relief valve, whose discharge pressure is 350 psig.

The cask cavity is filled, drained, vented, and sampled through two valves, one in each of two valve boxes atop the cask. These valves have quick-disconnect fittings for ease in operating. Both valve handles are secured during transit to prevent tampering. A pressure gage with quickdisconnect fittings is provided with the cask tool kit. The shieldingwater enclosure is protected from overpressure by a 200-psig relief valve and is also served by fill and drain valves located in two valve boxes.

The IF-300 cask is equipped with an audible alarm system, which activates if the cask temperature exceeds a predetermined value. This indicates either the failure of the cooling system or a loss of water from the external water jacket.

Each engine-blower combination is provided with a device to permit visual verification of the equipment operation. This visual indicator, combined with the audible alarm, will determine the cause of the overtemperature situation.

A procedures and notification manual will accompany each shipment. This manual and the operating procedures provided by local management are to be followed in all cask operations, such as loading, unloading, decontamination, maintenance, and inspections. 


\subsubsection{Material to be Shipped}

The sources and nature of various types of radioactive materials that are shipped routinely between branches of the nuclear industry are discussed below.

7.1.2.1 Irradiated Fue1 - Spent fue1, discharged from a power reactor, is usually allowed to "cool" for at least 120 days before it is shipped to a reprocessing plant. This cooling allows short-half-life radioisotopes in the fuel to decay, reducing the levels of penetrating radiation and the heat produced by the assembly.

The light water reactor fuel that will be received will come from pressurized water reactors (PWRs) and boiling water reactors (BWRs). PWR assemblies are the larger of the two in cross section, containing 400 to $450 \mathrm{~kg}$ of uranium in each 160-in,-1ong assembly; BWR assemblies contain about $200 \mathrm{~kg}$ of uranium each and are approximately $170 \mathrm{in}$. in overall length.

Table 7.1.1 presents the heat output per kilogram of uranium versus cooling time for both the PWR and BWR assemblies irradiated to 35,000 megawatt-days per metric ton of uranium (MWD/MTU). Differences in heat output are due primarily to variations in the specific power of the two types of reactors.

After irradiation, the spent fuel produces not only large amounts of penetrating gamma radiation but also large numbers of neutrons from spontaneous fission or $(\alpha, n)$ reactions in transuranium elements (e.g., plutonium, americium, and curium), which build into the fuel by neutron capture in uranium.

Table 7.1.1. Total Decay Heat Power of PWR and BWR Fue $1^{\alpha}$

\begin{tabular}{ccc}
\hline $\begin{array}{c}\text { Cuoling Ilme } \\
\text { (days) }\end{array}$ & \multicolumn{2}{c}{ Transuranic Plus Fission Product Power } \\
\cline { 2 - 3 } & $\begin{array}{c}\text { PWR Fucl } \\
\text { (watts/kg U) }\end{array}$ & $\begin{array}{c}\text { BWR Fine. } \\
\text { (watts / kg U) }\end{array}$ \\
\hline 90 & 29.39 & 24.7 \\
120 & 24.03 & 19.7 \\
150 & 20.01 & 16.4 \\
180 & 17.62 & 14.6 \\
210 & 15.24 & 12.9 \\
240 & 13.09 & 11.6 \\
270 & 11.61 & 10.6 \\
300 & 10.79 & 9.4 \\
\hline
\end{tabular}

$a_{\text {Irradiated to } 35,000 \mathrm{MWD} / \mathrm{MT} \text {. }}$ 
7.1.2.2 Uranium and Plutonium Product - Uranium and plutonium products are collected separately as liquid nitrates from ion-exchange columns and placed in suitable (critically safe) storage containers. Product is either concentrated to about $250 \mathrm{~g} /$ liter of heavy metal or converted to a solid form, such as the oxide, and shipped. Product should be almost free from fission products. Little shielding, if any, is required for handling uranium-235. Plutonium, however, is likely to need both gamma and neutron shielding.

Although large quantities of plutonium can now be shipped in the liquid nitrate form, regulations have been proposed which would in the future limit liquid shipment to $20 \mathrm{Ci}$ of plutonium. ${ }^{2}$ If such a rule is passed, most plutonium would be shipped in solid form.

7.1.2.3 Radioactive Wastes - Radioactive wastes generated in fuel reprocessing plants are categorized according to the type of radiation associated with them. Some wastes are in a combustible form when gencrated but cain be cumves led lu a noncombusctble form for shipment. Some low-level wastes containing radioactivity in amounts from a trace to several curies per cubic foot do not require shielding. Higherlevel waste might be reduced in volume to concentrate the alpha and beta-gamma activity to higher levels per cub1c foot, which might require some shielding.

Waste produced and concentrated in the reprocessing plant might contain several million curies per container and might be shipped in solid form, stable to above $1600^{\circ} \mathrm{F}$, in a shielded shipping cask similar to that used for spent fuel.

\subsubsection{Shipping Requirements}

The following information provides guidance when shipments of radioactive material are to be made. When radioactive materials are shipped by common carrier not under exclusive-use arrangements, the number of packages must be limited to prevent excessively high dose rates from the accumulation of many packages and to prevent the accumulation of large quantities of fissile material. This is done by assigning each package a transport index (TI) and making sure that the sum total of all TI's on any one vehicle is less than 50 .

7.1.3.1 Transport Index - As a simple indicator of the radiation dose rate from an individual package, the regulations define one TI as being equal to $1 \mathrm{millirem} / \mathrm{hr}$ at $3 \mathrm{ft}$ from the surface of the package. The number of packages stored or handled in one area or loaded on one car or vehicle must be so limited that the sum of their TI values does not exceed 50. This limitation is intended to prevent a large aggregation of packages, each with a significant radlation level, from producing a much higher than desirable total radiation level because of the additive effect of the radiation from all of the packages. 
Simple tables of minimum separation distances ${ }^{3-7}$ from people and from unexposed photographic film are specified for packages of radioactive materials in storage and on vehicles, in terms of the sum of the TI's in each group of packages. The transport worker or carrier's agent is required to read each $\mathrm{TI}$, add the total value of the TI's, determine from the tables in the regulations the distance those packages must be kept from film and from continuously occupied areas, and ens ure that those separation distances are provided.

The TI system has also been adapted for limiting aggregations of packages that contain fissile radioactive materials to ensure nuclear criticality safety. The shipper determines, in accordance with specific criteria laid down in the NRC regulations, a nuclear safety 'II value that is to be assigned to the fissile-material package. Then, before shipping, the shipper assigns to each package of tissile material the nuclear safety $\mathrm{TI}$, as calculated, or the radiation level TI (described earlier), whichever is higher. The transport worker, as in the case for radiation levels, adds the $T I$ values and, by complying with the limitation on the total value of TI's in any one vehicle or location (50), keeps the total amount of fissile material in all types of packages within safe limits.

7.1.3.2 Warning Labels - Each package of radioactive material is required by U.S. Department of Transportation (DOT) regulations ${ }^{8}, 9$ to be marked on two opposite sides with a distinctive warning label. Each of three label formats bears the unique trefoil radiation symbol. The label alerts persons who handle the package that it may require special handling. If the background color of the label is all white, the radiation is minimal, and nothing special is required for that package. However, if the background of the upper halt of the label is yeliow, a radiation level that requires consideration may exist at the outside of the package, and an indication of what controls must be exercised for that package will be specified (e.g., the 'll may be given). If the package bears a yellow label with three stripes, the rail or highway vehicle in which it is carried must be placarded.

7.1.3.3 Placards - A truck or rail car that carries any package labeled with a "radioactive yellow III" label must be placarded on the outside.10,11 'Le placard for rail cars bears the distinctive trefoll symbol; the placard for trucks bears the word "RADIOACTIVE" in letters large enough to catch the eye. The principal purposes of placards are to advise freight handlers of the presence of radioactive material with TI's inside the vehicle, to indicate the presence of special types of shipments (e.g., Fissile Class III, as defined in Table 7.1:2, special-permit, or large-source packages) and to warn passersby and emergency crews that sh1pments of radioactive material are in the vehicle. This marking or placarding is intended to discourage persons from remaining unnecessarily long in the vicinity of the vehicle so as to minimize exposures that might result from loitering in the vicinity. Also, the placard should alert emergency crews to the need for taking appropriate precautions in case such vehicles are involved 
1. Carrier means any person engaged in the transportation of passengers or property, as common, contract, or private carrier, or freight forwarder, as those terms are used in the Interstate Commerce Act, as amended, or the U.S. Postal Service.

2. Close Reflection by Water means immediate contact by water of sufficient thickness to reflect a maximum number of neutrons.

3. Containment Vessel means the receptacle on which principal reliance is placed to retain the radioactive material during transport.

4. Fissile Classification means classification of a package or shipment of fissile materials according to the controls needed to provide nuclear criticality safety during transportation as follows:

a. Fissile Class I. Packages which may be transported in unlimited numbers and in any arrangement and which require no nuclear criticality safety controls during transportation. For purposes of nuclear criticality safety control, a transport index is not assigned to Fissile Class I packages. However, the external radiation levels may require a transport index number.

b. Fissile Class II. Packages which may be transported together in any arrangement but in numbers which do not exceed a transport index of 50. For purposes of nuclear criticality safety control, individual packages may have a transport index of not less than 0.1 and not more than 10. However, the external radiation levels may require a higher transport index number but not to exceed 10 . Such shipments require no nuclear criticality safety control by the shipper during transportation.

c. Fissile Class III. Shipments of packages which do not meet the requirements of Fissile Classes I or II and which are controlled in transportation by special arrangements between the shipper and the carrier to provide nuclear criticality safety.

5. Fissile Materials means uranium-233, uranium-235, plutonium-238, plutonium-239, and plutonium-241.

6. Large Quantity means a quantity of radioactive material, the aggregate radioactivity of which exceeds that specified for a transport group. 
in accidents. Vehicles that carry carload or truckload lots of radioactive materials, packages with significant external radiation levels, packages that contain large quantities of radioactive material, or Fissile Class III shipments are required to be marked with a "RADIOACTIVE" placard.

7.1.3.4 Shipper's Certification - Before delivering a package to a carrier for transport, the shipper must determine that no "significant" loose radioactive contamination is on the outside of the package, that the radiation levels on the surface of the package and at a specified distance from the package do not exceed the limits given in the DOT regulations, and that the marking and labeling comply with the requirements. The shipper also must certify 12,13 in writing on the shipping papers that the radioactive materials are properly classified, described, packaged, marked, and labeled and are in proper condition for transport according to the applicable DOT regulations,

\subsubsection{Control of Radiation and Contamination During Unloading *}

All shipping packages or casks are received via truck or rail. Specific areas of the plant are designated as a receiving and/or storage area and are equipped to permit personnel to monitor external radiation and contamination of the incoming package. Written procedures specifically covering receipt of these packages are available and must be followed.

Packages and labeling of packages must be visually inspected to ass ure that a11 plant, NRC, and DOT shipping regulations have been met. Contents must be closely monitored to assure that the material received is that which was expected and that described on the bill of lading.

Operating personnel must smear the cask to determine the extent of external transferable contamination and to determine whether the cask might have had, or has, a leak. The cask must be monitored to determine external dose rates.

7.1.4.1 Radiation Level Limitations - The radiation emitted from individual packages of radioactive material is limited by the DOT regulations ${ }^{14}$ to no more than $200 \mathrm{mil1}$ irems/hr on the eurfacc (to limit the direct exposure to persons handling the parkage) and to no more than $10 \mathrm{millirems} / \mathrm{hr}$ at a point $3 \mathrm{ft}$ from the surface of the package (to limit the radiation level to which persons and property in the vicinity of the package would be exposed). If a package is shipped in a closed truck or in a rail car under exclusive-use conditions (which means that it is loaded by the consignor and $1 \mathrm{~m}$ loaded by the consignce), the radiation level at a point $3 \mathrm{ft}$ from the surface of the package is limited

\footnotetext{
${ }^{*}$ See also Sect. 7.2 .2 .
} 
to $1000 \mathrm{milli}$ rems $/ \mathrm{hr}$ provided the radiation level does not exceed $200 \mathrm{millirems} / \mathrm{hr}$ at the surface of the vehicle, $10 \mathrm{millirems} / \mathrm{hr}$ at a distance $6 \mathrm{ft}$ from the outside surfaces of the vehicle, and 2 millirems/ hr in either the driver's compartment or other normally occupied positions in the truck or rail car.

7.1.4.2 Surface Contamination Limits - The DOT regulations ${ }^{15}$ also require the absence of significant removable radioactive contamination on the external accessible surfaces of packages when they are shipped. Levels of removable contamination on the surfaces are determined by a wipe test. This test consists in wiping the cask surface with a filter paper, placing the paper in a radiation detector, and determining whether activity has been removed from the cask surface by the action of wiping. The regulations consider that the level is "not significant" if the radioactivity on the wipe does not exceed $10^{-11} \mathrm{Ci} / \mathrm{cm}^{2}(2200 \mathrm{dis}-$ integrations/min per $100 \mathrm{~cm}^{2}$ ) for beta-gamma emitters and $10^{-12} \mathrm{Ci} / \mathrm{cm}^{2}$ (220 disintegrations/min per $100 \mathrm{~cm}^{2}$ ) for alpha emitters. Any fixed contamination of the surface is limited by the external radiation level limitations discussed in the previous paragraphs.

The DOT regulations ${ }^{16}$ limit the temperature at any accessible surface of the cask to not more than $122^{\circ} \mathrm{F}$ at any time during transport, except that for full-load or exclusive-use shipments the temperature may be as high as $180^{\circ} \mathrm{F}$.

Should either external radiation levels or contamination levels exceed those specified in the operating procedures, technical supervisors need to be informed, and the package may be moved to a decontamination facility.

\subsubsection{Decontamination Procedure ${ }^{*}$}

The decontamination facility should be equipped to monitor the temperature and pressure of the incoming packages and casks. Equipment should also be provided to cleanse the nutside of the containers by means of high-pressure sprays and brush scrubbing with wash solution and/or specific chemical reagents. Facility operating procedures describe the specific techniques to be used. Waste solutions are released to the radioactive drain system and caught in special tankage. Protective clothing is required for decontaminating packages and casks.

Spent-fuel casks that contain water coolant inside of the cask must be monitored for contamination before the cask can be unloaded. Casks designed to employ water coolant will be equipped with vent and flushing valves to permit this monltoring operation.

\footnotetext{
See also Sect. 7.2.2.
} 
If exterior contamination is within acceptable limits, the cask may be transferred to the unloading pool. Should contamination be excessive, the cask must be flushed and the supervisor notified. Operating procedures will indicate what other steps are required before the cask is transferred to the unloading pool.

When spent-fuel casks are lowered into a water-filled receiving or unloading pool, the top of the cask may be $25 \mathrm{ft}$ below the surface. The water serves as a radiation shield permitting the operating personnel to view the fuel elements when unloading them and placing them in storage racks.

\subsubsection{Criticality Control During Unloading ${ }^{*}$ and Shipping}

Spent BWR or PWR fuel can be removed from the shipping container only after the cask is in position under water in the unlooding hasin ani the cask lid has been opened or removed. The spent fuel not only is highly radioactive but also contains significant quantities of fissile material. It must be handled in such a way that a critical arrangement of fuel assemblies cannot be formed.

Most receiving facilities have storage racks located under water in the unloading basin. When spent fuel is removed from the cask, either one assemlily at a time is removed and placed in available positions in the storage rack, or the entire basket containing a number of fuel assemblies is withdrawn. Specific operating procedures for the cask in question must be consulted.

The storage racks that contain the spent fuel are designed to maintain sub-criticality under all normal operating conditions. The fuel, handled under water with a crane, should not be dropped, placed in unauthorized locations, tipped over, or handled in any other unspecified manner. Should broken or ruptured fuel assemblies be received, they should be handled in accordance with specific operating instructions.

Uriticality control must also be exercised in the packaging and shipping of uranium and plutonium product material (Sect. 7.11.4). Such material is handled under controlled conditions inside a cell or glove box prior to shipping. The product must be placed in containers designed to limit quantities to those which can be safely handled or transported in the shipping packages, The packages are also designed to romnin rritieally safe even if severely damaged in an accident or flooded with water while arranged in a fashion most favorable to achieve criticality.

${ }^{*}$ See also Sect. 7.2 .5 . 


\subsubsection{Accountability Control During Shipping and Unloading *}

Source and special materials (Sect. 5) in transit are moved upon request of the licensed entity responsible for them (the shipper), who retains this responsibility until the authorized receiver officially accepts the material. The material must be accompanied by shipping records (AEC Form 741) which identify the shipper and the receiver, the shipping cask and its contents, and the security seal numbers. The shipper's gross and tare weights for the package and his estimate of the quantity of source and special materials in the shipment are listed along with a sketch showing the packing arrangement and any special handling instructions that may be needed during transit or unloading. The shipping records are kept in the possession of the courier-escort for unirradiated source and special material, but such records for irradiated (and thus radioactive) material are attached to the shipping package or carried by the driver of the transport vehicle.

Before a shipment of source or special material enters the receiving area, operating personnel of the reprocessing plant must inspect the security seals on the truck or rail car for tampering; if the shipment consists of several items, the seals on each item must be inspected. The operating personnel must also examine the shipping records to verify that the cask or package received is the one expected and the one described in the records. They then record on forms supplied by the plant management the cask number, gross and tare weights, cask or coolant temperature data, time of arrival, and other pertinent information and forward copies of this along with the shipping records to the plant accountability office.

If the cask is liquid cooled, the liquid is sampled to determine whether any accountable materials have leaked into it, since any source or special material found in the coolant must be taken into account in the accountability records. Coolant thus contaminated must be collected for disposal or recovery of the valuable materials, depending on the quantity of such material that it contains. The cask may need to be decontaminated (Sect. 7.1.5) but is usually only flushed before being transferred to the unloading pool, lest valuable material be lost in the decontaminating procedure.

When spent fuel assemblies are unloaded from the shipping cask, each assembly is identified by serial number. A record form or card is started, showing the assembly's identity, estimated content of source or spectal materlal, and the location where it is to be stored until recovery processing is begun. This form or card follows the assembly or other batch of material through the reprocessing plant. Copies of the record are sent to the accountability office, where the data become the plant's official record of the material. If a discrepancy is detected between the plant's data and the data on the shipping records,

\footnotetext{
* Sec aloo sect. $7.2,5$
} 
the accountability office initiates action to confirm or disprove the discrepancy. If it is confirmed, the shipper and the NRC are officially notified, and such other action as the NRC and regulatory agencies may direct is taken.

The aim here is to be sure that (1) some error was not made by the shipper, (2) source and special material was not diverted during transport, and (3) safety of the general public is maintained.

If no discrepancy is found, the cask contents are officially accepted as an item of plant input, and the quantity of source and special material stated on the shipping records is entered on the receiving record. Note that so far the actual content of source and special material has not yet been determined; we have only verified the number of pieces that are present.

The fuel assemblies must be disassembled and as much hardware removed as possible to reduce the quantity of inert material to be handled in the dissolvers. When each assembly is moved to the disassembly facility, the form started for it in the receiving area moves to the new area also, and the transfer is noted. As the disassembly progresses, the storage location (bin, rack, etc.) where the active components of the assembly are stored is entered on the form. 
REFERENCES FOR SECTION 7.1

1. Directory of Packagings of Transportation of Radioactive Materials, WASH-1279, USAEC, October 1973.

2. Fed. Regist., 38(147): 20482-20483 (Aug. 1, 1973).

3. 49 CFR $177.842(b)$ (for motor vehicles).

4. 49 CFR $174.586(h)$ (for railroad cars).

5. 49 CFR $175.655(j)(2)$ (for railroad cars).

6. 14 CFR 103.23(c) (for aircraft).

7. 46 CFR 146.19-35 (for ships).

8. 49 CFR 173.399.

9. 49 CFR $173.402(a)(8)$.

10. 49 CFR 174.54 .

11. 49 CFR 177.823 .

12. 49 CFR 173.427 .

13. 49 CFR 173.430 .

14. 49 CFR 173.393(i) and (j).

15. 49 CFR 173.393(h).

16. 49 CFR 173.393(e). 


\subsection{SPENT-FUEL RECEIVING AND STORAGE FACILITY}

Fuel discharged from a reactor after having "burned up" about $70 \%$ of its original uranium-235 content fissioning while making electric power is called "spent fuel." It is shipped to a fuel reprocessing plant as described in Sect. 7.1 , where the remaining. $30 \%$ of its fissile content is decontaminated, made into new fuel assemblies, and recycled to a reactor to be used again to produce power. In a typical reprocessing plant, a spent-fuel receiving and storage facility is provided to hold the fuel until the plant is ready to reprocess it.

\subsubsection{Genera1 Description}

A receiving and storage facility is a large, massive concrete and steel structure set deep into the ground and designed to survive a Safe Shut down Earthquake.* All spent fuel to be recovered in the plant is handled in this facility tirst. A typical fac1lity cunluius a deep-water receiv ing pool for the shipping casks and a shallower water-filled storage basin, where the contents of the casks are stored while awaiting processing. A water makeup system is provided that will survive the design basis earthquake, tornado, flood, or fire and be able to make up evaporative losses to the storage pool, even if the cooling system becomes inoperable. The facility provides means for inspecting a cask, monitoring it, and preparing it for the underwater removal of its fuel load and for strict criticality control and accountability.

The fuel is unloaded from the casks under water for both cooling and radiation shielding purposes. Special handling, such as encapsulation or canning of broken or cracked fuel assemblies, is performed, as necessary, in the cask unloading pool. The fuel removed from the shipping cask is transferred, one assembly at a time, to storage canisters by special tools attached to a fuel-assembly transfer crane or hoist. The storage canisters are then transferred individually to predetermined locations in the fuel storage basin, where the canisters are stored in racks in a critically safe array until the fuel is processed. For processing, the canisters are taken from storage in a planned sequence, and by means of a special conveyor they are transferred under water to an entry port in a mechanical processing cell, where a crane removes the assemblies from the storage canisters. The canisters are returned to the storage pool and replaced in a storage rack for reuse. The unloaded casks are removed from the pool to a cask decontamination area, where the empty casks are cleaned, monitored, and prepared for return to the reactor site.

\footnotetext{
* Defined in Code of Federal Regulations, Title 10, Part 100 (10 CFR 100).
} 
7.2.2 Shipping-Cask Decontamination (see also Sects. 7.1 .4 and 7.1.5)

A cask in which spent fuel is received is removed from the transport vehicle by a 100-ton-capacity crane and set within a curbed decontamination stall. Washdown solutions for removing dirt and low-activity residual contamination from the cask prior to its return shipment are drained to a low-activity waste treatment facility. The decontamination area is served by an elevator-type platform that facilitates preparation for underwater unloading and decontamination by traveling high-pressure water sprays. In the decontamination area, the internal temperature and pressure of the cask are measured and the coolant sampled. If necessary, the cask pressure is relieved into a duct connecting the cask decontamination area to the air washer of the building ventilation system.

\subsubsection{Cask Unloading Pool}

The cask unloading pool is adjacent to the storage pool and is used for the withdrawal of fuel assemblies from the shipping cask and their placement in fuel storage canisters (Figs. 7.2.1 - 7.2.4). The two pools connect to each other by a watertight gate. The unloading pool may be about $26 \mathrm{ft}$ by $24 \mathrm{ft}$ and filled with demineralized water to depths of $29 \mathrm{ft}$ and $44 \mathrm{ft}$. The deeper section provides the personne1 shielding necessary for removing irradiated fuel assemblies from a shipping cask resting on the bottom. The 29-ft-deep shelf area is used for temporary placement of the cask in a shroud that minimizes contact between the cask's outer surface and the pool water and for storage of the cask lid during unloading operations. The chamber between the cask and the shroud is pressurized with water from a head pot to further minimize contact of the cask externals with pool water.

The unloading pool is lined with stainless steel and equipped with both a leak-detection and a water collection and return system between the liner and the concrete wall. The watertight gate isolates the unloading pool from the storage pool in the event that highly contaminated cask coolant must be circulated through the water treatment system directly without prior dilution with storage-pool water.

The unloading pool is served by a 100-ton cask handling crane with its two 5-ton auxiliary hoists. The design is such that casks and cranes cannot be transferred over the fuel storage pool. A 1-ton fuel transfer hoist is installed on a service bridge which extends across the pool. An operator on the service bridge uses this hoist and attached extension tools to remove fuel from the cask and to place the assemblies in storage canisters. The hoist design includes a mechanical stop that prevents the raising of fuel above a minimum depth for water shielding (the 5-ton hoists may also be used to unload assemblies). Floating boxes of transparent plastic are used on the surface of the basin water as an aid to viewing. 


\section{ORNL-DWG 76-1745}

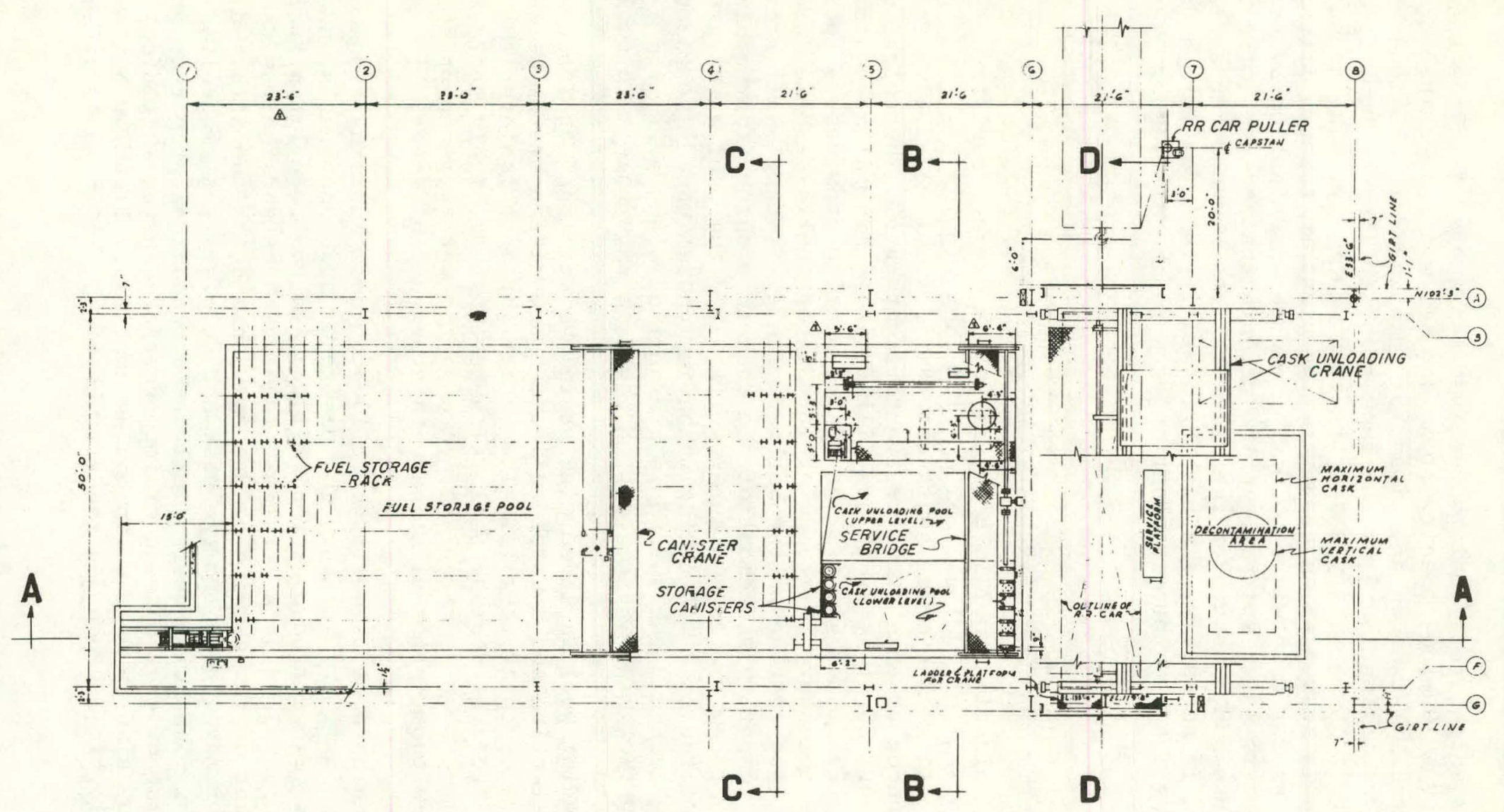

Fig. 7.2.1. Plan of Fuel Receiving, Unloading, anc Storage Areas of a Comnercial Reprocessing Plant 


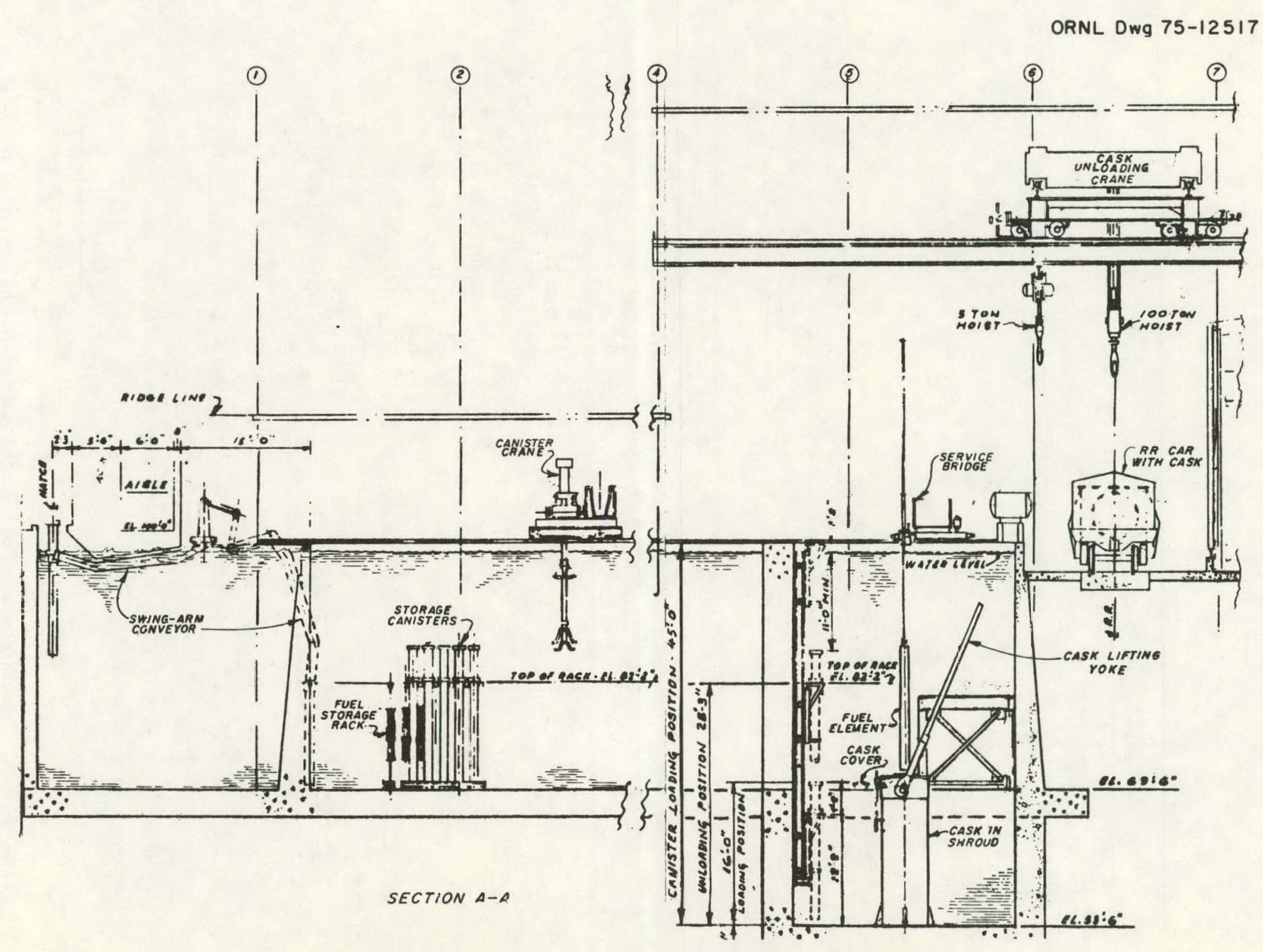

Fig. 7.2.2. Section of Fuel Receiving, Unloading, and Storage Areas of a Ccmmercial Reprocessing Plant 

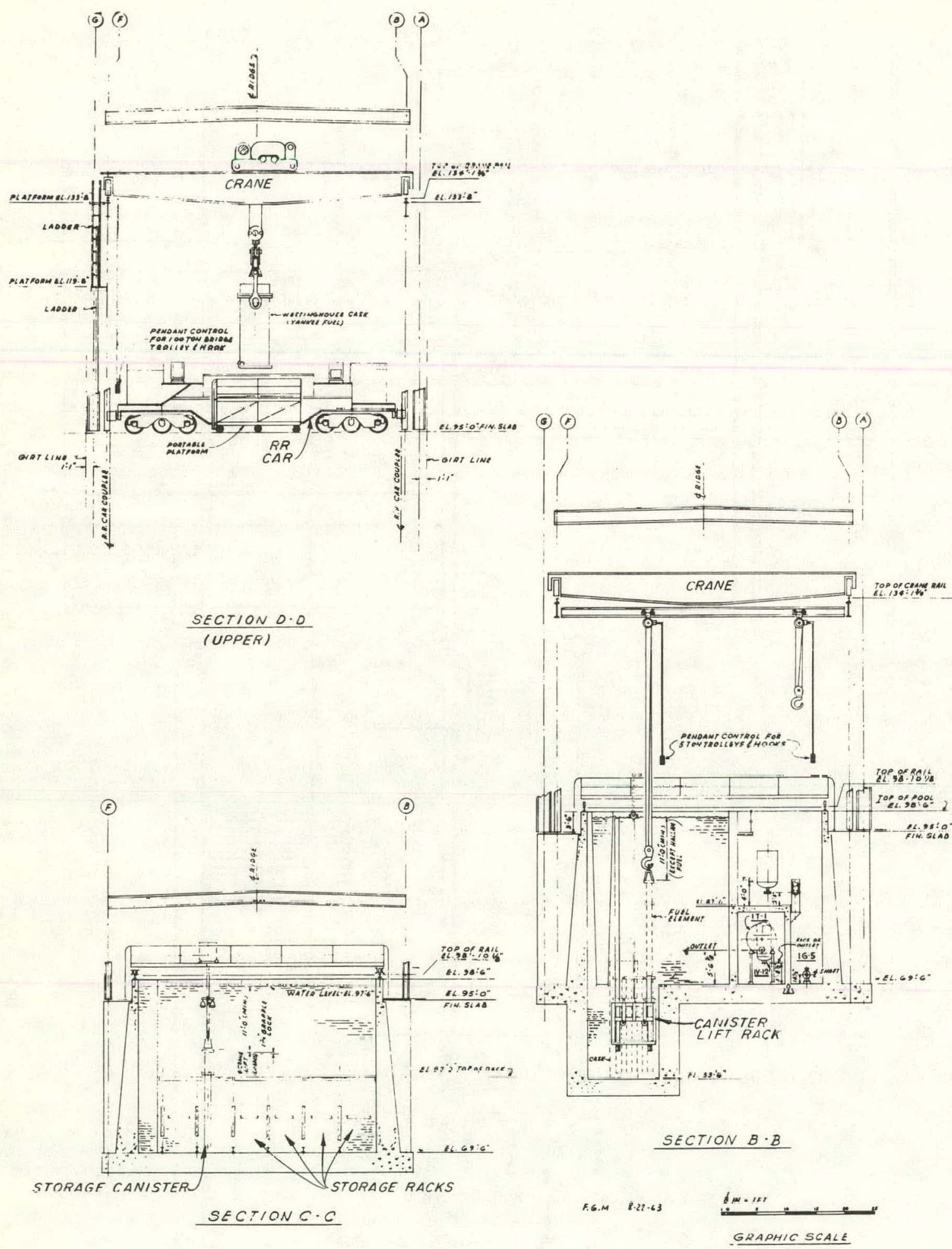

Fig. 7.2.3. Sections of Fuel Receiving, Unloading, and Storage Areas of a Commercial Reprocessing Plant 
ORNL Dwg 75-12516

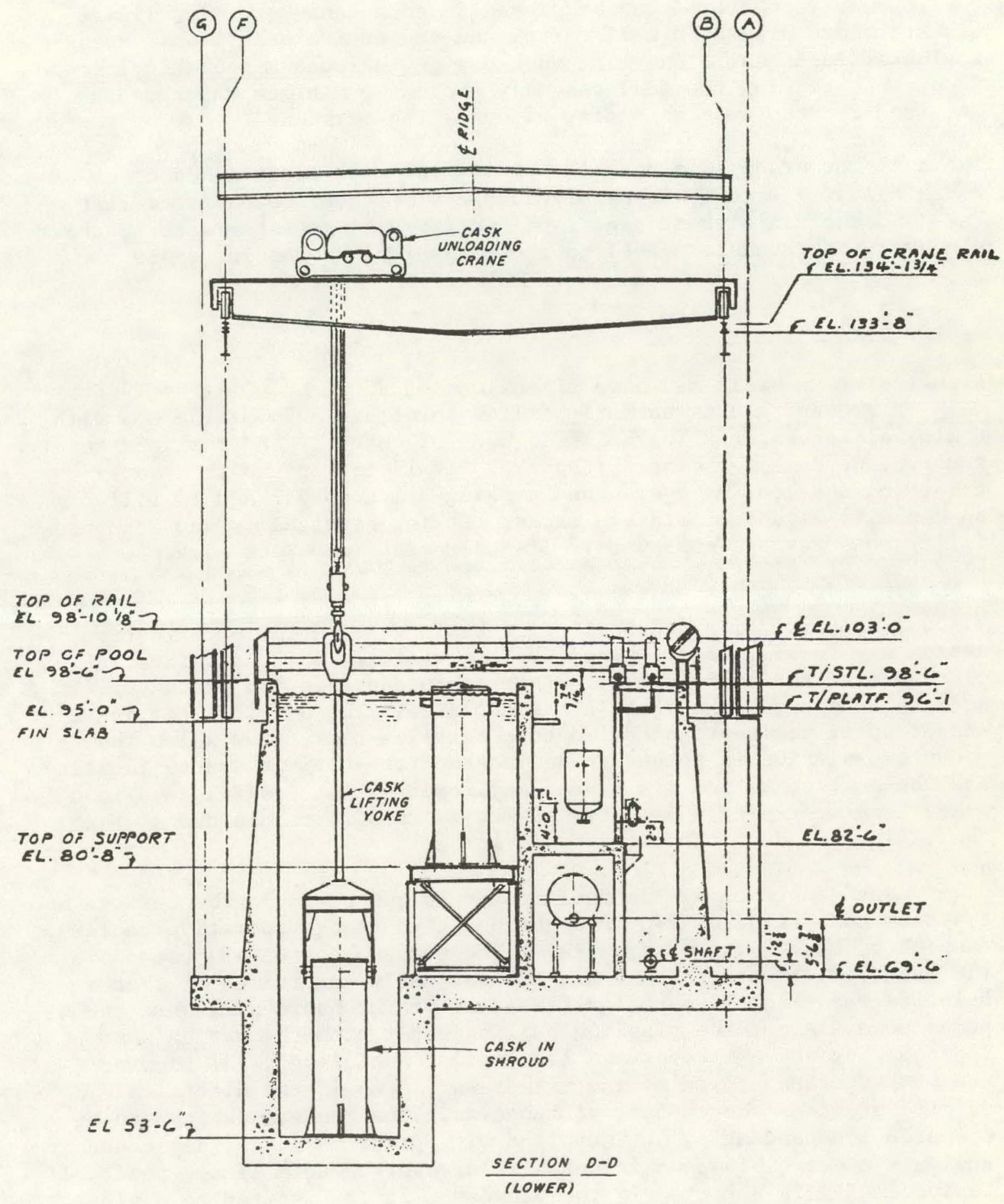

Fig. 7.2.4. Cask Unloading Area of a Commercial Reprocessing Plant 
Storage canisters (Fig. 7.2.5), fabricated of aluminum, hold fuel assemblies up to $16 \mathrm{ft}$ in length and about $9 \mathrm{in.} \mathrm{by} 9 \mathrm{in}$. in cross section. Two or three of the smaller assemblies, such as those from boiling-water reactors, can be placed in each canister. The filled canisters are placed in a lift rack and the entire rack transferred to the storage pool. The lift rack design includes a mechanical stop to prevent raising the fuel assembly above the minimum water depth required for the safe shielding of operating persumul.

The canister crane is a movable-bridge type with an attached crane of 2-ton capacity used to transfer canisters between the canister lift rack and the canister storage rack and from the storage racks to the conveyor that transfers fuel to the mechanical processing cell.

\subsubsection{Fue1 Storage Basin}

A fuel storage basin may have dimensions of $75 \mathrm{ft}$ by $40 \mathrm{ft}$ by $29 \mathrm{ft}$ deep or greater and is normally filled to within $2 \mathrm{ft}$ of the top with demineralized water. The basin is made of concrete and designed to survive the safe shutdown earthquake. It is equipped with a water treatment and cooling system and a swing-arm conveyor and is filled to capacity with fuel storage racks. Strict criticality and accountability measures are employed in its operation (see Sect. 7.2.5).

7.2.4.1 Purification and Cooling of Basin Water - The purification system may consist of a 500-gpm ur larger filter which utilizcs replaceable tilter media and a 100-gpm nonregenerable ion exchanger, both units housed in a water treatment area. The spent filter media and/or spent resin are slurried to a settling tank, from which the decanted solution is pumped to an intermediale-activity waste facility, and the settled solids are loaded semiremotely into waste drums in a waste treatment pit. The water purity is usually maintained so that the maximum conductivity is 250,000 mohs.

Decay heat generated by the fuel stored in the basin may be removed by a system consisting of two 1200-gpm pumps and two evaporative coolers, each of $6,000,000 \mathrm{Btu} / \mathrm{hr}$ capacity. The pumps are mounted just above the water treatment area and are automatically controlled so that a 6-in. decrease in the normal water level of the basin will shut the pumps down. Also, the pipeline pulling water from the basin is so located that any 2-ft decrease from normal pool level will uncover the pump suction and terminate withdrawal, even if the electrical safety interlock should fail to function. The coolers, which can be operated independently, are supplied with plant water as the secondary coolant, and the blowdown is normally discharged to a sludge pond. If radioactivity is detected in the blowdown, it is diverted to a plant interceptor system. The cooling water system can be connected to an emergency power source. 
ORNL-DWG $76-1694$

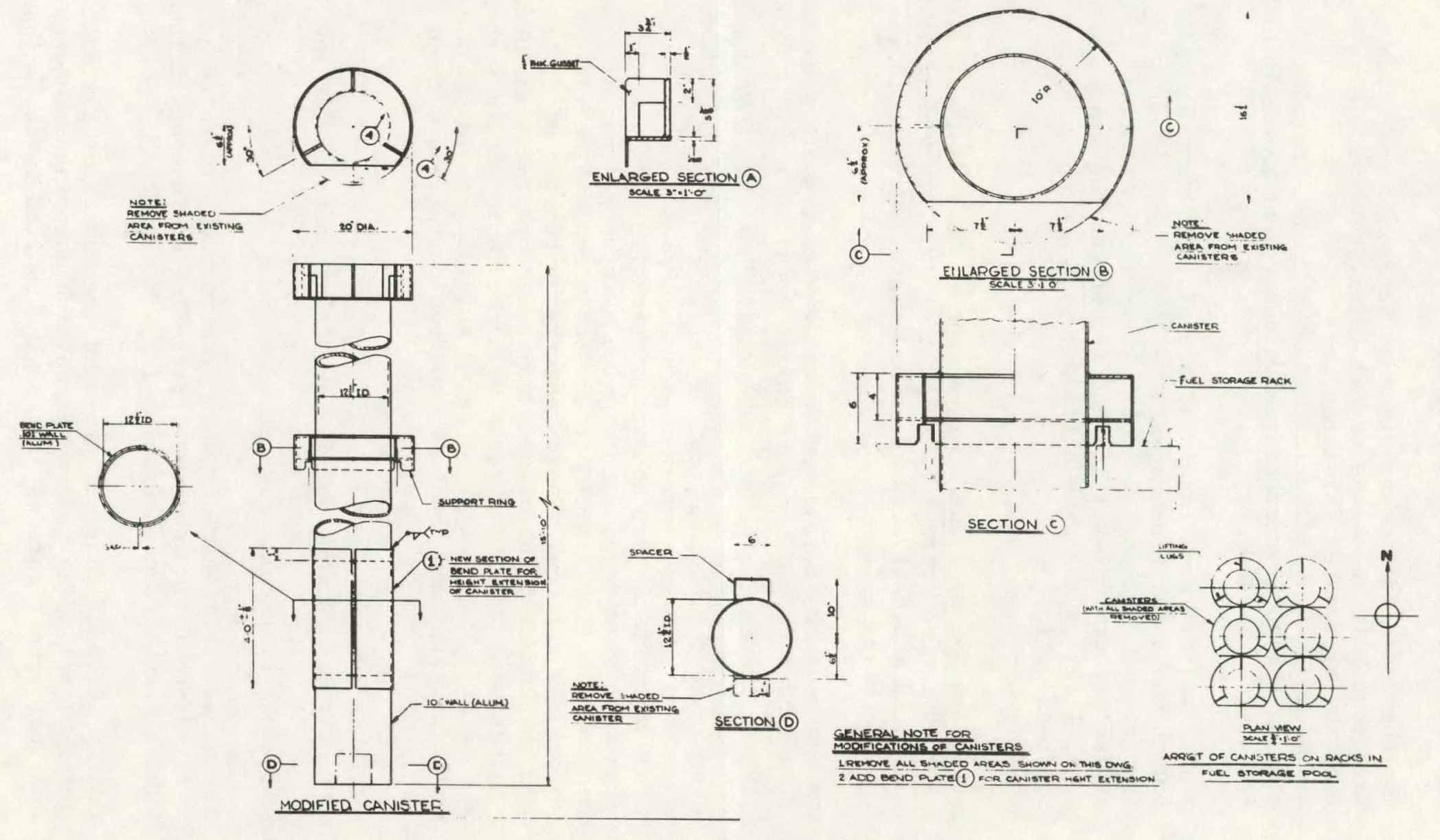

Fig. 7.2.5. Storage Cannisters 
Loss of basin water is guarded against by

1. the absence of drains or siphons that could lower the pool more than $2 \mathrm{ft}$ below the normal level, thus providing at least $9 \mathrm{ft}$ of water shielding,

2. cooling the pool water to remove decay heat and minimize evaporative losses,

3. monitoring the pool level and sounding an alarm at levels lower than 6 in. from normal,

4. a leak detector (level indicator) between the stainless steel liner of the cask unloading pool and the adjacent concrete walls.

7.2.4.2 Swing-Arm Conveyor and Storage Rack - Once fuel assemblies have been placed in the storage racks of the basin, they must be removed as scheduled and delivered by an underwater conveyor to the mechanical processing cell.

A swing-arm conveyor or similar mechanical device transfers canisters, one at a time, under water to a port in the mechanical processing cell, where the fuel assembly is withdrawn by a crane for subsequent mechanical processing in the cell. Materials from the mechanical cell can also be returned to the storage pool if desired.

A fuel storage rack system may consist of para1lel aluminum beams submerged in the fuel storage pool to provide 42 storage rows of about 26 canisters per row ( 1092 total storage positions). The racks and canisters provide a critically safe geometry by the use of a minimum edge-to-edge spacing of 8 in. between adjacent rows and 4 in. between canisters in the same row. The racks hold the canisters in such a way that there is a minimum of $11 \mathrm{ft}$ of water shielding above the fuel. They are built to withstand the safe shutdown earthquake without dropping the stored fuel or tipping over.

\subsubsection{Criticality and Accountability (see also Sects. 7.1.6 and 7.1.7)}

Protection against criticality is provided by

1. technical specifications which restrict the fuels to be received to those whose preirradiation enrichment is less than 5 weight percent uranium-235,

2. confirmation of the fuel type and the number of assemblies prior to unloading by comparison with shipping documents and fuel specifications previously supplied by the shipper, 
3. critically safe geometry in the fuel storage canister design that makes a criticality event impossible,

4. moving only one fuel canister at a time and using an arrangement that avoids moving fuel assemblies over stored fuel,

5. fuel storage racks that guarantee safe geometric spacing and that will not allow unsafe rearrangement of the storage canisters, even during a safe shutdown earthquake.

Fuel is supplied to the mechanical processing cell according to a strict administrative procedure specified in a Reprocessing Campaign Letter of Authorization. This procedure not only identifies each subassembly but limits the number that can be brought into the processing cell to a total of 3. The fuel cannot be moderated to criticality in the cell, since there is no way for sufficient water to accumulate to cover the assemblies.

\section{3 FUEL DISASSEMBLY AND SIZE REDUCTION}

In the early days of spent-fuel reprocessing, the fuel elements were dissolved completely by caustics and acids, and mechanical treatment was not required. The power reactor fuel elements made of Zircaloy (an alloy of zirconium metal and tin), Incone1, and stainless steel (or a combination of these materials) are very difficult to dissolve, and if dissolved, their process streams would require very costly and exotic metals to contain them. However, this can be avoided by mechanically breaking these fuel elements into short pieces and leaching out the fissile and fertile fuel, leaving the unfueled cladding intact or as "hulls." Nitric acid, which is used for this leaching, can be easily accommodated in process equipment made of stainless steel. Thus, the mechanical processing operations of cropping, disassembly, and shearing of spent power reactor fuel elements into short pieces ( 1 to 2 in. 1 ong) have now become a vital function practiced in all reprocessing plants. These operations are carried out in a heavily shielded and remotely operated facility containing air or an inert atmosphere of nitrogen or argon. This facility is located adjacent to the fuel storage basin, and the operations carried out in it are generally referred to as headend processing of spent fuel, because these steps prepare the fuel for recovery in the downstream PUREX solvent-extraction process portion of the plant.

Typical head-end fuel reprocessing steps $^{1}$ used at one commercial reprocessing plant are shown in Fig. 7.3.1. However, the deshrouding options of plasma or mill cropping of fuel are not practiced at this time. In contrast, a second reprocessing plant has proposed to use disassembly equipment to shear a single layer of about nine fuel rods rather than the entire assembly. A third plant plans to crop a subassembly in the shear rather than in a separate out-of-shear operation. 


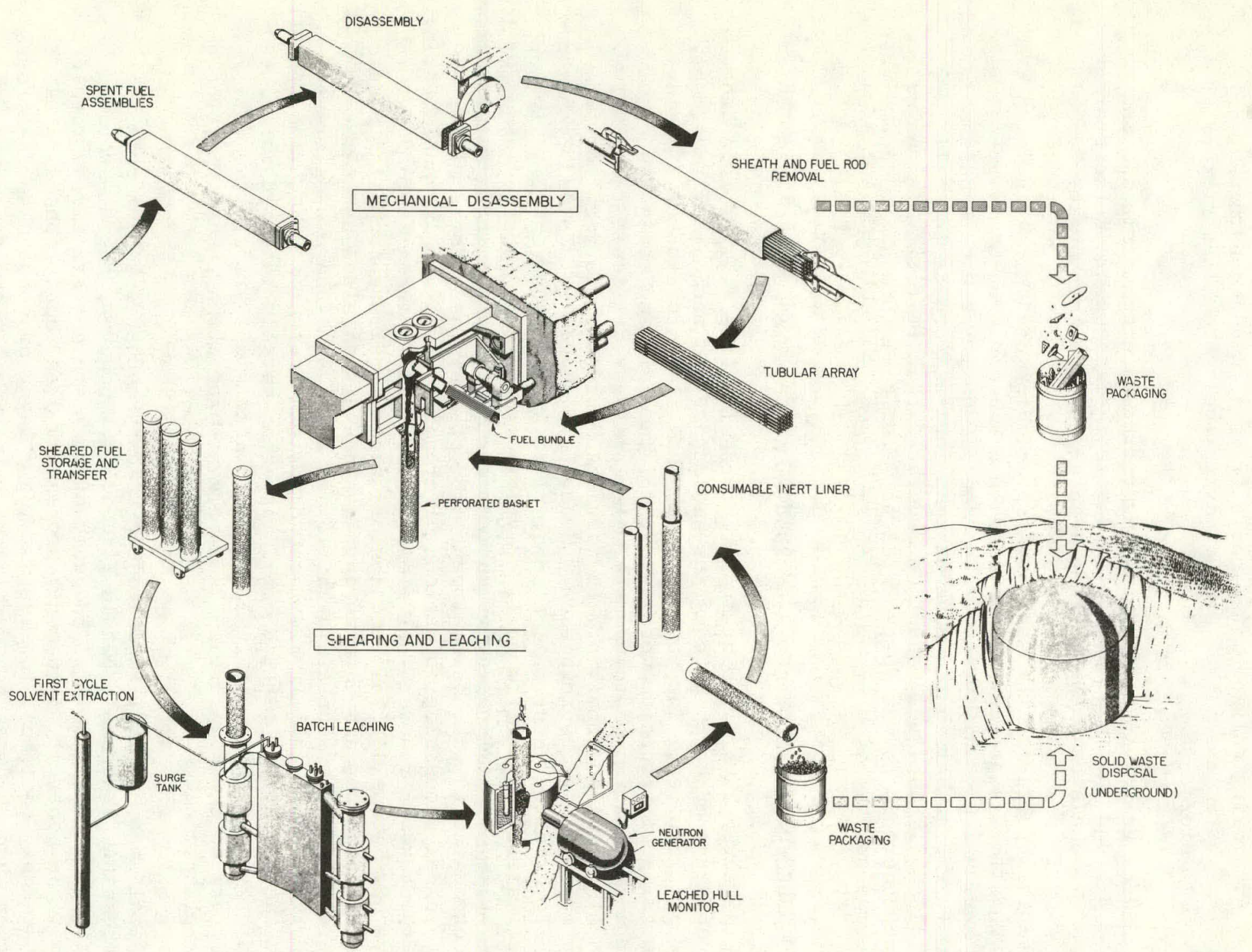

Fig. 7.3.1. Head-End Fuel Reprocessing Equipment at a Commercial 
Also, this plant plans to shear an entire subassembly and supply sheared product directly to the dissolvers from the shear rather than use an intermediate step of containing the sheared product in baskets, as is done at the first plant.

\subsubsection{Description of Typical Fue1 Assemblies}

Some typical power reactor fuel subassemblies are shown in Figs. 7.3.2 and 7.3.3.2 A typical fuel subassembly from a fast breeder reactor, which will probably not be available for reprocessing in quantity until about 1990, is shown in Fig. 7.3.4.1 In contrast to the light water reactor (LWR) fuels, its fuel pellets are made of a mixture of uranium dioxide and plutonium dioxide.

In the early days of reactor development, a typical LWR subassembly ranged in size from about $4 \times 4$ in. in cross section to about $9 \times 9$ in. and varied in length from about $7 \mathrm{ft}$ up to $12 \mathrm{ft}$ or more. Each subassembly (Fig. 7.3.5) ${ }^{2}$ was comprised of an array of fuel rods (tubes) 0.3 to $0.4 \mathrm{in}$. in diameter filled with uranium dioxide $\left(\mathrm{UO}_{2}\right)$ pellets. The fuel rods were spaced usually in a square array by an arrangement of grids placed from 6 to 12 in. apart from one end of the subassembly to the other. Early subassemblies used stainless steel tubes, grids, sheaths, and inlet and outlet nozzles. Now, the fuel tubes are nearly always Zircaloy-2, the grids Inconel, and the inlet and exit coolant nozzles stainless steel. The ratio weight of metal (Zircaloy-2, Incone1, stainless steel, etc.) to that of nuclear fuel is about 1.2, which means that for every ton of fuel recovered, 1.2 tons of metallic waste must also be handled and disposed of.

A subassembly may weigh from 70 to $150 \mathrm{~kg}$ and emit as much as several kilowatts of decay heat. In general, the fuel is also allowed to stay in the storage facility until the heat emission is low enough not to be a problem during reprocessing. Decay heat emission (up to $10 \mathrm{kilo-}$ watts per assembly) will be a problem with the fast breeder fuels, however, and cooling will have to be provided until the fuel is mechanically converted into sma11 pieces suitable for leaching.

\subsubsection{Description of a Typical Mechanical Processing Cel1}

A typical mechanical processing cell is usually a rectangular structure whose interior is approximately $14 \mathrm{ft}$ wide, $50 \mathrm{ft}$ long, and $25 \mathrm{ft}$ high. The walls may be made of 4-ft thick high-density concrete or 5-1/2-ftthick ordinary concrete to provide radiation shielding for operating personnel. For example, if an operator were spread-eagled on the exterior face of the shield wall, he would receive a radiation exposure of about $0.25 \mathrm{mrad} / \mathrm{hr}$ or less. The floor and interior walls (at least to wainscot height) are usually covered with stainless steel to aid in controlling radioactive contamination. Areas of the cell not protected by stainless steel are painted with a light-colored radiation-resistant protective coaling to afd viewing and decontamination. 

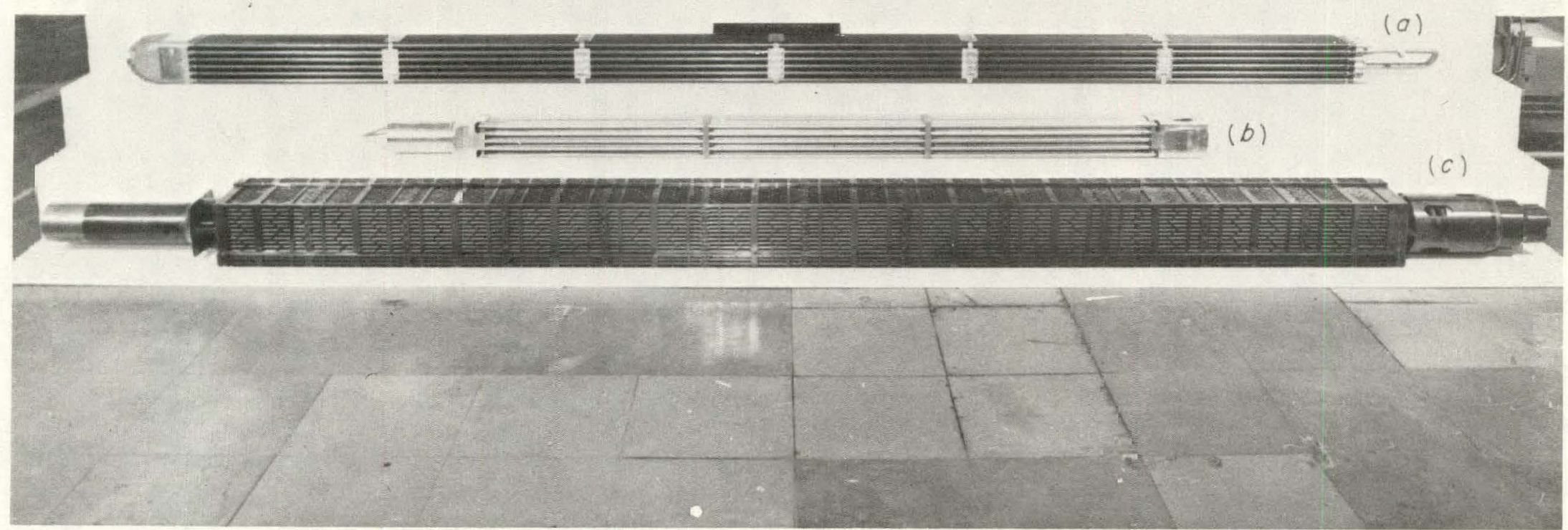

Fig. 7.3.2. Fuel Subassemblies

a. DRESDEN $-\mathrm{Zr}-2-\mathrm{UO}_{\hat{L}}$

b. ELECTRIC POWER - SS - $\mathrm{UO}_{2}-\mathrm{ThO}_{2}$

c. $\mathrm{CON}$ EDISON - $\mathrm{SS}-\mathrm{UG}_{2}$ 


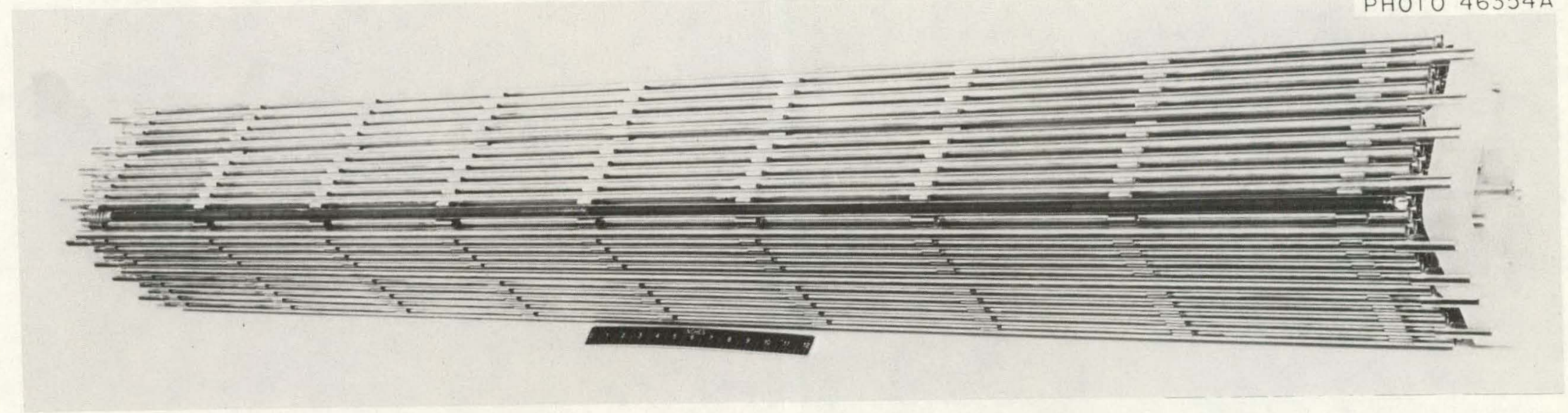

Fig. 7.3.3. Prototype Fuel Subassembly, Nuclear Merchant Ship Savannah 


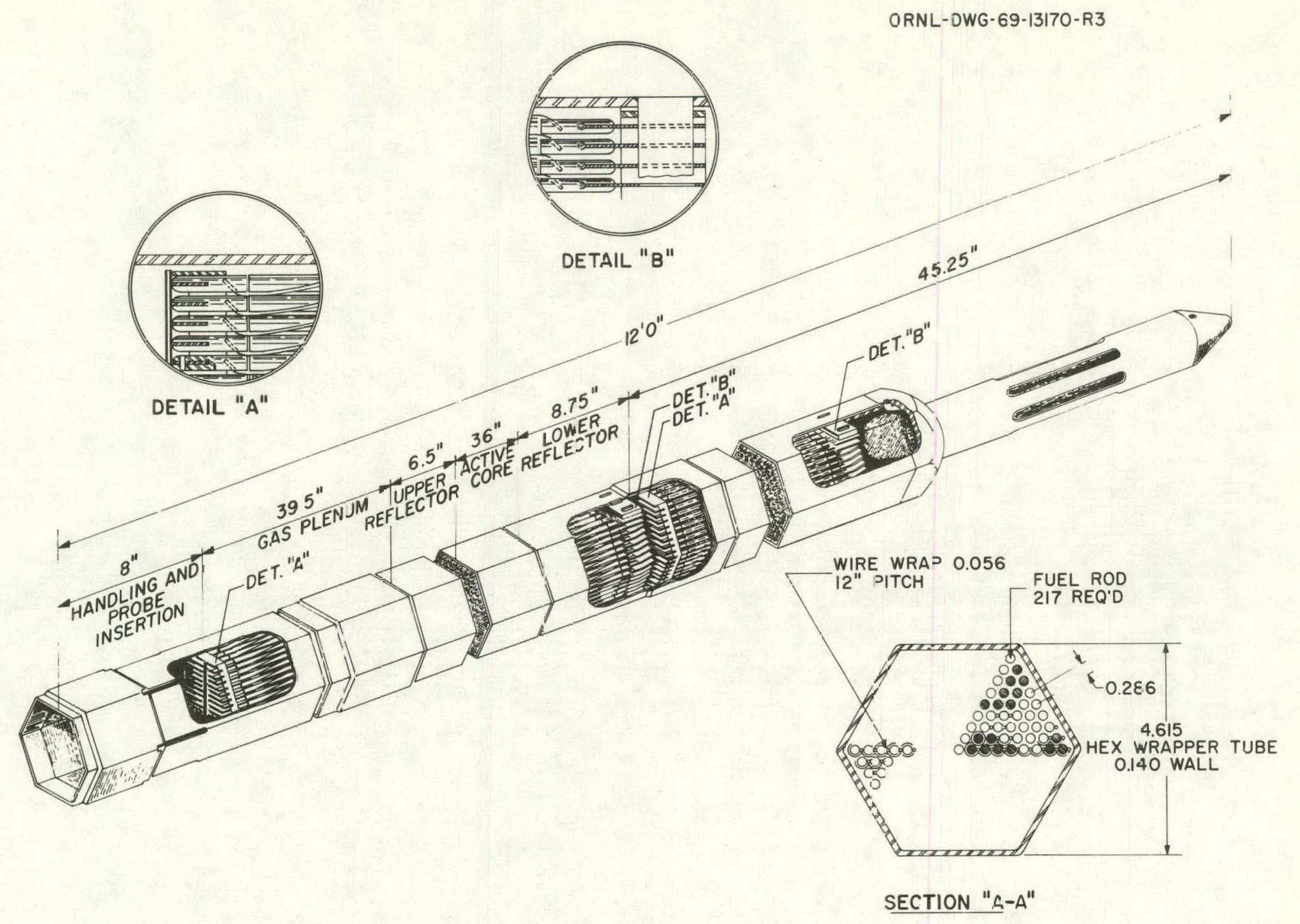

Fig. 7.3.4. Fast Test Reactor Driver Subassemb1y (FTR or FFTR) 


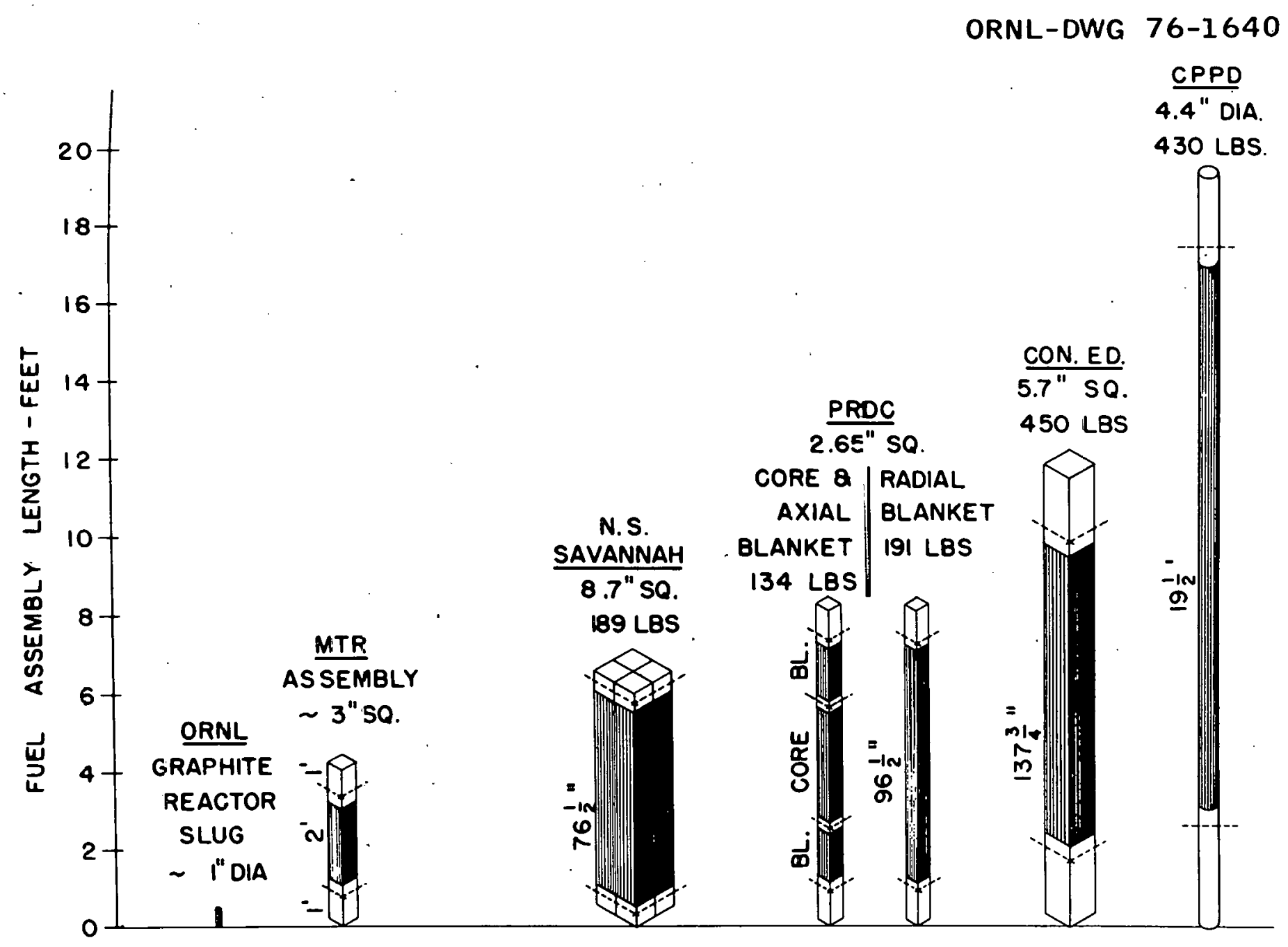

Fig. 7.3.5. Relative Sizes and Weights of Some Early Power Reactor Fue1 Assemblies 
The walls contain viewing windows at suitable intervals to permit surveillance of the entire cell. Direct viewing is also supplemented by $\mathrm{TV}$ cameras in the cell that connect to monitors outside the cell walls. The cell interior is illuminated by a high-intensity lighting system (sodium vapor, mercury, or xenon), usually used in conjunction with an incandescent system.

Generally, a mechanical cell is provided with a ventilation system in which several thousand cubic feet of air per minute is withdrawn from the surrounding operating areas into the cell, maintaining the cell at a slight negative pressure. The air discharged from the cell is filtered through roughing ( $85 \%$ efficient) and absolute ( $99.97 \%$ efficient for 0.3-micron particles) filters prior to being exhausted through the plant ventilation system and up a tall stack. The cell is also provided with "hot" drains connected to the appropriate plant waste system to handle liquid effluents (water, acid, caustics, etc.) that may contain radioactive materials.

The mechanical processing cell connects to both the fuel storage basin and the chemical processing part of the reprocessing plant. All fuel to be processed must pass through this facility before going in an altered form to the chemical part, as it cannot be handled or processed in the chemical plant in its original configuration. The arrangement of the mechanical processing cell in relation to the other cells at one commercial plant is presented in Fig. 7.3.6, which also includes a schematic flow pattern of the fuel during mechanical processing, the type of equipment used, and the mechanical devices employed to operate the equipment. The fuel storage basin and the mechanical processing cell and equipment are shown in Fig. 7.3.7 and the general purpose cell and chemical processing cells in Fig. 7.3.8.

\subsubsection{Description of Typical Mechanical Processing Cell Operating Equipment}

A mechanical processing cell contains several pieces of equipment for handling the fuel assemblies during the various mechanical preparation operations and for maintenance and repair of the process equipiment and the cell facility itself. The principal equipment components are two 2-ton bridge-mounted cranes for handling fuel, a bridge-mounced power manipulator, and several master-slave manipulators. Without these pieces of equipment the cell cannot be operated. The equipment is operated remotely from the mechanical operating alsles.

Bridge Cranes - The two 2-ton bridge-mounted cranes for handling fuel are used to transport the fuel assemblies to the various mechanical preparation work stations. They are also used in heavy maintenance and repair operations. The two cranes travel the length of the cell on the same track. They are normally controlled independently of each other by separate remote control consoles; however, they may be controlled 


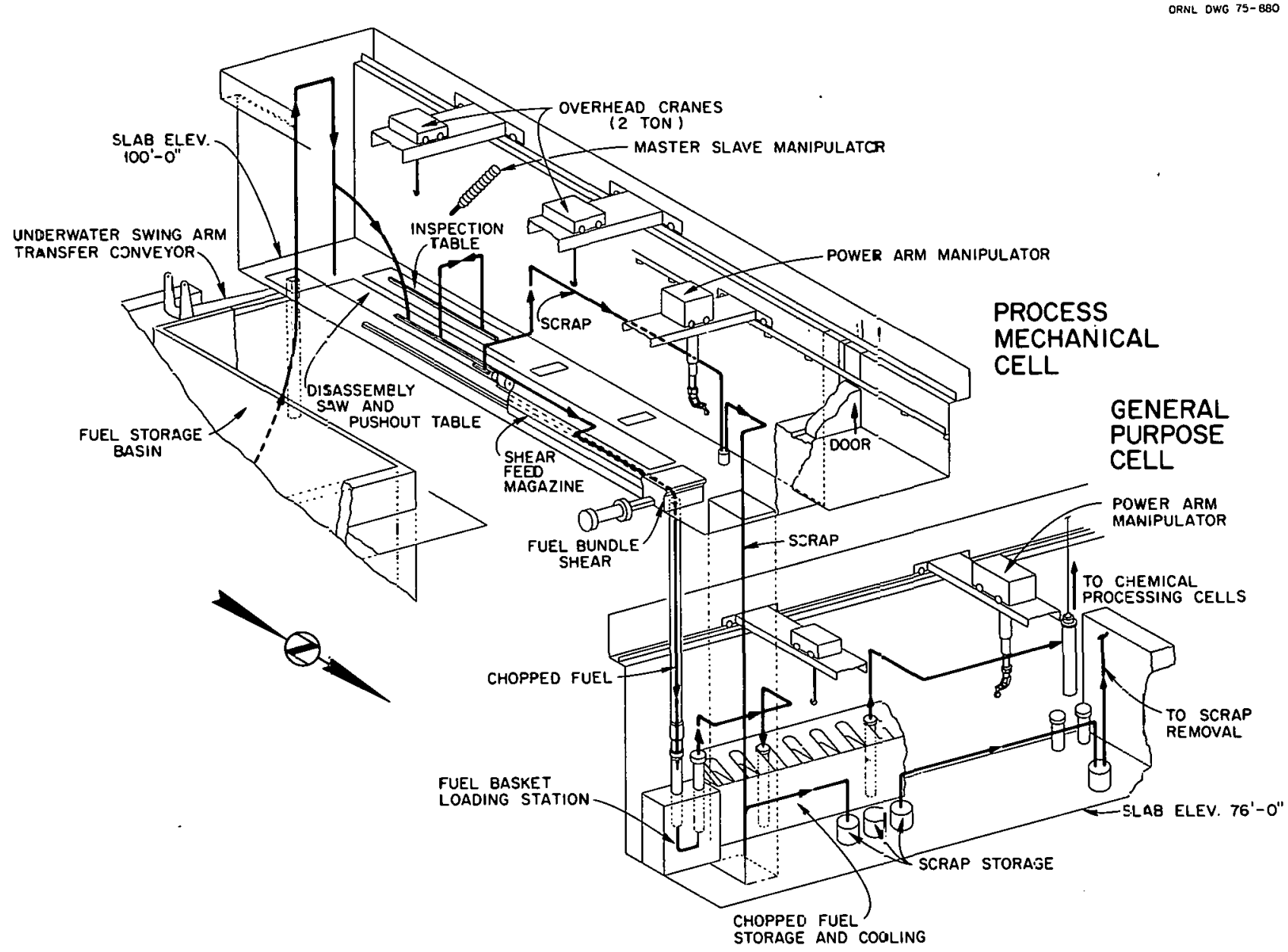

Fig. 7.3.6. Arrangement of the Head-End Mechanical Cells and Equipment in $a$ Commercial Reprocessing Plant 


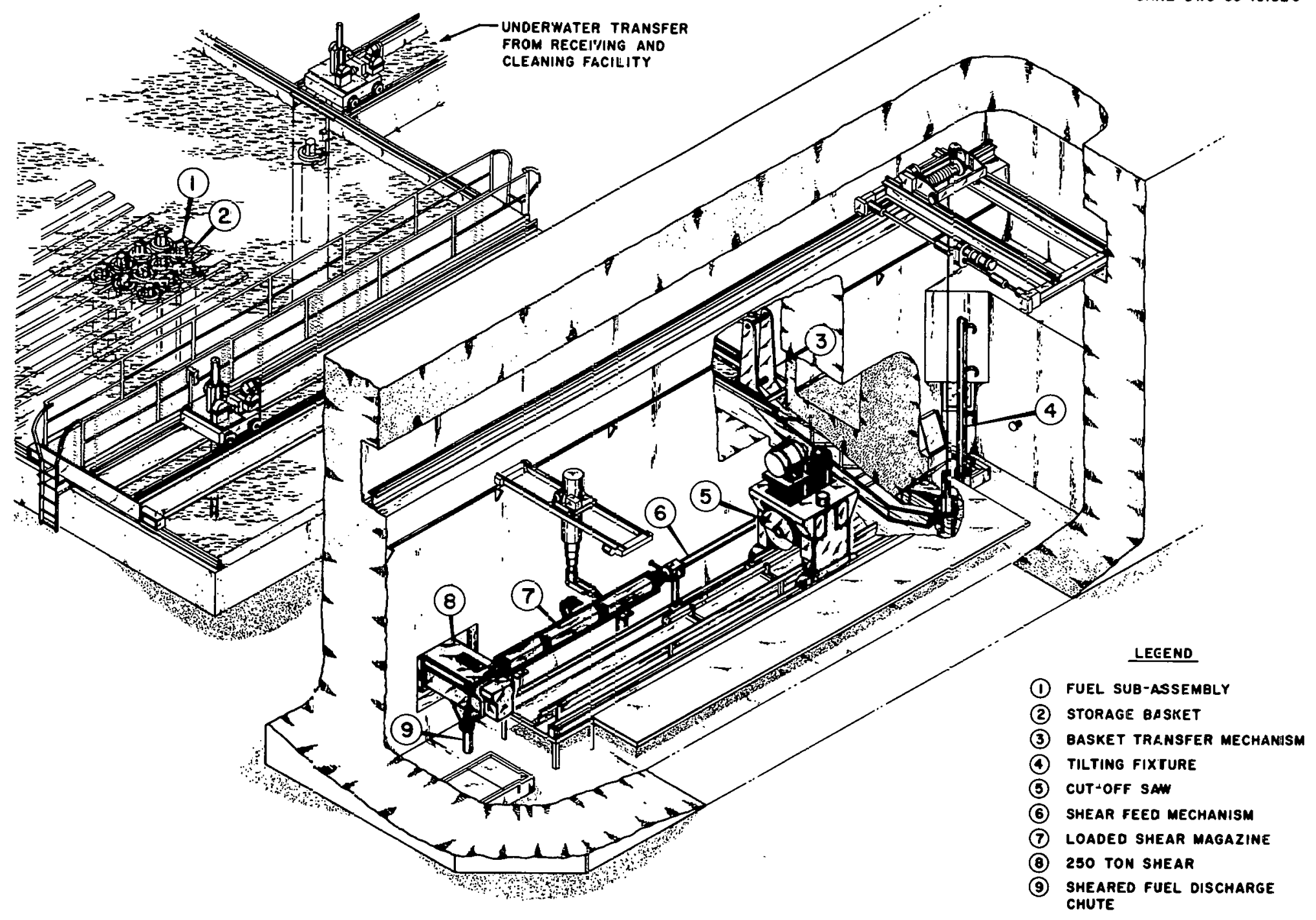

Fis. 7.3.7. Head-End Reprocessing Facility Storage Basin and Mechanical Processing Cell 
ORNL DWG 69-13189

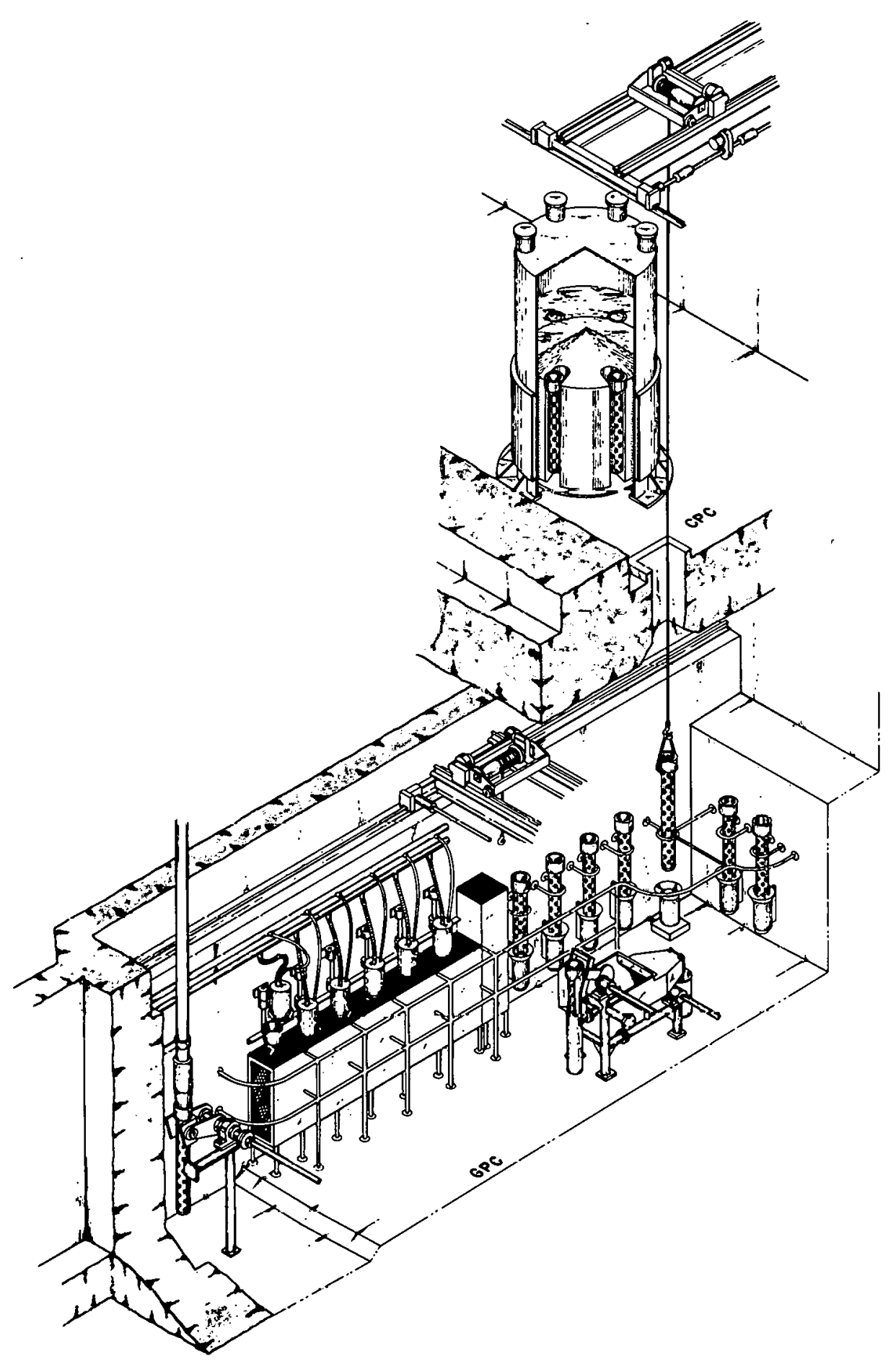

Fig. 7.3.8. Reprocessing Facility [General Purpose (GPC) and Chemical Process (CPC) Cells] 
as one unit for moving heavy equipment. Each hoist also travels the width of the cell on a trolley located on the crane bridge. The units are the manufacturer's standard equipment, but adapted to the cell environment.

Power Manipulator - The mechanical processing cell power manipulator is a bridge-mounted unit which travels the length of the cell on tracks below the 2-ton bridge crane tracks and travels the width of the cell on a trolley mounted on the bridge. It has shoulder, elbow, wrist, and hand motions, which a crane does not have, and can handle objects weighing $150 \mathrm{lb}$ or less in any position. If fills a need between lightweight master-slave manipulators and the heavy-duty cranes. The manipulator is mounted on a telescoping boom that permits the positioning of the gripper from the floor line to $14 \mathrm{ft}$ above the filoor. The unit's characteristics are those of a standard commercial power arm (Fig. 7.3.9) modified for the local cell environment.

Master-Slave Manipulators - The master-slave manipulators are used for remote handling of small objects, such as hand tools and related equipment used in the maintenance and inspection operations required with mechanical preparation of fuel assemblies within the mechanical processing cell. The master-slave manipulators are the manufacturer's standard heavy-duty, extended-reach mode1. They are powered by the operator in normal usage; the extended-reach feature is electrically powered.

Generally speaking, a master-slave manipulator (Fig. 7.3.10) is limited to a straight lift of $60 \mathrm{lb}$ and the hand of $20 \mathrm{lb}$. Master-slave units are mounted in the shield walls of the cell, the motion being transmitted through the wall by flat steel tapes and pulleys sealed within rotary shafts or by a more recent electronic feed-through system.

Although all three types of operating equipment described above have rather specific duties and mechanical operations to perform, it is their combined and intertwined use that makes the operation of a mechanical cell possible.

\subsubsection{Description of Some Mechanical Processing Cell Process Equipment}

A mechanical processing cell may contain a saw for cropping a subassembly, specialized equipment for dismantling and pulling the fuel rods from gridded subassemblies, and a shear for breaking an entire subassembly or a layer of fuel rods into short pieces (about 1 in. 1ong). These mechanical equipment components, which are maintained and operated remotely by cranes, power arms, and master-slave manipulators as described in Sect. 7.3.3, are usually custom-made and are probab1y one-of-a-kind pieces of equipment. 
ORNL-DWG 76-1690

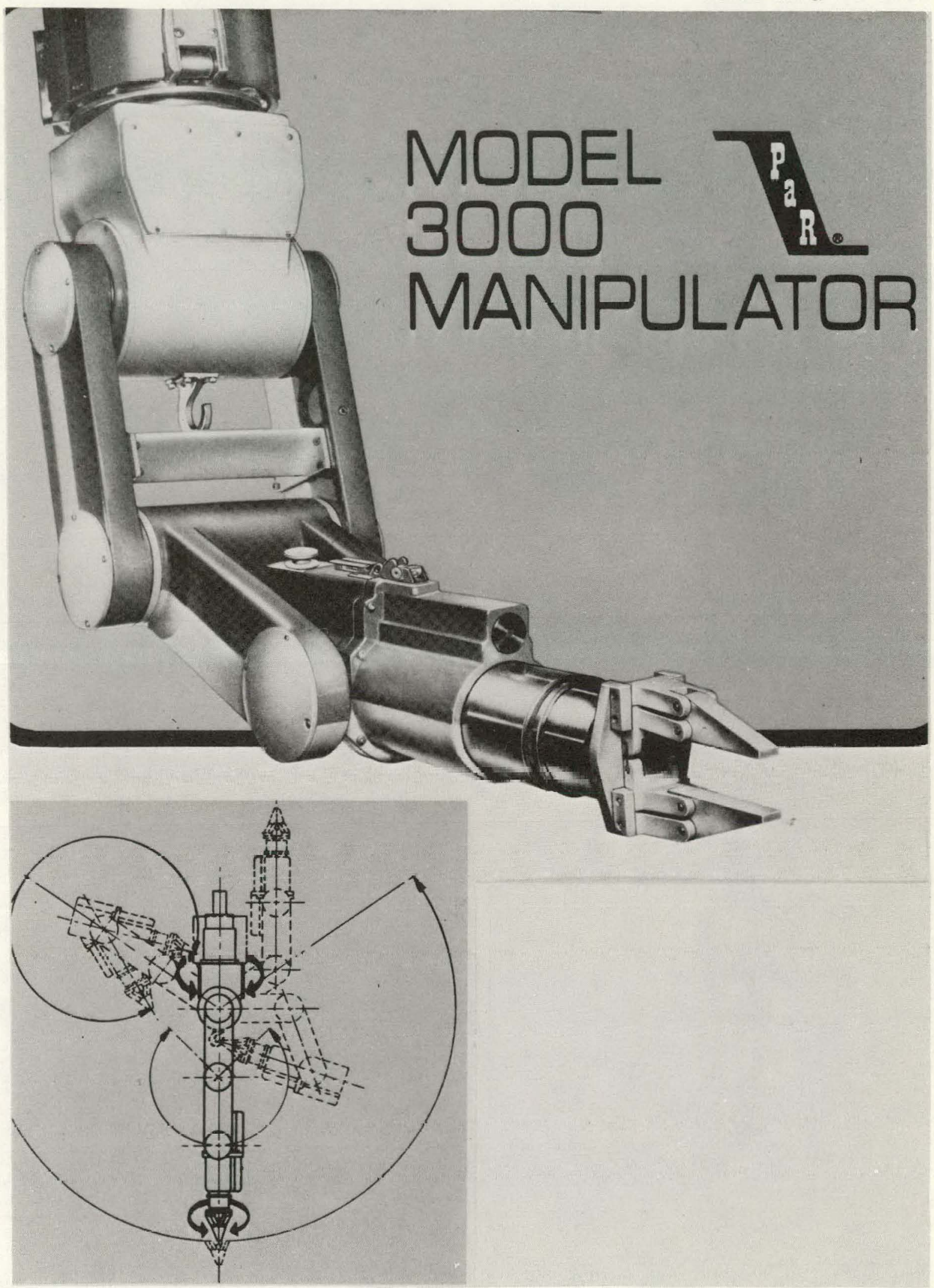

Fig. 7.3.9. A Commercial Power-Arm Manipulator 


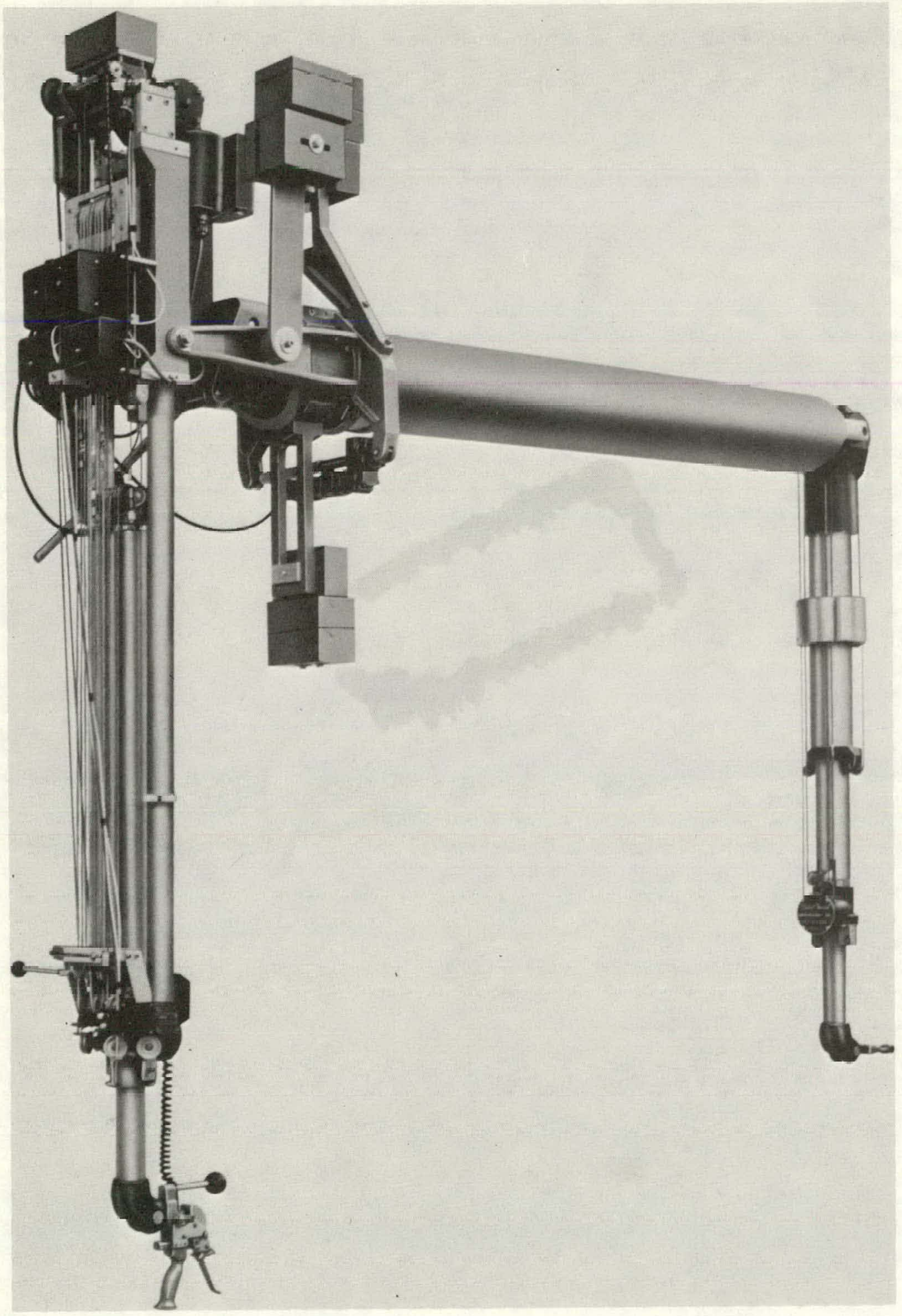

Fig. 7.3.10. A Commercial Master-Slave Through-The-Wall Manipulator 
Cutoff or Cropping Saw - Saws are used to remove the unfueled inlet and outlet coolant nozzles from a subassembly. These pieces contain no valuable materials and, as such, are tramp metal and a nuisance to the subsequent processing operations. One commercial plant tried a customdesigned abrasive disk saw for cutting transversely to remove the nozzles. This particular saw proved to be so unwieldy in actual use that it was discarded, and simple commercial band saws were successfully substituted. Several ends are collected in drums and stored in a waste depository. Manipulator-held electrically powered rotary hand saws with the appropriate blades have also been used quite successfully in slitting operations during disassembly of a fuel unit. Another commercial plant does not use saws for cropping, preferring to perform this operation in the shear. Another plant is able to take apart the particular fuel used there by removing retaining washers and nuts with a special mechanical device, and cropping is not required. These methods allow the nozzles and shrouds to be reused, if desired.

A plasma arc torch and an electric arc saw (nonconsumable rotary electrode) can also be used for cropping, but these methods have not been applied in commercial reprocessing plants or hot-cell facilities.

Disassembly - One commercial plant plans to remove the appropriate end nozzle, withdraw the fuel tubes, and shear them in a single side-by-side nine-rod layer. A prototype model illustrates this principle in Fig. 7.3.11. The ejector plate in Fig. 7.3.11 displaces a row of fuel rods several inches forward into the gripper head, which clamps to the end of the rods and withdraws them. Another method now being developed involves the circumferential cutting of the inlet nozzle and withdrawal of the entire fuel rod array as a single bundle. All the methods just enumerated involve sawing or cutting operations, and the saw blades and cutters must be routinely replaced remotely with manipulators.

Shearing - In general, in the United States, fuel is sheared in the form of a cropped subassembly. Some of the smaller capacity foreign plants may shear single fuel rods or a multirod array. A 250-ton prototype subassembly shear, from which all the large commercial shears including those abroad were designed, is shown in Fig. 7.3.12. In this figure, the white structure section just to the right of the operator standing in the foreground may be considered as the shiclding wall of the cell. Thus, the hydraulic cylinder is outside the shield wall, and the shear and its feed mechanism are inside the cell. The shear blade moves on a horizontal plane from right to left in the figure, and a fuel assembly, restrained at a right angle to it, is fed in the appropriate increments horizontally into the shearing mechanism by a feed device. The restraining mechanism is a set of dual "gags" which hold the fuel while it is being sheared. The sheared product falls by gravity down an inclined or vertical chute into baskets or directly into a leacher (dissolver). The shear cavity can be filled with an inert gas, if desired, when shearing Zircaloy-clad fuels. 


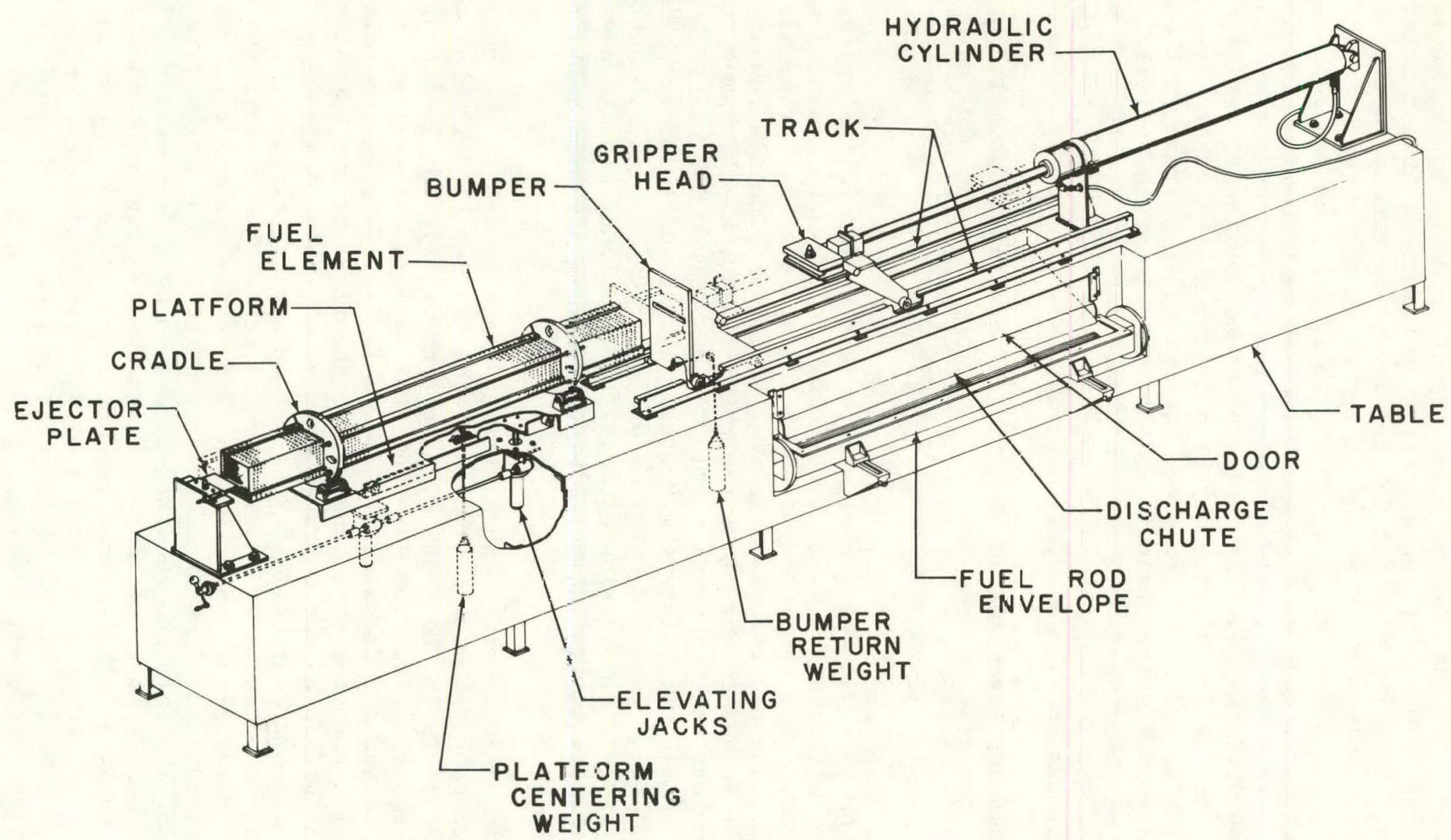

Fig. 7.3.11. Prototype Consolidated Edison Core B Multi-Tube Withdrawal Vechanism 


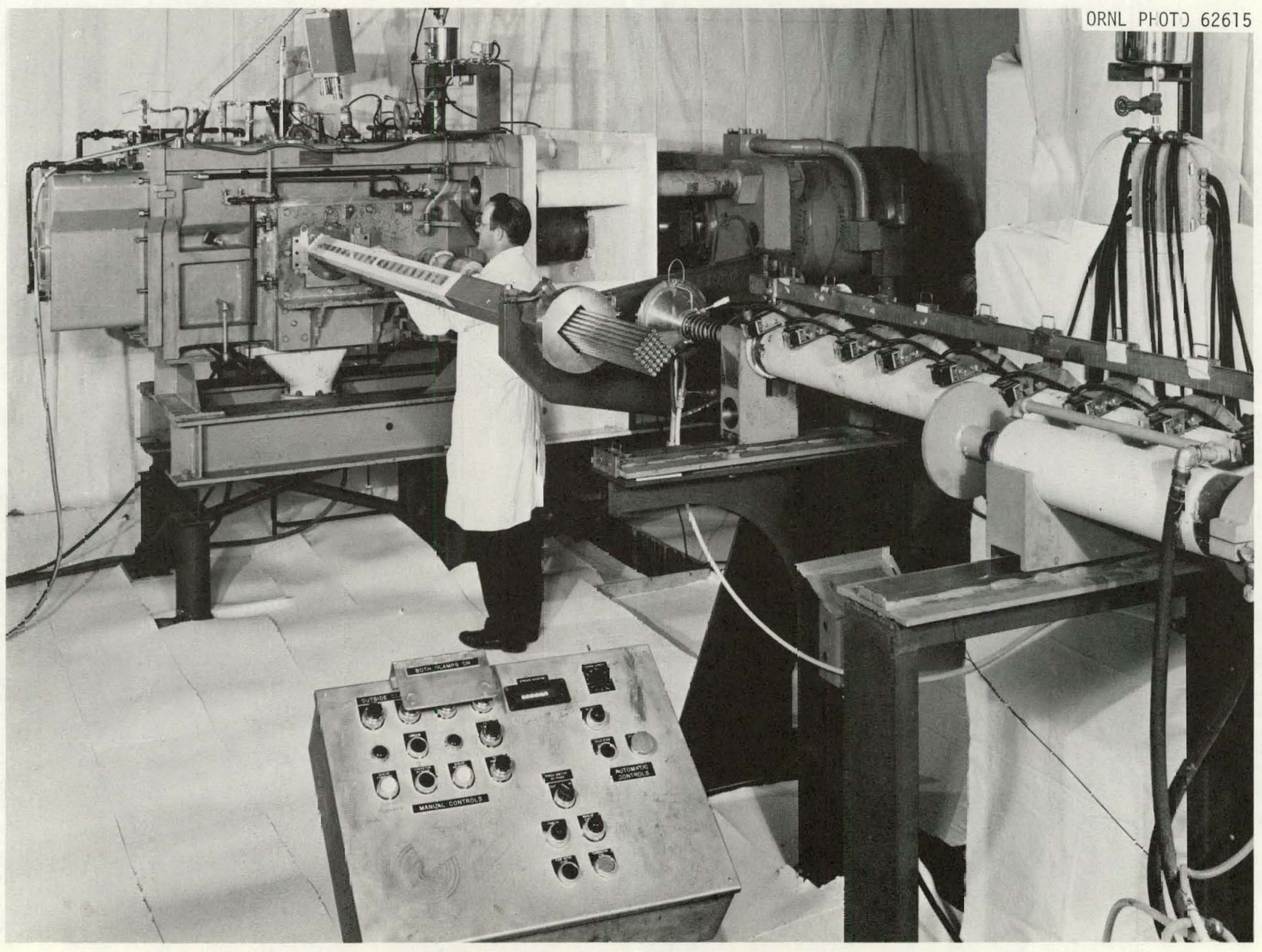


A typical sheared product from the early LWR prototype fuels is shown in Fig. 7.3.13 and that for present day LWR fuel in Fig. 7.3.14.

A shear is so designed that the fixed and moving blades can be replaced remotely. A moving blade may become dull and require replacement after shearing 200 to 300 metric tons of spent fuel. A fixed blade has a life many times that of a moving blade and needs to be replaced only after months of operation. Special tools and other mechanical aids are required for the remote replacement operations.

\subsubsection{Fire Control}

There are two principal types of flammable materials in a mechanical processing ce11, organic and inorganic.

Organic materials include oils and greases used as lubricants; hydraulic fluids powering equipment components; plastic electrical wire insulation; plastic bellows used to seal manipulators and other devices that penetrate the cell walls; and miscellaneous materials, in limited quantities, that may be introduced into the cell to aid in a maintenance or repair operation.

Fires of an organic origin are especially serious in reprocessing facilities because of the small carbon smoke particles produced during combustion. These particles are capable of plugging the high-efficiency filters of the off-gas system. These filters may then rupture and release radioactive particles.

The most serious hazard in inorganic category of materials is the Zircaloy hulls remaining after the removal of the fuel from the fuel rods. Zircaloy metal is somewhat pyrophoric and should be handled carefully. There may be small quantities of uranium or thorium metal present in reprocessing plants; however, most of these materials will be in the oxide form. Graphitic materials may also be included in this classification. A metal tire produces small particles of metallic oxide which also may be carried into the off-gas system and fonl the filters like the carbon particles mentioned above.

The simplest (but expensive) way to prevent fires of both categories in a mechanical processing cell (or other similar facilities) is to provide it with an incrt argon atmosphere. In certain cases, nilrogen can be used for this purpose. However, if an inert atmosphere is used, an oxygen or water content of about 100 parts per million must be maintained to prevent bearing surfaces and moving electrical contacts from wearing out. Metallic surfaces rubbing against each other require an oxide layer for long wear life, and oxygen is necessary to keep this oxide layer constant1y renewed.

For cells containing an air atmosphere, a carbon dioxide $\left(\mathrm{CO}_{2}\right)$ gas system is generally used to flood the cell and extinguish all fires of an organic origin. This would also include fires in electrical equipment components. 


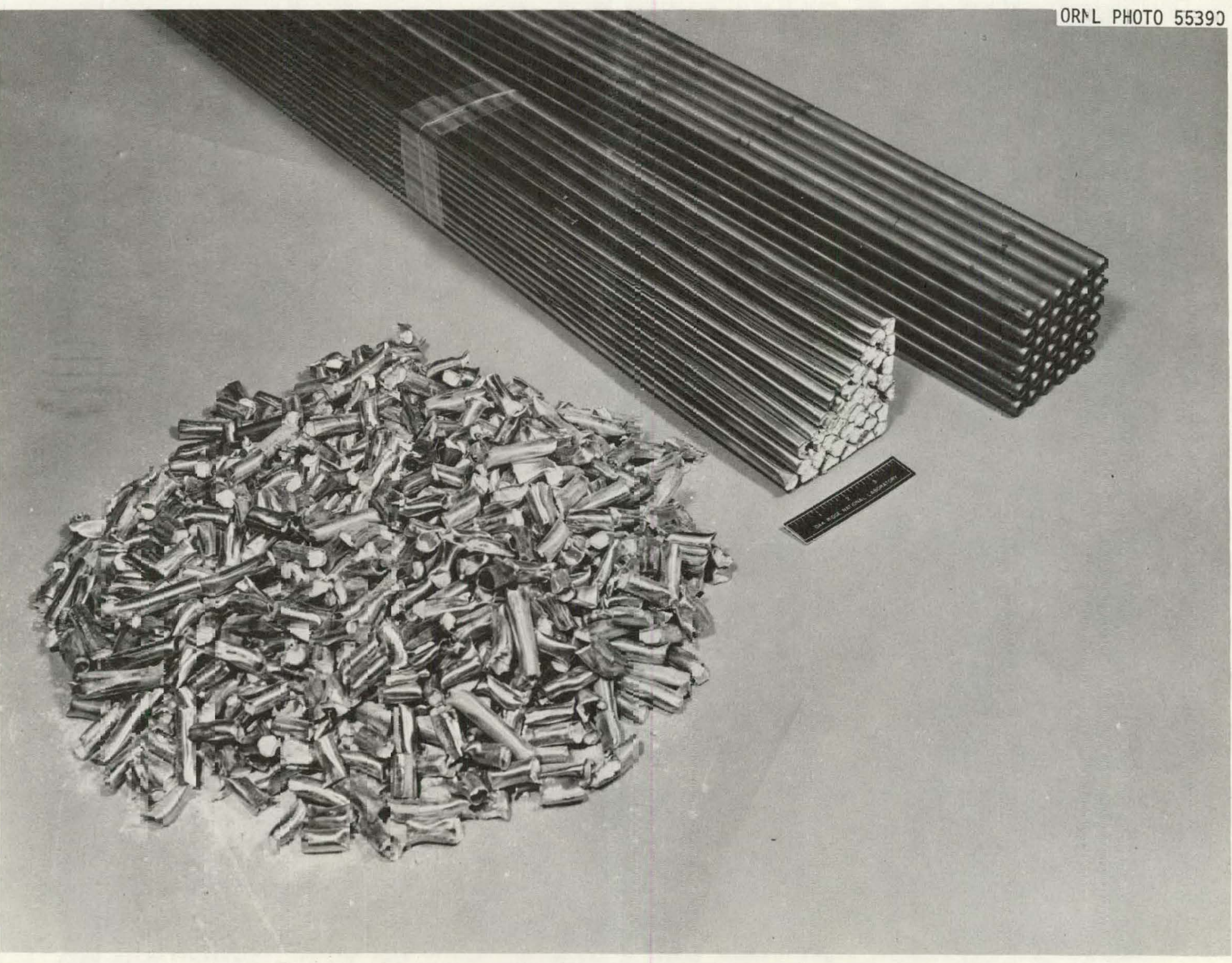

Fig. ¡.3.13. Early Day LWR Fuel - Its Shape After Shearing and The Shearec Produzt 


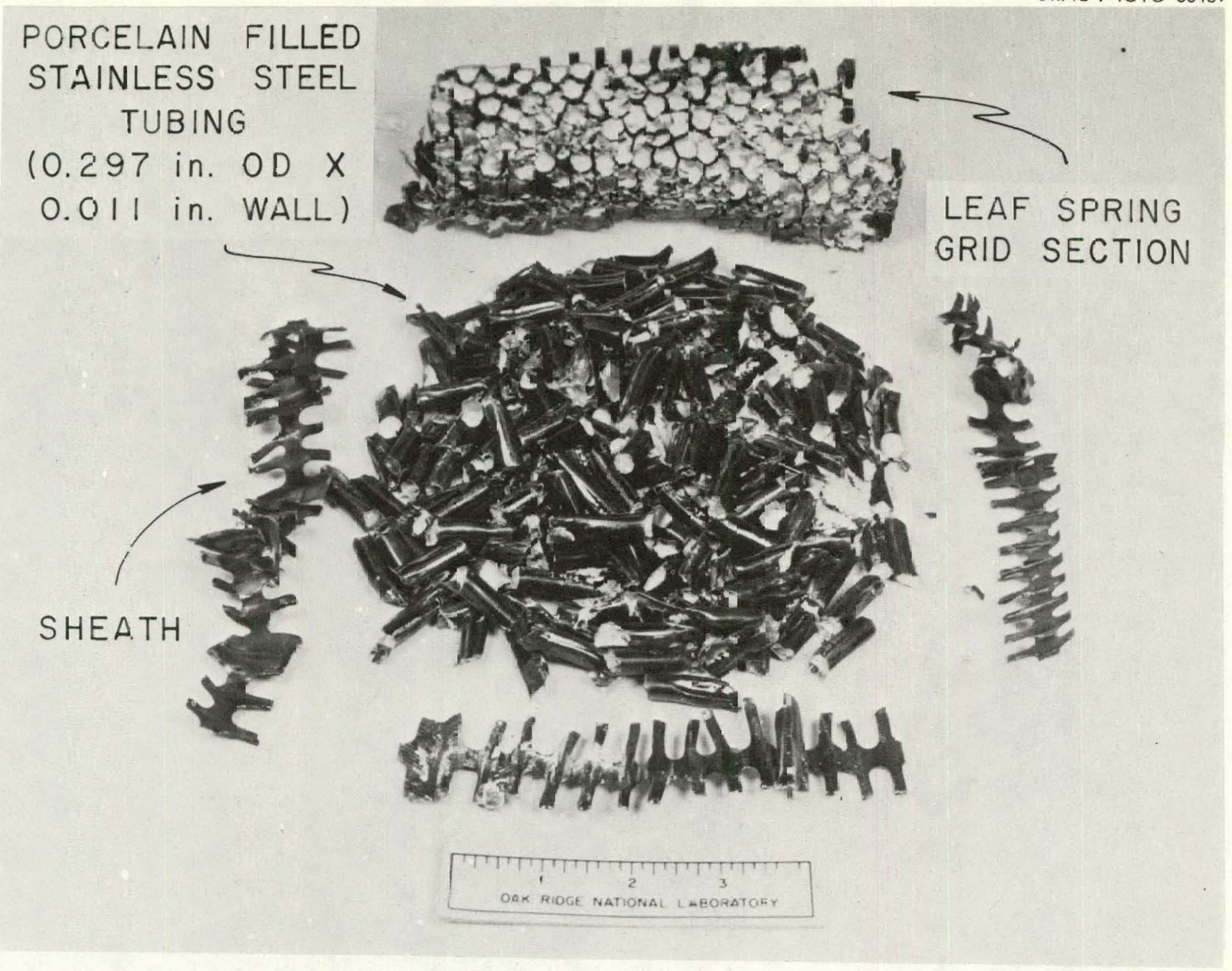

Fig. 7.3.14. Present Day Sheareł LWR Fuel 
A sprinkler system or any system delivering water as a stream, spray, or fogging mist is never used to extinguish a fire because water is a moderator for neutrons and might possibly promote a criticality event if sufficient fuel were in a cell.

Metal fires are usually not extinguishable unless in an inert atmosphere. Plastic bags of graphite and of dehydrated salt (sodium chloride) are kept in a cell and are placed on top of the burning metal at the outset of the fire. Most metals burn quietly, much like the charcoal briquettes . used in back-yard grills. Thus, the metal fire, being covered with graphite or salt, slowly burns until the metal is consumed. Water and carbon dioxide are never used on metal fires.

\subsubsection{Criticality Control and Accountability}

Criticality in a meclianical processing cell is controlled by three strictly adhered-to methods:

1. administrative edict,

2. design of the facility so that it cannot be flooded with a neutron moderatur,

3. limiting the number of fuel assemblies that can be handled in the cell at the same time.

In this respect, each fuel type must be reviewed and hard and fast control measures taken, based on the enrichment of its fissile material. For example, fuels enrlched to $5 \%$ or less are limited to no mole than three subassemblies, which cannot pass over or under each other while being handled. Fuels whose enrichment is greater than $5 \%$ are usually limited to no more than one subassembly in the cell at a time.

Accountability measures consist of strict bookkeeping procedures based on authorization letters for the processing of a given limited quantity of fuel. A material balance made by a highly accurate standard procedure compares the amount of fuel entering the plant (number of subassemblies and a chemical analysis of the contents of an accountability vesse1) with the amount of processed product reclaimed, along with the product 1osses. The two quantities must agree within closely defined limits. 
REFERENCES FOR SECTION 7.3

1. C. D. Watson, A. R. Irvine, et al., A Study of the Reprocessing of Spent Fast Test Reactor Fuel (and other LMFBR Fuels) in the Nuclear Services Plant, ORNL-TM-2906, August 1971.

2. Proceedings of the AEC Symposium for Chemical Processing of Irradiated Fuels from Power, Test, and Research Reastors, Richland, Washington, October 20-21, 1959, TID 7583, January 1960. 


\subsection{CHEMICAL MAKEUP}

\subsubsection{General}

Radiochemical reprocessing plants require a number of cold chemicals in closely controlled homogeneous solutions. These solutions may be prepared by dissolving solid chemicals in aqueous solution or by diluting concentrated commercially available liquid chemicals.

The makeup and distribution of these process streams are accomplished by the application of conventional unit operations including (a) dissolution of solids and blending of liquids by agitation in tanks;

(b) line blending of liquids by injection of one stream into another; (c) transfer of liquids by pumping or gravity; (d) heat transfer by the use of heating or cooling coils, heat exchangers, and jet injection of live steam; and (e) measurement of liquid flow rates, for example, by the use of rotameters.

\subsubsection{Typical Methods of Making Up Solutions from Solids}

Preparation of solutions from solids involves the addition of a weighed amount of a solid chemical to a measured volume of a liquid dissolvent. Normally, sufficient solution is prepared to provide at least an 8-hr supply to allow sufficlent time for sampling and analysis to verify. that the solution meets the specifications. When practical, the solid chemicals are used in commercially available packages of known quantity to avoid time-consuming weighing. Dissolution of the solid is accomplished by mixing, using a mechanical agitator, a circulating pump, or air sparging.

After the solution has been found to meet specifications, it is routed to a head tank, from which it is fed to the process by pumping or by gravity.

\subsubsection{Dilution of Liquids}

Preparation of solutions from commercially available liquid chemicals, such as certain acids or bases, involves the simple dilution of the concentrated liquid to the desired analysis, using water or, in the case of organic solvents, using an organic diluent. As in the preparation of solutions from sollds, mixing of the liquid chemical with the diluent is accomplished by means of mechanical agitators, pumps, or air spargers.

\subsubsection{Continuous Methods}

The previously described methods of preparation of solutions are usually carried out batchwise. In some cases, particularly when large volumes of solutions are required, continuous methods are employed. Continuous 
methods are particularly applicable to the preparation of solutions by dilution of liquids. In this operation the two liquid streams are measured either by flowmeters or metering pumps and mixed in pipelines or baffled tanks. The combined flow is routed to a surge tank, where a continuous density measurement is taken and used to control the flow of one of the constituents while the flow of the other constituent is maintained at a constant rate.

The continuous method may also be adapted to the preparation of solutions from solids by continuously metering a solid chemical into a dissolving tank being fed by a metered rate of liquid. Concentrated batches of solutions may also be prepared from solids and continuously diluted to obtain the desired concentration.

\subsection{FUEL DISSOLUTION}

In order to recover and purffy the valuable materials in spenc fucl elements, the reprocessing plant must convert them into forms suitable for chemical processing. To accomplish this, the corrosion-resistant fuel elements are dissolved in a suitable reagent (dissolvent) and the resultant solution modified for subsequent processing steps.

Dissolution may take place on fuel material and cladding together, or it may be performed selectively by eilher of two methods:

1. decladding, whereby the cladding is dissolved away from the fuel by one reagcnt and thon the fuel dissnlved hy another reagenl, UL

2. leaching, in which the cladding is meshanically breached or sheared and the exposed fuel dissolved without dissolving the cladding.

Fuel elements vary widely in shape and chemical composition. They are fabricated from materials selected for their desirable nuclear cross sections, corrosion resistance, and compatibility with the reactor coolant. Fuels are composed of alloys, ceramics, or cermels (bonded mixtures of ceramic and metal). Because of these variables, a number of dissolvents and dissolving schemes are required.

\subsubsection{Chemistry of Fuel Dissolution}

The chemistry of the dissolution of any type of fucl element is complex. An irradiated fuel element contains nuclear fuel, alloying and bonding materials, cladding materials, structural material, fission products, which include all the elements having atomic numbers between 30 (zinc) and 66 (dysprosium), and elements formed by neutron activation of all the elements in the materials listed above. This complexity is further compounded by the variety of kinds of fuel elements. It is not 
necessary, however, to present a comprehensive treatise covering all aspects of the dissolution of all kinds of fuel elements. The major factors can be gleaned from discussion of the dissolution of only a few of the more common types of fuel elements.

Many power reactor fuel elements contain uranium dioxide pellets enclosed in fuel tubes (or fuel pins). This class of fuel elements is usually chopped or sheared into small pieces and the spent fuel dissolved, leaving the empty pieces of cladding essentially unaffected.

Dissolution of fuels containing uranium dioxide with nitric acid occurs by the reactions: ${ }^{*}$

$$
\mathrm{UO}_{2}+\mathrm{HNO}_{3} \rightarrow \mathrm{UO}_{2}\left(\mathrm{NO}_{3}\right)_{2}+\mathrm{NO}+\mathrm{H}_{2} \mathrm{O}
$$

and

$$
\mathrm{UO}_{2}+\mathrm{HNO}_{3} \rightarrow \mathrm{UO}_{2}\left(\mathrm{NO}_{3}\right)_{2}+\mathrm{NO}_{2}+\mathrm{H}_{2} \text {. }
$$

The first reaction is more likely at low acid concentrations and the second at high acid concentrations. ${ }^{1}, 2$

Dissolution of plutonium dioxide, which may or may not have been present in the original fuel but which is likely to be present in the irradiated fuel element, is very complex. The most desirable and predominant reaction (over 95\%) occurs as:

$$
\mathrm{PuO}_{2}+\mathrm{HNO}_{3} \rightarrow \mathrm{Pu}\left(\mathrm{NO}_{3}\right)_{4}+\mathrm{H}_{2} \mathrm{O} \text {. }
$$

Other types of fuel elements contain mixed thorium-uranium oxide, uranium-molybdenum alloy, or uranium-aluminum alloy. The dissolution of thorium-uranium oxides requires a fluoride catalyst, which, in turn, requires the presence of aluminum nitrate for complexing excess fluoride to minimize corrosion of the stainless steel dissolver vesse1. 3 Uraniummolybdenum alloys will dissolve in nitric acid containing ferric ions ${ }^{\dagger}$ to stabilize the molybdenum in solution.

Aluminum is easily dissolved in either nitric acid or caustic. Hydrogen gas is evolved in either case, and nitrogen oxides are formed during dissolution in nitric acid. Unless the subsequent separations process uses aluminum as a salting agent, the aluminium cladding material is usually dissolved in boiling caustic according to the reaction:

$$
\mathrm{Al}+\mathrm{NaOH} \rightarrow \mathrm{NaAlO}_{2}+\mathrm{H}_{2}+\mathrm{H}_{2} \mathrm{O}
$$

\footnotetext{
* For simplicity, chemical equations in this Guide have not been numerically (stoichiometrically) balanced.

For definition of this term, see Section 7.8.1.
} 
The aluminum-bearing caustic solution is removed, and the fuel-bearing material is then dissolved in acid.

Hydrogen formation is undesirable because of the potential explosion hazard. Nitrate and nitrite ions suppress the formation of hydrogen according to the reactions:

$$
\mathrm{NaNO}_{3}+\mathrm{H}_{2} \rightarrow \mathrm{NaNO}_{2}+\mathrm{H}_{2} \mathrm{O}
$$

and

$$
\mathrm{NaNO}_{2}+\mathrm{H}_{2} \rightarrow \mathrm{NH}_{3}+\mathrm{NaOH}+\mathrm{H}_{2} \mathrm{O} \text {. }
$$

Heat must be applied to start most of the reactions discussed above. After starting, the reaction gives off heat (1s exothermic), requiring that the reaction vessel be cooled to control the reaction rate and prevent expulsion of radioactivity by pressurization or foaming. Finally, after the reaction has proceeded nearly to completion, heat must again be applied to assure complete dissolution of the last bits of the fuel elements.

\subsubsection{Fuel Dissolution Equipment}

Equipment for fuel-element dissolution must provide for (1) adding the fuel and the dissolvent, (2) ensuring proper contact between the fuel and the dissolvent, (3) controlling the rate of the dissolution reaction, (4) removing and treating gaseous by-products, (5) removing the product solution, and (6) leaching and removing the undissolved solids. 'the dissolution must be carried out in such a manner that no radioactive matter is released to the environment and there is no possibility of nuclear criticality* occurring because of maloperation or any other circumstance.

Dissolvers are designated as batch or continuous, terms that refer to how the fuel elements are added. Another common designation describes the shape of the vessel - pot, annular (doughnut shaped), column, or slab. Shapes other than simple pots are used to assure nuclear criticality safety.* Batch pot dissolvers have been widely used for spentfuel dissolution. The chief advantage of batch dissulution is simplification of fuel charging, since charging a single large barch of spent fuel at one time requires little operator attention or automatic equipment.

Batch dissolutions are normally operated at boiling temperature. Steam jackets or coils are provided to bring the charge up to temperature, and since most of these reactions are exothermic, additional heat may

* See Section 7.5.5. 
not be required. The dissolution rate must be controlled by admitting cooling water to the jacket or coils in some cases, e.g., when the dissolver vacuum becomes too low. Excessive dissolution rates can also be controlled by varying the dissolvent feed rate or the catalyst concentrations.

Dissilver vessels are equipped with a chute or opening designed for charging either whole fuel elements or baskets of sheared fuel pins. These vessels usually have heavier walls and are made of more corrosionresistant materials than other process vessels. The spent fuel can be charged to the dissolver (1) by lowering individual elements, assemblies, or buckets containing small pieces or slugs or (2) by dropping or dumping in the pieces or slugs. A special crib located in the lower portion of the dissolver provides protection against impact for the heat transfer coils and instrumentation lines within the vessel and also serves to contain the fuel as it dissolves.

7.5.2.1 Detailed Description - The only dissolver that has actually been used to dissolve fuel elements in a commercial processing plant ${ }^{4}$ (Fig. 7.5.1) is an annular vessel into which fuel elements or pieces of them are introduced in baskets and in which the dissolutions are all performed batchwise.

This dissolver has provision for six baskets of fuel elements or sheared fuel. Baskets up to $8 \mathrm{in}$. inside diameter and $7 \mathrm{ft}$ long may be used. Several smaller baskets are also used as required for various reasons such as criticality control during dissolution of enriched fuels. The dissolver has an 8-ft-diam outer shell. In the lower part of the vessel, there is an inner shell that forms a 3-in.-thick annulus with the outer shell. Six equally spaced 10-in.-diam vertical barrels through the inner shell intersect with the annulus and accommodate the baskets. The inner shell, which has a conical top, encloses a concrete core containing a nuclear poison (boron). The vapor space above the normal liquid level occupies the full 8-ft diameter of the dissolver.

The dissolver is equipped with a jacket for heating or cooling. Air spargers are arranged at the bottom of the annulus and above the central core to stir the contents and suspend fines. Sampling tubes, solution addition lines, instrument lines, thermocouple wells, spray rings to rinse baskets as they are removed, and an eductor for removing liquid are connections necessary for proper operation of the dissolver.

A downdraft condenser returns a portion of the nitrogen oxides to the dissolver as nitrous and nitric acids. This helps maintain the liquid level and solution strength during the dissolution. The off-gas treatment equipment includes a caustic scrubber and filters. 
$\therefore \quad 7-54$
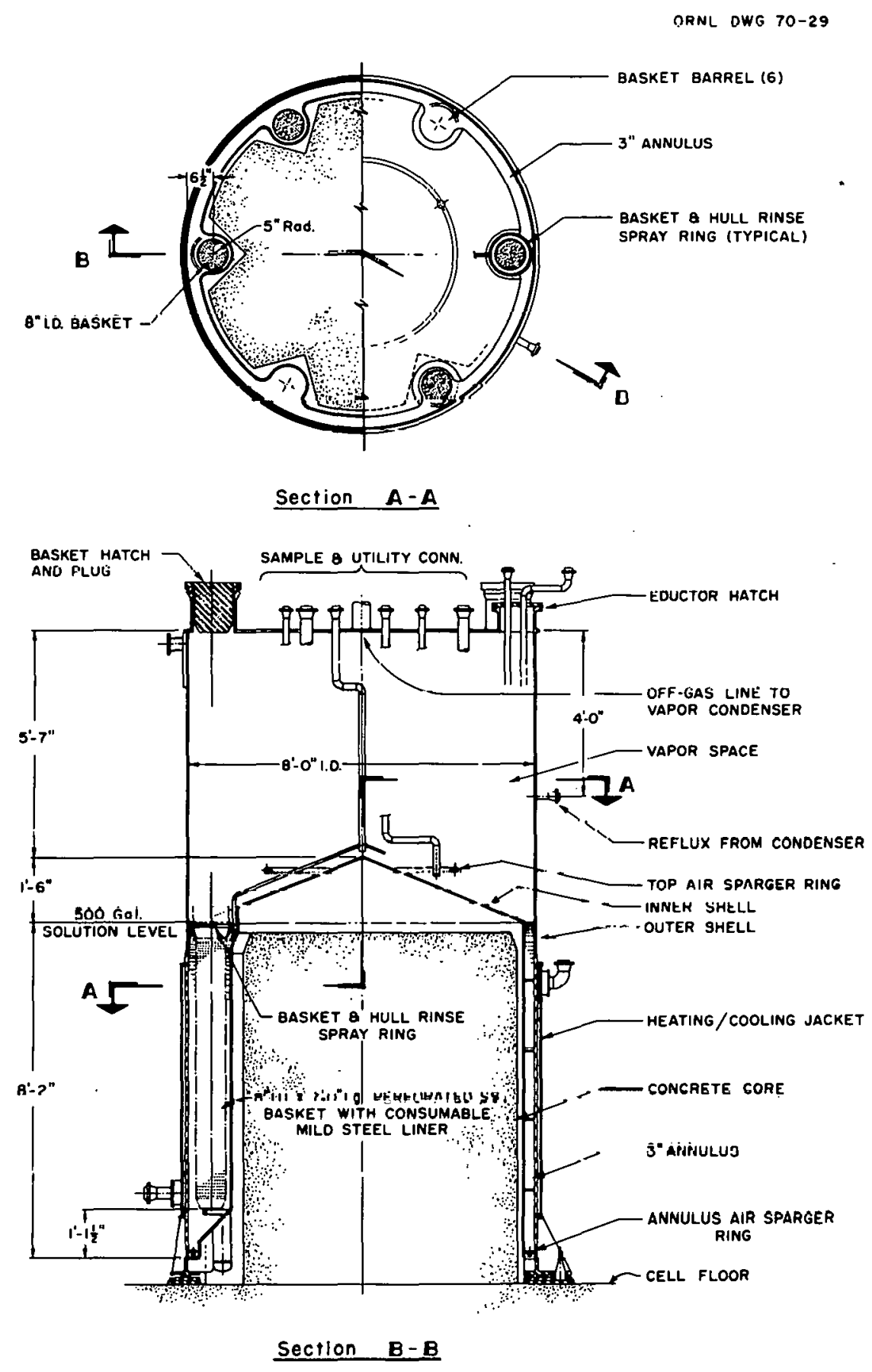

Fig. 7.5.1. Batch Dissolver 
7.5.2.2 Instrumentation - Control instrumentation must be adequate to prevent runaway reaction rates and excessive off-gas peaking. Batch dissolvers are generally controlled by the dissolver pressure (vacuum) and the pressure drop across the off-gas condenser. If the fuel charge is to be contacted with sequential batches of dissolvent, each called a cut, or if a heel is to be left, the specific gravity of the dissolver solution is used as the basis for terminating the cut. Continuous dissolvers are controlled by the specific gravity of the effluent and the rate of flow and temperature rise of the condenser cooling water.

Liquid level and solution density may be measured using air-purged pneumatic differential pressure transmitters* and panel-mounted recorders. A pressure cell connected to the liquid level system alarms if the liquid level drops to a preset low level. Temperatures are monitored at various positions in the equipment. A thermocouple that senses the temperature of the liquid in the pot is connected to a recorder-controller which records the temperature, actuates alarms if the temperature leaves the acceptable range, and initiates signals that control the flow of sieam and cooling water to the jacket. A pressure recorder-controller that receives signals from the steam inlet line may also be used to limit the reaction and provide diagnostic information. The pressure in the dissolver vapor space is recorded and is used to actuate an alarm in the event of reduced vacuum. The alarm signal can also be used to provide an alternative to the pot temperature system for shutting off the steam and/or turning on jacket cooling water to control the rate of the dissolution reaction.

Other necessary instrumentation for either batch or continuous dissolvers includes means for measuring dissolvent feed rate and sparge rate. Additional useful information includes the off-gas temperature and the radiation level of the dissolver. A microphone attached to the dissolver may help to indicate the vigor of the reaction. When evolution of hydrogen is significant, a meter to determine its concentration in the off-gas is desirable.

\subsubsection{Typical Dissolution of Chopped Fuel}

Chopped fuel contained in perforated baskets is brought into the chemical processing cell. Each basket is picked up by the dissolver loading crane and deposited in one of the barrels of the dissolver (Fig. 7.5.1). When all of the fuel is charged, the required quantity of acid is metered into the dissolver and verified by readings of the dissolver liquid level and specific gravity instruments. The lower air sparger is turned on, cooling water flow to the reflux condenser is established, and steam is admitted to the dissolver jacket. The dissolution reaction begins at about $90^{\circ} \mathrm{C}\left(194^{\circ} \mathrm{F}\right)$, at which time the

$\bar{*}$ See Sections 8.1 .4 and 8.1 .6 . 
steam is turned off to prevent the dissolution reaction from producing gases at a higher rate than the off-gas system will handle and still maintain a negative pressure in the dissolver. The reaction subsides after 8 or 9 hours, steam is again admitted to the dissolver jacket, and the solution is boiled 3 or 4 more hours to assure complete dissolution. The liquid level, specific gravity, temperature, and pressure in the dissolver and the off-gas temperature are monitored and recorded throughout the dissolution.

When the dissolution reaction is complete, the solution is cooled to about $100^{\circ} \mathrm{F}$ and transferred by steam jet to the accountability and feed adjustment tank. Rinse acid is sprayed into the dissolver and subsequently jetted to the feed adjustment tank. The baskets containing the hulls are removed from the dissolver and loaded into a shielded cask for transport to the burial area.

\subsubsection{Control of Gaseous Effluent During Dissolution}

As stated above, a major factor in controlling the gaseous effluent during dissolution is the proper regulation of the reaction rate to assure that the gases are confined to the dissolver off-gas treatment system. Both radioactive and nonradloactlve gases are emitted from a dissolver. ${ }^{3}$ The principal radioactive gases from dissolution of longcooled LWR fuels include iodine, krypton, and xenon; radioactive particles are also carried on liquid droplets entrained* in the off-gas. Nonradioactive gases include steam, air, nitrogen oxides, hydrogen, and ammonia. Steam is a major constituent; in nitric acid dissolution the heat of reaction is so great that 95 percent of the gas generated is steam. Air is present from inleakage, instrument air, and sparging. Air or oxygen may be added to convert lower oxides of nitrogen to nitrogen dioxide to promote recovery of nitrlc acld. Hydrogen or ammonia is generated by caustic dissolution of aluminum cladding or alloys, and hydrogen is evolved in some acid systems.

The absorption of nitrogen oxides can be achieved simply by passing the gases through a downdraft condenser in which they react with condensing water vapor. This has several advantages. Since the condensed steam drains down the wall of the tube, the entire tube area is wetted and available for the absorption reaction. Thus, most of the nitrogen oxides are absorbed and returned to the dissolver as nitric acid, yielding greater acid efficiency and less change in acid concentration during dissolution. This results in a more uniform reaction.

The off-gas is then put through a caustic scrubber, in whych the nitrogen oxides that escape absorption in the condenser react with sodium. hydroxide according to the following reactions:

\footnotetext{
${ }^{*}$ For definition of this term, see Section 7.7 .1 .
} 


$$
\mathrm{NO}_{2}+\mathrm{NO}+\mathrm{NaNO}_{2} \rightleftharpoons \mathrm{NaNO}_{2}+\mathrm{H}_{2} \mathrm{O}
$$

and

$$
\mathrm{NO}_{2}+\mathrm{NaOH} \rightleftharpoons \mathrm{NaNO}_{3}+\mathrm{NaNO}_{2}+\mathrm{H}_{2}
$$

Also, entrained nitric acid in the form of droplets is neutralized by reaction with the caustic.

Hydrogen in the off-gas is usually diluted to a concentration below its explosive 11m1t by the addition of air. Xenon and krypton from longcooled LWR fuels are diluted with plant ventilation air and released through a stack to achieve atmospheric diffusion that keeps the release rates below the limits imposed by federal regulations.

Enough radioiodine is usually present to require its removal from the off-gas and storage for decay. Although there are other methods for removing radioiodine from off-gàs streams such as mercuric nitrate, silver reactors have been used most extensively in plants that reprocess a few tons of irradiated LWR fuels per day. In this process the gas stream is heated and passed through a bed of silver zeolite. The silver reacts with iodine, removing it from the gas stream:

$$
\mathrm{Ag}+\mathrm{I}_{2}+\mathrm{H}_{2} \mathrm{O} \rightarrow \mathrm{AgI}+\mathrm{AgIO}_{3}+\mathrm{H}_{2}
$$

Chlorine and bromine are also removed. The optimum operating temperature for the iodine-silver reaction is $190^{\circ} \mathrm{C}\left(374^{\circ} \mathrm{F}\right)$. At temperature below $110^{\circ} \mathrm{C}\left(230^{\circ} \mathrm{F}\right)$, essentially no iodine removal occurs. Thus, temperature control is very important to the success of this power.

\subsubsection{Criticality Control (see Section 6.2)}

The basic factors affecting criticality apply to dissolvers the same as they apply to any other system. Criticality can be avoided by (1) making the dissolver vessel and all connected vessels geometrically safe, (2) limiting the total mass of fissionable material in the dissolver system to a safe amount, (3) maintaining the concentration of fissionable material below the maximum safe value, or (4) using fixed or soluble neutron poisons to assure safety from criticality. Usually, the system is designed and operated to be safe in two completely independent ways if simple geometry is not used as a control.

If concentration control is being used, many. factors must be considered to assure that the solution cannot become unstable. Instability may occur by some inherent condition or by addition of improper chemicals, causing fissionable materials to precipitate into a concentrated form that is not critically safe. If safe geometry is being used, the design must eliminate the possibility of expelling the solution from the geometrically safe dissolver into a condenser or receiver that is not 
geometrically safe. It must also be impossible for the solution to leak from the dissolver into a floor liner or sump that is not geometrically safe.

In the dissolver shown in Fig. 7.5.1, criticality is controlled by a combination of geometric and concentration methods. ${ }^{4}, 5$ For each kind of fuel element processed, there is a safe geometry (diameter) for the chopped-fuel baskets that must never be exceeded. The baskets are held firmly in place in the dissolver to assure a stable geometry for neutron reflection. A solid concrete core in the center of the dissolver provides at least 30 in. of concrete containing 0.5 weight \% natural boron between adjacent baskets. The neutron absorption properties of the concrete are such that thermal neulruls enleriing it are totally absorbcd and no neutrons are reflected back into the dissolver. Such concrete serves here as a "fixed poison."

As the fuel goes into solution, the concentration of fissionable material in the dissolver increases, and the amount remaining in each baskel decreases. For each kind of fuel, the operating concentration is kept below $70 \%$ of the concentration that is considered to be the maximum safe concentration for that fuel.

There are three mechanisms which operate during a dissolution to promote uniformity of the solution through mixing:

1. Air spargers located in the bottom of the tank and on top of the conical section over the concrete-filled central core are adequate to vigorously mix the tank contents. The primary air supply is connected to the emergency power systein, and a separate air supply system comes on automatically if the pressure fails in the air sparger header.

2. Heat supplied by the steam coils sets up vigorous convection currents, which promote mixing.

3. 'The dissolution reaction gives off heat, which causes localized boiling and rapid upflow of solution near the baskets, and gases formed by the reaction add to this sparging action.

Concentration is controlled by assuring that the correct quantities of fuel and acid are charged to the dissolver. In many cases it is not possible to add more fuel than is desired, because one dissolver charge completely fills the six dissolver baskets. After the fuel shearing operation, however, the dissolver baskets are always weighed full to make sure they are not overloaded as well as to provide a dissolver charge weight for accountability purposes. There is no way for fuel to enter the dissolver except in the dissolver baskets.

If the total number of moles of acid added is correct but the volume is too high, the resulting uranium concentration will be lower than the maximum allowable value, and the factor of safety will be higher. 
If the number of moles of acid is too low but the volume of dissolvent is correct, the fuel will not dissolve completely, and the resulting uranium concentration will be lower than the maximum allowable concentration. If the number of moles of acid added is too high but the volume is correct, the desired safety factor will still be maintained, because only the total charge of fuel can be dissolved. The situation that must be guarded against is the charging of the proper number of moles of nitric acid but at too high a concentration and therefore too low a volume. This could lead to too high a uranium concentration. To prevent this possibility, the entire acid charge is made up outside the cell, analyzed, and certified before it is charged. After the acid is charged to the dissolver, the dissolver liquid level and specific gravity are read, recorded, and compared with the calculated charge. Unless the liquid level instrument detects the minimum depth of liquid needed for a safe concentration, the instrument automatically prevents introduction of steam into the heating coils.

Since dissolution involves boiling at total reflux, ${ }^{*}$ there is a possibility that the acid solution could become concentrated by a loss of water vapor, and this possibility must be guarded against throughout the dissolution. The primary safeguard is provided by instrumentation that will automatically shut the steam off and introduce cold water into the jacket if the liquid level drops below the predetermined set point. There are several other safeguards based on the fact that water could be boiled off only if the total-reflux condenser failed to operate:

1. If the cooling water to the condenser should be shut off or greatly reduced, this would cause changes on the condenser flow indicator, temperature indicator, and off-gas temperature recorder. Since these instruments plus the specific gravity indicator, dissolver volume recorder, and other process control instruments are read continually at the control panel, the operator can shut the steam off manually if any parameter deviates from normal.

2. The negative pressure maintained on the dissnlver would decrease, and the recorder-controller would automatically shut the steam off and introduce cold water to the jacket.

3. Failure of the condenser cooling water supply would stop or reduce the reflux, which has a cooling effect on the dissolver solution. This would result in an increase in the temperature of the dissolver solution, which would in turn result in the steam being shut off automatically.

After being terminated, the dissolution would be resuned only after complete diagnosis and correction of the problem and readjustment of the dissolver solution as needed.

\footnotetext{
${ }^{\star}$ For definition see Section 7.7.1.
} 
Besides assuring that both the amount and the concentration of acid are maintained within acceptable limits, it is also necessary to assure that no precipitate of fissionable material forms that might settle into a critical configuration. The most direct defense against this is to prevent any precipitation. During the processing of enriched fuels, no chemicals that will precipitate fissionable isotopes are permitted in the cold chemical makeup area used for the dissolver. There are no lines connected to the dissolver or any of its auxiliary equipment that connect to any source of a precipitating agent, with the exception of the off-gas scrubber which operates with caustic. The scrubber is so designed that no scrubber solution can flood the gas inlet and be drawn back into the dissolver. If the vacuum in the offgas system were to fail, the dissolution would be shut down automatically. Some fine caustic mist might diffuse back from the scrubber to the dissolver, but the quantity that could possibly get back via this mechanism is insignificant in relation to the free acid content in the dissolver. The subsequent acid dissolution and final acid cleanout of the system after its use for caustic decladding of natural uranium fuel and prior to a campaign to process enriched fuels preclude the possibility of residual caustic in the system. Caustic supply lines are disconnected and blanked off prior to enriched campaigns.

Even though criticality is avoided because of the variety of reasons discussed above, an additional, independent safeguard is provided. A tank of boric acid is maintained which can be drained into the dissolver by gravity. This dumping is actuated manually from the control panel. This solution can be used to quench a nuclear reaction should one occur, and it may be used as an ultimate safety feature if the shift foreman decides that a situation of incipient criticality has been allowed to occur.

\section{REFERENCES FOR SECTION 7.5}

1. R. F. Taylor et al., J. Applied Chem. 13, 32-40 (1963).

2. M. Shabbir and R. G. Robbins, J. Applied Chem. 18, 129-34 (1968).

3. J. T. Long, Engineering for Nuclear Fuel Processing, Gordon and Breach, New York, 1967.

4. Safety Analysis Report, Spent Fuel Processing Plant, Nuclear Fuel Services, Inc., AEC Docket No. 50-2-1, July 1962.

5. C. D. Watson et al., A Study of Reprocessing of Spent Fast Test Reactor Fuel (and Other LMFBR Fuels) in the Nuclear Fuel Services Plont, ORNL/TM-2906, August 1971. 


\subsection{SOLVENT EXTRACTION}

The basic method for recovering and purifying uranium, plutonium, and neptunium from irradiated fuels is solvent extraction, a technique that achieves separation of various substances by treatment with a selective organic solvent. The PUREX flowsheet for reprocessing irradiated fuel uses liquid methods in which the fuel dissolved in an aqueous phase is contacted by a selective organic solvent, tributyl phosphate (TBP), in a kerosene-type diluent. This solvent has a specific affinity for uranium, thorium, neptunium, and plutonium and is essentially immiscible with water. Because of these factors and because of the difference between the specific gravitles of the two phases, the organic phase floats on top of the aqueous, allowing a physical separation to be made. Rejected materials, such as fission products and ionic contaminants, leave the solvent-extraction system in the aqueous phase. The organic phase, laden with the valuable materials (products), is then "scrubbed" to remove remaining impurities and sent to a "partioning" step to separate the valuable materials from each other by transferring one of them back to an aqueous phase while keeping others in the organic phase. 'lhe organic phase is then "stripped" to transfer the remaining valuable material to another aqueous phase for further purification.

There are several types of mechanical devices that have been designed to separate the organic phase from the aqueous phase. These include mixer-settlers, centrifugal contactors, pulse columns and packed columns. Mixer-settlers operate as the name implies - a tank where the organic phase and the aqueous phase are mixed and a tank where they are allowed to settle out. As many stages as necessary for the desired separation may be connected together. Centrifugal contactors are essentially mixer-settlers in which settling is aided by centrifugal force instead of by gravity alone. Pulse columns are liquid-liquid contactors where the rate of mass transfer is aided by pulsating the liquids through the column packing or through perforated plates. Packed columns also operate as the name implies in that the two phases must follow a circuitous path through the packing, where new interfacial areas are continuously generated.

\subsubsection{Definition of Terms}

The following definitions are intended to clarify the usage of words and phrases in this text and are not intended to be technically precise.

Aqueous - A water solution.

Density - The weight in grams of one milliliter (ml) of solution.

Specific Gravity - The ratio of the weight of a unit volume of a material to the weight of a unit volume of water at $4^{\circ} \mathrm{C}$. In the metric system, density and specific gravity are equivalent. 
Distribution Coefficient (DC) - The ratio at equilibrium of the concentration of a material in the organic phase of a solvent-extration system to its concentration in the aqueous phase in contact with the organic. (See Section 7.6.2 for details.)

Extraction Factor (EF) - The ratio at equilibrium of the quantity of a material in the organic phase to its quantity in the aqueous phase in contact with the organic. The EF equals the DC times the ratio of the volumes (or in a system operated continuously, the flow rates) of organic to aqueous. (See Section 7.6.2 for details.)

Decontamination Factor (DF) - A measure of the degree of removal of undesirable materials from a desired product. For example, the DF of uranium from zirconium may be calculated:

$$
\mathrm{DH}=\frac{\not \mathrm{gr} \text { in feed }(\mathrm{r} / \mathrm{m} / \mathrm{m} /)}{\mathrm{U} \text { in feed }(\mathrm{g} / \text { liter })} \div \frac{\not / \mathrm{r} \text { in produrt }(\mathrm{r} / \mathrm{m} / \mathrm{m} 1)}{\mathrm{U} \text { in product }(\mathrm{g} / \text { liter })}
$$

Separation Factor (SF) - A measure of the degree of separation of two desired products. It is the ratio of the distribution coefficients. For example, the SF of uranium from plutonium product would be $\mathrm{DC} U \mathrm{UC} \mathrm{Pu}_{\mathrm{U}}$, whereas the $S F$ of plutonium from uranium product would be $\mathrm{DC}_{\mathrm{Pu}} / \mathrm{DC}_{\mathrm{U}}^{\mathrm{U}}$.

Entrainment - The carrying of small droplets of organic suspended in an aqueous phase or aqueous suspended in an organic phase. Entrainment can result in a decrease in decontamination factor, a loss of product, a loss of solvent, or an operational hazard (see Section 7.6.8.6).

Flooding - An undesirable condition in a solvent-extraction unit in which the organic and aqueous phases are emulsified and do not disengage within the required time (see Sections 7.6.8.4 and 7.6.8.6).

Salting Agent - In a nitrate system, materials added to Increase the nitrate concentration. Nitric acid is frequently used as a salting agent. When material being extracted provides the nitrate, it is referred to as "self-salting" (see Section 7.6.2).

Solvent Saturation - The percentage of saturation is the percentage of the solvent that has complexed or otherwise extracted salts from the aqueous phase. 'IBP forms a definite complex with melals it extracts. When all the TBP in a solution is tied up in these complexes, the solvent is said to be $100 \%$ saturated. For each 'I'BP solution there is, therefore, a maximum concentration that is speciflc for the compound extracted. Normally only complexes of the TBP with metal salts are considered; the complex with nitric acid is neglected.

Solvent Degradation Products - Usually the di- and monobutyl phosphates resulting from the decomposition of the TBP solvent. These are discussed in Section 7.6.2.1. 
Pulse Column - A mechanical device for contacting an organic with an aqueous solution (see Section 7.6.8.1).

Extraction Column or Section - A pulse column or section of a column designed to facilitate the transfer of a product salt from the aqueous to the organic phase (see Sections 7.6.4 and 7.6.8).

Scrub Column or Section - A column or section of a column designed to remove undesirable materials from an organic phase without removing the product (see Sections 7.6.4 and 7.6.8).

Partitioning Column - A column designed to transfer one or more products selectively from an organic to an aqueous phase while leaving other products in the organic phase (see Section 7.6.5).

Stripping Column - A column designed to transfer a product or products from an organic to an aqueous phase (see Section 7.6.6).

Compound Column - A column designed to do more than one of the above operations, e.g., both extract and scrub.

Coextraction - A system designed to simultaneously purify more than one product. In a coextraction cycle, two or more products are extracted and stripped together without separation from each other. In a partitioning cycle, two or more products are separated from each other.

Reflux - This term has similar meanings in solvent extraction (see Section 7.6.2) and in distillation (see Section 7.7.2); it means that a portion of the product stream is recycled to the feed. In the extraction step, reflux results in a greater concentration of salts around the feed point than that at the exit of the column. For instance, when the exit solvent is $80 \%$ saturated, the solvent at the feed plate may be $95 \%$ saturated. When reflux would cause solvent at the feed plate to be more than $100 \%$ saturated, there will be an inevitable loss of product in the aqueous phase.

Stage - In a continuous operating unit such as a pulse column, a stage is synonymous with "theoretical stage." There is sometimes confusion in the literature, because a single contactor such as a mixer-settler unit may be called a "stage."

Theoretical Stage - A concept or an actual mechanical device in which the compositions of the organic and aqueous phases are brought to equilibrium, i.e., the concentrations of the salts in the two phases remain constant with additional contact time. Due to the kinetics in a pulse column, the length of column equivalent to one theoretical stage may be different for different salts in the solution; for instance, the length of a stage for uranium is likely to be different from the length of a stage for fission product zirconium (see Section 7.6.8). 
Multistage - A cascade of units or a length of column that results in more than one theoretical stage.

Valence - A number representing the combining power of an atom; the number of electrons gained, lost, or shared by an atom involved in chemical reaction (see Section 7.6 .3 ).

Plutonium Polymer - The very large hydroxy-nitrate molecules containing thousands of plutonium atoms resulting from conversion of $\mathrm{Pu}(\mathrm{IV})$ under low-acid conditions (less than about $0.3 \mathrm{~N}$ acid) (see Section 7.6.2.3).

\subsubsection{Chemistry of Solvent Extraction}

The principles of solvent extraction can be understood by considering the basic principles of dissolving any material that is not chemically changed by dissolution, such as salt ( $\mathrm{NaCl}$ ) in water. Such materials dissolve when the attraction of the material is stronger for the solvent than for other molecules of its own kind. For instance, salt dissolves in water because its. sodium and chloride ions ${ }^{*}$ have a higher attraction to water than they do to the salt crystal. Certain materials dissolve more easily in some solvents than in others. Kerosene rather than water is used to dissolve oils. The solvent-extraction process for nuclear fuel recovery is based on the fact that although uranyl nitrate and plutonium nitrate will dissolve in water, under some conditions they are even more soluble in TBP in an organic diluent, while most of the fission products do not dissolve in TBP.

When uranyl nitrate in $2 \mathrm{M} \mathrm{HNO}_{3}$ is contacted with $30 \%$ INBF in dulient, the equilibrium concentration of uranyl nitrate in the organic phase will be about four times the uranyl nitrate concentration in the aqueous phase. This ratio of concentrations ( 4 to 1 in this case) is called the distribution coefficient or $\mathrm{DC}$ 0/A (see definition). If the volumes (or, in the case of continuous operation, the flow rates) of the organic phases are considered, the amount of uranyl nitrate in each phase will be known. 'l'his ratio is the extraction factor (EF O/A) :

$$
\text { DC } 0 / A \times \text { Volume Ration } 0 / A=E F \quad 0 / A \text {. }
$$

Since the organic-to-aqueous ratio is usually the one reported, this term 0/A will hereafter be understood but will be omitted.

When a solvent mixture has dissolved all of the material possible, it is said to be saturated. ${ }^{+}$When it has dissolved half this amount it is referred to as $50 \%$ saturated, etc. Obviously when the TBP is saturated with one material, for example, uranyl nitrate, it cannot also dissolve

\footnotetext{
*For definition see Section"7.8.1.

† See definitions in Section 7.6.1.
} 
other less soluble materials such as the fission products, and so the higher the percent saturation, the greater the decontamination from ionics and fission products. On the other hand, as the saturation approaches $100 \%$, high product losses tend to result. The percent saturation, therefore, is an important consideration in the operation of a solvent-extraction plant.

The DC of each material varies widely depending upon the operating conditions; for example, the DC of uranyl nitrate decreases with increasing temperature and will vary as the. squares of both the TBP concentration in the organic and the nitrate concentration in the aqueous. Small changes in the concentrations of these materials, therefore, make much larger changes in the uranyl nitrate DC. Advantage can be taken of the salting effect, which drives uranyl, plutonium, and other nitrates from the aqueous into the organic phase by increasing the nitrate concentration. Nitric acid is thus used as a salting agent.* Also, self-salting ${ }^{*}$ increases the DC of uranyl and other nitrates, since these salts produce nitrate ions when they dissolve in water:

$$
\mathrm{UO}_{2}\left(\mathrm{NO}_{3}\right)_{2} \stackrel{\mathrm{H}_{2} \mathrm{O}}{\longrightarrow} \mathrm{UO}_{2}^{2+}+2 \mathrm{NO}_{3}^{-}
$$

Uranyl nitrate has a much higher DC than uranyl sulfate or plutonyl nitrate (see Section 7.6.2.3). The DC of plutonium(IV) is higher than that of plutonium(VI), which is in turn much higher than the DC of plutonium(III) or plutonium polymer. Fission-product ruthenium has several chemical forms in the nitrate system, some of which are highly extractable by TBP.

The purpose of the solvent-extraction process is to separate the various materials from each other. The degree of separation of the materials is measured by comparing the ratio of their concentrations in the feed to the ratio of their concentrations in the product of the separation process. The measure of this separation is called the decontamination factor (DF) when a product is separated from an undesirable material, as, for instance uranium from fission-product zirconium:

$$
\mathrm{DF}=\frac{\text { Concentration } \mathrm{Zr} \text { in feed }}{\text { Concentration } \mathrm{U} \text { in feed }} \div \frac{\text { Concentration } \mathrm{Zr} \text { in product }}{\text { Concentration } \mathrm{U} \text { in product }} .
$$

When the products are separated from each other, the corresponding term is the separation factor (SF). For example, for the separation of uranium from plutonium:

$$
\mathrm{SF}=\frac{\text { Concentration } \mathrm{Pu} \text { in feed }}{\text { Concentration } \mathrm{U} \text { in feed }} \div \frac{\text { Concentration } \mathrm{Pu} \text { in product }}{\text { Concentration } \mathrm{U} \text { in product }}=\frac{\mathrm{DC}_{\mathrm{U}}}{\mathrm{DC}_{\mathrm{Pu}}}
$$

\footnotetext{
${ }^{*}$ See definttions in Section 7.6.1.
} 
Since the degree of separation of the various products from each other and from fission products in the nuclear fuel recovery plant must be much greater than is common in the chemical industry, careful attention must be given to the details of the operation to assure that products meet specifications. The parameters of particular concern in each operation will be discussed in later sections.

7.6.2.1 Tributy1 Phosphate and Normal Dodecane - Tributyl phosphate (TBP) is an organic phosphate in which a number of neutral inorganic salts have a very high solubility. When used in the solvent-extraction plant it is usually diluted with a straight-chain hydrocarbon called normal dodecane (NDD). Some physical properties of these materials are given in the following table.

\begin{tabular}{lccc}
\hline & TBP & NDD & 30\% TBP in NDD \\
\hline Molecular weight & 266.32 & 170.34 & \\
Flash point, ${ }^{\circ} \mathrm{C}$ & 145 & 78 & 85 \\
Density, $20^{\circ} \mathrm{C} / 20^{\circ} \mathrm{C}$ & 0.9730 & 0.7487 & 0.819 \\
Viscosity at $20^{\circ} \mathrm{C}$ & & & \\
$\quad($ centipoises) & 3.32 & 1.4216 & 1.83 \\
Solubility in $\mathrm{H}_{2} \mathrm{O}$ (g/liter) & 0.39 & & 0.25 \\
Solubility of $\mathrm{H}_{2} \mathrm{O}$ in solvent & & & \\
$\quad(\mathrm{g} /$ liter) & 64 & & \\
\hline
\end{tabular}

Because undiluted TBP has nearly the same density as water, separating it from dilute aqueous solutions in a solvent-extraction plant would be difficult. Also, the DC of uranium in pure TBP is so large Llial iL is difficult to back-extract, or "strip" it from the organic phase. Diluting TBP to $30 \%$ by volume in the inert hydrocarbon NDD provides a solvent mixture with satisfactory properties.

TBP is a quite stable compound, but in the presence of 1 ight and other radiation and at high concentrations of acid or caustic, especially at elevated temperature, it decomposes slowly to lower-weight phosphates. The most frequent mode of degradation is a breaking of the bond between the organic and the phosphate parts of the molecule. Increasing degradation yields dibutyl phosphate, monobutyl phosphate, orchophosphorlc acid, and butanol. The butanol gives no problems in the process, but the series of phosphates are acids which are insoluble in the organic phase. These acids may be neutralized by reaction with sodium carbonate to give the equivalent organic-metal phosphate salts, which are not soluble in the organic phase but are slightly soluble in the aqueous and thus provide a means of their removal in a solvent-recovery step. 
In contrast to the TBP, the diluent degrades by adding nitrate groups, which give it a bright yellow color. Unlike the TBP degradation products, the organic nitrates do not react readily with caustic.

The presence of the degradation products in the solvent results in a decrease in decontamination from fission products, an increase in loss of uranium and plutonium to the aqueous waste and to the used solvent, and the formation of solids and sludges which cause less satisfactory mechanical operation of the plant.

7.6.2.2 Urany1 Nitrate - The uranium in the PUREX process is in the form of uranyl nitrate, $\mathrm{UO}_{2}\left(\mathrm{NO}_{3}\right)_{2}$, which gives an intense yellow color when dissolved in either water or TBP. Its solubility in water at room temperature $\left(25^{\circ} \mathrm{C}\right)$ is about 2.2 molar, and this saturated solution is quite acidic ( $\mathrm{pH}$ about 0.2 ). Uranyl nitrate dissolves in the TBPdiluent mixture by forming the complex $\mathrm{UO}_{2}\left(\mathrm{NO}_{3}\right)_{2} \cdot 2 \mathrm{TBP}$. Since this complex contains two moles of TBP per mole of $\mathrm{UO}_{2}\left(\mathrm{NO}_{3}\right)_{2}$, the maximum solubility is about $4.34 \mathrm{~g}$ of uranium per liter per percent TBP. The distribution coefficient of uranyl nitrate has been discussed in Section 7.6.2.

7.6.2.3 Ṕlutonium Nitrate - The plutonium in the PUREX process may be present as a variety of compounds and valence ${ }^{*}$ states, several of which may occur simultaneously. Plutonium(IV) nitrate, $\mathrm{Pu}\left(\mathrm{NO}_{3}\right)_{4}$, is the most extractable. Plutonium(VI) or plutonyl nitrate, $\mathrm{PuO}_{2}\left(\mathrm{NO}_{3}\right)_{2}$, is about half as extractable as $\mathrm{Pu}\left(\mathrm{NO}_{3}\right)_{4}$, but plutonium(III) nitrate, $\mathrm{Pu}\left(\mathrm{NO}_{3}\right)_{3}$, is less than a thousandth as extractable. Plutonium(IV) nitrate in solution has a dark brown color which at high concentrations may look black. Plutonyl nitrate is a light pink, but its color is seldom seen because it is usually masked by the much more intense color of the plutonium(IV) nitrate. Plutonium(III) nitrate has a dark blue color.

Plutonium(IV) nitrate will form an unextractable hydroxy-nitrate polymer containing thousands of molecules under low-acidity conditions. This polymer has properties that make its presence in the fuel processing solutions very undesirable. Because the polymer once formed is difficult to break, care should be used to prevent its formation. The addition of water to a solution, even the drainback of condensate, can give a localized area of low acidity resulting in the formation of polymer in a solution which if thoroughly mixed would be sufficiently acidic to prevent formation of polymer.

The valence states of plutonium and neptunium can be changed to the more extractable forms by chemicals called reductants and oxidizing agents. Specifically, plutonium(III) can be oxidized from this +3 valence to the +4 plutonium(IV) by the addition of an oxidizing agent

\footnotetext{
${ }^{*}$ See definition in Section 7.6.1.
} 
such as sodium nitrate or nitrogen dioxide gas. Conversely, the same material can be reduced from the +4 to the +3 valence by the addition of a reductant such as ferrous sulfamate or hydroxylamine.

\subsubsection{Feed-Adjustment Step}

The fuel solution from the leacher or dissolver must be adjusted to the desired concentrations of uranium, plutonium, and acid and must have the plutonium valence adjusted to convert the solution of a suitable feed for the solvent extraction operation. The plutonium from the leacher is a mixture of plutonium(VI) and plutonium(IV). Nearly all the plutonium(VI) may be converted to the more extractable plutonium(IV) by the addition of nitrite or by the use of $\mathrm{NO}^{-\mathrm{NO}_{2}}$ gas.

Care must be used in adjusting the concentrations to avoid the formation of plutonium polymer. When a dilution must be made, it should be done with a solution that is not less than $U . j$ if In nicric acid; us 15 the solution needs to be concentrated, care must be taken that condensate does not run back into the solution.

\subsubsection{Extraction Etcp}

The purpose of the extraction step is to extract the uranium, plutonium, and neptunium from the aqueous phase into the organic phase while keeping the fission products in the aqueous. When the solution compositions are correct, the most important factor controlling the operation is the flow ratio. The flow rates of the feed and the solvent need to be maintained such that the percent saturation of the exit solvent is kept at the specified value. Remember that $4 / 34 \mathrm{~g} / 1$ iter of either uranium or plutonium will saturate a $1 \%$ TBP solution. A sample calculation for determining the solvent flow rate is as follows:

Given: Feed concentration $350 \mathrm{~g}$ U/1iter, $5 \mathrm{~g} \mathrm{Pu} /$ liter

Feed flow rate

Solvent concentration

100 liters/hr

Desired saturation $30 \%$ TBP

$80 \%$

Calculate solvent flow rate to achieve desired solvent saturation:

$$
\frac{(350+5) \times 100}{30 \times 4.34 \times 0.8}=341 \text { liter } / \text { hr solvent flow rate }
$$

The flow ratio of the scrub* solution to solvent must also be carefully regulated. There will be excessive fission-product extraction when the scrub flow ratio is too low and excessive product loss when the flow ratio is too high.

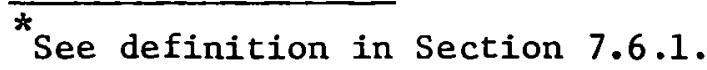




\subsubsection{Partitioning Step}

The purpose of the partitioning step is to transfer the plutonium from the organic phase to a countercurrent aqueous phase while at the same time keeping the uranium in the organic phase. This is accomplished by reducing the extractable plutonium(IV) to the unextractable plutonium(III) with either ferrous sulfamate or hydroxylamine nitrate. Because these are relatively slow reactions, several stages are provided to ensure that the reduction of the plutonium will be complete. The uranium is not reduced; therefore, most of it remains in the organic phase. The uranium that is stripped with the plutonium is reextracted with a small amount of fresh TBP.

\subsubsection{Stripping Step}

In the stripping step, the uranium is transferred from the organic phase back to an aqueous phase. Unlike plutonium, uranium is not easily reduced to a valence state that has a low distribution coefficient. The back extraction or stripping is therefore accomplished by using an aqueous phase that has very low acidity. The flow ratio of the organic to the aqueous must be sufficiently small that the concentration of uranium in the aqueous phase is not high enough to give excessive self-salting.

The low acidity in the stripping step provides a favorable environment for hydrolysis of TBP degradation products. In the presence of acid in the extraction and partitioning steps the degradation products are soluble in the organic phase. But in the low-acidity region at the top of the stripping column some of the degradation products are soluble in neither the organic nor the aqueous phase. They therefore precipitate as a gel on the metal surfaces. This gel causes the surfaces to be wetted only by the organic phase and changes the operating characteristics of the column. Under severe conditions the gel can plug the holes in the pulse plate and decrease flow in the column. This gel can be removed from the column by first contacting the gel with nitric acid to convert to the organic-soluble form, then with normal dodecane to dissolve it.

\subsubsection{Solvent Recovery}

The solvent used in the solvent-extraction system is relatively stable, but in the presence of high-intensity radiation there is a small amount of degradation of both the TBP and the diluent. The purpose of the solvent-recovery system is to remove the TBP degradation products. This system is not effective for removing the nitrated diluent.

In the solvent-recovery system, used solvent is contacted with aqueous sodium carbonate. The degradation products, which give an acid reaction are neutralized by the carbonate to give the sodium salts of the 
phosphates. These salts accumulate in the aqueous phase. The treated organic phase is then contacted with dilute nitric acid to remove residual carbonate, which could give difficulties in the extraction system. It is important that all of the aqueous carbonate be separated from the solvent before the acid is added. Otherwise, the degradation products that were removed by the carbonate wash will return to the organic phase.

Periodically a more drastic solvent cleanup will be necessary to remove solvent degradation products not removed by the carbonate wash. The most effective of these treatments is a vacuum distillation.

\subsubsection{Solvent-Extraction Contactors ${ }^{1}, 2$}

In fuel reprocessing the function of solvent-extraction contactors is to transfer the desired component such as uranium or plutonium efficiently. from one liquid phase to another. 'lhis is achieved rapidly and repeatedly by countercurrent contacting. The rate of transfer depends on the turbulence or motion and is directly proportional to the interfacial area. This is the area of the surface between the two phases. If the organic and aqueous phases are standing quietly in a bottle, the interfacial area is merely the area of the flat surface or interface between the two layers. If the bottle is shaken or stirred with an agitator, one phase will be broken up into small drops suspended in the other phase. The interfacial area then is still the surface area between the two phases but is much larger because it is inversely proportional to the diameter of the drops.

The amount of stirring or shaking necessary to generate a large amount of interfacial area is dependent on the physical properties of the system. Phases with a large density difference, high viscosity, and high interfacial tension require more power input.

Solvent-extraction contactors commonly used in plants for reprocessing nuclear fuels are (1) mixer-settlers, (2) pulse columns, and (3) centrifugal contactors. In all of them, mechanical energy is used to form dispersions or small drops of one phase in the other and to generate turbulence which promotes rapid transfer of solutes (dissolved substances) across the interface. The centrifugal contactor is a special kind of mixer-settler that uses centrifugal force in place of gravity to separate the dispersion into two liquid phases. All three types of contactors accomplish continuous multistage ${ }^{*}$ countercurrent flow of two phases.

A theoretical stage* is a concept or actual mechanical device in which the two phases are brought to equilibrium; i.e., the concentrations of salts in both phases remain constant with time. The distribution coefficient $^{*}$ is a constant that is characteristic of the chemical

\footnotetext{
* See definitions in Section 7.6.1.
} 
system. In practice, equilibrium is not usually obtained, and the efficiency of a mechanical stage is expressed as percent of a theoretical stage. "Multistage countercurrent" means that one phase enters a set of stages at one end of the system, flows in the opposite direction to the flow of the other phase, and exits at the end that the other phase enters. The two phases approach equilibrium in each stage, so that with a favorable distribution coefficient and flow ratio of the phases, the desired component can be essentially completely transferred from one phase to the other. Transfer from an aqueous phase to organic is called extraction; transfer in the reverse direction is stripping. In many systems a simple cascade of extraction stages is not sufficient to obtain satisfactory separation of two salts that extract to only slightly different degrees, i.e., have slightly different distribution coefficients or constants. ${ }^{*}$ In such a case a scrub* section of stages is added to the extraction section. This is called a compound cascade.* In the scrub section an aqueous stream is used to countercurrently scrub or wash the organic phase leaving the extraction section. This technique removes the less extractable solute from the organic phase. Becuuse usually this scrub stream also contains some of the more extractable solute, to avoid its loss the spent scrub is blended with the feed to the extraction section. Codecontamination or coextraction* usually means extraction of two product materials simultaneously. They are then separated from each other in partitioning* columns, where one product is preferentially stripped or removed from the solvent phase by the proper adjustment of flow ratios and chemical conditions to leave the other product in the solvent phase. Stripping columns next remove this other product from the solvent by contacting it with an aqueous solution of suitable composition to cause favorable distribution of the product into the aqueous phase.

7.6.8.1 Pulse Columns - of the several types of solvent-extraction contactors employed in reprocessing irradiated fuel, pulse columns are the type that have been selected within the commercial sector of the reprocessing field. Because many years of experience have been accumulated with pulse columns, only this type of contactor will be detailed here.

A pulse column is a tower or column containing perforated plates spaced along its length (height). The application of a pulsing motion to the liquid causes drops of one liquid to form in the other liquid as flow is forced through the perforated plates. Each liquid or phase enters at one end of the column and leaves at the other; the light phase enters at the bottom and flows up, countercurrent to the heavy phase, which flows down. Either phase may be formed into drops in the continuous phase; i.e., the column may be operated with either the aqueous phase continuous and containing organic drops or with the organic phase continuous and containing aqueous drops. Organic-continuous operation

* See definltions in Section 7.6.1. 
usually requires the use of plastic or "nozzle" plates to obtain stable operation. The important variables that affect the performance of pulse columns are flow rates and pulse frequency and amplitude. At low values of pulse frequency and/or amplitude the phases separate into layers on the plates between pulses, and the phases are forced through the holes on each pulse. At some higher pulse values, the phases do not separate between pulses, and the dispersed phase moves through the columns as drops. The large area of the drops promotes good transfer rates of solutes. At still higher pulse values, however, the mixing is so violent that the drops accumulate in the column, causing flooding.*

Description of a Typical Pulse Column - Pulse columns are often vertical pipes of 3- to 6-in. diameter, but columns have been built which have phase-contacting sections with inside diameters ${ }^{3}$ or up to 34 in. and with heights ${ }^{4}$ greater than $33 \mathrm{ft}$. In addition to the column shell itself, pulse columns are provided with feed distributors, phasedisengaging sections, interface control instrumentation, internal fittings, and a device for providing the pulse. The pulse generator is attached to the column through a pulse leg, which is ordinarily combined with one of the streams entering or leaving the bottom of the contactor. This pulse leg extends high enough that the hydraulic head (weight of liquid) in the column is almost balanced.

The phases are disengaged in enlarged calming sections at the top and bottom of the column. The disengaging sections can be in the shape of cylinders, boxes, or slabs, the latter being used when criticality is a concern (Section 6.2).

The interface in a pulse column is maintained in either the top or bottom disengaging section. The location of the interface is sensed by bubbler-type dip probes or by a remote float-type sensing device. The height of the interface can be varied by increasing or decreasing the opening of a valve in the heavy exit stream or by varying the air pressure on a pot in the column jackleg.

A schematic cross section of a typical pulse column is shown in Fig. 7.6.1, and Fig. 7.6.2 shows a set of pilot-scale columns.

Perforated Plates - The intimate contact of phases in pulse columns is nearly always achieved by forcing the liquids through perforated plates, although Raschig rings and other colum packings have also been used. Perforated plates are preferred because they allow greater flexibility in design, usually permit greater throughput, and frequently are less expensive than other kinds of packing.

Several plates are assembled to form a single unit or cartridge which is inserted into the column. In a small column the cartridge can be supported on a single central rod (Fig. 7.6.3); larger columns require

\footnotetext{
* See definitions in Section 7.6.1.
} 


\section{ORNL-DWG 75-17980}

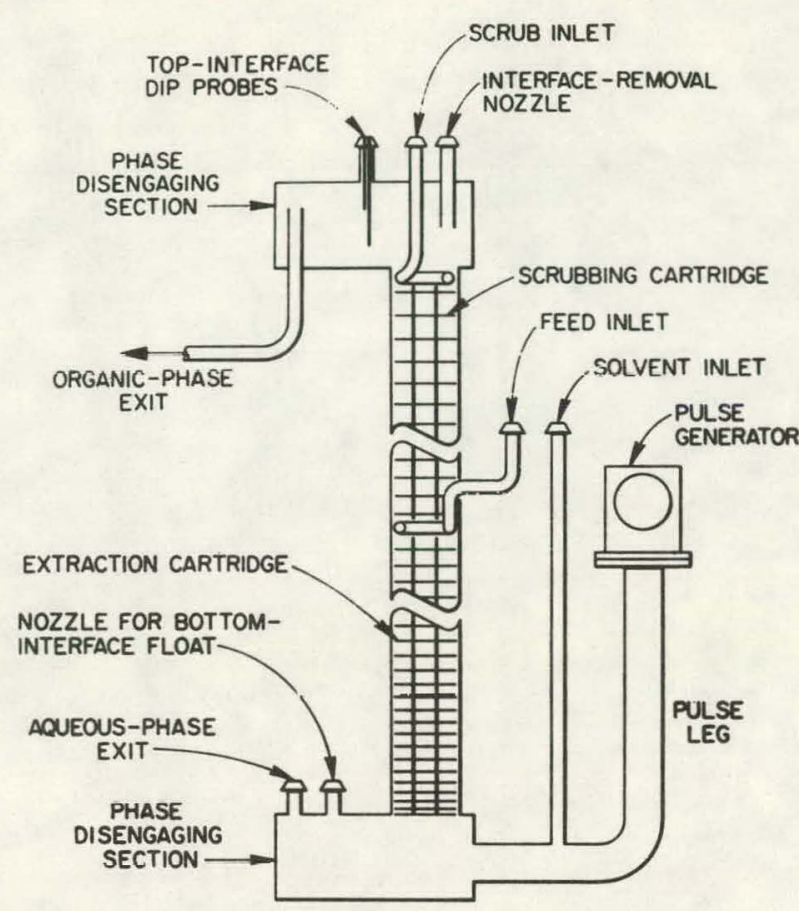

Fig. 7.6.1. Typical Solvent-Extraction Pulse Column with Extraction and Scrubbing Sections. Both top and bottom interface locations are shown, but only one is provided for in any given column.

several rods. Clearance between the plates and the column should be sufficient to permit a slip fit but must not be great enough to allow appreciable leakage between the plates and the column wall.

The most important variables in the design of perforated plates are material of construction, percentage of free area, perforation diameter, and plate spacing. The material of construction should be strung, corrosion- and radiation-resistant, and not wettable by the discontinuous phase. The most desirable combination of plate geometries (free area, perforation size, plate spacing) usually differs from one system to another, although for many systems a standard cartridge has been found to have properties near the optimum. The standard cartridge consists of plates with 1/8-in.-diam perforations and a 23 percent free area, the plates being spaced 2 in. apart. Departures from the standard are necessary, however, whenever requirements for throughput or efficiency justify the change.

Stainless steel is generally the most desirable material of construction for nitrate systems, but organic materials (plastics) have been used when wettability by the organic phase was sought. Plastic sieve plates must have proper structural stability. This is achieved by coating stainless steel plates with plastic or by using plastic thick enough to provide the desired stiffness. 


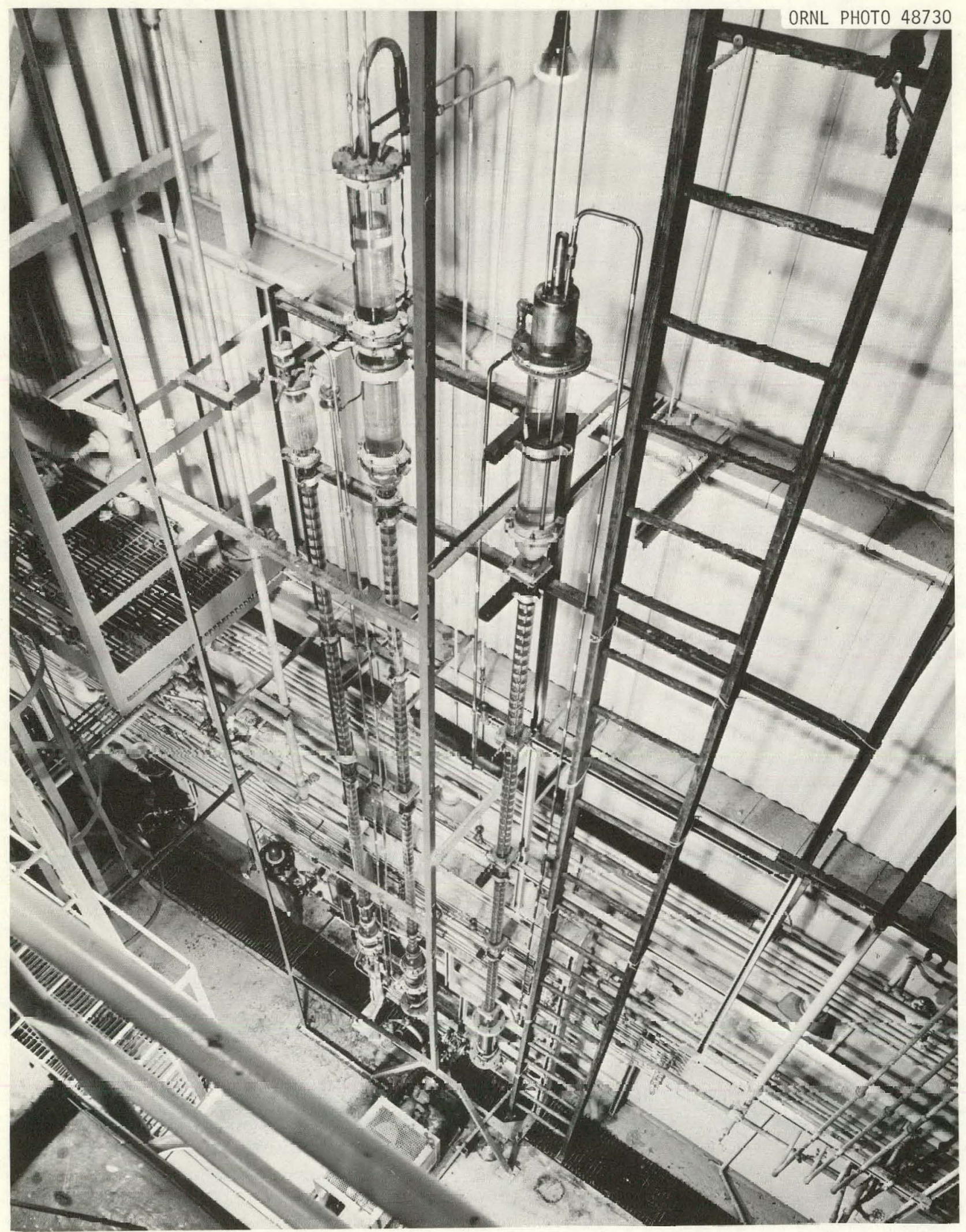

Fig. 7.6.2. View of ORNL Pilot-Scale Columns 


\section{ORNL-DWG 75-17981}

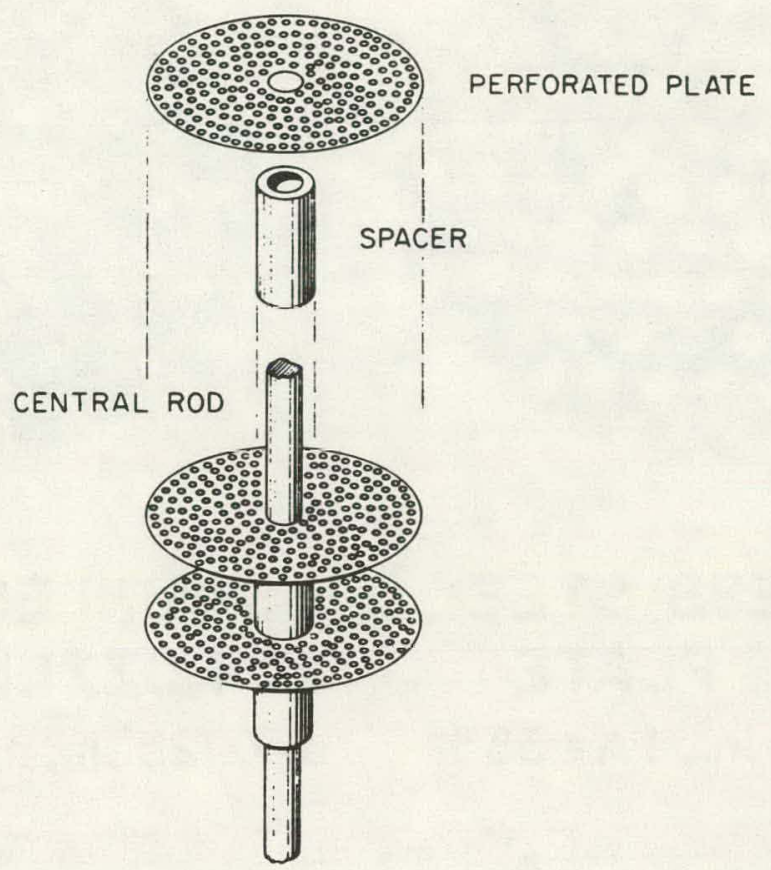

Fig. 7.6.3. Exploded View of Cartridge for a Small Pulse Column

A special design of stainless steel plate, called a nozzle plate, has been found to improve extraction efficiency and permit greater throughput than ordinary plates of the same perforation size and free area and to perform as well as or better than plastic plates, even when the organic phase is continuous. A nozzle plate differs from an ordinary sieve plate only in that the holes are indented slightly (Fig. 7.6.4) on the face oriented in the direction of travel of the dispersed phase. The improvement apparently is related to less wetting of nozzle plates by the dispersed phase, as only the perimeter of the nozzle opening is wetted. The nozzle depth should be at least $0.035 \mathrm{in}$. for optimum performance.

7.6.8.2 Pulsers - Two methods of providing energy to a pulse column are presently employed in reprocessing, pneumatic pulsing and mechanical pulsing. Mechanical pulsing has been satisfactory for pilot-scale operations, but pneumatic pulsing has been found to be efficient in commercial reprocessing because its advantages include (1) long-term maintenance-free operation, (2) ability to maintain a set pulse frequency and amplitude without fluctuations, (3) ability to allow varying the amplitude and frequency of the pulse for optimum operation, and (4) compactness. 

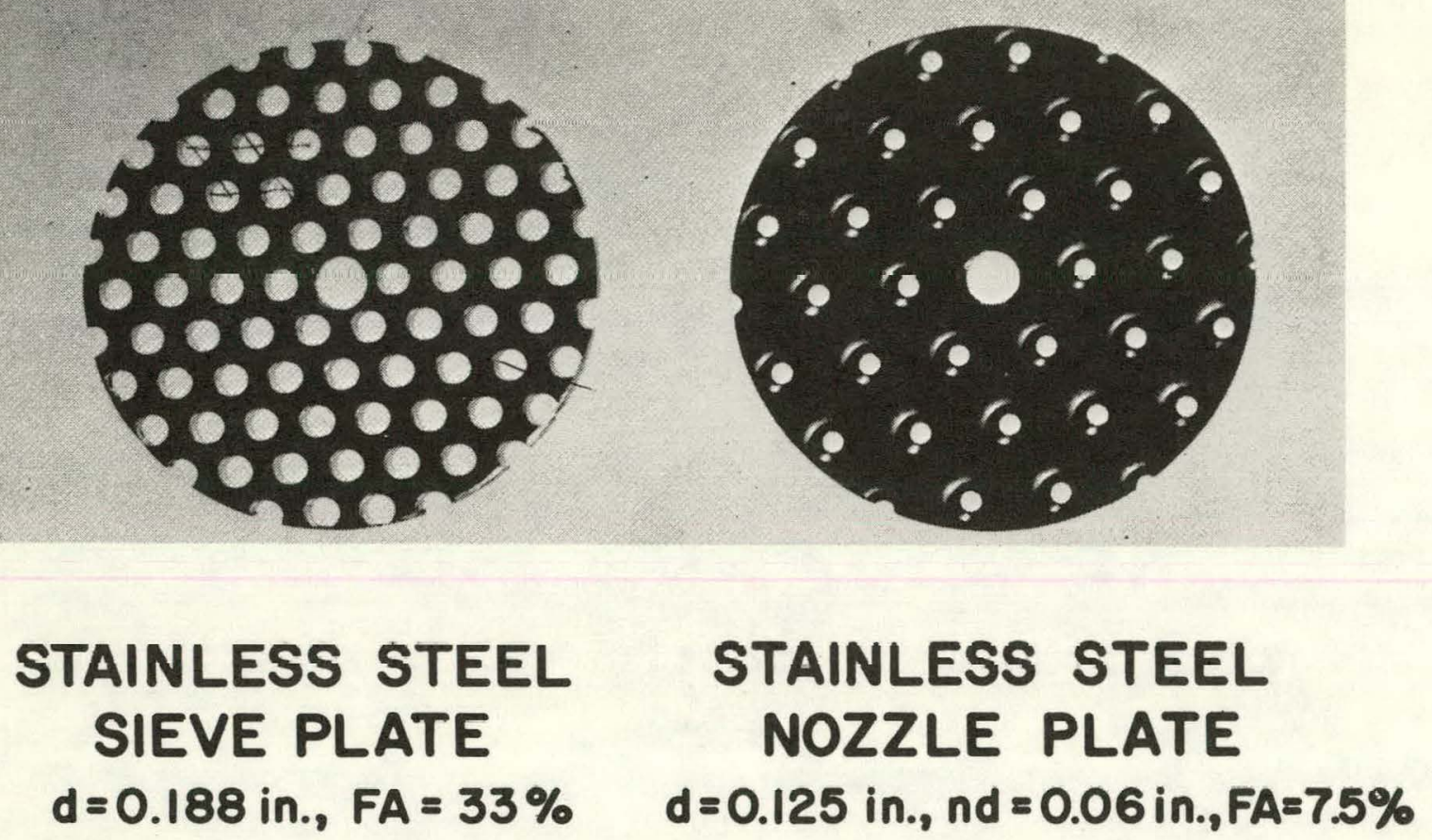

Fig. 7.6.4. Typical Sieve Plates Used in Purex Pulse Columns ${ }^{4}$

A typical arrangement, similar in most respects to the pulser systems currently in use in commercial plants, is shown in Fig. 7.6.5. Alr for the pulser, supplied at 50 psig, is reduced through a self-contained pressure regulator to about $25 \mathrm{psig}$ and then throttled through a control valve into the air reservoir. The capacity of the air supply system must be sufficient for the reservoir pressure to return to the set point during the exhaust half of each cycle. The inlet and exhaust valves tor the pulse air are nominal 1 -in. poppet-valves with oversized ports and with offset inlets and outlets for minimum pressure drop. These valves are operated by a pair of motor-driven cams. The pulse frequency and amplitude can be controlled separately, the frequency by the speed of the cam drive and the amplitude by the pressure in the air reservoir.

Radioactive contamination of the pulse air is minimized by pulsing the least radioactive stream at the bottom of the column; for extraction, this is the entering organic stream. The pulse leg is attached as close to the base of the column as feasible. A reservoir of solvent between the base of the column and the pulse leg is desirable in order to prevent drawing some of the aqueous phase into the pulse leg; hydraulic instability would result if the density of the fluid in the pulse leg were to change sharply. 
ORNL Dwg 74-9179

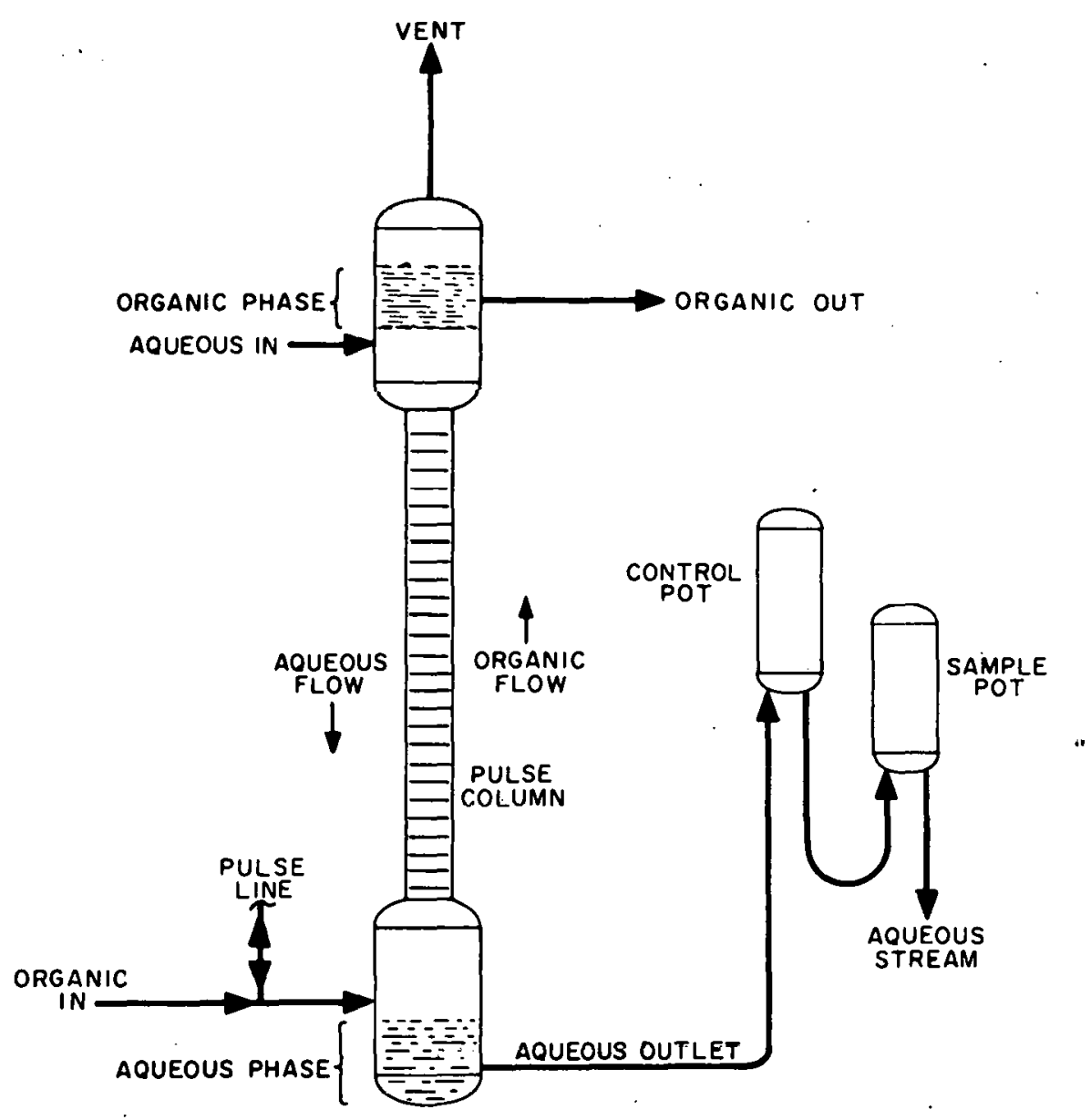

Fig. 7.6.5. Air-Pulsed Pulse Column Used at ICPP 
Radioactive contamination of the pulse air is minimized by pulsing the least radioactive stream at the bottom of the column; for extraction, this is the entering organic stream. The pulse leg is attached as close to the base of the column as feasible. A reservoir of solvent between the base of the column and the pulse leg is desirable in order to prevent drawing some of the aqueous phase into the pulse leg; hydraulic instability would result if the density of the fluid in the pulse leg were to change sharply.

Three operating hazards must be guarded against: (1) backup of contaminated liquid into the air supply system, caused by a failure in the air supply; (2) blowing of air through the pulse column to contaminate the column off-gas system, caused by the air inlet valve's remaining open too long; and (3) displacement of contaminated liquid into the piping area, caused by the air exhaust valve's remaining open too long. If adequate headroom is not available in the shielded area to circumvent. these problems, they can be guarded against by a seal loop in the air supply line and by limit switches on the inlet and exhaust valves.

7.6.8.3 Instrumentation - Instrumentation is generally necessary to sense the location of the interface between the aqueous and organic phases in the disengaging section. The signal from the sensor is used to control the rate of flow of the aqueous phase from the column to maintain the interface level at the desired position. Detection or sensing of the interface at the top of the column is usually accomplished by the use of the same principle commonly used to remotely measure liquid depth in tanks (see Section 8.1.7). The density of the organic phase can be used to calculate the loading of uranium in the organic, provided the temperature is known and accurate calibrations have been made.

It is more difficult to sense the interface position in the bottom disengaging section of a column operated with the organic phase continuous than to sense the interface at the top of the column. Use of an air bubbler system is not desirable because introduction of air at the bottom of the column causes loss of pulse because of the compressibility. of the air. The interface position can be sensed either by a float with a remote signal or by use of a liquid purge system. The latter requires no instrumentation to the radioactive cell and is less susceptible to fouling than the float system. The liquid purge system consists of two small-diameter sensing pots connected to the bottom disengaging section at points spanning the desired range of interface position.

Small equal purges of liquid of constant density are maintained through the two sensing pots. Either organic or water may be used. Horizontal surge capacity at each entry to the column is important to reduce pulse effects. The difference between the liquid levels in the sensing pots, which is measured by air bubblers and a differential pressure transmitter, is directly related to the interface position. 
The interface position in a pulse column is controlled by the rate of flow of the aqueous phase from the bottom of the column. This is usually done by varying the air pressure applied to a pressure pot on the aqueous effluent line. The pressure pot is located at some distance below the top of the column so that with no air pressure the hydrostatic head of the column forces aqueous out and application of air pressure stops aqueous flow. The air pressure is controlled by the interface position signal to automatically control the interface position at the desired point. In cases where it is necessary to elevate the aqueous stream above the top of the colum the interface signal can be used to control the flow rate of air to an air-lift pump connected directly to the aqueous effluent from the column.

Frequently the hydrostatic pressure at the bottom of the column is measured to provide early warning of flooding. " At steady state, the holdup of the dispersed phase and the pressure at the base of the column are constant. An increase in holdup, which would be detected by a change in pressure, may indicate flooding, which is further confirmed by an increase in fluw lale of the concinuous-phase ettluent and a decrease in dispersed-phase flow.

7.6.8.4 Operating Variables and Method of Control - Variation of the pulse amplitude and frequency affects the efficiency and flow capacity of the pulse column. Usually the column is operated in the emulsion region, which means that pulse conditions are such that only partial coalescence of drops occurs and some dispersion persists. Increase of either pulse amplitude or frequency decreases drop size and increases holdup of the dispersed phase, thus increasing the efficiency. Further increases, however, lead to flooding. Since a column is usually designed to operate at about $80 \%$ of flooding, if product losses are higher than desired, they may be reduced by increasing the efficiency through increasing the pulse frequency. On the other hand, if an increase in flow rate is desired, then the pulse amplitude or frequency should be reduced. Generally, the pulse amplitude should not be much greater than half the plate spacing. Of course, as shown in Section 7.6.2, adjustment of such flowsheet conditions as flow ratios, solvent strength, salting strength, and temperature can be used to improve recovery and/or capacity.

7.6.8.5 Typical Startup and Operation - Initial startup of columns that are empty is usually made with "cold" solutions; i.e., solutions containing salting agents and acids typical of actual process solutions but free of radioactive materials. After the columns are hydraulically balanced and flows are stable, the radioactive feed is introduced. The column is filled with aqueous phase until the interface-position

See definition in Section 7.6.1. 
instrument (see description, Section 8.1.7) just shows an interface. If the aqueous effluent is controlled by a pressure pot, air pressure is alternately applied and relieved until the seal leg is filled, as indicated by a steady pressure reading on the pot. After control of the aqueous effluent is established, the aqueous feed is shut off and organic flow is started. When the level of the organic phase reaches the density probe, the aqueous may be started and both flows continued until a steady interface position and column pressure are obtained. The procedure is essentially the same for either aqueous- or organiccontinuous operation; only the relative quantities of the phases needed to fill the column change.

When operating a series of pulse columns such as extraction, scrub, and strip cycles, it is important to avoid large changes in the operating parameters in any one coliuin that would cause upsets in the other columns. For example, if the interface is raised 1n the extraction column, this causes an increase in the flow of organic out of the column into the next columin, which could cause leimporary flooding or an imbalance of flow ratio, which could result in loss of product or decontamination. Frequently, smoother startup and operation can be obtained by starting the flow rates at about $75 \%$ of design flow rates and then increasing to the design rates after achieving reasonable approach to steady state.

\subsubsection{Common Difficulties}

1. Flooding ${ }^{*}$ - Flooding of a pulse column is a phenomenon in which the capacity of the column for countercurrent flow of two immiscible phases is exceeded and the dispersed phase accumulates in the column. Continued operation of the column at flooding eventually results in some of the dispersed phase flowing out with the continuous phase. Columns are usually designed to operate at less than $80 \%$ ol maximum flow capacity to allow some safety factor. Flooding of a column at design conditions indicates an abnormal condition, which probably can be determined by review of the following common causes: erratic flow or surging of process streams to the column or of the interface levels in the colum, change in pulse amplitude and/or frequeucy, change in physical or chemical properties of the process streams that may increase the time required for phase separation, or physical restriction of pulse plates by solids or stable emulsion. The flooding usually can be relieved by decreased pulse frequency, provided this does not cause intolerable loss of product due to lower column efflclency at the lower pulse frequency. Sometimes when a particular batch of feed is the cause of flooding, it may be necessary to run at reduced flow rates to avoid high product loss.

* See definitions in Section 7.6.1. 
2. Entrainment and Loss of Product - Entrainment is the carryover of small drops of the dispersed phase from the column along with the opposite phase. Generally the continuous phase contains the haze; i.e., entrainment is greater in the phase that is continuous. For an aqueous-continuous extraction column, loss of organic phase by entrainment could result in some loss of product that was extracted into the organic. Where entrainment loss is important, the loss can be reduced by passing the effluent stream through a decanter that has a large cross section and permits the entrained drops to coalesce and settle out of the main stream.

The pulsing conditions affect the amount of coalescence. High amplitude and/or frequency decreases the drop size of the dispersed phase. Because the settling rate of drops is directly proportional to size, small drops settle slowly and are subject to carryover as entrainment. The ratio of flow and holdup in the column also affects drop size and entrainment. A very dilute dispersion of small drops is formed when the ratio of dispersed phase to continuous phase is small, resulting in entrainment.

3. Low Decontamination Factors - The dependence of decontamination factors on the parameters of the chemical flowsheet is described in Section 7.6.2. Decontamination factors are also directly dependent on the efficiency of the pulse columns. The efficiency is increased with increased pulse amplitude and frequency up to the point of flooding or high entrainment. Low decontamination factors result from poor dispersion, flooding, or high entrainment. Surging flows, which may be caused by poor interface control or malfunction of liquid pumps, also can cause low decontamination factors. When low decontamination factors are encountered, all the instrument readouts should be carefully analyzed to determine whether there is an equipment malfunction. If none is found, the trouble is probably due to the flowsheet, and the important parameters described in Section 7.6.2 should be checked.

\section{REFERENCES FOR SECTION 7.6}

1. Thomas B. Drew and John W. Hooper, Advances in Chemical Engineering, 1956, vol. I, p. 289.

2. J. T. Long, Engineering for Nuclear Euel Reprocessing, Gordon and Breach, 1967.

3. E. R. Irish, Description of Purex Process, USAEC Report HW-60116, Hanford, Washington, May 19, 1959.

4. R. G. Geier, "Application of The Pulse Colum to The Purex Process," Symposium of the Reprocessing of Irradiated Fuels, Brussels, Belgium, MCO 1957, USAEC Report TID-75.34, book 1, pp. 110-119. 


\subsection{EVAPORATION}

Evaporation is the mechanism by which a solution is concentrated by boiling away the solvent from the solutes (dissolved substances). By means of this unit operation, lower-boiling liquids can be separated from liquids having higher boiling points or from solids. It offers a high degree of separation between volatile and nonvolatile components of solutions that are not amenable to treatment by low-temperature operations such as precipitation, filtration, and ion exchange.

\subsubsection{Definition of Terms}

Entrainment is the carrying over of liquid droplets and/or solid particulates with the vapor rising from the surface of the boiling liquid.

Disengagement section is an enlarged chamber in an evaporator, where the velocity of a flowing vapor-liquid mixture is reduced to a value such that the liquid separates from the vapor by gravity (the droplets fall out).

Reflux is the continuous return of a part of the boiled-off vapor to the system as a liquid in order to concentrate a low-boiling component in the vapor.

Fractionation is distillation in which vapor rising from the evaporator is separated into components (fractions) of different boiling points as it comes in contact with condensed vapor previously evolved from the same solution. A transfer of heat and of lower-boiling component occurs when two fractions thus come in contact, and a product richer in the lower-boiling component is obtained. The condensate is enriched if its boiling point is greater than the temperature of the vapor, and the vapor is enriched if its temperature is greater than the boiling point of the condensate.

Thermosiphoning is the movement of liquid between two vessels joined at their tops and bottoms, when heat is applied to one vessel (leg) in such a way that vapor and entrained liquid rise and pass over to the top of the cold vessel. The increased head of liquid in the cold leg and decreased head in the hot leg cause cold liquid to transfer by gravity flow to the hot leg.

\subsubsection{Purpose (Uses in the Process)}

Evaporation has wide application in the nuclear industry ${ }^{1}$ and is an important step in fuel reprocessing by the Purex solvent-extraction flowsheet. It is used to reduce the volumes of liquid waste and of product solutions, to reduce the amount of radioactive materials in liquid effluents, to recover nitric acid $\left(\mathrm{HNO}_{3}\right)$ for reuse, and to reduce the amount of caustic soda $(\mathrm{NaOH})$ needed to neutralize acidic waste before storage. 
In the Purex flowsheet, the streams that are evaporated are

1. high-activity waste from the first solvent cycle (coextraction of uranium and plutonium),

2. intercycle uranium stream,

3. second-cycle waste, and

4. product uranium and plutonium streams.

\subsubsection{Description of Equipment}

Evaporators must be simple and dependable pieces of equipment in order to keep maintenance needs to a minimum. An evaporator consists basically of a device to transfer heat for boiling the solution or slurry, devices to separate the vapor phase from the liquid phase, and a device to condense the vapor back to a liquid to be collected in another vessel or sent out of the plant as effluent.

Steam is usually the heat source for evaporation and concentration. Evaporator capacity is often limited by foaming and entrainment problems rather than by heat transfer coefficients. In the simplest evaporators, steam is supplied to a jacket around the lower part of a pot, but this arrangement usually gives a low rate of evaporation. Internal coils of pipe or bundles of tubes to supply steam heat improve the efficiency of evaporation, because the vapor generated agitates the solution uniformly (Figs. 7.7.1 and 7.7.2). Such heating tubes or coils of evaporators are more likely to develop leaks than other pieces of process equipment are, because they are subject not only to corrosion and thermal stresses but also to vibration resulting from the boiling action. In general, evaporators are so designed and operated that if a leak in a heating tube occurs, the steam will leak into the process part of the vessel instead of the process solution leaking into the steam side. This arrangement avoids radioactive contamination of the steam and condensate return systems, which might spread contamination to other parts of the plant. It is possible to design internal tube bundles or coils to be replaced by remote maintenance techniques.

The heating tubes may be mounted outside the pot in a thermosiphon-type evaporator (Fig. 7.7.3), in which the feed enters the bottom of the heater section and rises through steam-heated tubes where it boils, the vapor rising and carrying entrained liquid along with it at a rapid rate. This mixture rushes into the flash chamber, striking an impingement baffle which deflects the liquid downward while the vapor sweeps around the end of the baffle and turns upward. This change of direction and the slowing down of the vapor in the larger-diameter flash chamber cause more liquid droplets to fall out of the stream, thus making this chamber serve as a disengaging section of the evaporator. The liquid falls into the cold leg and is recirculated by natural convection through the heater section. 
ORNL DWG-72-1393RI

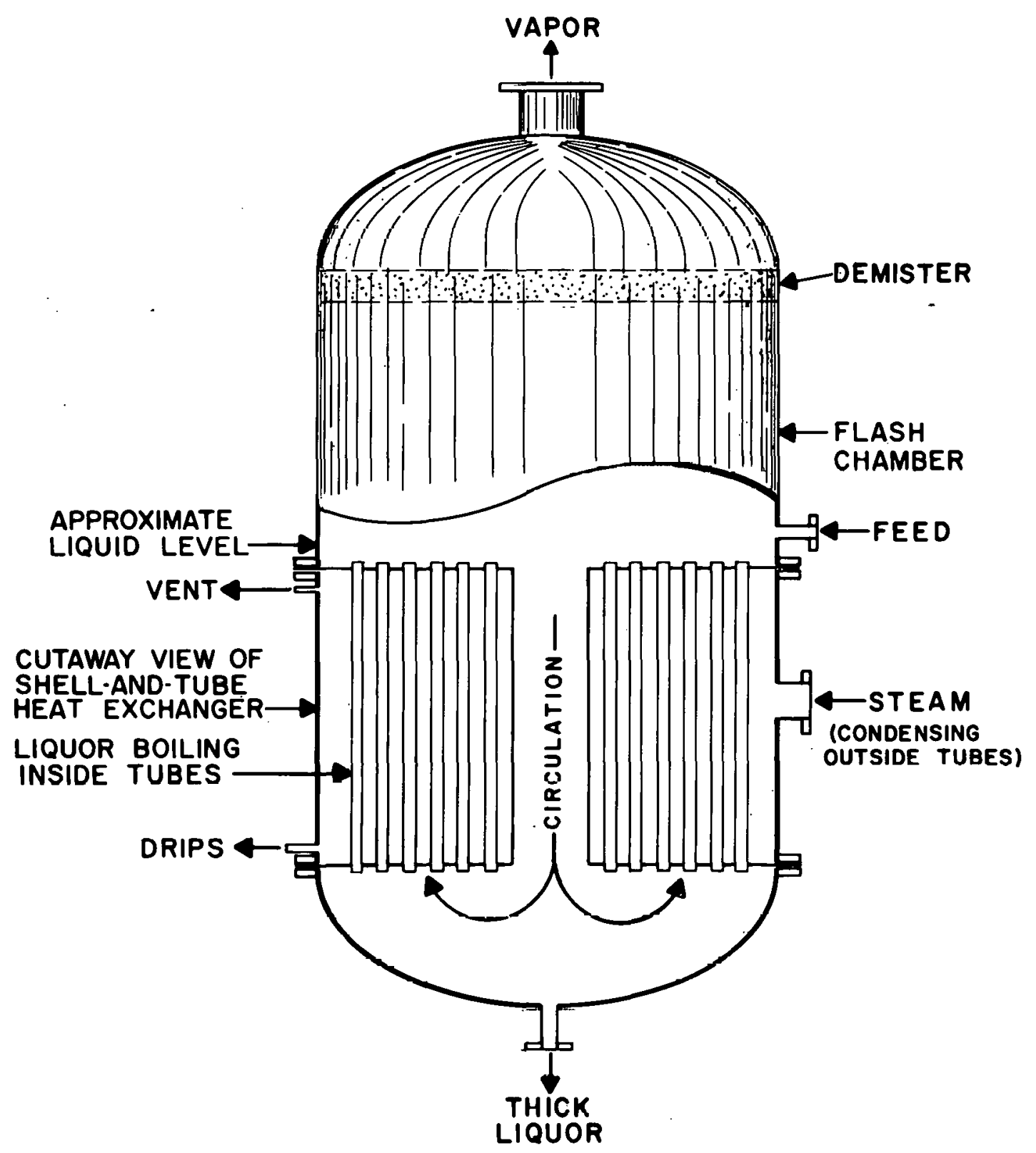

Fig. 7.7.1. Short Vertical-Tube (Calandria or Standard) Evaporator 
ORNL DWG. 73-5934

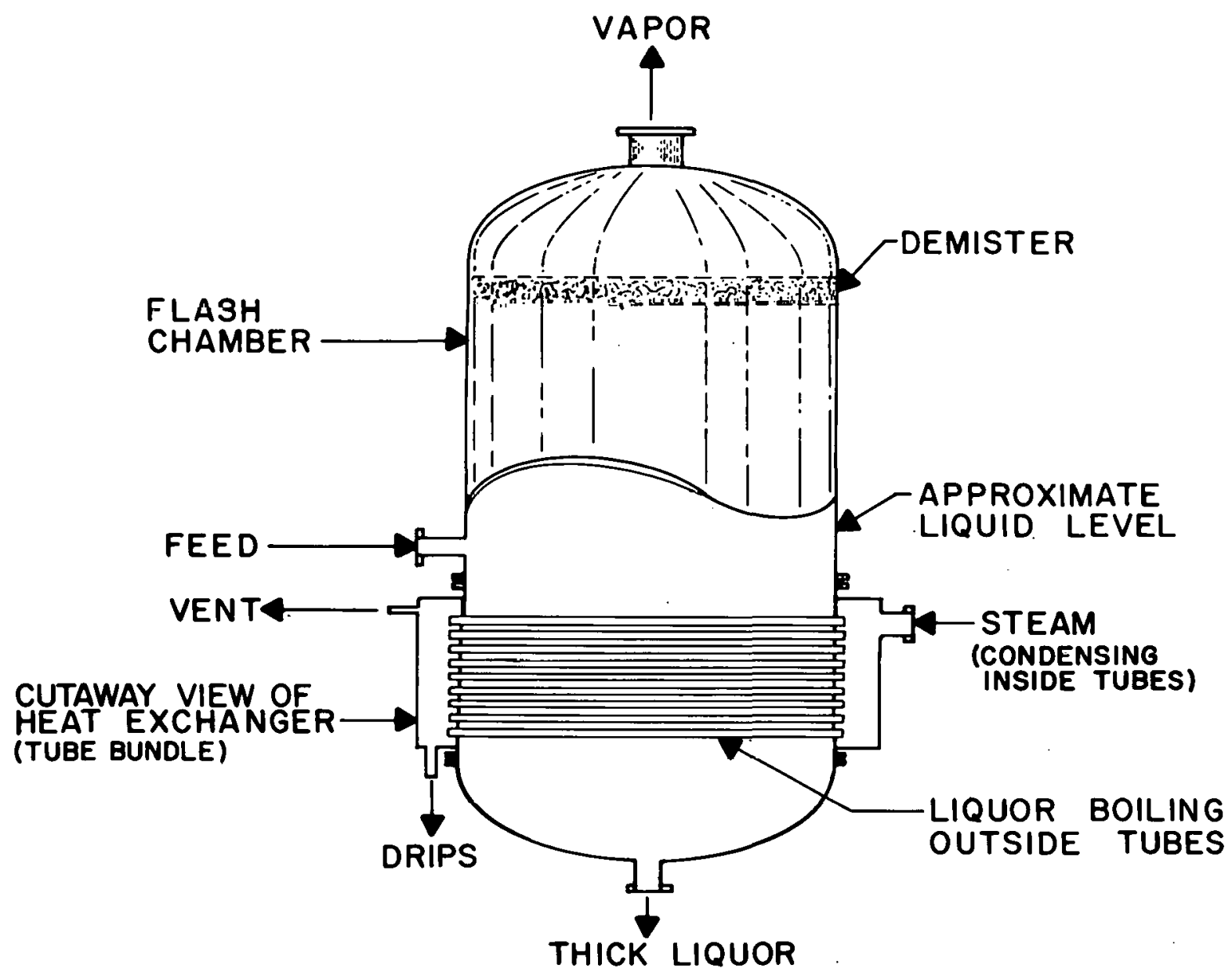

Fig. 7.7.2. Horizontal-Tube Evaporator (Classic Construction) 
ORNL DWG 72-1395R1

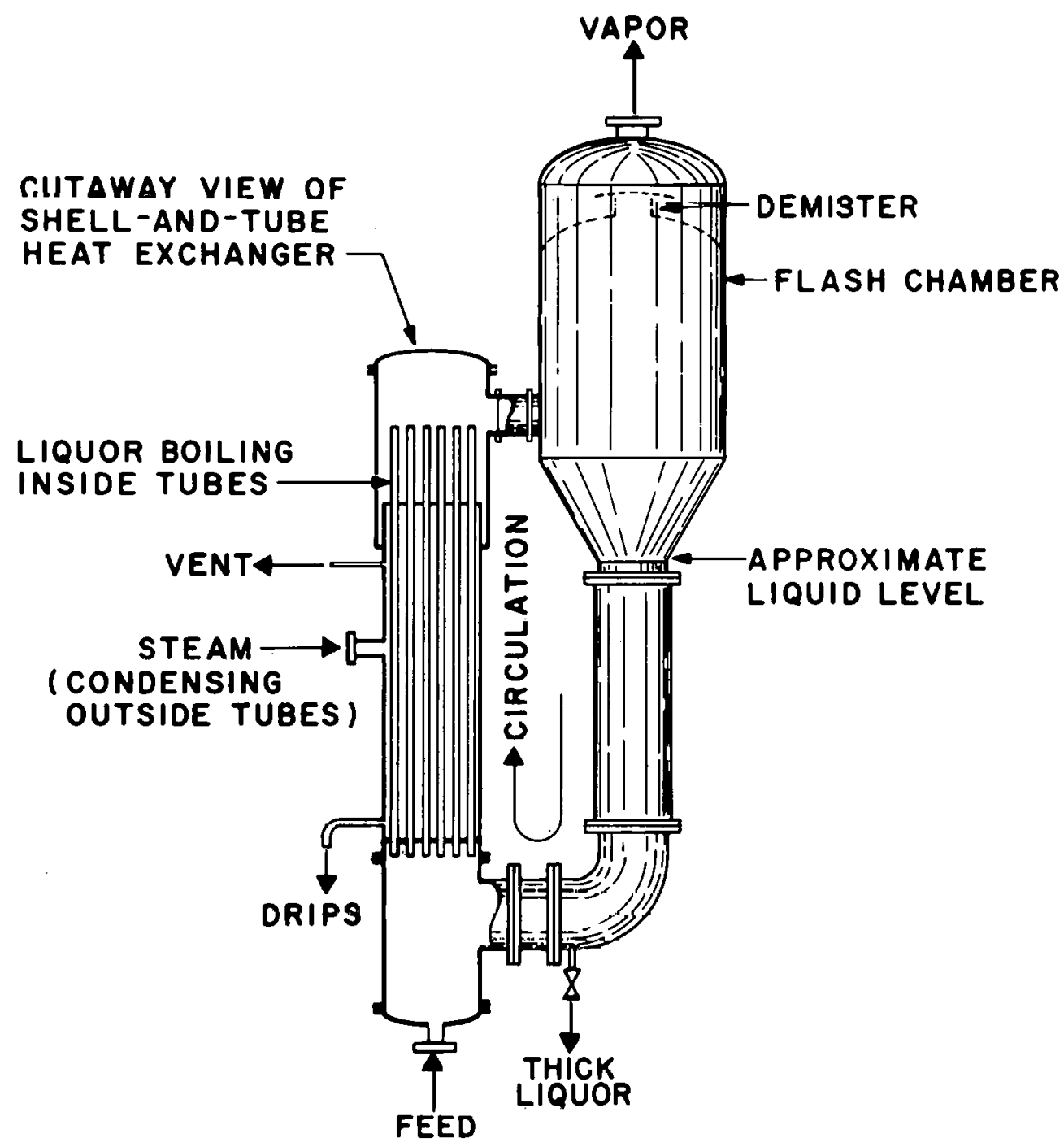

Fig. 7.7.3. Long Vertical-Tube Evaporator with External Heater and Natural Circulation (Thermosiphon). 
The vapor rises to the top of the evaporator and passes through a demister device, which may contain baffles to make the vapor change direction several times or may contain wire mesh (Figs. 7.7.1 and 7.7.2) on which liquid droplets collect before draining down the vessel walls. It is of utmost importance to obtain the best possible separation of liquid from vapor, as even small quantities of droplets carried over the vapor cause either loss of product or contamination of the "overheads," thus defeating the purpose of the evaporation step. After passing through the demister, the vapor usually passes through a bubblecap column for further removal of entrainment before reaching a watercooled condenser which converts the vapor again to a liquid.

The concentrated liquor ("bottoms") is drawn off the bottom of the evaporator, either continuously or in batches. If this liquor becomes too concentrated, solids may precipitate from it, causing problems with plugging of instrument probes and the drain line. The wiped-film evaporator shown in Fig. 7.7.4 overcomes some of the problems encountered in evaporating solutions and slurries to high concentrations by continuously scraping the inner wall and removing a filii uf sullds.

Thermosiphon evaporators are used to concentrate the intercycle and product streams in the Purex process, and the large waste evaporator at the Idaho Chemical Processing Plant (ICPP) is a natural-circulation thermosiphon type equipped with a bubble-cap tower to improve decontamination of the vapor. The ORNL evaporator for intermediate-activity liquid waste is a simple pot with internal heating coils and a wire-mesh demister. These large waste evaporators can handle $500 \mathrm{gal} / \mathrm{hr}$ and those at some newer nuclear power plants over $2,000 \mathrm{gai} / \mathrm{hr}$.

\subsubsection{Modes of Evaporator Operation ${ }^{2}$}

There are several modes in which evaporators and concentrators can be operated: batch, semicontinuous (or semibatch), and continuous. In batch operation, feed and product flows are intermittent, process conditions are generally programmed with time, and steady-state conditions are never attained. In continuous operation, feed and product flows are kept constant, and process conditions are constant with time; the operation is at steady state. In semicontinuous operation, the vapor is drawn off continuously while solution to be concentrated is fed to the evaporator continuously also, but the concentrated liquor is drawn off batchwise after the desired degree of concentration has been achieved.

For batch operation the usual procedure is to charge to the evaporator the entire quantity of solution or slurry to be evaporated; to initiate boiling; to remove, condense, and collect the vapors continuously; and to terminate the evaporation and remove the thick liquor when its concentration, density, or viscosity has reached the level desired. This mode of evaporation is often used in the laboratory or when a very small volume of material is to be concentrated. 
ORNL DWG. $73-5935$

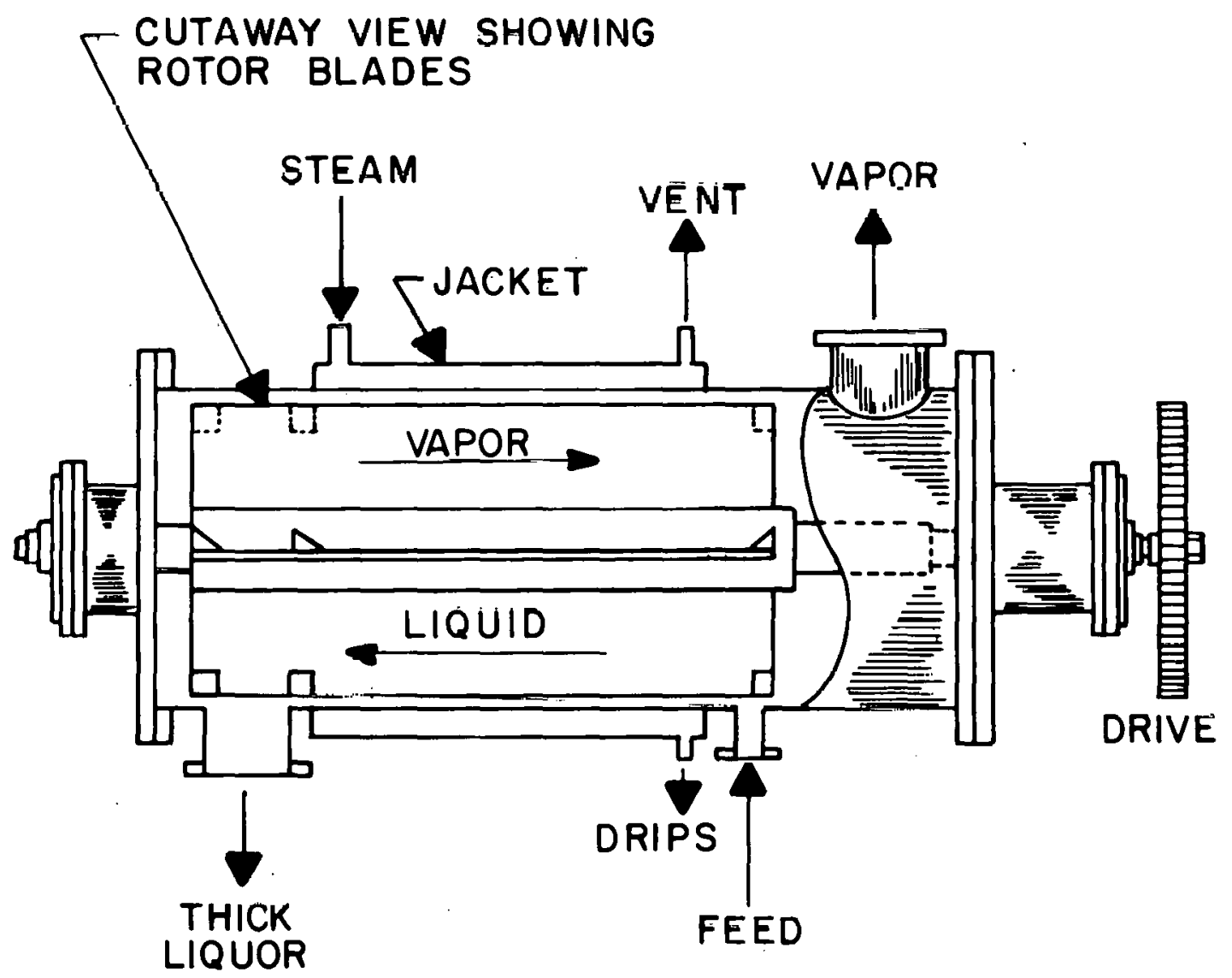

Fig, 7.7.4. Turbulent-Film Evaporator. (This type evaporator is also called thin-, agitated-, and wiped-film. Units may be horizontal or vertial and the heated walls may be tapered.) 
For semicontinuous operation, a predetermined quantity of solution or slurry is charged to the evaporator; boiling is initiated; and vapors are continuously removed, condensed, and collected. Feeding of solution or slurry to the evaporator is continued at a rate approximately equal to the rate at which the condensate is removed, i.e., at a rate to maintain a constant liquid volume in the evaporator. Evaporation is continued until the feed is exhausted or a desired concentration of thick liquor is reached. The thick liquor is then removed from the evaporator.

For continuous evaporation, startup of the evaporator is carried out as for the semicontinuous operation described above. After the desired concentration of thick liquor has been reached, a thick-liquor stream is withdrawn continuously from the evaporator. Pressures, temperatures, concentrations, and the flow rates of feed, condensate, and thick liquor are held constant.

\subsubsection{Curiliul uf Opesallisg Vallables ${ }^{3}$}

It is important in evaporation to maintain control in such a manner as to avoid boilover, foaming, surging, and any irregularity that would cause the liquid to reach the condenser. The rate of evaporation is controlled by regulating the pressure or the flow of the steam supply, usually by means of an automatic valve. The difference between the temperature of the condensing steam and the boiling point of the liquid being evaporated is the driving force. Boilover is prevented by keeping the rate of evaporation under control and by keeping the liquid level at the proper point. During startup in a pot-type evaporator it is helpful to air sparge the pot contents to cause even distribution of heat, thereby avoiding "bumping" (localized superheating that causes sudden vaporization of a mass of liquid with attendant entrainment of drops).

When an evaporator is run batchwise or semibatchwise (semicontinuously), the completion of the evaporation is determined by the density of the liquor, which indicates the concentration of the solution. If the liquor becomes too concentrated, problems with plugging lines are likely to develop. It is often desirable to analyze samples of both the liquor and the condensed overheads periodically in order to determine whether the evaporation is proceeding satisfactorily. Evaporation of waste must be stopped before the solution becomes saturated with salts. The salts form a film on the heating surface, causing a reduction in heat transfer and also increasing the chance of boilover or "bumping." Knowing the solubility of the salts and measuring the volume of condensate collected can allow the operator to determine when the end point of concentrating the solution has been reached.

In continuous evaporation, the feed rate is usually controlled by the density of the bottoms by means of an automatic instrument. When the density of the solution in the evaporator exceeds the density control set point, the liquid head becomes greater than the air pressure to the 
head pots on the product line jackleg, thus causing the evaporator solution to dump to the product storage tank. As the liquid in the evaporator falls, the liquid level control causes the feed valve to open, and feed is pumped to the evaporator. The density of the entering feed, being low, causes the liquid head to become lower than the air pressure on the head pots of the jackleg, and flow to the product tank stops. As the liquid level rises to the level control set point, the feed valve closes.

Foaming is controlled by adding antifoam agents and by suddenly heating or chilling the foam by means of coils of pipe installed in the area above the normal liquid level. It is helpful to know when foaming is occurring. 'l'herefore, some evaporators are equipped with conductivity probes that extend to various levels above the normal liquid level. Foam tends to short out any of these probes it contacts, thereby sending a signal that indicates the level of the foam in the vessel.

In many cases, the top of the evaporator consists of a short bubblecap column (Figs. 7.7.5 and 7.7.6) or packed column, which removes liquid entrained in the vapor. The feed to the evaporator usually enters near the top of the deentrainment column so that the hot, rising vapor can strip out entrained organic solvent before the feed enters the main body of the evaporator. Stripping of evaporator feed streams is done to prevent the occurrence of a violent reaction between TBP or TBP-diluent and nitric acid or nitrate salts at high temperature. Because experiments have shown that solutions of TBP and nitric acid will not react violently at $125^{\circ} \mathrm{C}$ or below, the maximum temperature for evaporation is set at $125^{\circ} \mathrm{C}$ (by limiting the steam supply pressure to 25 psig).

Also, in intercycle evaporators, the feed is stripped of solvent degradation products which would affect the performance of later solventextraction cycles.

The disengaging section of a thermosiphon evaporator presents a criticality problem because of its large diameter. Therefore, this type of evaporator is provided with an overflow line that lets excess solution flow to a storage tank; later the solution is returned to the evaporator.

Product concentration in a thermosiphon evaporator can be controlled by use of a stream of dilution water while the evaporator operates at a constant boil-up rate. Finer control is thus attained if the boil-up rate were varied.

\subsubsection{Instrumentation}

Pneumatic instruments used in evaporators include liquid level, pressure, and density indicators and liquid level and density controllers. 

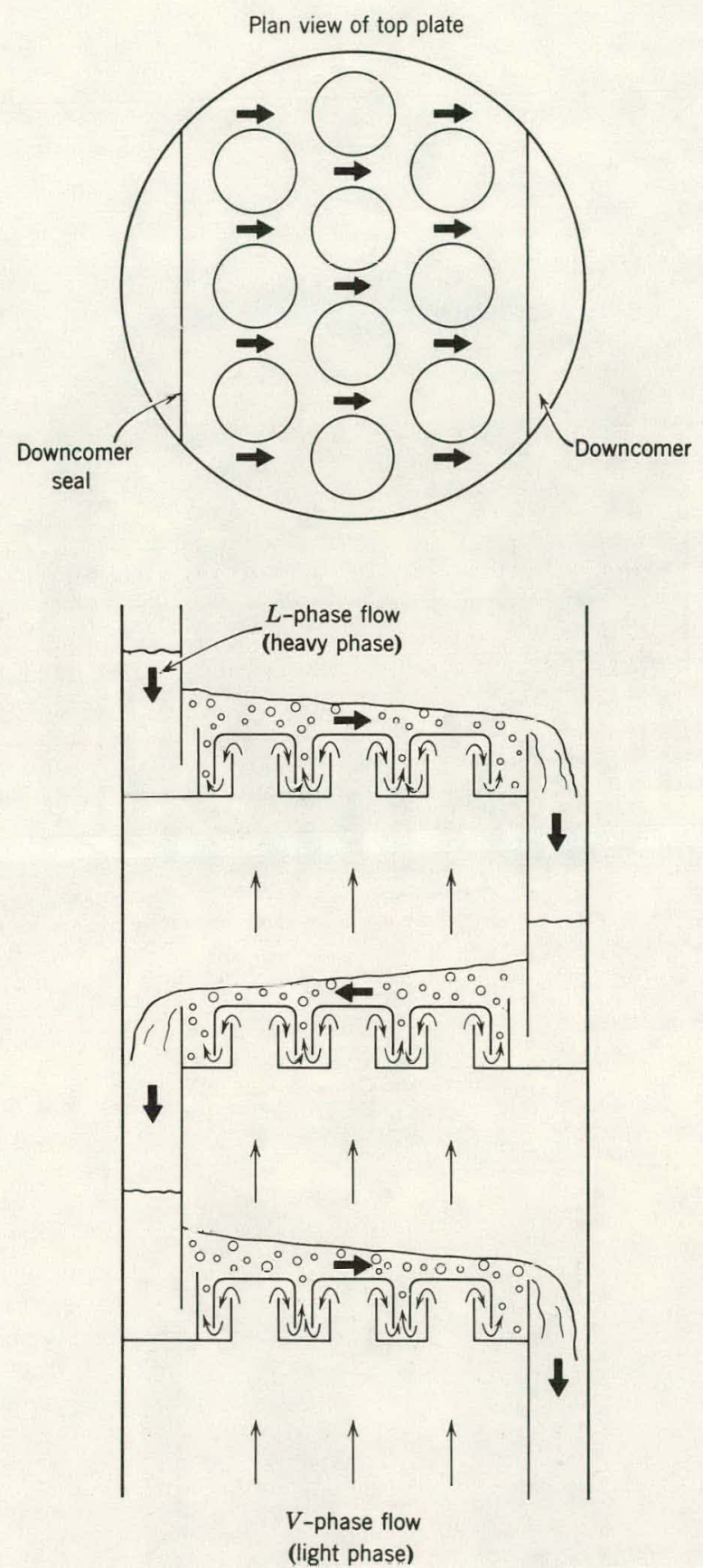

Fig. 7.7.5. Typical Bubble Cap Column 


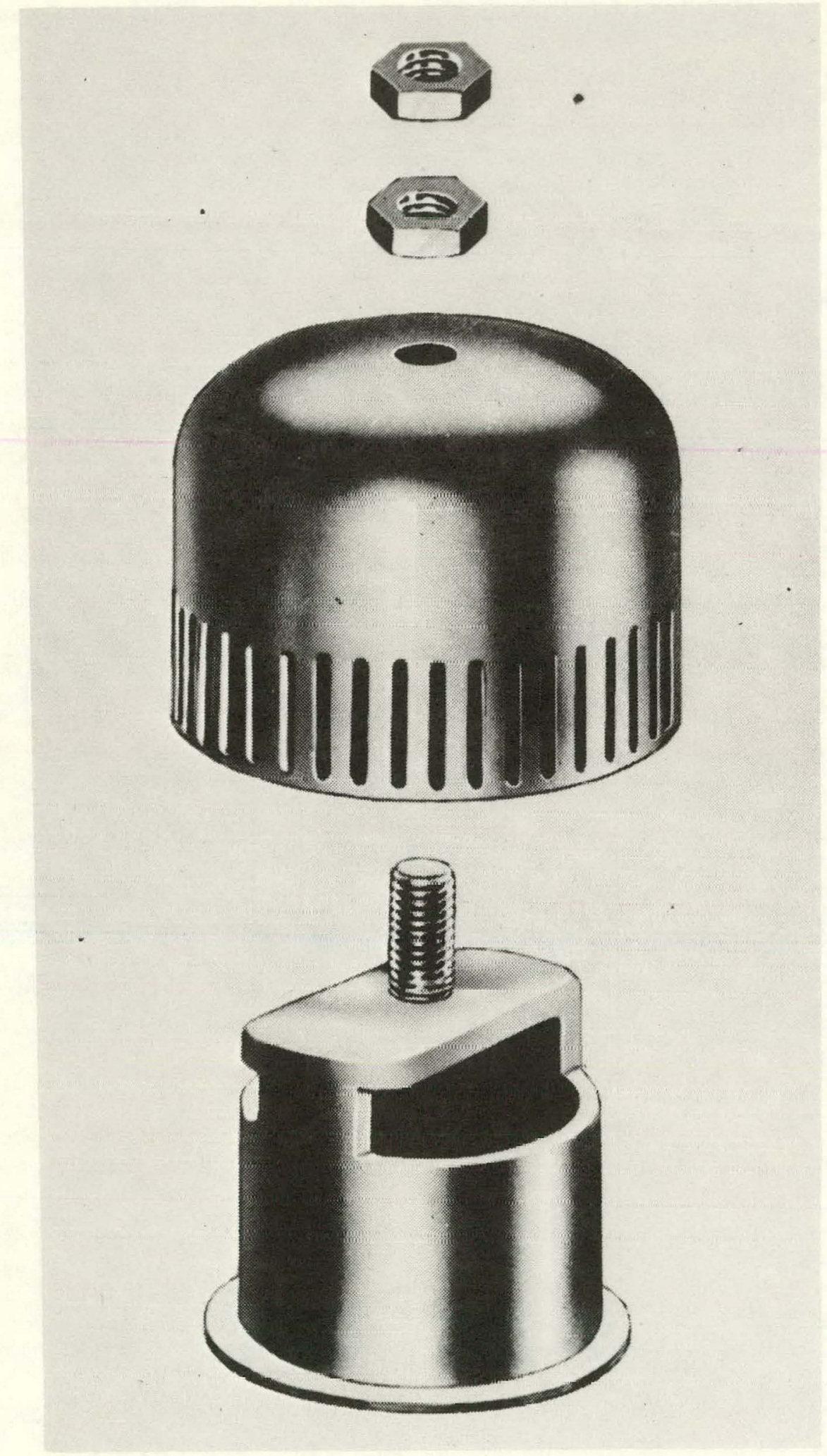

Fig. 7.7.6. Exploded View of a Bubble Cap 
Thermocouples are located in the region of the boiling liquid and in the condenser cooling-water supply and drain lines.

A pressure regulator and pressure gage are placed in the steam supply line, and pressure indicators are connected to the vapor disengaging space and to other points whose pressure may be of interest.

Conductivity probes are sometimes placed at several elevations above the normal boiling surface in order to detect foam levels.

\subsubsection{Recovery of Nitric Acid From Solvent-Extraction Waste}

In the PUREX flowsheet, nitric acid leaves the solvent-extraction system in the aqueous waste streams, along with most of the fission products and other dissolved solids from the irradiated fuel. When the waste is concentrated by evaporation, the resulting vapor contains nitric acid and nitrogen oxides, which are recovered by absorption in water in a packed column or a bubble-cap column (sometimes mounted atop the evaporator) and concentrated by fractionation* (often in another bubble-cap column or a sieve-plate column) to about 60 weight percent $\mathrm{HNO}_{3}$ for reuse in the solvent-extraction process. In this nitric acid recovery operation, decontamination factors of $10^{6}$ to $10^{9}$ for nonvolatile fission products and of $10^{2}$ to $10^{4}$ for volatile fission products are obtained (as measured by the ratio of radionuclide concentrations in the evaporator bottoms to the concentration in the recovered nitric acid). The degree of acid recovery is limited by the amount of solids (sodium nitrate and iron) accumulated in concentrating the evaporator bottoms and also by the fact that nitric acid forms an azeotropic (constant-boiling) mixture with water at the composition 38.3 mole percent $\left(68\right.$ wt \%) $\mathrm{HNO}_{3}$ that boils at $121.9^{\circ} \mathrm{C}$. The acid cannot be concentrated beyond this point by evaporation or fractionation.

The absorption step consists in contacting the nitric acid-water vapor from the evaporator with water near the boiling point. With a feed containing about $10 \mathrm{wt} \% \mathrm{HNO}_{3}$, the absorption operates in the region below the azeotropic concentration, where water is more volatile than nitric acid. In the bubble-cap column (see Figs. 6.7.5 and 6.7.6), the upper rises by bubbling through successive layers of liquid, each layer cascading across a tray on which are mounted the bubble caps that conduct the vapor. The downcomers that connect the trays are the conduits that allow the liquid to flow downward from tray to tray after it overflows the dam formed across each tray by the downcomer to create a liquid seal across the tray. By such means the vapor bubbles come into intimate contact with the liquid on each tray, and a mass exchange occurs by which the vapor becomes leaner in nitric acid as it rises, while the liquid absorbs more and more nitric acid as it descends through

For definition of this term, see Section 7.8.1. 
the column. Thus the vapor will approach the composition of pure water, and the liquid leaving the bottom tray or plate of the column will contain 30 to $40 \mathrm{wt} \% \mathrm{HNO}_{3}$.

This product is charged as feed to a fractionator, which acts in a similar manner. Since the acid is still below the 68 wt \% azeotropic composition, it can be concentrated to approach that constant-boiling composition, although about $60 \mathrm{wt} \%$ nitric acid is the usual strength taken from the bottom of the fractionator. The distillate off the top of the column will contain only about 0.01 wt $\% \mathrm{HNO}_{3}$. This operation may be performed under a vacuum to reduce corrosion of the vessel by maintaining a lower boiling temperature.

Vapors at the top of the column are condensed in a barometric condenser that maintains the vacuum on the fractionator. Part of the condensed vapor leaving the top of the column is returned as reflux to the top plate of the column, which causes an increase in concentration of the lower-boiling component in the vapor by returning some of the higherboiling component to the column.

Acid in low-activity waste is recovered in one evaporation step.

\section{REFERENCES FOR SECTION 7.7}

1. J. T. Long, Engineering for Nuclear Fuel Reprocessing, Gordon and Breach Science Publishers, Inc., 1967.

2. H. W. Codbee, Ues of E'vaporation for the l'reatment of Liquids in the Nuclear Industry, ORNL-4790, 1973.

3. A. S. Foust, L. A. Wenzel, C. W. Clump, L. Maus, and L. B. Anderson, Principles of Unit Operations, John Wiley and Sons, Inc., 1964. 


\subsection{ION EXCHANGE}

Ion exchange is the preferred process for purifying and concentrating fissionable materials preparatory to their conversion into metals. It usually follows solvent extraction in fuel reprocessing and provides the final separation of a fissionable material, either from remaining fission products or from other fissionable materials.1,2

Ion exchange is a sorption process in which specific ions in an aqueous phase exchange with other ions on special solid granules when the solution comes in contact with the solid. By changing the composition of a succeeding aqueous phase, a valence change can be induced which allows selected ions to be desorbed from the solid. The use of a zeolite in water softening and the subsequent regeneration of the zeolite is an example of the ion-exchange process.

\subsubsection{Definition of Terms}

The following definitions are intended to clarify words and phrases in this guide.

Ions - Atoms or groups of atoms which have gained or lost electrons-they are the dissociation products of acids, bases, and salts dissolved in water; that is, each of these compounds breaks down into positively and negatively charged groups or fragments (ions) when dissolved.

Anions - Negatively. charged ions, as $\mathrm{NO}_{3}^{-}, \mathrm{SO}_{4}^{2-}, \mathrm{Cl}^{-}$.

Cations - Positively charged ions, as $\mathrm{H}^{+}, \mathrm{Na}^{+}, \mathrm{Ca}^{2+}$.

Valence - A number representing the combining power of an atom; the number of electrons gained, lost, or shared by an atom involved in chemical reaction.

Synthetic resins - Polymerized organic solids containing positively or negatively charged ionic groups which exchange with ions in aqueous solution when the solid and solution come into contact.

Diffusion - The migration of ions through the water solution.

Distribution coefficient (DC) - Ratio at equilibrium of the concentration of an ion sorbed on the ion-exchange resin to its concentration in the aqueous phase in contact with the resin.

Decontamination factor (DF) - A measure of the degree of separation of impurities from the desired product. 


\subsubsection{Basic Chemistry}

Synthetic resins (sorbing materials) are polymerization products containing cross-linked branch chains. It is important to know the percentage of cross-linking because this determines the resin's physical properties such as strength, diffusion rate, and swelling; the greater the cross-linking, the lower the swelling and shrinkage that occur during the sorption-desorption cycle, but the lower the diffusion rate. Also, in purifying uranium in nitrate solutions with ion-exchange resin, the greater the cross-linking in the resin, the greater the separation of uranium from impurities.

Ion-exchange resins are of two types, anionic and cationic. ${ }^{3}$ The former type exchanges its anions for anions in solution, the latter exchanges its cations for cations in solution. Anlonic resins are subdivided into strong- and weak-base resins. Lationic reslins are subdivided into strong- and weak-acid resins.

The active sites of anionic resins are usually amine substituent groups (nitrogen compounds containing hydrocarbons). Simple amine groups produce weak-base resins. Complex or large amine groups produce strongbase resins.

Sulfonic groups produce strong-acid cation resins. Carboxylic groups produce weak-acid resins.

A cationic resin ( $R$ ) in the acid form (exposed to acid before use) will exchange hydrogen ions $\left(\mathrm{H}^{+}\right)$for metal lons $\left(\mathrm{M}^{+}\right)$in aqueous solution, as follows:

$$
\mathrm{nHR}+\mathrm{M}^{\mathrm{n}+} \rightleftharpoons \mathrm{MR}_{\mathrm{n}}+\mathrm{ni}^{+}
$$

Anionic resin in the hydroxyl form will exchange hydroxyl ions $\left(\mathrm{OH}^{-}\right)$for anions in aqueous solution, as follows:

$$
\mathrm{nROH}+\mathrm{A}^{\mathrm{n}-} \rightleftharpoons \mathrm{R}_{\mathrm{n}} \Lambda+\mathrm{n} \mathrm{OH}^{-} \text {. }
$$

Metal ions are eluted (desorbed) from the cationic resin by contacting the resin with strong acid, which makes the reaction go to the left, or by adding complexing agents. Anions are eluted from anionic resin by contacting with strong bases or complexing agents. In all instances, the elution must be done in such a way that maximum separation of the product is attained.

To determine the efficiency of an ion-exchange operation, a material balance across the system is required in order to determine the decontamination factor (DF) for major contaminants. The concentrations of the fissile material and of the impurities in the feed and product are used to determine the DF for each specific impurity. An example is the separation of plutonium from uranium in anion exchange as follows: 


$$
\mathrm{DF}_{U}=\frac{\frac{\text { g/liter } \mathrm{U} \text { in feed }}{\mathrm{g} / \text { /iter } \mathrm{Pu} \text { in feed }}}{\frac{\text { g/liter } \mathrm{U} \text { in product }}{\mathrm{g} / \text { liter } \mathrm{Pu} \text { in product }}}
$$

To determine the efficiency of the elution step, the waste solution must be analyzed for fissile material and major impurities. The amounts of specific elements in various streams must be accounted for, as for example:

$$
\mathrm{Pu} \text { in feed }=\mathrm{Pu} \text { in product }+\mathrm{Pu} \text { in waste. }
$$

\subsubsection{Plutonium Purification by Ion Exchange}

By controlling its valence, plutonium may be purified by either anion exchange or cation exchange. Anion exchange is the method for separating plutonium from neptunium and uranium. To provide the maximum distribution coefficient for sorbing plutonium on an anion exchange resin, plutonium is converted to $\mathrm{Pu}\left(\mathrm{NO}_{3}\right)_{6}{ }^{2-}$ and the feed maintained at $7 \mathrm{MHNO} \mathrm{HN}_{3}$. (The high acid concentration and use of hydroxylamine produces the $\mathrm{Pu}\left(\mathrm{NO}_{3}\right)_{6}{ }^{2-}$ complex but leaves the neptunium and uranium as cations.) Sorption is improved if the temperature of the solution and resin is about $60^{\circ} \mathrm{C}$.

The sorption equation is:

$$
2 \mathrm{RNO}_{3}+\mathrm{Pu}\left(\mathrm{NO}_{3}\right)_{6}{ }^{2-} \rightleftharpoons \mathrm{R}_{2} \mathrm{Pu}\left(\mathrm{NO}_{3}\right)_{6}+2 \mathrm{NO}_{3}^{-} \text {. }
$$

The waste solution (raffinate) leaving the anion-exchange column contains neptunium, uranium, and a trace of plutonium. The valence of the neptunium is adjusted to convert it to an anion by use of ferrous nitrate and hydrazine in $7 \mathrm{M}$ nitric acid. The hydrazine is used to prevent formation of nitrite, which would destroy the ferrous ions. This adjusted feed. is passed through an anion-exchange column to sorb neptunium and plutonium. The uranium passes out of the column in the raffinate as a cation.

Cation exchange is used for final recovery and purification of plutonium. The main objective is to concentrate the plutonium. The feed consists of $\mathrm{Pu}^{3+}$ complex.

The sorption equation follows:

$$
3 \mathrm{HR}+\mathrm{Pu}^{3+} \rightleftharpoons \mathrm{PuR}_{3}+3 \mathrm{H}^{+} .
$$

Scrubbing - After the resin in the first colum is loaded with plutonium, it is scrubbed with $7 \mathrm{M}$ nitric acid to remove the raffinate containing neptunium, uranium, fission products, corrosion products, and salting agents without desorbing plutonium from the resin. The loaded resin in the second column is scrubbed with $7 \mathrm{M}$ nitric acid for the eame reason, 
but the neptunium remains sorbed on the resin. The final raffinate is transferred to the solvent-extraction system for purification of uranium or to the concentrator.

Cation-exchange resin containing sorbed plutonium is scrubbed with $0.25 \mathrm{M}$ sulfuric acid to remove uranium, zirconium, and niobium. The sulfate is removed from the column by following with demineralized water.

Elution - Plutonium sorbed on an anion-exchange resin is desorbed by passing $0.5 \mathrm{M}$ nitric acid through the column. The dilute acid converts the plutonium to a cation. The same reaction occurs when an anionic resin containing neptunium is eluted with $0.5 \mathrm{M}$ nitric acid.

Plutonium sorbed on cation-exchange resin is eluted from the resin by use of strong nitric acid containing sulfamic acid. The sulfamic acid is a reducing agent, which prevents gassing that would result if $\mathrm{Pu}^{3+}$ were oxidized by nitric acid.

\subsubsection{Ion-Exchange Equipmentl, 4}

An ion-exchange column may be a cylindrical vessel (having its axis vertical) which is filled with sorbing granules. Feed solution is pumped through this column (either upflow or downflow) and collected in a product storage tank. Elutriant may also be pumped through the column, by either route, and collected in a solution storage tank from which it is returned to a solvent-extraction system for recovery of tissile materials. Usually, two of these resin columns are operated in parallel so that one may be eluted while the other is being loaded.

Another ion-exchange system is general use is the Higgins quasicontinuous contactor, shown in Fig. 7.8.1. In this, four different operating sections are connected in the form of a loop: loading and scrubbing, resin storage, resin actuation, and elution. By means of controlled valving, as shown with black valves closed and white open, the operation proceeds as tollows:

1. In Fig. 7.8.1b, feed is passed through the resin in the loading section and plutonium is sorbed while neptunium, uranium, and other impurities leave in the waste stream. When the resin becomes saturated with plutonium, feed flow is stopped, and wash water (ocrub) ic pacced through the resin to remove adhering impurities.

2. At the same time, another part of the resin (in the lower vessel) is eluted to convert plutonium to the cation form, which causes it to desorb from the resin and leave the unit in the product stream. Also, some loaded resin, previously forced into the resin reservoir, drains by gravity flow through the now open section of three-way valve 1 into the resin return leg above valve 2 . 

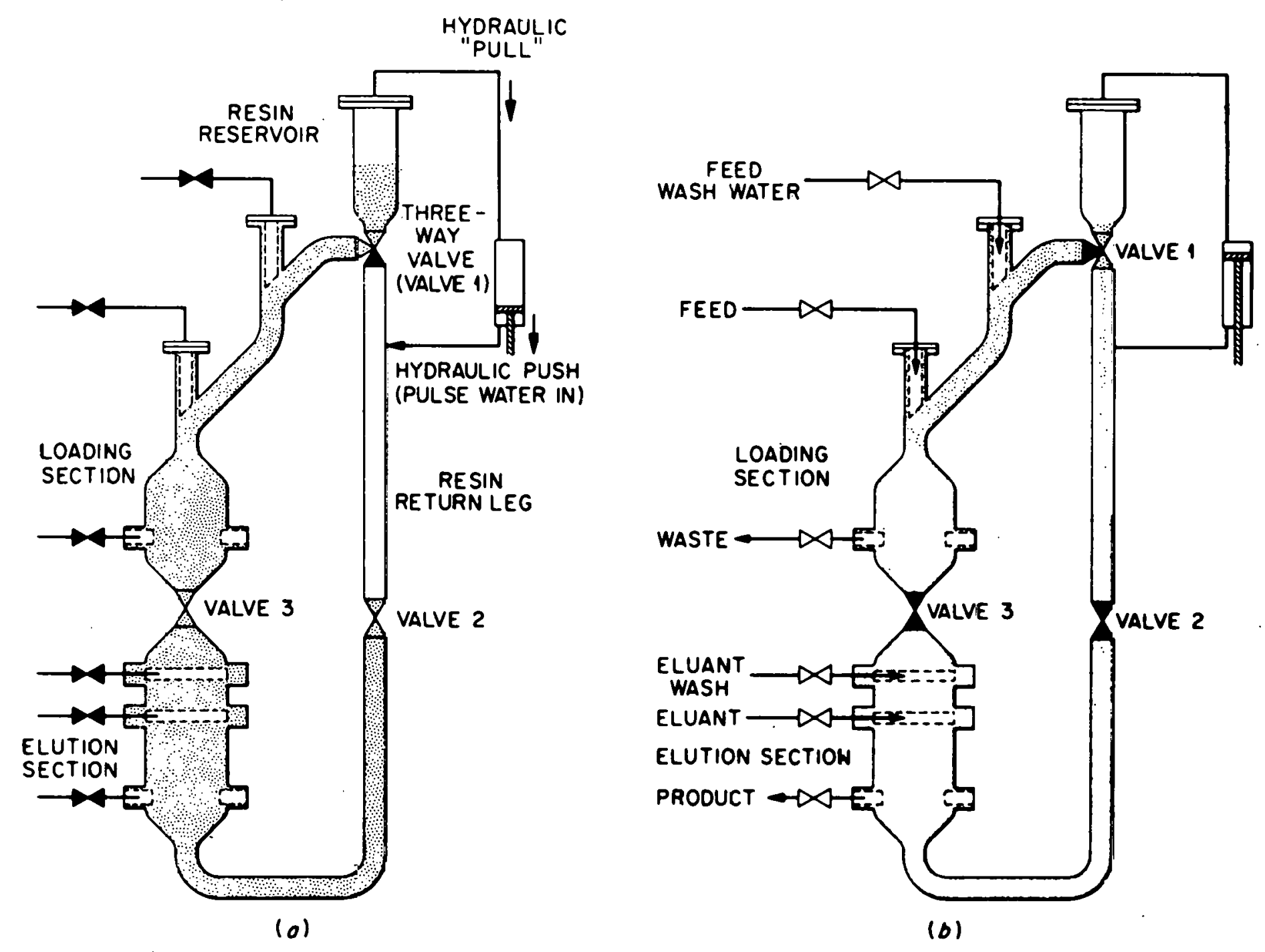

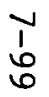

Fig. 7.8.1. Mode of Operation of a Higgins Quasi-Continuous Ion-Exchange Contactor. (a) During Pulse Period. (b) During Sorption Period. 
3. When the above operations have been completed, valves for feed and outlet streams are closed and isolation valves set as shown in Fig. 7.8.1a. Here push water (in pulses) forces loaded resin from the resin return leg into the elution section, eluted (stripped) resin into the loading section, and loaded resin into the resin reservoir through the open section of three-way valve 1 , all in a clockwise direction at the same time.

The resin is moved by short pulses, so it moves as a dense bed. Continuous force would cause fluidization and mixing of variously treated sections of resin.

\subsubsection{Operating Variables and Restrictions}

In anion exchange, sorption is improved if the temperature of the resin and feed is maintained at about $60^{\circ} \mathrm{C}$.

The composition of the feed must be held between close limits to gain maximum separation of the desired metal from impurities, as discussed in Section 7.8.3.

Anion-exchange resin has a process life expectancy of two to six months. Resin degradation is caused by radiolysis, chemical attach, and mechanical attrition. Chemical attrition comes from the presence of nitrite ion.

Gas formation during the various operations is undesirable. The gas restricts flow through the resin in the downward direction and favors channeling, which reduces separation etticiency.

Resin columns must not be allowed to drain dry after being placed in service, since dried resin deteriorates rapidly.

Vessel size and geometry are designed to meet strict criticality specifications so that no chance of a nuclear excursion can occur.

\subsubsection{Safety Precautions Required}

A11 vessels in the system must be designed so that a nuclear critical mass or concentration of uranium or plutonium cannot collect under any conditions. Spacing between vessels and from those in other systems must meet the same requirements.

Because they are the largest likely source of radioactive exposure to personnel, resin beds should be scanned for gamma radiation to determine the radioactivity of the resin before men work in an ion-exchange ce11.5 
Instrumentation must indicate liquid level and the density of any and all solutions in the system. Samples of all solutions must be taken to determine an accurate, up-to-date material balance.

The resin must not be exposed to high concentrations of nitric acid at temperatures above $70^{\circ} \mathrm{C}$. At high temperatures, acid attack on the resin is severe.

\section{REFERENCES FOR SECTION 7.8}

1. J. T. Long, Engineering for Nuclear Fuel Reprocessing, Gordon and Breach Science Publishers, Inc., 1967.

2. E. R. Irish and W. H. Reas, "The Purex Process, A Solvent Extraction keprocessing lethod for Irradiated Uranium," Symposium on the Reprocessing of Irradiated Fuels, TID-7534, book 1, 1957.

3. W. H. Walker, W. K. Lewis, W. H. McAdams, and E. R. Gilliland, Principles of Chemical Engineering, McGraw-Hill Book Company, New York and London, 1937.

4. M. Benedict and T. H. Pigford, Nuclear Chemical Engineering, McGrawHill Book Co., New York, Toronto, London, 1957.

5. R. H. Rainey, Laboratory Development of a Pressurized Cation Exchange Process for Removing the Daughters of ${ }^{232} \mathrm{U}$ from ${ }^{23} \mathrm{U}$, ORNL-4731, 1972. 


\subsection{CONVERSION OF URANYL NITRATE TO URANIUM HEXAFLUORIDE}

The operation of a nuclear reactor removes much of the uranium-235 isotope from the fuel by fission. The uranium that is recovered from this spent fuel in a fuel reprocessing plant must have its uranium-235 content increased (enriched) in order for it to be used again for the fabrication of new fuel elements. Uranium is enriched by passing uranium hexafluoride $\left(\mathrm{UF}_{6}\right)$ gas through a series of barriers that allow uranium-235 atoms to pass through at a slightly higher rate than the uranium-238 atoms. This is done at government-owned gaseous diffusion plants. Uranium recovered from spent fuel by the solvent-extraction process described in Section 7.6 is in the form of uranyl nitrate solution. The fuel reprocessing plant either may return the purified uranium to the customer or may further process it to produce uranium hexafluoride for shipment to a gaseous diffusion plant for enrichment. If uranium hexafluoride is to be produced, some purification of the uranium may be done during or following the conversion of uranyl nitrate to uranium hexafluoride. The process and equipment used to convert uranyl nitrate to uranium hexafluoride and the methods used to collect and purify uranium hexafluoride are discussed in this section.

Two typical flowsheets for the conversion of uranyl nitrate to uranium hexafluoride are shown in Fig. 7.9.1. The first flowsheet is similar to that used in the large-scale production of uranium hexafluoride leed material for gaseous diffusion plants.1,2 The processing steps are: (1) denitration of uranyl nitrate to produce uranium trioxide $\left(\mathrm{UO}_{3}\right)$, (2) reduction of uranium trioxide with hydrogen to produce uranium dioxide $\left(\mathrm{UO}_{2}\right)$, (3) hydrofluorination (reaction with hydrogen fluoride) of uranium dioxide to produce uranium tetrafluoride $\left(\mathrm{UF}_{4}\right)$, and (4) fluorination (reaction with fluorine) of uranium tetrafluoride to produce uranium hexafluoride.

A somewhat simpler flowsheet, which requires only two steps, was used at Midwest Fuel Recovery Plant. * The two steps used in the flowsheet are: (1) denitration of $\mathrm{UNH}$ to produce $\mathrm{UO}_{3}$, and (2) fluorination of $\mathrm{UO}_{3}$ to produce $\mathrm{UF}_{6}$. The hydrogen reduction and hydrofluorination steps are not used in this process. Although this method of $U_{6}$ production is simpler and requires fewer steps, it is sometimes more economical to include the hydrogen reduction and hydrofluorination steps.

Uranium hexafluoride is produced as a gas in the fluorination step. The most widely used method of collecting gaseous uranium hexafluoride is with cold traps in which the uranium hexafluoride deposits as a solid. Solid sorbents are also used for collection of uranium hexafluoride. Methods of purifying uranium hexafluoride include distillation

\footnotetext{
* Construction of the Midwest Fuel Recovery Plant ${ }^{3}$ has been completed and it has been operated using unirradiated fuel, however, startup using irradiated fuel has been delayed indefinitely because of operational problems.
} 
ORNL Dw9. 74-4392
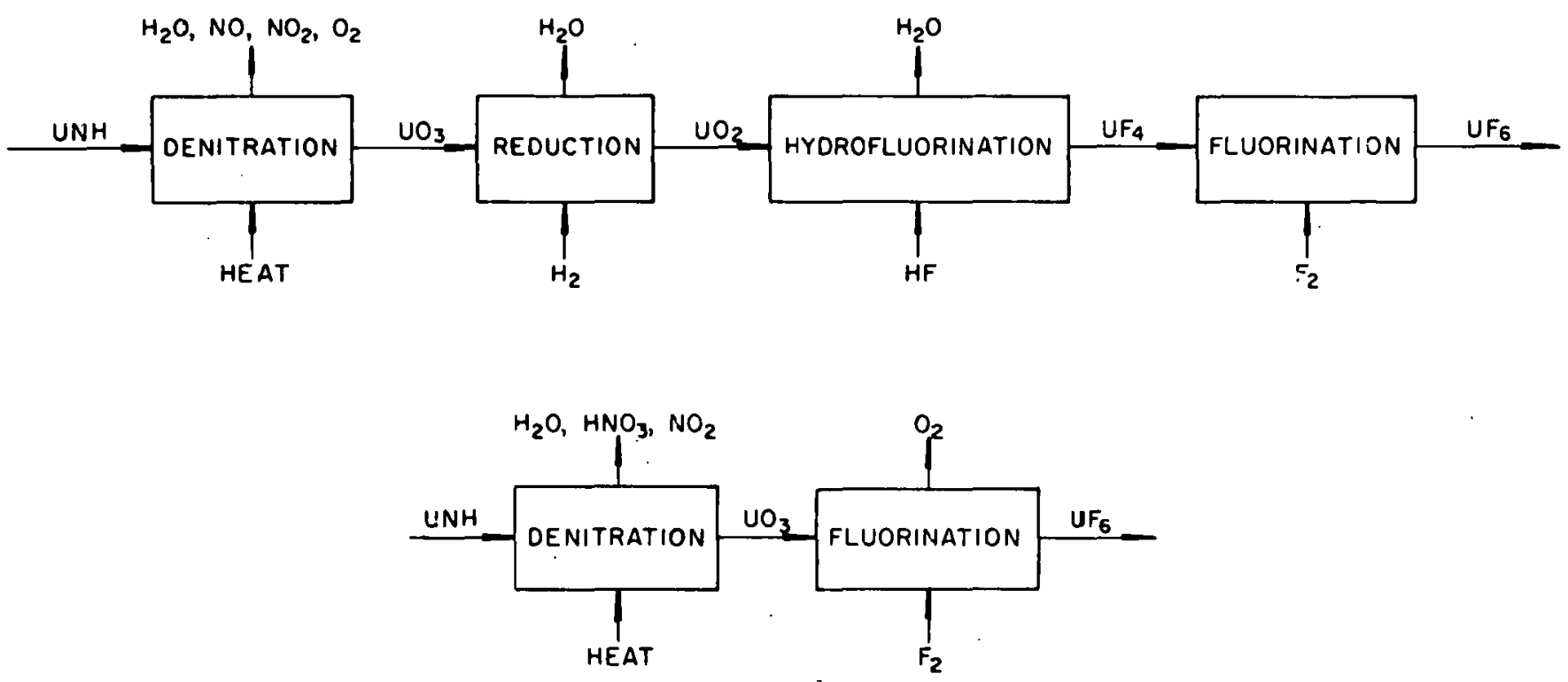

Fig. 7.9.1. Two Simplified Flowsheets for the Conversion of $\mathrm{UNH}$ to $\mathrm{UF}_{6}$ 
and the use of solid sorbents such as sodium fluoride and magensium fluoride. The major processing steps in the conversion of uranyl nitrate to uranium hexafluoride and the methods for the collection and purification of uranium hexafluoride are discussed in more detail below.

\subsubsection{Conversion of Urany1 Nitrate to Uranium Trioxide}

The conversion of uranyl nitrate to uranium trioxide (denitration of uranyl nitrate) is accomplished by heating the uranyl nitrate solution, first to evaporate water and then to decompose the uranyl nitrate by the reaction

$$
\mathrm{UO}_{2}\left(\mathrm{NO}_{3}\right)_{2} \cdot \mathrm{xH}_{3} \mathrm{O} \stackrel{\text { heat }}{\longrightarrow} \mathrm{UO}_{3}+\mathrm{NO}+\mathrm{NO}_{2}+\mathrm{O}_{2}+\mathrm{xH}_{2} \mathrm{O} .
$$

The removal of water in the first step raises the freezing point of the uranyl nitrate solution, and it must be kept hot $\left(60\right.$ to $\left.116^{\circ} \mathrm{C}\right)$ to prevent freezing. ${ }^{4}$ The concentrated uranyl nitrate solution is then fed to a denitrator or calciner operated at temperatures in excess of $300^{\circ} \mathrm{C}$, where the remaining water is evaporated and the uranyl nitrate is decomposed to produce uranium trioxide. Several types of calciner have been used for the denitration step. These include batch units, which consist of heated stainless steel pots equipped with stirrers, and continuous units, which use heated troughs equipped with agitators for stirring the powder and transferring it through the troughs. ${ }^{4}$ More recently, pot and trough calciners for denitration have been replaced by fluidized-bed calciners. ${ }^{3}, 5$ In the fluidized-bed calciner the concentrated uranyl nitrate solution is sprayed into the fluidized bed, where the uranyl nitrate decomposes and deposits on the surface of the uranium trioxide bed material (see Fig. 7.14.1). Beads of aluminum oxide or zirconium oxide are typical seed materials for such beds. Operating conditions must be set to give the desired particle size and physical and chemical properties to the uranium trioxide produced. Variables that are important in the operation are temperature, fluidization rate, feed concentration, feed rate, feed composition, and the operating characteristics of the feed nozzle. The operation of a fluidized-bed calciner is described in Section 7.14.

\subsubsection{Reduction of Uranium Trioxide to Uranium Dioxide}

The uranium trioxide produced in the denitration step must be reduced to uranium dioxide before it can be converted to uranium tetrafluoride by hydrofluorination. Hydrofluorination of uranium trioxide would produce uranyl fluoride $\left(\mathrm{UO}_{2} \mathrm{~F}_{2}\right)$, which is not the desired reaction. Uranfum trioxide is reduced by hydrogen to produce uranium dioxide as shown in the equation

$$
\mathrm{UO}_{3}+\mathrm{H}_{2} \longrightarrow \mathrm{UO}_{2}+\mathrm{H}_{2} \mathrm{O}
$$


which is carried out at approximately $600^{\circ} \mathrm{C}$. The reaction is exothermic (heat is produced).

It is desirable to produce uranium dioxide that can be easily hydrofluorinated. Fluidized-bed reactors have been widely used for reduction of uranium trioxide. ${ }^{4-6}$ In a typical fluidized-bed reduction reactor (see Fig. 7.9.2), uranium trioxide particles are fed into the top of the bed by a screw conveyor. The bed material is composed mainly of uranium dioxide particles. Inert gases plus hydrogen and nitrogen produced by cracking (decomposing at high temperature) ammonia are used to fluidize the bed. The uranium dioxide product is removed near the bottom of the bed by a second screw conveyor. Some of the important variables in the operation of the reduction system are temperature, feed rate, bed depth, and the amount of excess hydrogen used. ${ }^{5}, 6$

The general operating characteristics of the fluidized bed discussed in Section 7.13 also apply to the operation of the uranium trioxide reduction system. In addition, special precautions must be taken in operating the reduction system because of the explosion hazard of hydrogen. Since explosive mixtures are formed when hydrogen is mixed with air in the range of 4.1 to 74.2 volume percent $\mathrm{H}_{2}$, precautions must be taken to exclude air from the equipment in which hydrogen is used. Also, the uranium dioxide produced may be pyrophoric and could ignite if exposed to air.

\subsubsection{Hydrofluorination of Uranium Dioxide}

The uranium dioxide produced in the reduction step is converted to uranium tetrafluoride by the reaction of gaseous hydrogen fluoride according to the reaction

$$
\mathrm{UO}_{2}+4 \mathrm{HF} \rightleftharpoons \mathrm{UF}_{4}+2 \mathrm{H}_{2} \mathrm{O}
$$

The reaction is reversible, and the uranium tetrafluoride produced could be converted back to uranium dioxide by reaction with water if the processing conditions are not carefully controlled. Because heat is given off by the reaction, cooling may be needed to maintain the desired temperature.

Stirred-bed and fluidized-bed reactors are commonly used for the hydrofluorination step ${ }^{4-6}$ (see Fig. 7.9.3). The stirred-bed reactor consists of electrically heated horizontal tubes about $16 \mathrm{in}$. in diameter and $22 \mathrm{ft}$ long. A stirrer is located inside each tube to mix and convey the powder. Three units are usually operated in series. Uranium dioxide powder is fed to the top reactor, while anhydrous (water-free) hydrogen fluoride gas is fed to the bottom unit and flows countercurrently to the flow of powder.

When fluidized-bed reactors are used, two beds are usually used in series to increase the hydrogen fluoride efficiency. Uranium dioxide is fed to the first hydrofluorinator near the top of the bed by a screw conveyor. 
ORNL Dwg 74-4946

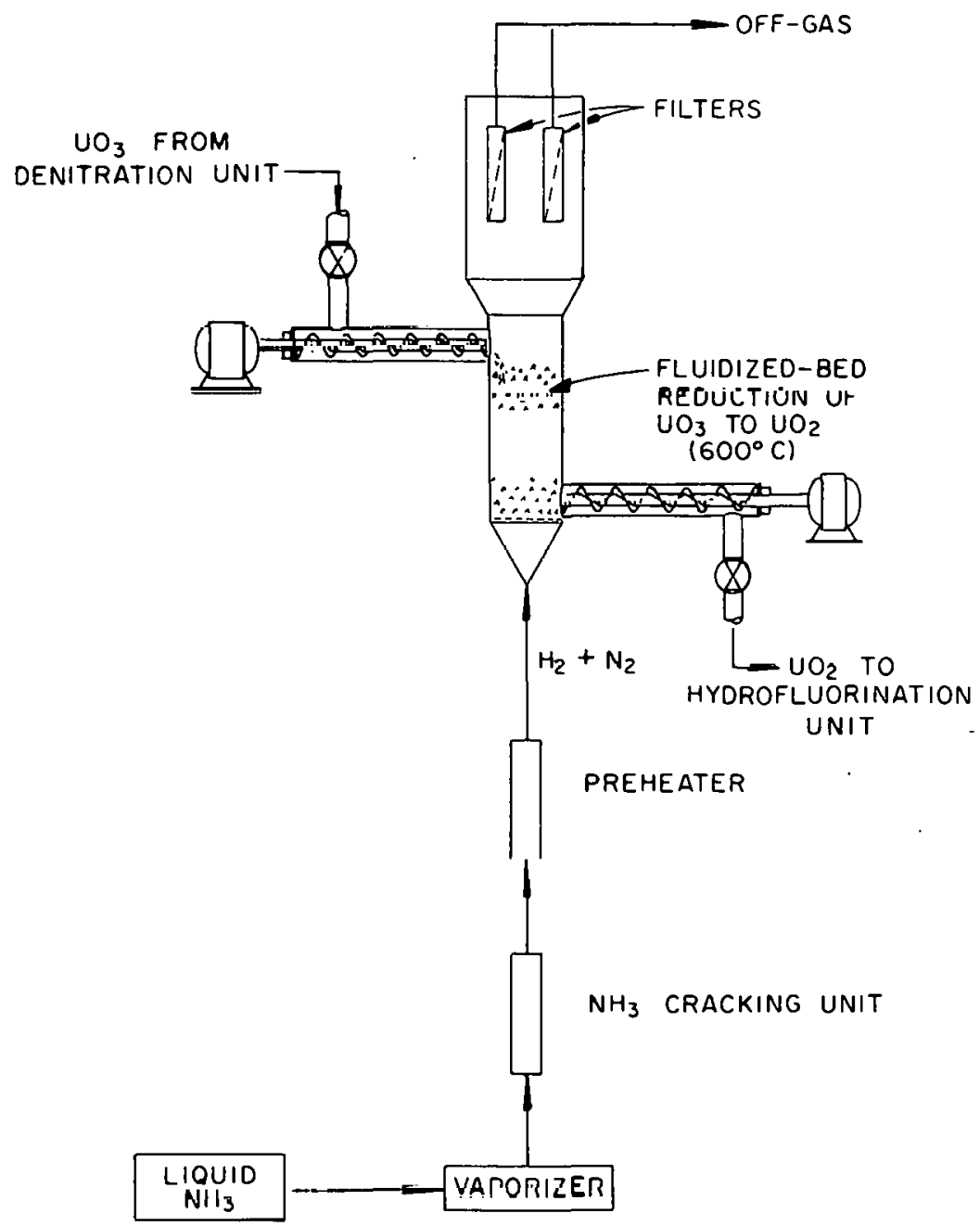

Fig. 7.9.2. Schematic of a Typical Fluidized-Bed Reduction Unit 


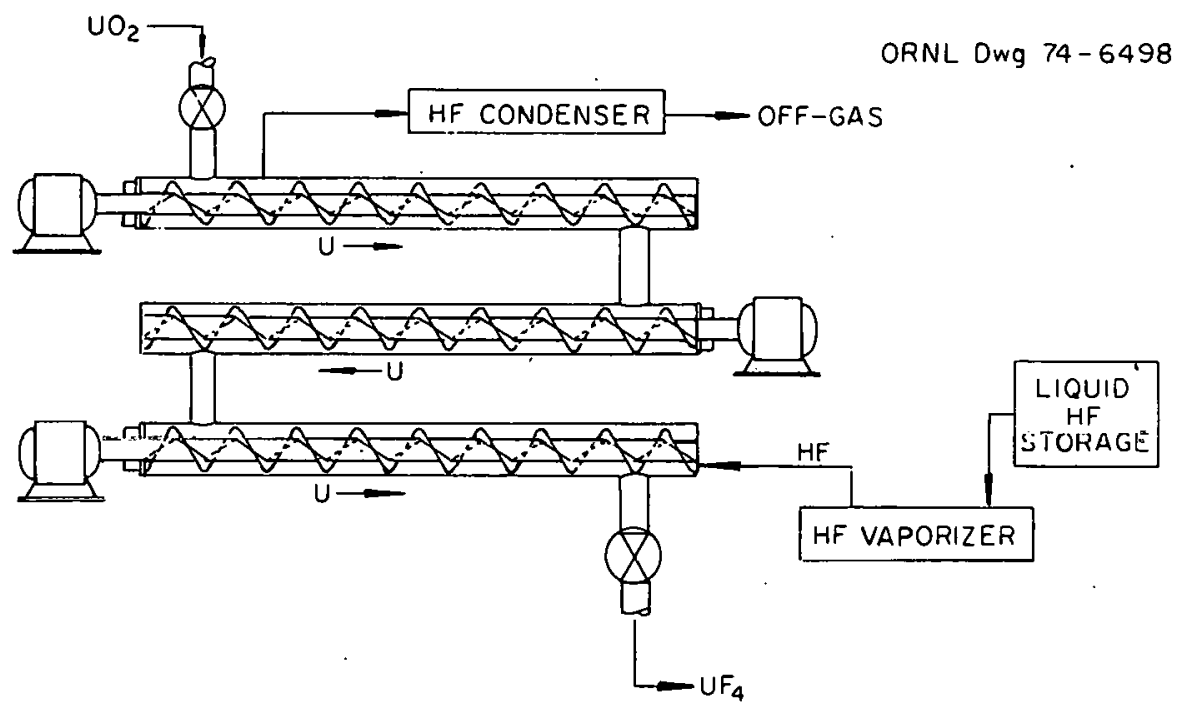

Stirred Ded Ilydifluoinalivin Jyslem.

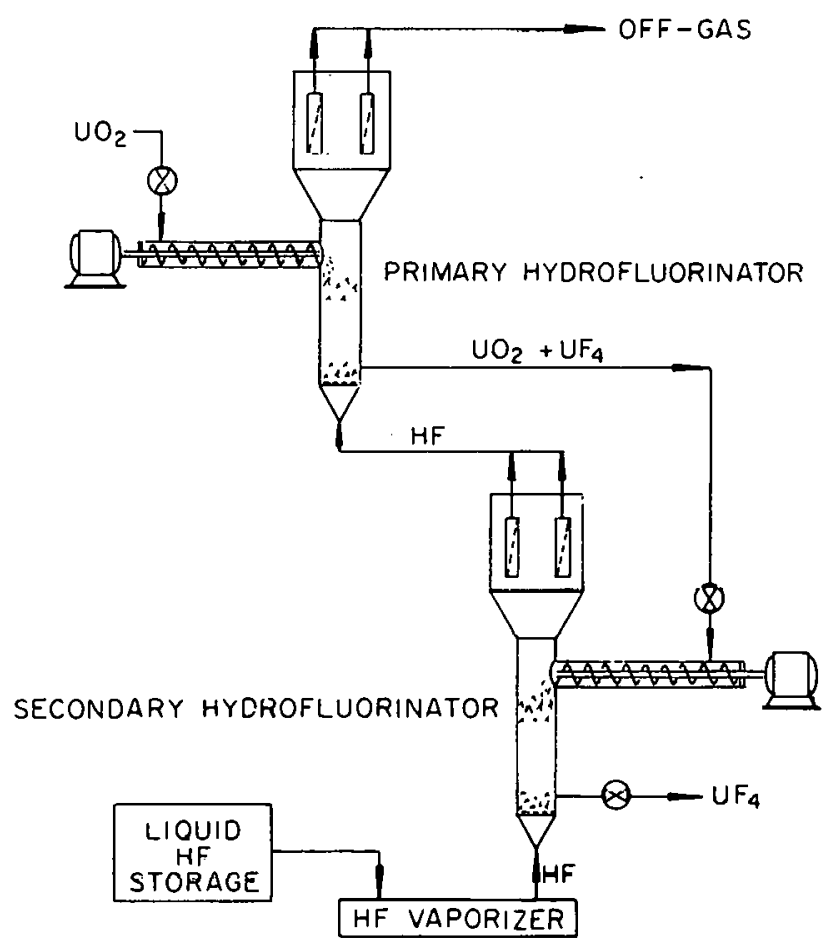

Fluidized-Bed Hydrofluorination System.

Fig. 7.9.3. Schematic Diagrams of a Stirred-Bed Hydrofluorination System and a Fluidized-Bed Hydrofluorination System. 
A mixture of uranium tetrafluoride and unreacted uranium dioxide is withdrawn near the bottom of the first hydrofluorinator and fed to the upper section of the second hydrofluorinator. Uranium tetrafluoride is withdrawn at the bottom of the second hydrofluorinator. The gaseous hydrogen fluoride used in the reaction also serves as the fluidizing gas; however, if the quantity of hydrogen fluoride required for the reaction is insufficient for good fluidization, an inert gas may be mixed with the hydrogen fluoride. The hydrogen fluoride enters the second reactor first and flows countercurrently to the flow of powder. Both hydrofluorinators are operated at about $475^{\circ} \mathrm{C}$. It is important that good fluidization be maintained and that hot spots be avoided, since uranium tetrafluoride has a relatively low melting point $\left(960^{\circ} \mathrm{C}\right)$ and caking of the bed could occur. Operating temperature and the amount of excess hydrogen fluoride used are also important in determining product quality. ${ }^{5}, 6$

Gaseous hydrogen fluoride used in the process is provided by vaporizating liquid hydrogen fluoride (boiling point $19.4^{\circ} \mathrm{C}$ ). Hydrogen fluoride is a very corrosive and toxic material; it causes severe burns and irritation. The hydrogen fluoride is normally contained within the processing equipment and does not present a hazard to operating personnel. If contact with hydrogen fluoride is likely, however, special protective clothing and respiratory equipment are necessary.

Since hydrogen fluoride is corrosive and toxic, special treatment is necessary to remove it from the off-gas stream. It is particularly corrosive to fiberglass filters, which are commonly used in off-gas systems to remove particulate material. Typical ways of removing hydrogen fluoride from off-gas streams are by scrubbing with potassium hydroxide $(\mathrm{KOH})$ solution and by reaction in beds of soda lime or sodium fluoride (NaF).

\subsubsection{Fluorination of Uranium Tetrafluoride and Uranium Trioxide}

In the two flowsheets being discussed, uranium hexafluoride is produced by reaction of either uranium tetrafluoride or uranium trioxide with fluorine gas. The two reactions are:

$$
\mathrm{UF}_{4}+\mathrm{F}_{2} \rightarrow \mathrm{UF}_{6}
$$

and

$$
2 \mathrm{UO}_{3}+6 \mathrm{~F}_{2} \rightarrow 2 \mathrm{UF}_{6}+3 \mathrm{O}_{2} \text {. }
$$

Both reactions are highly exothermic, and cooling is necessary to maintain the desired temperature. The uranium hexafluoride is produced in the form of a gas. In addition to the equipment needed to perform the actual fluorination, special equipment is necessary to collect the uranium hexafluoride, to generate the fluorine, and possibly to further purify the uranium hexafluoride. Before discussing the equipment and methods used in the production and purification of uranium hexafluoride, It is first helpful to know some of its properties. 
7.9.4.1 Properties of Uranium Hexafluoride - At room temperature, uranium hexafluoride is a white, volatile solid (density is $5.1 \mathrm{~g} / \mathrm{cm}^{3}$ at $68^{\circ} \mathrm{F}$ ) that slowly sublimes. * If solid uranium hexafluoride is heated at atmospheric pressure, when the temperature exceeds $133.5^{\circ} \mathrm{F}$ (the sublimation point); it will quickly change from a solid directly to a gas, no 1iquid phase being formed. At higher pressures and temperatures, solid uranium hexafluoride can be melted to form a clear colorless liquid (density is $3.0 \mathrm{~g} / \mathrm{cm}^{3}$ at $300^{\circ} \mathrm{F}$ ). Figure 7.9 .4 gives the vapor pressure and phases (solid, liquid or gas) as a function of temperature. ${ }^{7}$ For example, assume that a product cylinder is almost full of pure uranium hexafluoride and is at room temperature $\left(70^{\circ} \mathrm{F}\right)$; then from Fig. 7.9.4 it can be determined that the contents would be a solid, and the pressure of vapor above the solid would be about $1.6 \mathrm{psia}$. If the cylinder is slowly heated, the pressure would increase because of the increased vapor pressure. At 22 psia and $147.3^{\circ} \mathrm{F}$ (the triple point), some of the solid would begin to change to a liquid, so that the cylinder would contain solid, liquid, and gaseous uranium hexafluoride at the same time. If the temperature is increased above $147.3^{\circ} \mathrm{F}$, all of the solid would melt, and the cylinder would contain only liquid and gas. As the temperature continued to increase, the pressure inside the cylinder would also increase because of the increased vapor pressure, as shown in Fig. 7.9.4. If impurities such as hydrogen fluoride (which has a higher vapor pressure than uranium hexafluoride) are present, the pressure inside the cylinder would be greater than the pressure indicated by the vapor pressure curve. Measurement of the pressure inside the cylinder at a given temperature is one method that is used to determine whether hydrogen fluoride is present in the uranium hexafluoride.

Uranium hexafluoride is a highly reactive substance. ${ }^{7}$ It reacts chemically with water, most organic compounds, and some metals. It does not react with oxygen, nitrogen, or dry air. Materials such as copper, nickel, aluminum, and Teflon are sufficiently inert to be used in handling uranium hexafluoride. When released to the atmosphere, uranium hexafluoride reacts with moisture in the air to produce a white cloud of uranyl fluoride. Respiratory protection and skin protection are required for personnel who must enter an area where uranium hexafluoride is present.

7.9.4.2 Equipment Used for Fluorination - Two types of equipment are commonly used for fluorination of uranium tetrafluoride: the tower reactor ${ }^{2}, 4,8$ and the fluidized-bed reactor. ${ }^{1}$ A fluidized bed was used at Midwest Fuel Recovery Plant ${ }^{3}$ for the fluorination of uranium trioxide.

A typical tower reactor is constructed of an 8-in.-diam Monel pipe mounted vertically. Cooling coils are wrapped around the outside of the pipe to remove heat produced by the reaction (see Fig. 7.9.5). Finely divided uranium tetrafluoride powder is introduced at the top of the

\footnotetext{
* When a solid sublimes it goes directly from a solid to a gas without going through a liquid phase.
} 


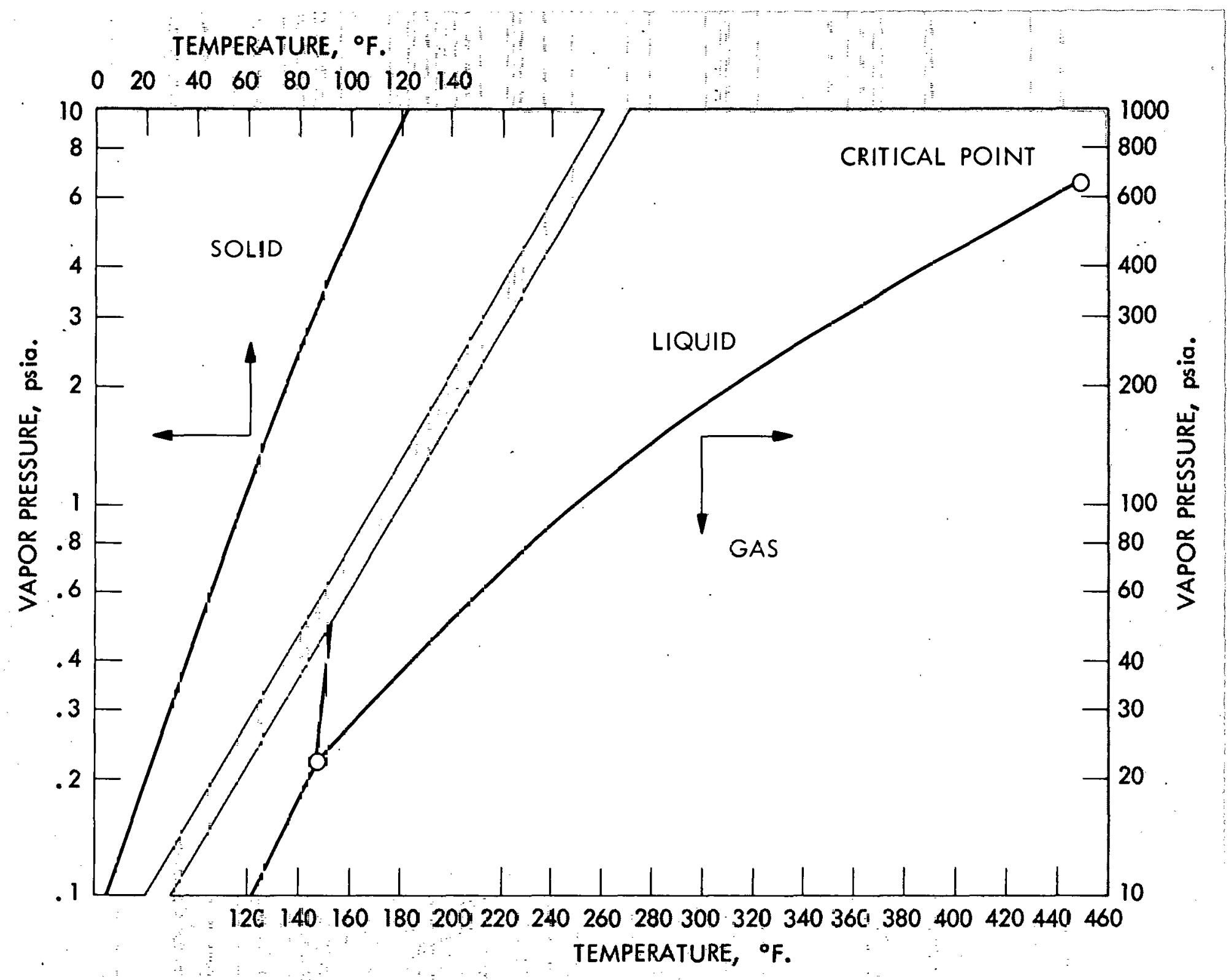

Fig. 7 9.4. Phase Diagram and Vapor Pressure Curve for $\mathrm{UF}_{6}$. 
ORNL DWg 74-6499

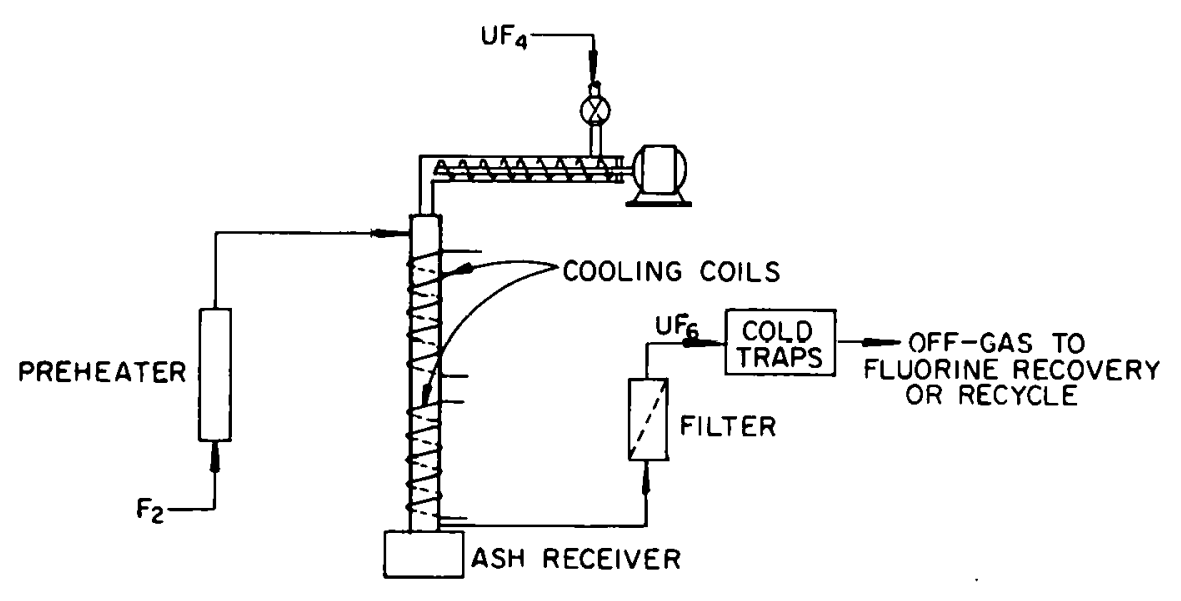

Fluorine Tower Reoctor

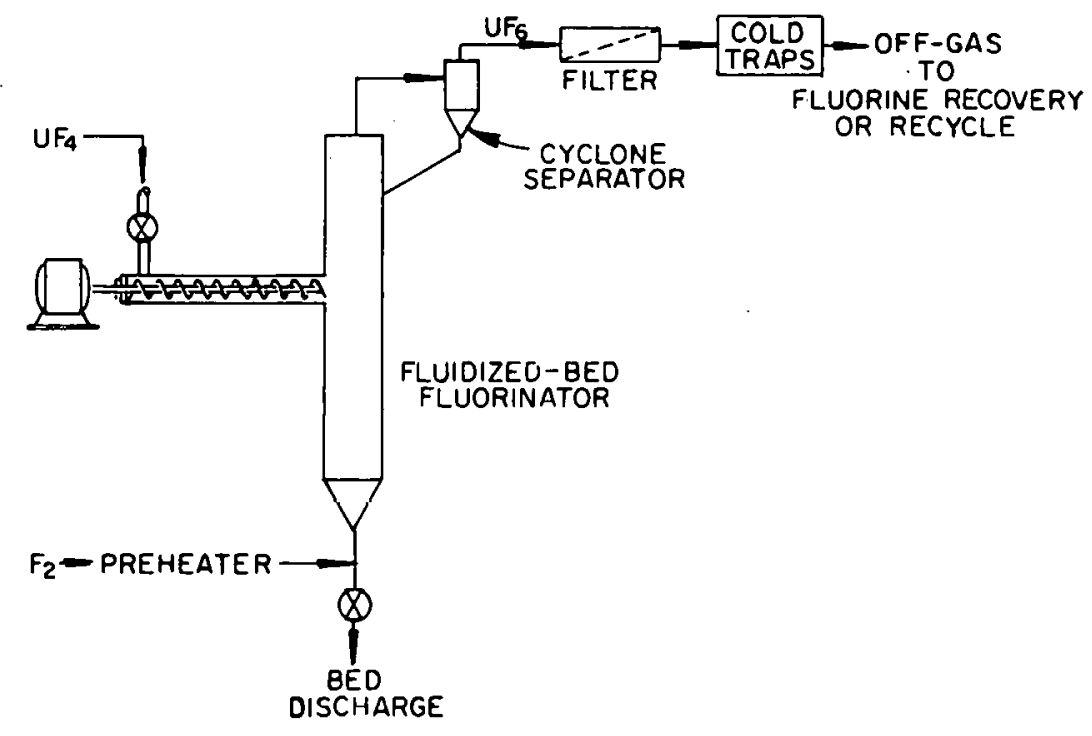

Fluldized-Bed Fluorinator

Fig. 7.9.5. Schematic Diagram of a Fluorination Tower and a Fluidized Bed for Production of $\mathrm{UF}_{6}$ and $\mathrm{UF}_{4}$. 
tower along with fluorine that has been preheated to about $300^{\circ} \mathrm{C}$. The fluorine quickly reacts with the uranium tetrafluoride to produce uranium hexafluoride. The temperature of the reactor is kept between $454^{\circ} \mathrm{C}$ and $538^{\circ} \mathrm{C}$. About $2 \%$ of the uranium tetrafluoride passes through without reacting and must be recycled. The uranium hexafluoride gas from the reactor is collected by cold trapping as described later.

In a typical fluidized-bed reactor, uranium tetrafluoride or uranium trioxide is fed into a fluidized bed of inert material, such as fused alumina or calcium fluoride, at about $427^{\circ} \mathrm{C}$ to $537^{\circ} \mathrm{C}$ (see Fig. 7.9.5). A mixture of fluorine gas and inert gas, such as nitrogen and/or oxygen, is used for fluidization. An excess of fluorine is used so that the feed material is quickly fluorinated and there is very little accumulation of unreacted material in the fluidized bed. Heat is necessary to bring the bed to operating temperature, but once the reaction has begun, cooling is required. Important variables in the operation of a fluidized-bed fluorinator are temperature, fluorine concentration, fluidization rate, and feed rate.

Since uranium hexafluoride is a solid at room temperature, it is necessary to keep all lines that transfer uranium hexafluoride above the triple point to prevent solid plugs from being formed.

7.9.4.3 Fluorine Generation and Disposal - Fluorine is produced by passing an electric current through a molten mixture of potassium fluoride and hydrogen fluoride $(\mathrm{KF} \cdot 2 \mathrm{HF}) .2,4,9$ The mixture has a melting point of $161^{\circ} \mathrm{F}$. The electrical current causes the hydrogen fluoride to be decomposed as follows:

$$
2 \mathrm{HF}+\mathrm{H}_{2}+\mathrm{T}_{2}
$$

Fluorine gas is given off at the anode (positive electrode) and hydrogen gas at the cathode. Hydrogen fluoride is added to the fused salt bath of electrolyte to make up for the amount that is decomposed.

The cells used for fluorine generation consist of a Monel vessel. (89 in. $x 38$ in. $x 41$ in. high) with a water jacket for maintaining the temperature at about $215^{\circ} \mathrm{F}$. The water jacket is used to heat the cell to operating temperature, but once the cell is in operation the water jarket is used for cooling.

Carbon electrodes are used for the anode and steel electrodes for the cathode. Skirts, which extend at least 4 in. into the potassium fluoridehydrogen fluoride electrolyte, are placed around the top of the anode to collect the fluorine. The fluorine gas is piped from these skirts to the fluorine supply header. The hydrogen gas evolved collects outside the skirts and goes to a hydrogen collection header. The hydrogen is a byproduct that may or may not be useful in the process. Both the fluorine and hydrogen gases are passed through condensers operated at about $-84^{\circ} \mathrm{C}$ to remove hydrogen fluoride before leaving the fluorine generation area. A typical cell has a 6000-ampere capacity and produces about 8.4 pounds 
of fluorine per hour. Several cells are operated in series to supply the quantity of fluorine needed. The fluorine production rate can be changed by varying the number of cells in service and also by varying the voltage across each cell, which in turn varies the cell current.

Instruments used to operate the fluorine cells include controllers and recorders for temperature, voltage and current, and electrolyte level and controls to balance the pressures in the hydrogen and fluorine gas headers. The electrolyte level is controlled by the addition of gaseous hydrogen fluoride to the electrolyte. A level-measuring device admits the hydrogen fluoride to the cell as necessary to maintain the desired level. The cell may also be sampled to determine the hydrogen fluoride content of the electrolyte. Since the hydrogen and fluorine gas compartments inside the cells are separated by only about 4 in. of electrolyte, it is necessary to keep the pressures in the hydrogen and fluorine headers very nearly the same to prevent mixing of hydrogen and fluorine. Fluorine and hydrogen gases react explosively when mixed. Precise instruments are used to balance the pressures in the two headers. Safety circuits may also be used to shut the system down if the pressure difference between the two headers exceeds acceptable limits.

Two common difficulties encountered in the operation of fluorine cells are polarization and failure due to corrosion of metal components. To repair cells that have failed, the electrolyte can be drained and the cell disassembled. When a cell becomes polarized, the voltage drop across it increases from a normal value of 8-12 volts to 15-45 volts. Special procedures, which involve the addition of lithium fluoride to the electrolyte and operating at reduced current, are used to depolarize the cells.

Fluorine and hydrogen fluoride are very toxic when inhaled and produce severe burns on contact with the skin. Fluorine is also very reactive and corrosive. It will ignite spontaneously with most organic compounds to which it is exposed. Materials such as copper, nickel, and Teflon can be used for handling fluorine; they should be clean and free of oil or grease, however, before exposure to fluorine. The following types of safety hazards must be guarded against in the operation of fluorine cells: (1) electrical shock, (2) thermal burns, (3) chemical exposure, and (4) hydrogen explosions.

Since fluorine is highly reactive and toxic, it is desirable to remove the unreacted fluorine from the fluorinator off-gas before it is discharged from the facility. In off-gas streams that contain relatively large amounts of fluorine, much of the fluorine can be recovered by passing it through beds of uranium tetrafluoride, which are later sent to the fluorinator to complete the fluorination. ${ }^{8}$ Several methods are available for removal of small quantities of fluorine from gas streams. These include scrubbing the gas stream with a caustic solution such as potassium hydroxide. Fluorine can also be removed from a gas stream by reaction with solids in a packed or fluidized bed. Solids such as activated alumina and charcoal have been used for this purpose. 
7.9.4.4 Collection of Uranium Hexafluoride - Cold trapping is the most common method of collecting gaseous uranium hexafluoride produced in the fluorination step. ${ }^{1,3,8}$ It is standard practice to use two cold traps in series, with the first trap (primary trap) operated at about $0^{\circ} \mathrm{F}$ to collect a large fraction of the uranium hexafluoride, while the secondary trap is operated at a lower temperature $\left(-50^{\circ} \mathrm{F}\right)$ to collect most of what remains. Uranium hexafluoride collects as a solid in the traps. The last traces can be removed by passing the gas stream through beds of solids such as activated alumina, sodium fluoride, and uranium tetrafluoride or by scrubbing with a caustic solution such as potassium hydroxide.

A typical cold trap is shown in Fig. 7.9.6. The cold trap contains both heaters and cooling coils on the outer surface. The inside of the trap contains fins to aid in cooling the gas stream. The cold trap is enclosed by thermal insulation.

At least two sets of traps are required for continuous operation, so that one cold trap can be on stream while the other is being drained. When one trap becomes filled, it is taken out of service by closing the inlet and outlet valves and stopping the flow of refrigerant to the cooling coils. The heaters are then used to melt the uranium hexafluoride under its own vapor pressure (about $165^{\circ} \mathrm{F}$ and 35 psia). The liquid can then be drained from the cold trap to the purification system or to a product cylinder. After it has been drained, the heaters are turned off, and the trap is cooled to operating temperature before being returned to service.

The following types of instruments are used for operation of cold traps: (1) temperature controllers and recorder, (2) pressure recorders, and (3) weight recorders. Temperature control is important while the uranium hexafluoride is being trapped and while it is being melted and drained. During the trapping step the cold trap temperature determines the amount of uranium hexafluoride removed from the gas stream. The lower the temperature, the larger the fraction that will be collected from the gas stream. Control of the temperature during the melting step is important to ensure that the uranium hexafluoride is melted without overpressurizing the trap. Overheating would result in excessive pressure inside the trap. Pressure instruments may be used to measure the pressure drop across the trap as well as the internal pressure. A weight-measuring instrument can be used to indicate the amount of uranium hexafluoride present.

7.9.4.5 Purification of Uranium Hexafluoride - If the uranium is not completely purified in the solvent extraction step, further purification can be done after the uranium has been converted to uranium hexafluoride. The hexafluoride will mainly contain volatile fission products and possibly corrosion products that are volatilized in the fluorination step, since the nonvolatile impurities will remain behind in the fluorinator. Two methods of purification will be discussed: distillation and the use of solid sorbents. 


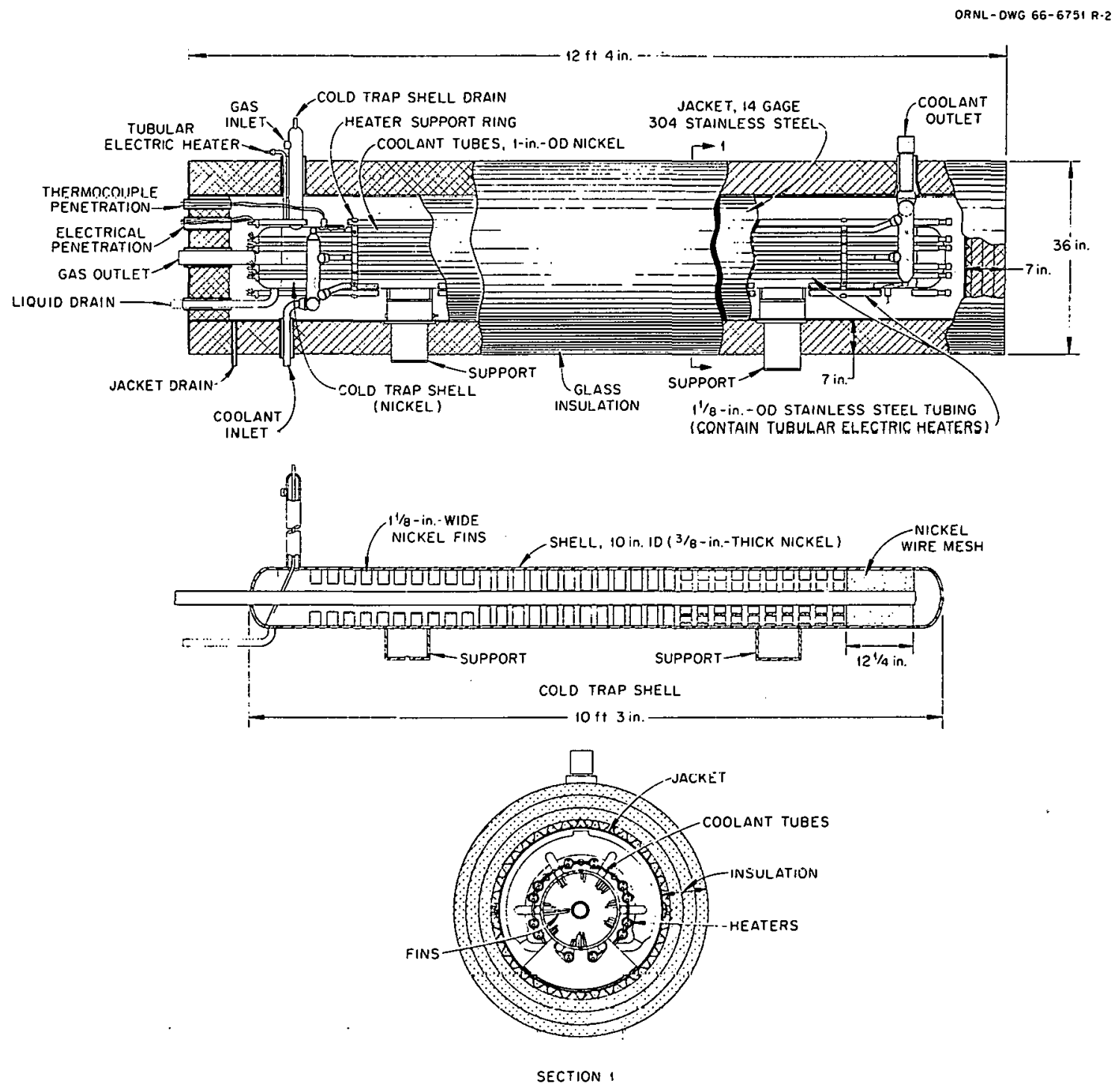

Fig. 7.9.6. Cold Trap Used for Collecting $U_{6}$. 
Since most of the impurities normally present have boiling points that are different from that of uranium hexafluoride, distillation can be used as a means of separation. The distillation of uranium hexafluoride is similar to conventional distillation methods with the exception that it must be carried out above atmospheric pressure to obtain the liquid phase necessary for distillation. In the purification system operated by Allied Chemical Company to produce feed material for gaseous diffusion plants, two distillation columns were used. 1 One colum operated at $93^{\circ} \mathrm{C}$ and $85 \mathrm{psia}$ and the other at $115^{\circ} \mathrm{C}$ and 95 psia.

A typical uranium hexafluoride distillation system (Fig. 7.9.7) consists of a vertical column containing the liquid and vapor phases. A heated pot (reboilcr) io located at the bottom of the column for boiling tire liquid to produce the vapor phase, which travels up the column. A heat exchanger (condenser) is located at the top of the column to condense the vapor and produce a liquid. Tempered water is circulated through the condenser to maintain it at the desired temperature. A portion of the liquid from the condenser (the reflux) is allowed to flow back down the colum, where it contacts the vapor phase in each of the trays in the column. In general, increasing the reflux improves the separation of uranium hexafluoride from impurities. The feed is introduced at about the center of the column. The impurities that are more volatile than uranium hexafluoride concentrate in the upper portion of the column and can be removed there, while the less volatile impurities concentrate in the reboiler. The following conditions must be controlled in the operation of the distillation system: (1) the temperature in the reboiler, which determines the rate at which vapor is sent to the bottom of the column, (2) the temperature of the column, which must be kept hot to prevent freezing of the uranium hexafluoride, (3) the temperature of the condenser, which must condense the vapors without freezing them, (4) .the feed rate to the column, (5) the amount of liquid reflux and the rate at which product and waste are removed, and (6) the pressure at the condenser outlet, which must be kept at about 22 psia to produce a liquid uranium hexafluoride phase.

Fission products and corrosion products have been removed from uranium hexafluoride by contacting it with sodium fluoride (NaF) and magnesium fluorlde $\left(\mathrm{MgF}_{2}\right)$. Under the proper conditions, impurities can be sorbed on sodium fluoride and magnesium fluoride while the uranium hexafluoride passes through a bed of these solids. Two common impurities in uranium hexafluoride, technetium and neptunium, can be removed by passing the gas through a bed of magnesium fluoride at $100^{\circ} \mathrm{C} .10$ Fluorides of plutonium and of corrosion products and of such fission products as ruthenium and niobium can be removed by passing the gas through beds of sodium fluoride at $400^{\circ} \mathrm{C} .11,12$ Uranium hexafluoride sorbs on sodium fluoride at $100^{\circ} \mathrm{C}$. One method of purification is based on sorption of uranium hexafluoride at $100^{\circ} \mathrm{C}$ and desportion at $400^{\circ} \mathrm{C}, 12,13$ 


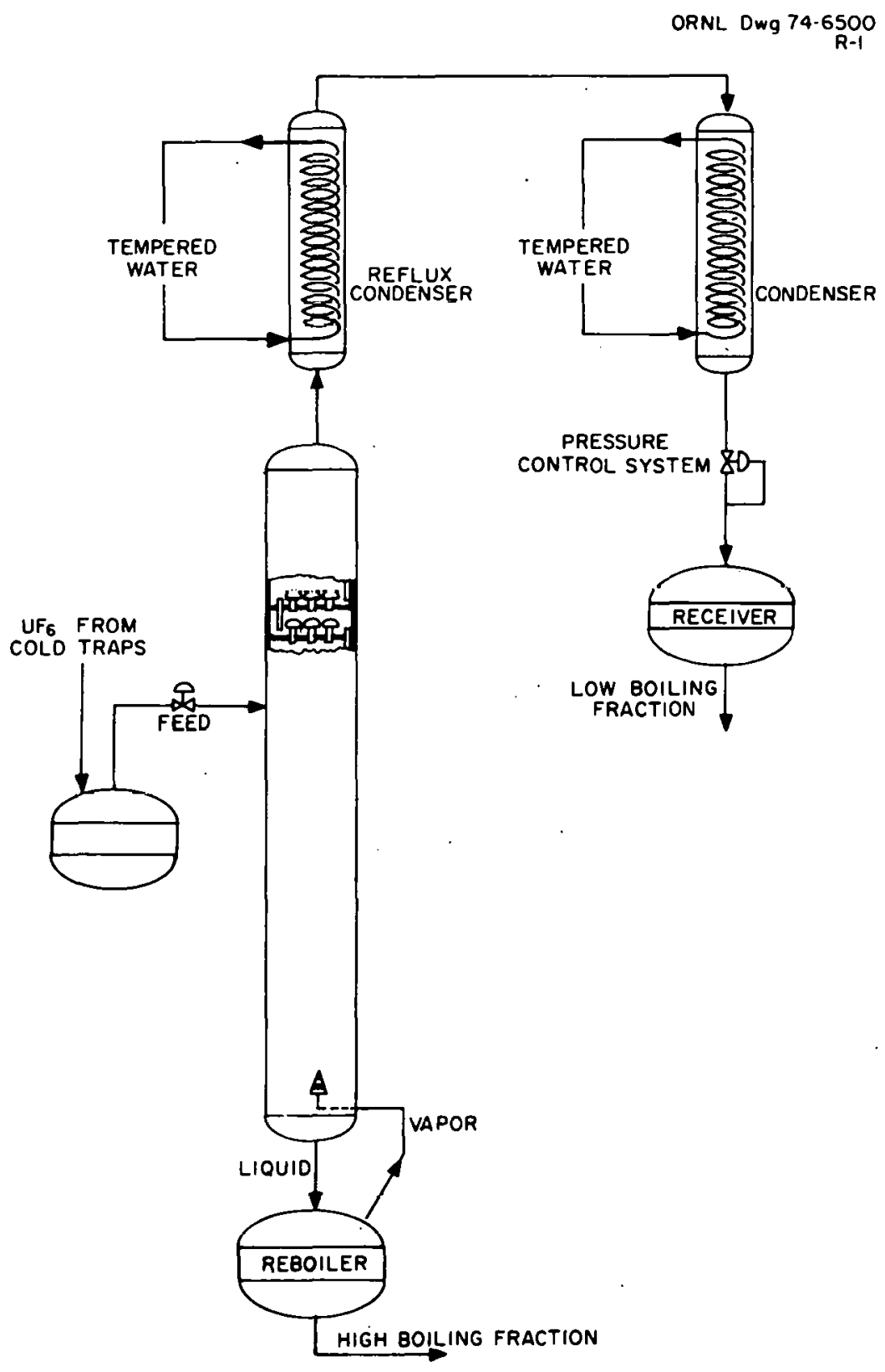

Fig. 7.9.7. System for Purification of $\mathrm{UF}_{6}$ by Distillation. 
7.9.4.6 Load-out of Uranium Hexafluoride Product - Standard cylinder designs of various sizes have been approved for the shipment of uranium hexafluoride. ${ }^{7}$ Figure 7.9 .8 is a drawing of a Model $30 \mathrm{~A}$ cylinder that will hold about $2-1 / 2$ tons of uranium hexafluoride. For criticality control the size of the product cylinder that can be used for a given application depends on the uranium-235 content (enrichment) of the uranium and the amount of moderator present in the uranium hexafluoride.

A typical system for filling cylinders is shown in Fig. 7.9.9. All the lines are maintained at $165^{\circ} \mathrm{F}$ to $180^{\circ} \mathrm{F}$ to prevent solidification of the uranium hexafluoride. The liquid is drained by gravity into an evacuated cylinder. Steps in the loadout procedure include the following: (1) the cylinder is inspected, evacuated, and weighed; (2) the cylinder connections (pigtails) are then connected, purged, and 1.eak tested; (3) valves are opened to allow liquid uranium hexafluoride to enter; (4) when the cylinder is loaded, the valves are closed and the pigtails purged; (5) the cylinder is then disconnected and weighed. The cylinder is not shipped until the uranium hexafluoride has solidified. Precautions must be taken not to overfill. or overheat a product cylinder, since this could cause overpressurization and possible rupturing of the cylinder. Liquid uranium hexafluoride samples may be obtained from the cylinder or cold traps by attaching metal sample cylinders through a piping arrangement similar to that used to product load-out. 


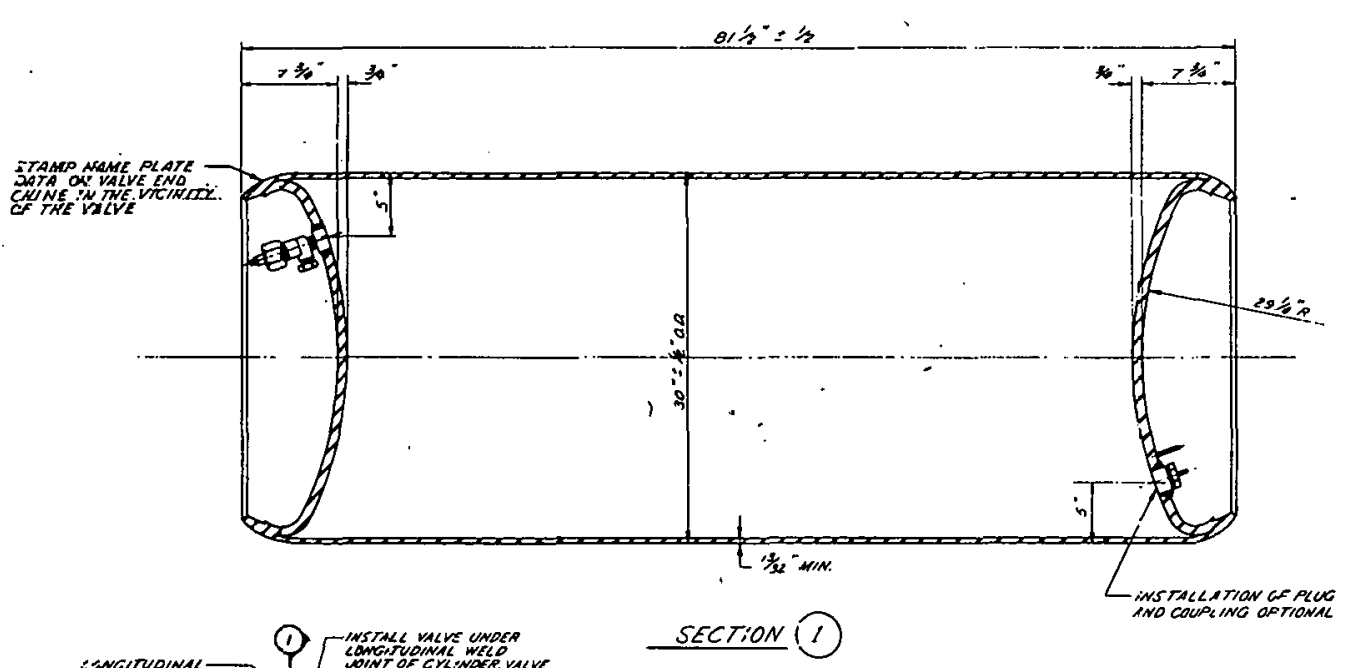

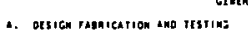

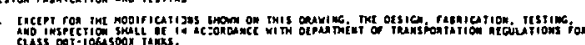

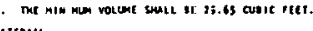

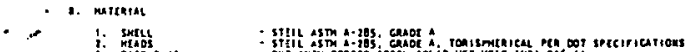

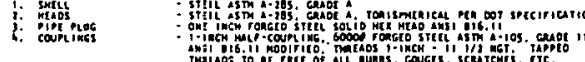

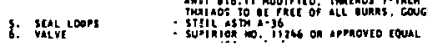

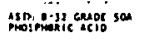

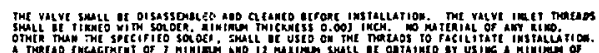

Pire nus isstalartor

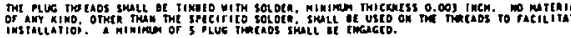

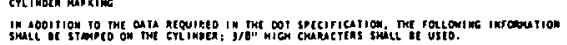

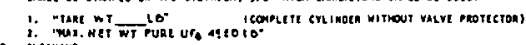

citux

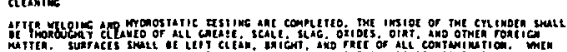

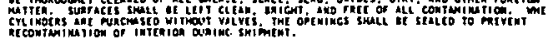

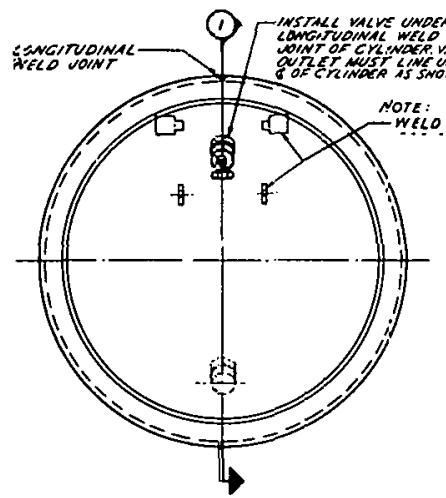

SECTION 1

VALVE ENO
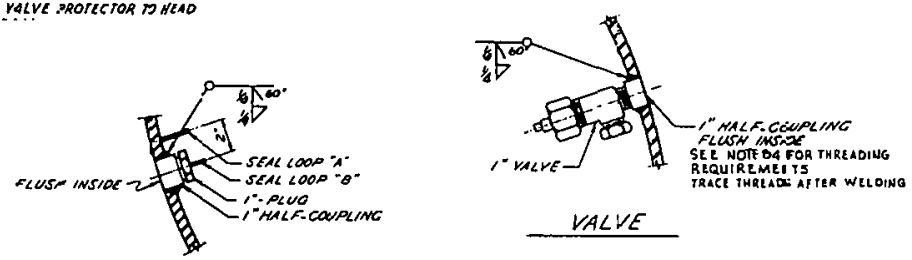

VALVE

DETAIL OF OPTIONAL PLUG

NoT:

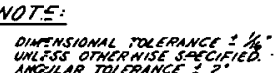

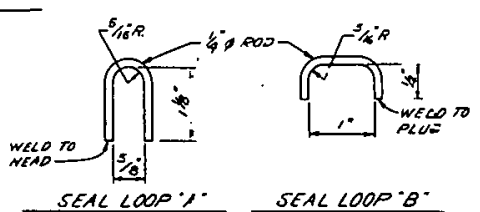

Fig. 7.9.8. Mode1 30A Cylinder. 
FILLING SYSTEM
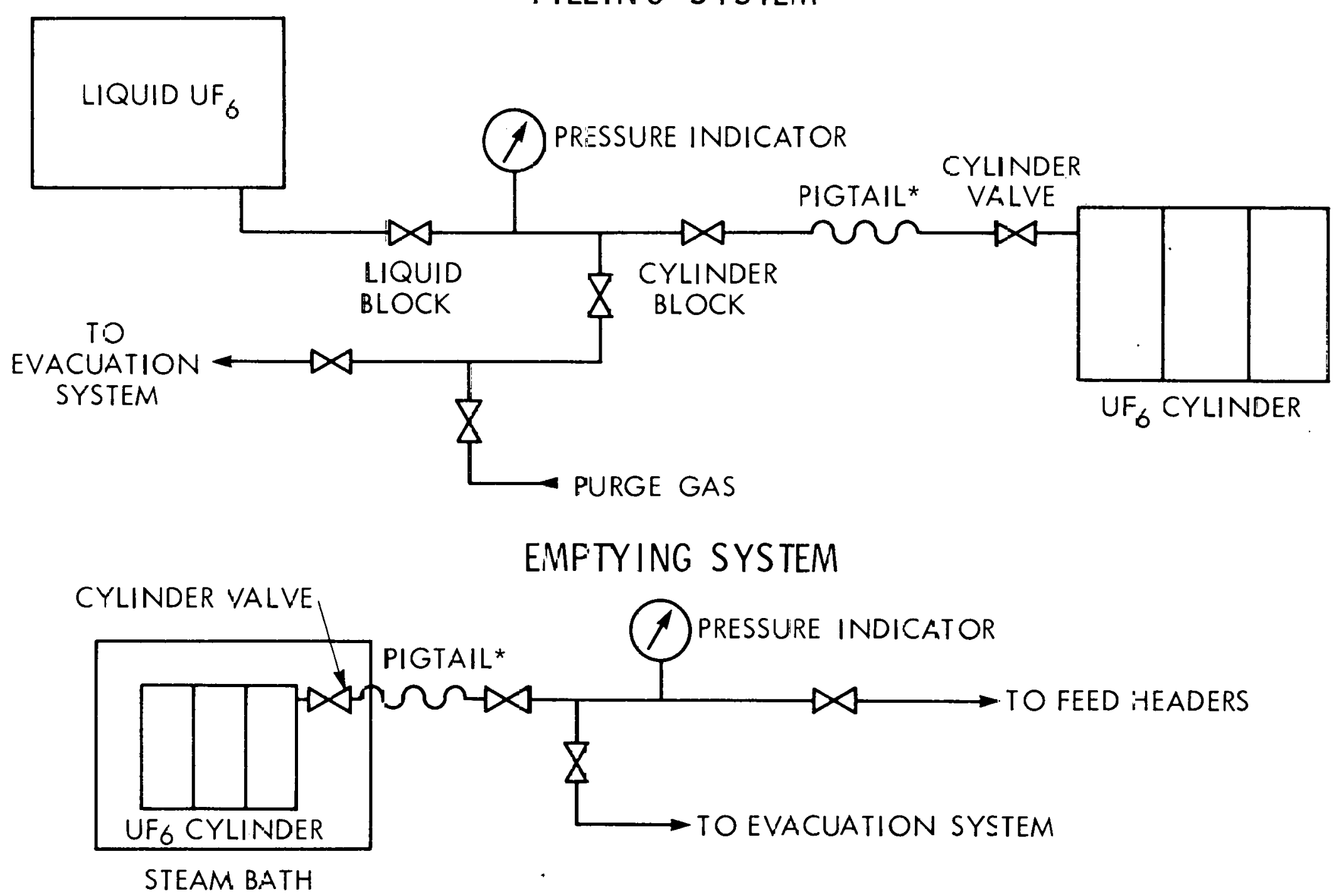

*SEMIFLEXIBLE TUBING CONNECTOF.

Fig. 7.9.9. Shows a Typical System for Filling Cylinders. 
1. W. C. Ruch, D. A. Peterson, E. A. Gaskill, and H. G. Tepp, "Production of Pure Uranium Hexafluoride from Ore Concentrates," Chem. Eng. Progress Symposium Series 56, No. 28, 1960.

2. Current Commission Methods for Producing $U O_{3}, U F_{4}$, and $U F$, Report TID-5295, 1956.

3. General Electric Company, Design and Analysis, Midwest Fuel Recovery Plant, Docket No. 50-268, 1966.

4. C. D. Harrington and A. E. Ruehle, Uranium Production Technology, D. Van Nostrand Company, Inc., Princeton, N.J., 1959.

5. S. Simecek and W. T. Trask, The Integrated Fluid-Bed System, Report MCW-1478, Mallinckrodt Chemical Works, Uranium Division, Weldon Spring, Mo., $196 \mathrm{~J}$.

6. A. H. Sutton, J. C. Bishop, M. H. Cohen, and K. J. Stahman, "Reduction and Hydrofluorination of Uranium Concentrates by Fluid Bed Techniques," Chem. Eng. Progress Symposium Series 62, No. 65, 1966.

7. Uranium Hexafluoride Handling Procedures \& Container Criteria, Report ORO-651, Rev. 3, August 1972.

8. W. R. Pedigo, C. R. King, L. A. Dean, J. E. Owen, and S. Bernstein, "Fluidized Bed Recovery of Fluorine in the Manufacture of $\mathrm{UF}_{6}$," Chem. Eng. Prog. Symposium Series 56, No. 282, 1966.

9. A. P. Huber, J. Dykstra, and B. H. Thompson, "Multi-Ton Production of Fluorine for Manufacture of Uranium Hexafluoride," Proc. $2 d$ United Nations International Conference on the Peaceful Uses of Atomic Energy, vol, 4, 1958.

10. W. R. Golliher, R. A. LeDoux, S. Bernstein, and V. A. Smith, Report TID-18290, Paducah Gaseous Diffusion Plant, 1960.

11. G. I. Cathers, R. L. Jolley, and E. C. Moncrief, NucZ. Sci. Eng. 13: 391-397 (1962).

12. W. H. Carr, "Volatility Processing of the ARE Fuel," Chem. Eng. Progress Symposium Series 56, No. 28, 1960.

13. W. H. Carr, L. J. King, F. G. Kitts, W. T. McDuffee, and F. W. Miles, Molten-Salt Fluoride Volatility Pilot Plant: Recovery of Enriched Uranizon from Aluminum-Clad Fuel Elements, Report ORNL-4574, 1971. 
7.10 PRODUCT WITHDRAWAL, STORAGE, AND PACKAGING

The packaging requirements for radioactive materials are detailed in Title 10, Code of Federal Regulations, Part 70, Subpart C. In addition to the general regulations covering radioactive materials in general, the NRC has enacted measures which will prohibit the shipment of more than 20 curies per package of plutonium in liquid form after June 17, 1968. After this date, quantities larger than this amount must be shipped in the solid form.

\subsubsection{Product Packaging and Storage}

The plutonium or neptunium product is withdrawn into storage cans after being converted to the oxide and blended.

A predetermined quantity of oxide is we1ghed into a storage can; the can is sealed and placed on a conveyor. Automat1c equipment prevents more than one can from being on the loading station at one time. The diameter and volume of the can are safe for water-moderated and-reflected plutonium or neptunium oxide.

The uranium hexafluoride product cylinder as shown in Figure 7.9.8 is a Model 30A steel cylinder, 30 in. in outside diameter and 81 in. long, with a wall thickness of $13 / 32$ in. The Model 30A cylinder has a minimum volume of 722 liters and a tare weight of $1600 \mathrm{~kg}(726 \mathrm{~kg})$. The cylinder has a half coupling welded into one end with a 1-in. valve screwed therein. To avoid hazardous leakage of the uranium hexafluoride, the valve is screwed tight into the coupling using Teflon tape to seal the threads of the valve into the coupling. Other sealants like pipe dope should not be used because of possible chemical reaction with uranium hexafluoride.

Sealed cans of plutonium or neptunium oxide are stored singly in cubicles of the oxide storage vault. Spacing between cans on the steel storage racks allows for criticality control and provides proper ventilation for removal of decay heat. Thick concrete walls protect personnel against radiation from plutonium in storage, and the vault is secured from personnel entry by NRC approved doors.

The storage and retrieval of the plutonium or neptunium cans are performed by a computer-controlled robot that picks up the can from a conveyor, moves it to a preselected storage cell, and places the can in the cell. The computer memory will retain the date, the material, the location, and the weight of the oxide in each can so that retrieval for further use of shipment is completely automatic.

Storage areas should adhere to the proposed ANSI standard N 16-5 entitled "Guide for Nuclear Criticality Safety in the Storage of Fissile Materials." 


\subsubsection{Product Preparation}

Preparation of plutonium and neptunium product is accomplished in identical equipment in which the ion-exchange product is concentrated and measured into the product storage container.

The plutonium product stream is concentrated from $15 \mathrm{~g}$ of plutonium per liter to a final concentration of $250 \mathrm{~g} / \mathrm{liter}$ with a nitric acid concentration of $8 \mathrm{M}$. Product control is accomplished by control of the density of the product solution, usually $1.58 \mathrm{~g} / \mathrm{cc}$. The concentrator is operated in a semicontinuous manner discharging product at the desired density to a product sample and rework tank, normally having the capacity to hold a batch of approximately 50 liters. Each batch is sampled and analyzed for product concentration and other specifications, and if within these specifications, it is ready for conversion to oxide.

The neptunium product preparation and load-out system is essentially identical to the plutonium system to assure nuclear safety in case of the undetected presence of plutonium in the neptunium product stream.

The principal difference in the neptunium process is that the product is concentrated from approximately $1.5 \mathrm{~g}$ of neptunium per liter to 250 g/liter; thus, the rate of output of neptumium product is much less than that of plutonium product.

Purified uranium hexafluoride product is packaged in accordance with procedures based on established NRC practice. 1

Confirmation that the preirradiation concentration of the uranium-235 isotope was below the $5.0 \%$ limit allowable in the shipping container is obtained prior to load-out. Also, assurance that the hydrogen fluoride concentration does not exceed specifications is obtained by maintaining the uranium hexafluoride at $93^{\circ} \mathrm{C}$ during the melt-down operation in the cold trap, while the pressure is bled down to less than 75 psig.

During load-out, the product shipping cylinder is continuously weighed to prevent overfilling and kept at a temperature of $90^{\circ} \mathrm{C}$ to maintain the product in the liquid state. During filling, the cylinder is held in a horizontal position on a dolly to minimize the possibility of its being dropped. A typical filling system is shown in Figure 7.9.9.

\subsubsection{Contamination Control Methods}

All handling of plutonium and neptunium solutions is conducted in process cells, hoods, or glove boxes to prevent spread of contamination. All spillage or leakage is immediately cleaned up. The hood is cleaned before and after each load-out operation. Also, prior to filling, the product cylinder is placed in a close-fitting plastic bag to minimize contamination of the cylinder during the load-out operation. 
In the uranium hexafluoride product load-out operation, protection is provided to minimize the consequences of release of uranium hexafluoride. Each cylinder is carefully inspected and pressure-vacuum cycled to assure integrity and leak tightness. All operations are conducted behind barriers to protect the cylinder and associated piping from damage. In the event of leakage, quick cooling of the affected cylinder valve or nearby piping is accomplished by a mobile pressurized carbon dioxide system. All personnel disconnecting uranium hexafluoride lines that have not been evacuated and purged use respiratory and clothing protection.

\subsubsection{Criticality Control Methods}

In the plutonium and neptunium product handling system, control of nuclear criticality is maintained by the following means.

1. All process equipment, cell floors, and sumps are designed to be geometrically safe for plutonium concentrations up to $400 \mathrm{~g} / 1$ iter. Transfer of concentrated plutonium solutions to equipment of less favorable geometry is rigidly controlled.

2. Homegeneous solic. as are maintained by excluding precipitating agents and avoiding polymer formation.

3. The product storage package is critically safe for any number of units in any array. When the cylinder is out of the container for loading and weighing, the load-out equipment is designed so that only one filled 10-1iter bottle at a time can be handled within the load-out hoods.

4. Administrative control is used to assure that the product bottle is kept in the storage container at all times except when it is within the load-out hood.

In the uranium hexafluoride packaging and storage system, assurance that criticality hazards have been reduced to a neg1igible level is provided by the following:

1. NRC tests which assure that the shipping cylinder is adequately safe for uranium hexafluoride up to $5 \%$ uraniun-235 so long as modoration doco not carecd the cquivalent of 0.5 weighit pertent IIF in $\mathrm{UF}_{6}$.

2. Controlling the hydrogen fluoride concentration below 0.5 weight percent $\mathrm{HF}$ in $\mathrm{UF}_{6}$ by bleeding the cold traps down to less than 75 puia at $93^{\circ} \mathrm{C}$.

3. Careful inspection of cylinder and tare weight to assure freedom from moderation.

4. Provision of a criticality monitor and evacuation alarm system. 


\subsubsection{Accountability Methods}

Strict accountability procedures are followed in product material handling. These involve the following:

1. The plutonium and neptunium product solutions are carefully sampled and analyzed prior to conversion and loading into the storage container. The uranium hexafluoride product sample is withdrawn from the loaded cylinder after it has been allowed to stand at $90^{\circ} \mathrm{C}$ for at least $8 \mathrm{hr}$ to assure uniformity.

2. Product output figures are obtained by careful weighing of shipping cylinders, using accurate and frequently calibrated scales.

1. E. L. Keller, Uranium Hexafluoride Handling Procedures and Container Criteria, USAEC Report ORO-651, Union Carbide Corporation, 1966. 


\subsection{SOLUTION TRANSFER}

\subsection{1 .1 Pumps}

Pumps are mechanical devices that are capable of transferring liquids under a variety of operating conditions and are classified into two main groups, centrifugal pumps and positive displacement pumps, each having its advantage over the other, depending on the process requirements of the liquid being pumped. Pumps differ widely in principle and construction. No one type of pump is of prime importance with respect to another; each type will perform efficiently under the proper conditions for which it is designed. As the name implies, positive displacement pumps forcefully push torth a detinite quantity of liquid for each stroke of the piston or revolution of the rotor. ${ }^{1}$ Centrifugal pumps are more simply constructed and can deliver varying volumes of liquid with varying pressure at a constant speed. ${ }^{1}$

Positive Displacement Pumps - Positive displacement pumps are used in radiochemical plants for metering process solutions because they can maintain pumping rates with less than $2 \%$ deviation at varying pressures. This class of pump can be of either the reciprocating type or the rotary type, delivering a finite volume of liquid for each stroke of a piston or plunger or for each revolution of meshing. gears or a circular rotor.

Positive displacement pumps can develop higher pressure heads than centrifugal pumps and are less subject to vapor binding because they can operate with the inlet under a pressure that is lower than atmospheric. Positive displacement pumps are quite flexible in their operation and can perform with little change in efficiency ovèri a wilde range of flow rates and discharge pressures. However, the pulsating delivery of the reciprocating pump is an undesirable feature in many applications, and the abrasive wear between the stator and gears of a gear pump and between the stator and rotor of a rotary pump result in a shortened life-span for these pumps. One precaution must be observed in the operation of all positive displacement pumps: No attempt should be made to throttle the discharge flow with a valve, because the positive pressure generated by this type of pump will cause severe damage to the piping, the pump, and other equipment should the valve become closed inadvertently.

Reciprocating Pumps - Basically, the reciprocating pump consists of a piston or a plunger moving forward and backward in a chamber, displacing on each forward stroke a volume corresponding to the chamber diameter and the length of stroke. The plunger type is different from the piston type in that the plunger moves past stationary packing, whereas a piston carries its own packing, called piston cups, with it. The liquid is drawn through an inlet check valve and into the pump chamber on the backward or suction stroke of the piston. On the forward stroke, the force exerted by the piston closes the inlet valve and opens the discharge check valve, expelling a finite volume of liquid out the discharge line. Figure 7.11 .1 is a cross section of a typical reciprocating pump. ${ }^{2}$ 


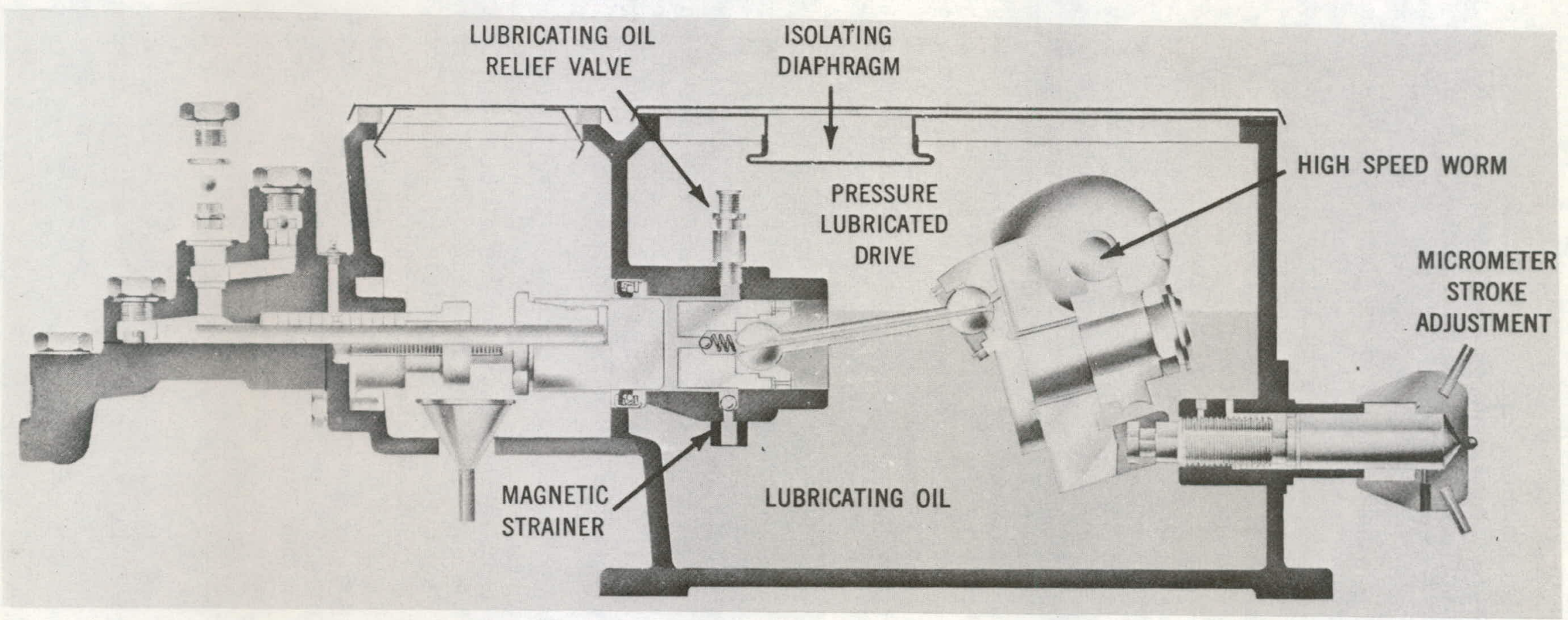

Fig. 7.11.1. Milton Roy Reciprocating Pump 
The capacity of a reciprocating pump is a function of the piston diameter, the length of the piston stroke, and the speed or frequency of the stroke. Fluctuations in the discharge pressure have very little effect on the capacity. Since the piston diameter is constant for a given pump, the capacity is a function of either the length of stroke or of the stroke frequency, or both. In some types of pumps (Figure 7.11.1 is an example) the length of the piston stroke can be adjusted manually at the pump or remotely by an electrically or pneumatically operated mechanism. The latter method finds particular application in inaccessible areas such as hot cells and canyons and in shielded cubicles, while pumps located in "cold" operating areas are normally hand-adjusted. Some pump manufacturers provide more flexible control by combining the stroke length adjustment with an adjustable speed-changing mechanism.

A type of pump that is highly adaptable for handling radioactive solutions is the oil-pulsed diaphragm reciprocating pump. Its unique construction isolates the liquid being pumped from most working parts, it presents no lubrication problems because all working parts are submerged in oil or the pumped fluid (check valves), it has no leaking shaft seal or stuffing box to leak, and it has a hydraulic pressure relief valve on the oil side to prevent overpressurization on the power stroke. The principle of the oil-pulsed diaphragm pump is analogous to that of an ordinary reciprocating pump in that a piston moving forward and backward in a cylinder displaces an exact amount of oil on each stroke, flexing a diaphragm. The diaphragm, located in the cavity formed by the two diaphragm support plates, acts as a barrier separating the oil from the liquid being pumped. Figure 7.11.2 is a cross section illustrating the principle of this type of pump. ${ }^{3}$ On the suction stroke the piston pulls oil out of the cavity, moving the diaphragm and pulling liquid through the inlet check valve into the cavity created in the reagent head by the movement of the diaphragm. On the pressure stroke the oil moves the diaphragm forward, forcing the inlet check valve to close and the Liquid in the cavity out through the discharge check valve into the discharge piping.

The diaphragm pump can be modified to include a remote reagent head that is located within the hot cell or shielded cubicles, and this makes it possible to keep the radioactive solutions contained within the cells or shielded cubicles. The pump head and the reagent head are connected by a pipe filled with a liquid that is compatible with the solution being pumped, thus eliminating a mixing hazard in the event that the diaphragm should rupture. This remote head arrangement permits the major part of the pumping mechanism to be located in a "cold" operating area for easy maintenance and operation. The use of mechanisms to remotely control the capacity by varying the stroke frequency makes this one of the most versatile pumps for metering process solutions in a radiochemical plant.

Rotary Pumps - The rotary pumps, another type of positive displacement pump, differs from the reciprocating pump in that it requires no check valves in its inlet and discharge ports and delivers relatively pulsefree flow. The speed of the rotor is the only variable affecting the pump's capacity. 


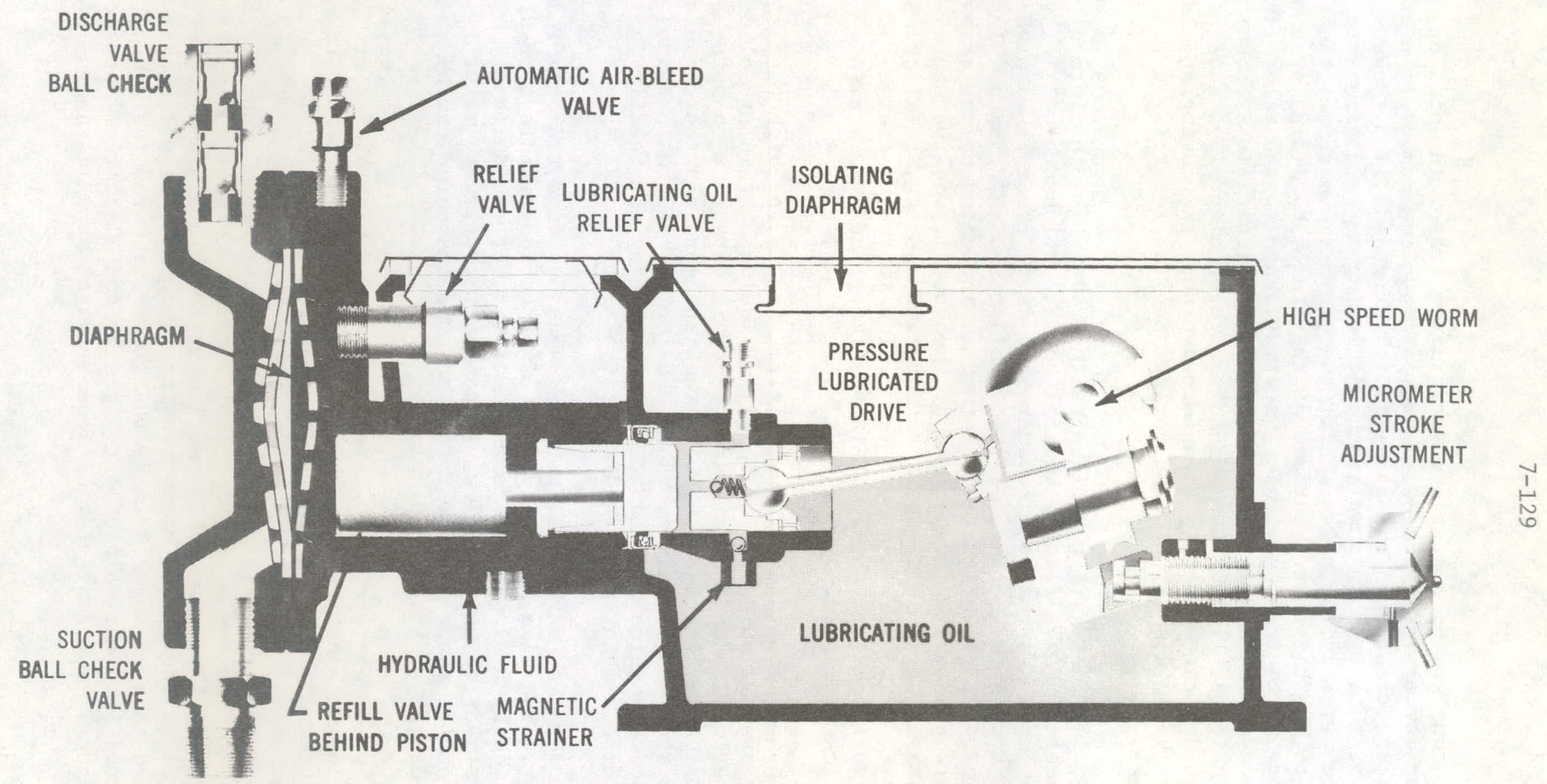

Fig. 7.11.2. Cutaway View of a Diaphragm Pump 
The rotary pump consists of a stationary casing or stator in which one or more rotating members are located. When one rotating member is used, it is mounted eccentrically on the drive shaft. Figure 7.11.3 shows cross sections of this type of pump at the beginning and end of a stroke. ${ }^{4}$ As the cam is revolved by the drive shaft, the eccentric movement causes the rotor ring to rub the entire surface of the stator by wiping around the circumference of the casing. The plunger attached to the rotor ring moves up and down in the slide pin which is free to rotate in a socket. As the arrows indicate, liquid enters when the rotor ring wipes down past the suction opening; the liquid is then forced around the casing and is discharged through the plunger and the outlet when the rotor is at the top of the stroke.

When two or more impellers are used in a casing, they take the form of toothed gear wheels ${ }^{5}$ (Fig. 7.11.4), helical gears, or lobed cams ${ }^{4}$ (Fig. 7.11.5). These impellers rotate with extremely small clearances between each other and between the surface of the impeller and the casing. In Fig. 7.11.4, the two toothed impellers rotate as indicated by the arrows. The liquid enters the suction connection at the bottom. As the spaces between the teeth of the impeller pass the suction opening, the liquid is trapped between them, forced around the casing to the discharge opening, and then forced out through this opening. The arrows also indicate this flow of liquid.

Although these pumps are especially well suited for moving high-viscosity solutions, they are not suitable for handling liquids containing solids or abrasive materials, because their efficiency is dependent on maintaining the very close clearances between the impellers and the rubbed surfaces of the stationary housing. The need for frequent maintenance limits their use to service in "cold" areas where they are readily accessible for direct maintenance and repair.

Centrifugal pumps - The centrifugal pump has wide use in a radiochemical processing plant. The size, capacity, and construction of this type of pump depend on the kind of service demanded of it. It can deliver solutions at a steady nonpulsing flow, it can be throttled to meter solutions over a wide range of flow rates, and the discharge can be closed without damage to the pump or piping.

The centrifugal pump consists of an impeller equipped with blades or vanes spinning inside a casing which has an opening for the liquid to enter at the center of rotation and another opening tangential to the periphery of the casing through which the liquid is discharged. The rotating blades create a partial vacuum at the center of the impeller, pulling liquid into the eye of the impeller through the suction inlet and throwing it radially outward by centrifugal force. As the liquid slides outward along the blades at increasing velocity, the velocity head is converted to a pressure head as the liquid is thrown off the tips of the blades into the volute of the casing and discharged out the tangential opening. A cutaway view of a centrifugal pump ${ }^{6}$ is shown in Fig. 7.11.6. 


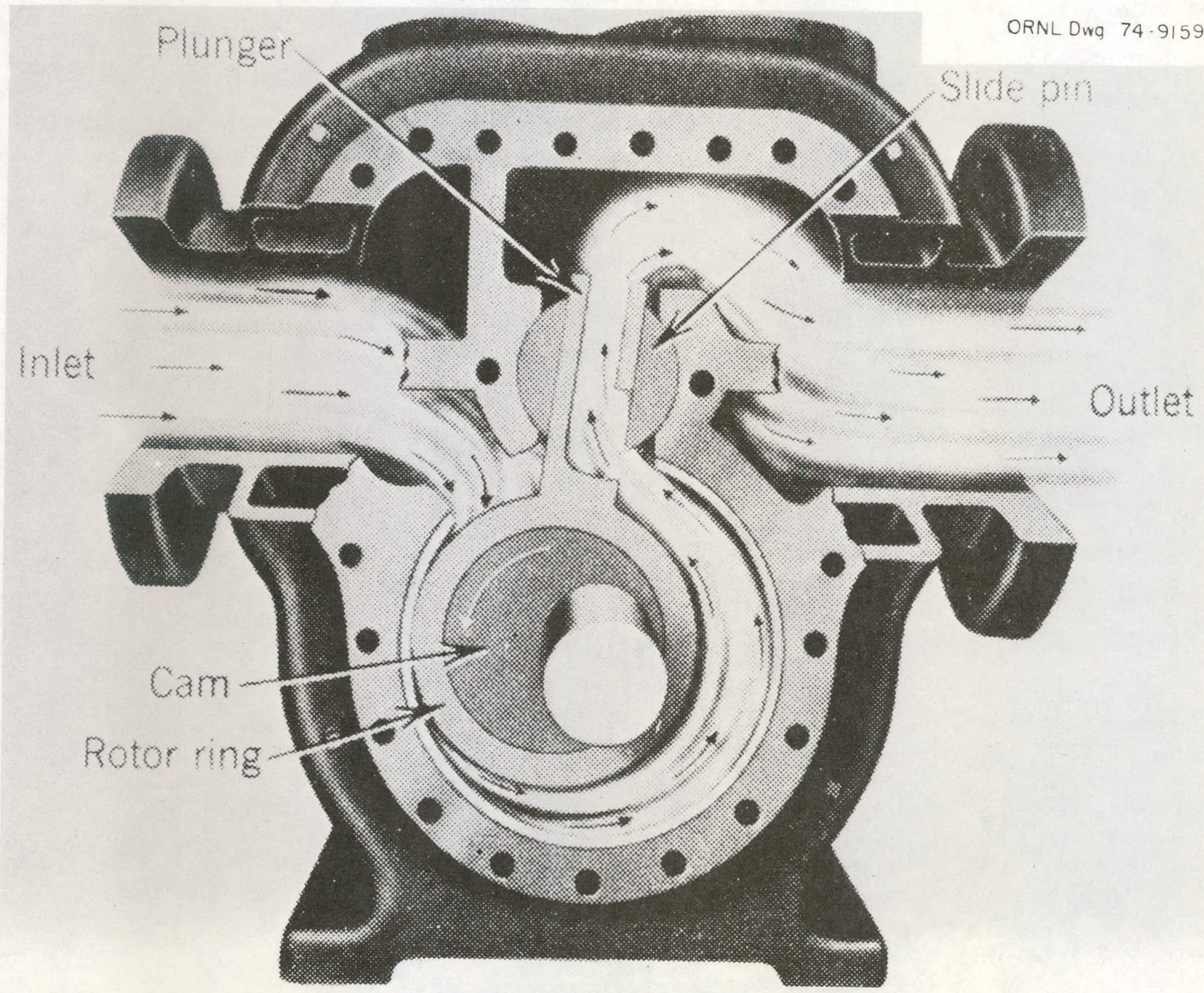

$\stackrel{\stackrel{N}{\omega}}{\stackrel{\omega}{\omega}}$

Fig. 7.11.3a. Cutaway view of cam pump at beginning of stroke 


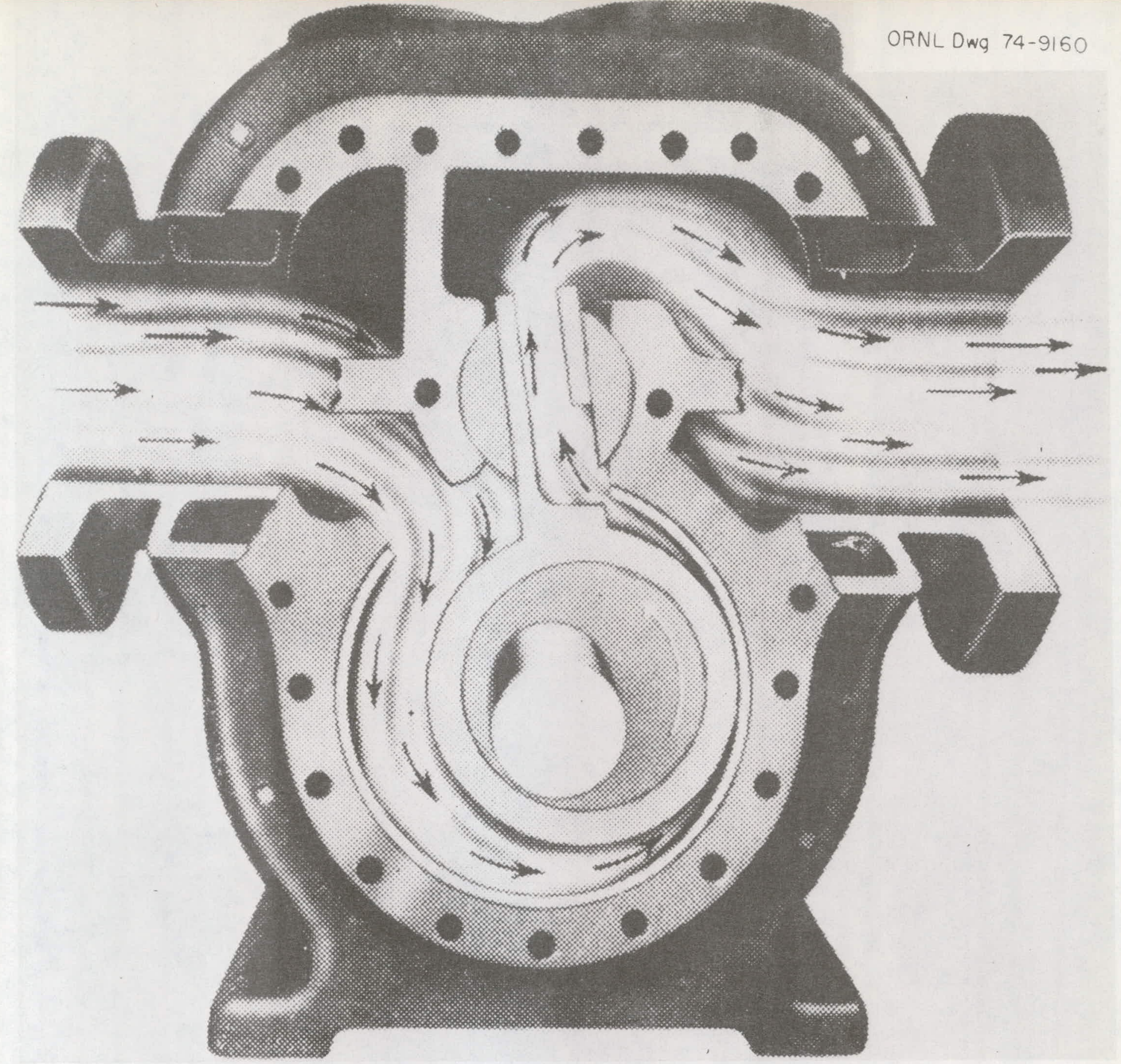

Fig. 7.11.3b. Cutaway view indicating operation approaching end 


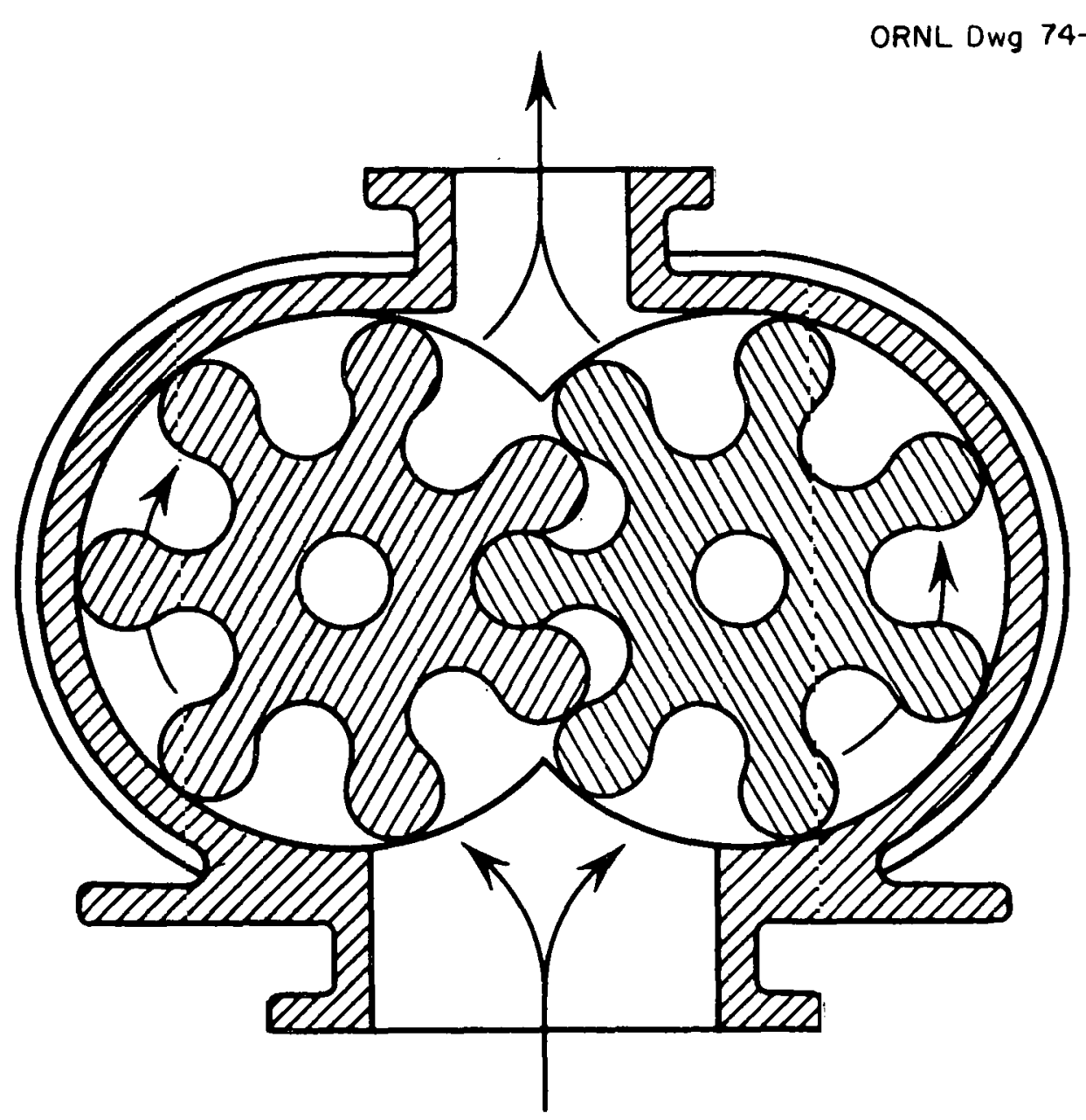

Fig. 7.11.4. Gear-type rotary pump having two impellers. (From Chemical Engineers' Handbook, Fifth Edition, by Robert H. Perry/Cecil H. Chilton, Copyright 1973, 1963 by McGraw-Hill, Inc.. used with permission of McGraw-Hill Book Company.) 


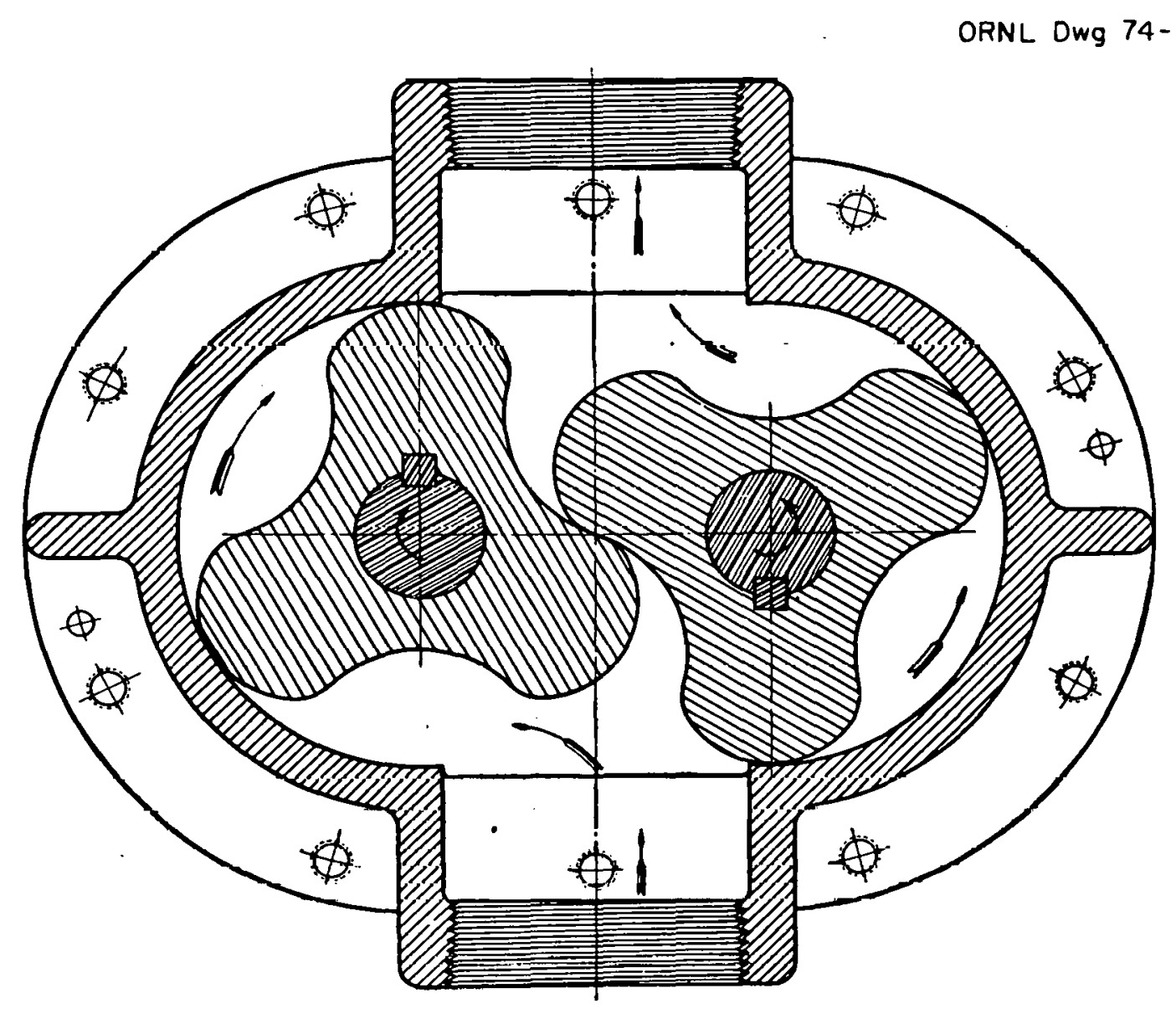

Fig. 7.11.5. Sectional Diagram of the Three-Lobe Pump (RootsConnersuizis Blower Com, ) 


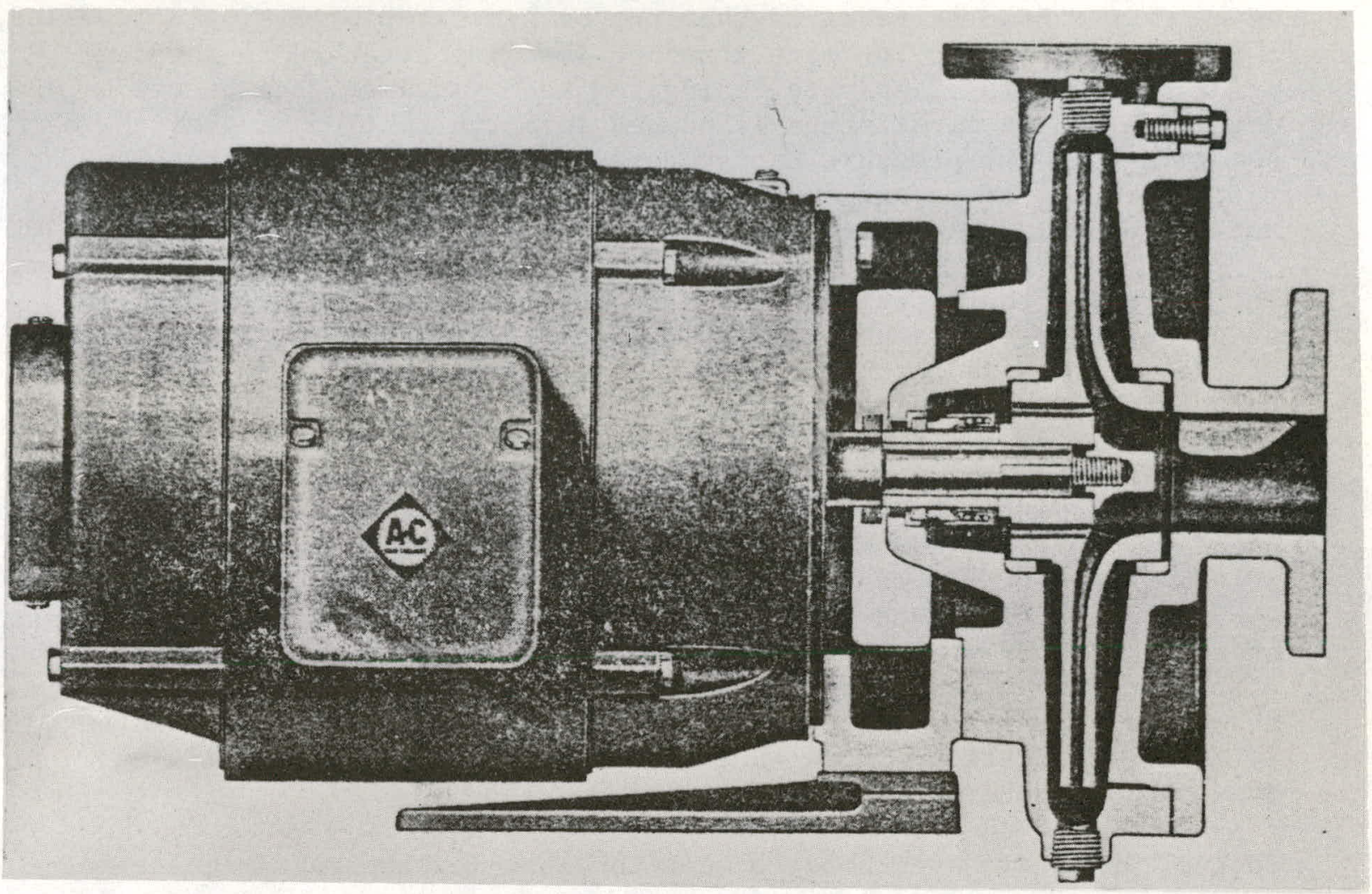

Fig. 7.11.6. Close-coupled Single-Impeller Centrifuge Pump. Courtesy of the Pump Division of Allis Chalmers Corp.

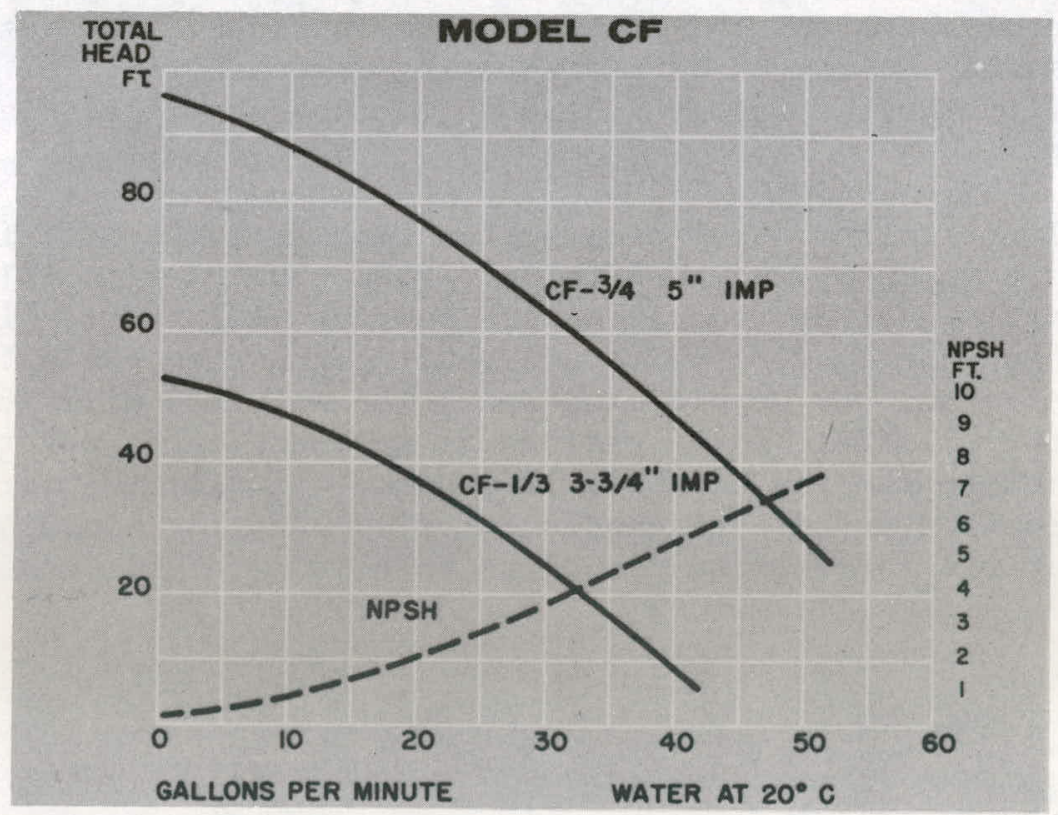

Fig. 7.11.7. Performance Curves for a Centrifuge Pump. Courtesy of Chempump Division of the Crane Company. 
If a greater head is required than can be generated by a single impeller, a multistage pump having more than one impeller attached to the same drive shaft, with a separate casing for each impeller, can be used. The discharge of the first stage is pumped into the suction side of the second stage; the pressure energy developed in the second stage is added to the liquid and passed on to the suction of the next stage, and so on until the desired head is developed.

The operating characteristics of a centrifugal pump are best described by performance curves supplied by the pump manufacturer. A typical set of these curves is shown in Fig. 7.11.7, which shows the relationship between the discharge head, the capacity, and the net positive suction head (NPSH) for a particular pump at a particular speed. A comparison between the two top curves shows the effect of increasing the impeller diameter and motor horsepower for pumps of identical dimensions and motor speeds. 'lhe NPSH is the pressure head at the pump inlet necessary to prevent cavitation (creation of a partial vacuum in a liquid due to separation of dissolved gases) and vapor binding, and this pressure must. exceed the vapor pressure of the liquid. Cavitation causes severe vibration in the pump and piping and must be eliminated to prevent mechanical damage to the pump; reducing the pumping rate will reduce or eliminate cavitation. More thorough explanations of cavitation and NPSH can be found in the literature.1,5

Special pumps are available to meet the zero-leakage requirements for handling radioactive solutions. The canned-motor pump has found wide use in this field because the motor and impeller are an integral unit contained in a single leakproof housing that has no packing, seals, or troublesome packing glands. The stator and motor are sealed in nonmagnetic, corrosion-resistant alloy cans which isolate them from the pumped solution, a portion of which is rectrculated Lhruugh the motor section to cool the motor and lubricate the bearings. The rulur and impeller assembly is driven by the rotating magnetic field of the induction-type stator. Figure 7.11 .8 is a cross-sectional view of this type of pump. 7

If a properly installed pump fails to function as it should, it may be vapor-locked because of an insutticient NYSH. The suction Inlet of a centrifugal pump must be flooded before pumping will start; flooding is done by opening the suction valve and venting the pump casing. Sometimes excessive amounts of air mixed with the solution will become trapped in the cavities of the casing and must be vented out the top of the casing before pumping action will resume. If fluid hammer occurs when the pump is started, the manufacturer's operating manual should be consulted for the recommended procedure to eliminate this condition. 


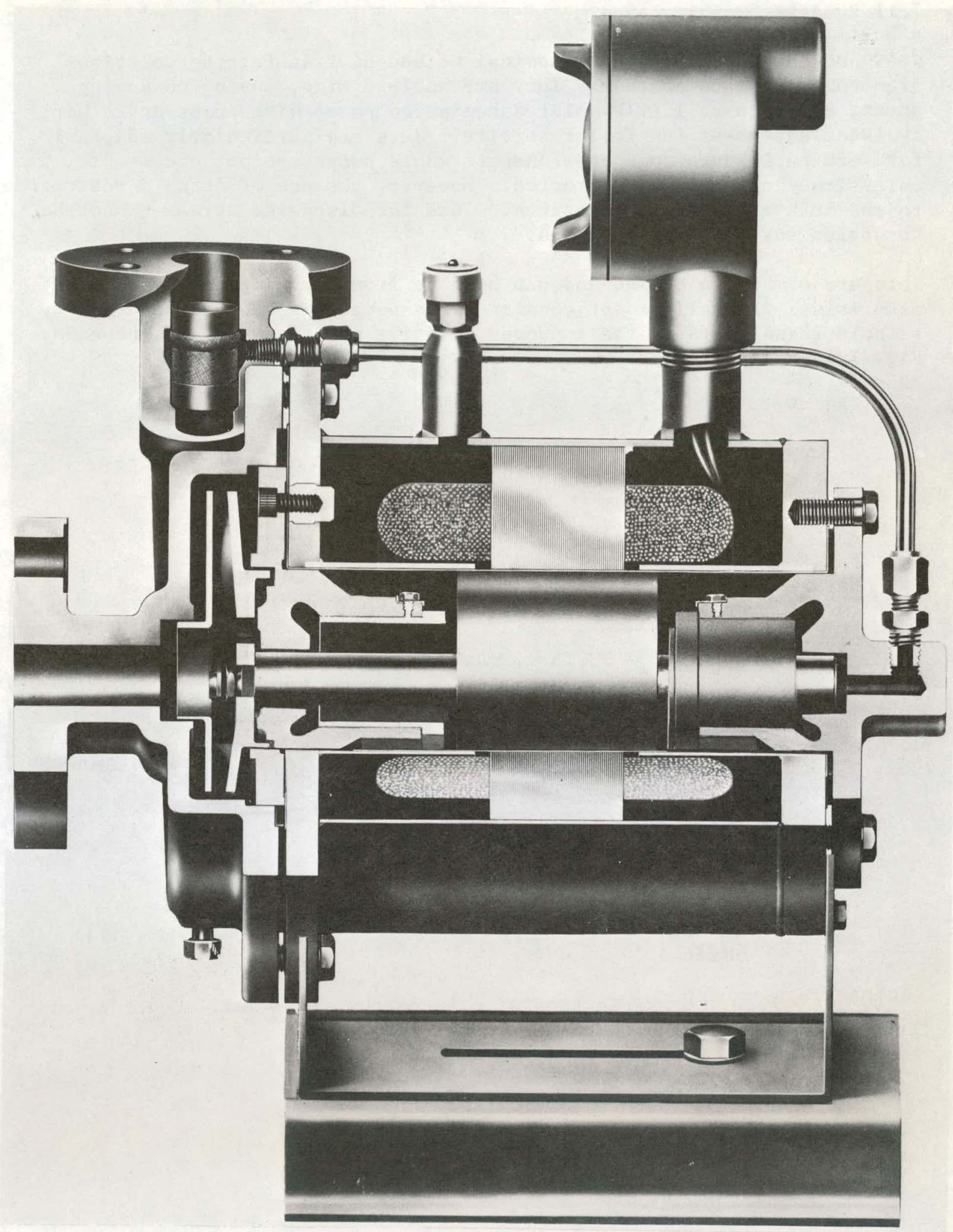

Fig. 7.11.8. Cutaway View of a Canned-Motor Centrifugal Pump 


\subsection{1 .2 Jets}

Jets provide a simple and economical method of transferring solutions from one vessel to another. They are self-priming, having no moving parts, and require little maintenance as compared with pumps and other types of equipment in similar service. Jets are particularly adaptable for service in hazardous environments where pumps are not acceptable unless they are explosion-proofed. However, the use of jets is restricted to the bulk transfer of solutions, since the discharge stream cannot be throttled for metering purposes.

Jets are simple in design and can be made from many corrosion-resistant materials. Basically a jet consists of a nozzle, a venturi, and a body to hold these parts in their proper relative positions, as is shown in Fig. $7.11 .9 .^{8}$

ORNL Dwg 74-7496

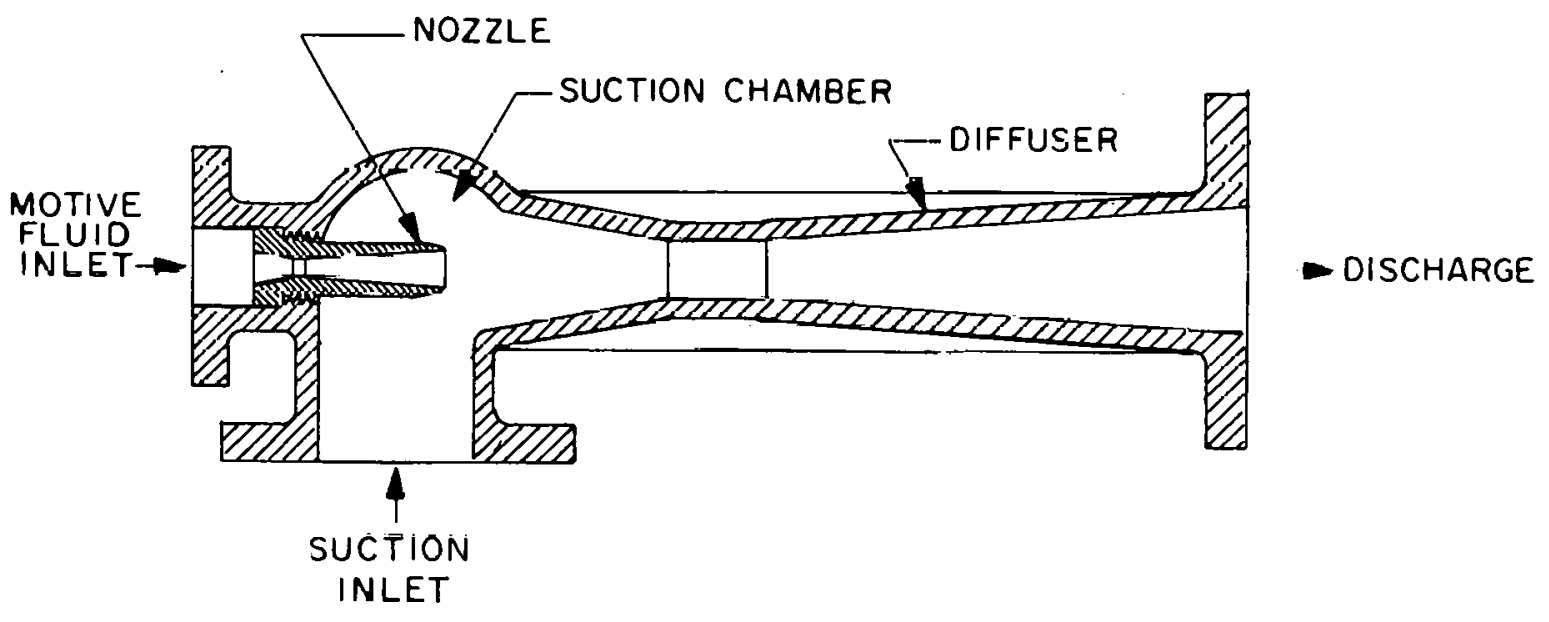

Fig. 7.11.9. Cross Section of a Penberthy Steam Jet. Courtesy of the Penberthy Division, Houdaille Industries, Inc. 
Motive power for the jet is provided by a high-pressure fluid directed through the nozzle (a converging-type nozzle for liquid-actuated jets or an expanding-type for gas-actuated jets). The motive fluid, discharged from the nozzle at high velocity, creates a vacuum in the suction chamber; the liquid to be moved is drawn up, entrained by the motive fluid, and discharged into a piping system against a back pressure that must be lower than the inlet pressure of the motive fluid. Water is used where mixing and dilution are acceptable; steam, which is the most commonly used motive force, is used where minimum dilution is desirable and a rise in temperature can be tolerated. Air is used in applications where the volume of the solution to be moved is small, such as aliquot (proportional) sampling of vessels and of flowing process streams, or where dilution or contamination cannot be tolerated. However, air can be used only if the back pressure on the discharge of the jet is very low.

Jets have very low efficiency, and their performance depends on installation details, type of solution being pumped, and the motive fluid. An adequate motive fluid supply and pressure are essential to the efficiency; so are proper details of installation. Each jet is designed to operate at a specific pressure range for a particular service; leading jet manufacturers recommend a 55- to 60-psig steam pressure for the most efficient jet performance at or near norwal atmospheric conditions. Important installation details are to have no turns or fittings within a distance of ten pipe dlameters from the jet discharge and to keep friction losses in the discharge piping at a minimum to avoid excessive back pressure. Some typical performance data supplied by a jet manufacturer ${ }^{9}$ are shown in Table 7.11.1.

A properly installed jet is relatively trouble-free and simple to operate. The following is a normal operating procedure for jetting solution from one vessel to another, using steam as the motive fluid:

1. Open the valves, if any, in the suction and discharge lines.

2. Make sure that the vessel to receive the liquid has the capacity to hold it plus the added steam condensate.

3. Open the steam supply valve.

4. Observe the liquid level and density recorders in the two vessels to assure that the transfer is taking place.

5. When the transfer is complete, close the steam supply valve and vent the uptake line between the jet and the vessel according to the operating procedures outlined for that particular job.

The condensed steam will add to the volume of the solution jetted, and this volume will vary with the vapor pressure of the solution and the efficiency of the jet, but normally $1 t$ will be about 3 to 5 vol. \%. 
Table 7.11.1. Performance Data for a 1-1/2-inch Schutte and Koerting Steam Jet

(Courtesy of the Schutte and Koerting Company)

\begin{tabular}{|c|c|c|c|c|c|c|c|c|c|c|c|c|c|c|c|c|c|}
\hline \multirow{5}{*}{$\begin{array}{c}\text { Suetion } \\
\text { LIf } \\
\text { In } \\
\text { Reof }\end{array}$} & \multirow{5}{*}{$\begin{array}{c}\text { Suction } \\
\text { Tomp. } \\
\text { : F. F. }\end{array}$} & \multirow{2}{*}{\multicolumn{16}{|c|}{ 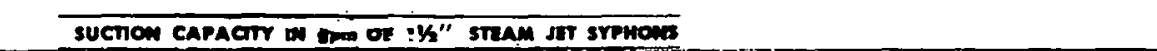 }} \\
\hline & & & & & & & & & & & & & & & & & \\
\hline & & \multicolumn{8}{|c|}{ O A. Dischierge Moed } & \multicolumn{8}{|c|}{$20 \mathrm{Fi}$. Olscheres Mood } \\
\hline & & & & & & & opt & $\sqrt{\pi n}$ & TEM & Kassu: & 0 & uol & & & & & \\
\hline & & 40 & 50 & $\infty$ & $\infty$ & 100 & 120 & 100 & 240 & $\$$ & 50 & $\infty$ & $\infty$ & 100 & 120 & 160 & 240 \\
\hline \multirow{6}{*}{1} & 70 & $\mathbf{5 2}$ & 51 & 51 & 49 & 46 & 4 & 37 & 20 & 26 & 47 & 4 & 40 & 45 & 41 & 25 & 9 \\
\hline & 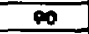 & 48 & 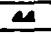 & 49 & 4 & 40 & 27 & $\mathbf{m}$ & 26 & 27 & 44 & 42 & 42 & 41 & 31 & 33 & 26 \\
\hline & 110 & 40 & 18 & 26 & 26 & 35 & 32 & 20 & 2 & 30 & $\pi$ & 37 & 37 & 36 & 34 & 50 & 23 \\
\hline & 120 & 35 & 32 & $\infty$ & 20 & 29 & 9 & 25 & & 29 & 9 & 21 & 21 & $\infty$ & 29 & 25 & \\
\hline & 150 & 26 & 25 & 24 & 24 & 24 & 24 & 21 & & 26 & 25 & 24 & 24 & 29 & 22 & 20 & \\
\hline & 165 & 17 & 17 & 17 & 18 & 10 & 17 & 17 & & 17 & 17 & IT & 17 & ir & 17 & 16 & \\
\hline \multirow{5}{*}{10} & 70 & 18 & In & 97 & 23 & $\infty$ & 29 & 25 & 50 & 27 & 26 & 37 & 23 & 31 & 29 & 25 & 19 \\
\hline & 90 & 24 & 34 & 29 & 20 & 27 & 23 & 21 & 17 & 26 & 32 & 32 & 29 & 26 & 23 & 20 & 17 \\
\hline & 110 & 20 & 25 & 20 & 23 & 20 & 21 & 10 & & 28 & 27 & 87 & 98 & 23 & 21 & 10 & \\
\hline & $130^{\circ}$ & 21 & 21 & 21 & 20 & 10 & 16 & 14 & & 21 & 22 & 22 & 21 & $i 0$ & 10 & 14 & \\
\hline & 145 & 16 & 16 & 16 & 16 & 14 & 12 & & & 10 & 16 & 16 & 16 & 14 & 12 & & \\
\hline \multirow{5}{*}{15} & 70 & 34 & 32 & $\infty 0$ & 26 & 23 & 21 & 10 & 14 & 24 & 23 & 32 & 27 & 24 & 23 & 19 & 15 \\
\hline & 90 & 20 & 28 & 26 & 23 & 20 & 10 & 16 & 12 & 23 & 20 & 27 & 23 & 20 & 19 & 16 & 12 \\
\hline & 110 & 24 & 22 & 12 & 19 & 17 & 15 & 13 & & 23 & 20 & 22 & 19 & 17 & 13 & 12 & \\
\hline & 130 & 17 & 17 & 17 & 15 & 13 & 11 & & & 17 & 17 & 17 & 14 & 13 & & & \\
\hline & 145 & 10 & 12 & 11 & 9 & & & & & 11 & 11 & 10 & 10 & & & & \\
\hline \multirow{4}{*}{20} & 70 & 26 & 23 & 21 & 10 & 16 & 15 & 13 & & 24 & 24 & 22 & 10 & 17 & 13 & 12 & \\
\hline & .90 & 22 & 19 & 17 & 13 & 14 & 12 & 11 & & 19 & 20 & 10 & 13 & 14 & 12 & 11 & \\
\hline & 110 & 18 & 16 & 14 & 12 & 11 & 10 & & & 17 & 16 & 14 & 12 & 11 & & & \\
\hline & 125 & 13 & 12 & 11 & & & & & & 12 & 11 & 10 & & & & & \\
\hline & & \multicolumn{8}{|c|}{ 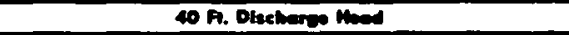 } & \multicolumn{8}{|c|}{ so F. Dheharere Mead } \\
\hline \multirow{7}{*}{1} & & 40 & 50 & $\infty$ & $\infty$ & 100 & 120 & 100 & 240 & $\$ 0$ & 50 & 60 & $\boldsymbol{\infty}$ & 100 & 120 & 100 & 240 \\
\hline & 70 & & 20 & 32 & 9 & 4 & 41 & 26 & $\overline{9}$ & & & II & 4 & 44 & 41 & 26 & 20 \\
\hline & 90 & & 18 & 26 & 4 & 42 & $m$ & 24 & 27 & & & 21 & 42 & 42 & 29 & 24 & 27 \\
\hline & 110 & & 20 & 36 & 27 & 27 & 29 & 20 & 24 & & & 24 & 37 & 26 & 34 & 20 & 24 \\
\hline & 100 & & 22 & 31 & 21 & $\infty$ & $x$ & 28 & & & & 26 & 20 & 20 & 21 & 23 & \\
\hline & 130 & & 34 & 24 & 24 & 29 & 29 & 20 & & & & 24 & 24 & 24 & 24 & 20 & \\
\hline & 105 & & 17 & 18 & 18 & 10 & 10 & 16 & & & & 18 & 18 & 18 & 10 & 16 & \\
\hline \multirow{5}{*}{10} & 70 & & & 24 & 34 & $\infty$ & 27 & 24 & 10 & & & & 38 & 50 & 28 & 23 & 18 \\
\hline & 90 & & & 26 & 29 & 20 & 24 & 20 & 17 & & & & 29 & 27 & 24 & 21 & 17 \\
\hline & 110 & & & 27 & 36 & 20 & 20 & 10 & & & & & 23 & 20 & 20 & 10 & \\
\hline & 130 & & & 22 & 21 & 10 & 16 & 14 & & & & & 21 & 19 & 17 & 14 & \\
\hline & 145 & & & 16 & 16 & 14 & 12 & & & & & & 16 & 14 & 13 & & \\
\hline \multirow{5}{*}{15} & 70 & & & 98 & 30 & 24 & 22 & 19 & 19 & & & & 27 & 24 & 21 & 18 & 14 \\
\hline & 8 & & & 20 & 24 & 20 & 10 & 16 & & & $E$ & & 24 & 21 & 18 & 16 & \\
\hline & 110 & & & 21 & 19 & 17 & 18 & & & & & & 19 & 17 & 13 & & \\
\hline & 120 & & & 17 & 14 & 12 & & & & & & & 14 & & & & \\
\hline & 145 & & & 11 & & & & & & & & & & & & & \\
\hline \multirow{3}{*}{20} & 70 & & & 21 & 19 & 16 & 15 & 12 & & & & & & 16 & 13 & & \\
\hline & $\%$ & & & 10 & 10 & 11 & 13 & 11 & & & & & & $19^{4}$ & II9 & & \\
\hline & 110 & & & & 11 & 10 & & & & & & & & & & & \\
\hline
\end{tabular}


Should a jet fail to function properly, there are a number of variables affecting the jet's operation. Some of these are as follows:

1. Steam pressure - An adequate steam pressure is necessary for proper operation of the jet. Should the pressure fall below the minimum recommended by the manufacturer, the vacuum developed will be insufficient to lift the solution in the suction line into the mixing chamber. If the pressure is higher than the designed maximum, the jet will operate satisfactorily with only a slight loss in rated capacity; however, the increased steam consumption dilutes the solution and raises its temperature.

2. Back pressure - A jet should not be discharged against a pressure exceeding its design value. Standard single-stage jets operating at normal atmospheric conditions are designed to operate against a back pressure of 1 psig or less. In nuclear plants handling radioactive solutions, this is seldom a factor because most vessels are under a slight vacuum or at atmospheric pressure.

3. Solution temperature - The capacity of a jet decreases with a rise in the solution temperature. For water the rate approaches zero near $160^{\circ} \mathrm{F}$. When the solution temperature is near the boiling point, the vacuum developed by the jet reduces the pressure in the suction line, causing the solution to boil.

4. Plugged lines - Sometimes bits of scale and foreign matter from the steam supply header will lodge in the throat of the jet or clog the strainer (if the steam supply line to the jet is equipped with one). Precipitated solids and crystal formation may plug the jet suction line in evaporators, dissolvers, and other vessels that undergo heating and cooling cycles. Usually water flushed down the suction line through the steam supply line is sufficient to dissolve or dislodge the plug. A plugged discharge line will force the steam down the suction line into the vessel; this is indicated by a rise in the solution temperature and a slight increase in the liquid level as the steam condenses. After the plug is removed, the jet must be allowed to cool, because an overheated jet will not pump.

\subsubsection{Air Lifts}

Air lifts are used in radiochemical plants to transfer liquids from one vessel to another whenever low flow rates are acceptable, especially where dilution or heating caused by steam jets is undesirable. Because they have no moving parts, air lifts are particularly suited for remote service in shielded cells. 
The air lift is a simple apparatus consisting of a vertical pipe with its lower end submerged in a liquid and a small pipe continuously metering air into it near its bottom. The bubbles of air entering the vertical pipe form a mixture of air and liquid that is lighter than a column of the liquid of the same height. Thus the hydrostatic head at any level in the pipe is less than the hydrostatic head at the same level outside the pipe, and if under the proper conditions the head difference is sufficient to raise the mixture of liquid and air above the top of the pipe, a flow up the pipe will begin and will continue as long as these conditions exist. Figure 7.11.10 illustrates schematically how the air lift operates. ${ }^{5}$

A more advanced explanation of the air lift is beyond the scope and intent of this manual, because it would have to include a rigorous mathematical analysis of the frictional losses in the pipe and the slippage between the air and liquid. However, an empirical formula ${ }^{5}$ that has been developed from practical usage is

$$
\mathrm{V}_{\mathrm{a}}=0.8 \frac{\mathrm{H}_{\mathrm{T}}}{\mathrm{C} \log \left[\left(\mathrm{H}_{\mathrm{S}}+34\right) / 34\right]},
$$

where $V_{a}$ is the volume of free air ( $\mathrm{ft}^{3}$ ) required to lift one gallon of water, $\mathrm{H}_{L}$ is the height ( $\mathrm{ft}$ ) the water is lifted, $\mathrm{H}_{S}$ is the submergence (ft), and $C$ is a constant from the following table:

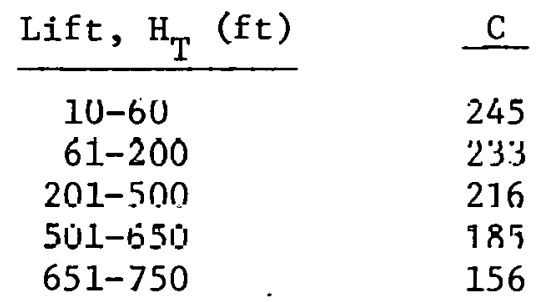

The variables affecting the air lift's performance are lift-pipe diameter, lift-pipe length, submergence, liquid density, liquid temperature, liquid viscosity, and nozzle design. ${ }^{10}$ Hipe diameter, submergence, temperature, and nozzle design are perhaps the major variables.

The type of nozzle through which the air is injected Into the luwer end of the lift pipe affects the air lift's capacity. The velocity and frictional losses of an air bubble rising through a column of liquid are dirertiy proportional to its diameter; hence, the smallest bubbles cause the least air consumption and the highest efficiency for an air lift.

The lift's capacity increases with the pipe diameter. However, too large a pipe lets the air slide by without lifting the liquid, and too small a pipe causes excesslve friction losses. Each set of operating conditions has an optimum pipe diameter. 


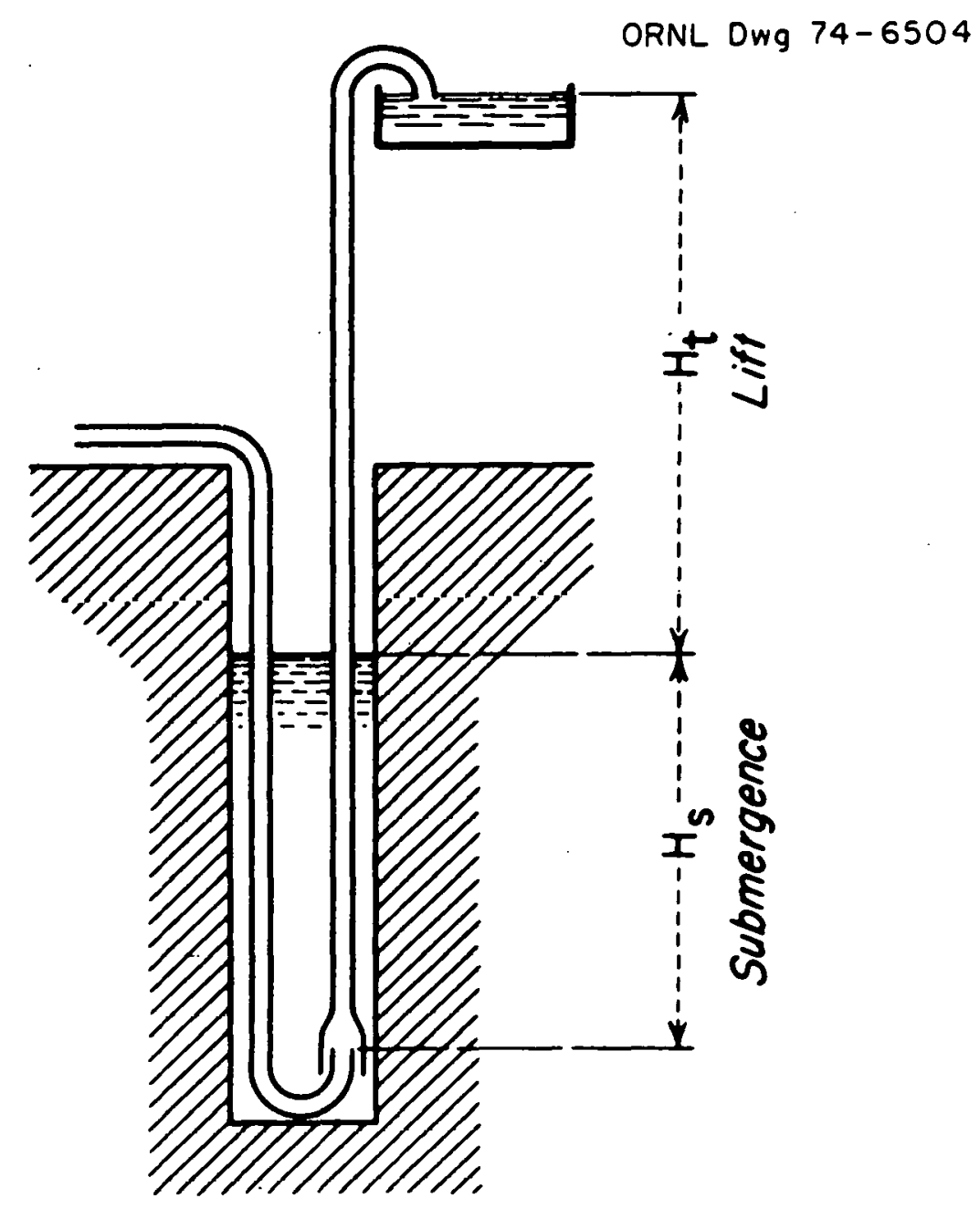

Fig. 7.11.10. Simplified Sketch of an Air Lift, Showing Submergence and Total Head. (From Chemical Engineers' Handbook, Fifth Edition, by Robert H. Perry/Cecil H. Chilton, Copyright 1973, 1963 by McGraw-Hill, Inc., Used by Permission of McGraw-Hill Book Company.) 
The submergence, defined as $\mathrm{H}_{\mathrm{T}} /\left(\mathrm{H}_{\mathrm{S}}+\mathrm{H}_{\mathrm{T}}\right)$, is probably the major variable affecting the lift's capacity, which varies directly with this submergence. The designed submergence should vary from 0.66 for a $20-\mathrm{ft}$ lift to 0.41 for a 500-ft lift. 11 An air lift should have a submergence greater than $35 \%$ to avoid excessive surging, cycling, and vibration; submergences greater than $65 \%$ are acceptable, but the amount of pipe required becomes excessive for the small net lift obtained. The effect of submergence on a l-in. pipe lifting water $40 \mathrm{ft}$ is shown ${ }^{11}$ in Fig. 7.11 .11 .

The air lift's capacity increases with temperature, provided the air rate for the maximum liquid flow is not exceeded; otherwise, the capacity decreases. If air is used as the motive gas, the pumped liquid must not be too near the boiling temperature, or steam will form in the pipe as a result of the decrease in pressure with helght, and an uncontrollable pumping rate will result. ${ }^{11}$

Air lifts have no moving parts and are ideal for remote installations because of their relatively maintenance-free construction. Should the lift fail to function properly, some factors to check are the following:

1. Air pressure - The pressure required is slightly greater than the pressure exerted at the air inlet by the free-standing liquid in the vertical pipe.

2. Submergence - The submergence decreases as the level in the supply vessel or well is lowered, reducing the pumping rate.

3. Air flow rate - In starting up, a blowback of air downward from the air inlet and out the bottom of the pipe might occur if the air is turned on suddenly.

4. Air humidity - If the air is too dry when concentrated solutions, are being pumped, the forming of crystals at the air inlet may restrict or stop the air flow completely. 
ORNL-LR-DWG. 15901

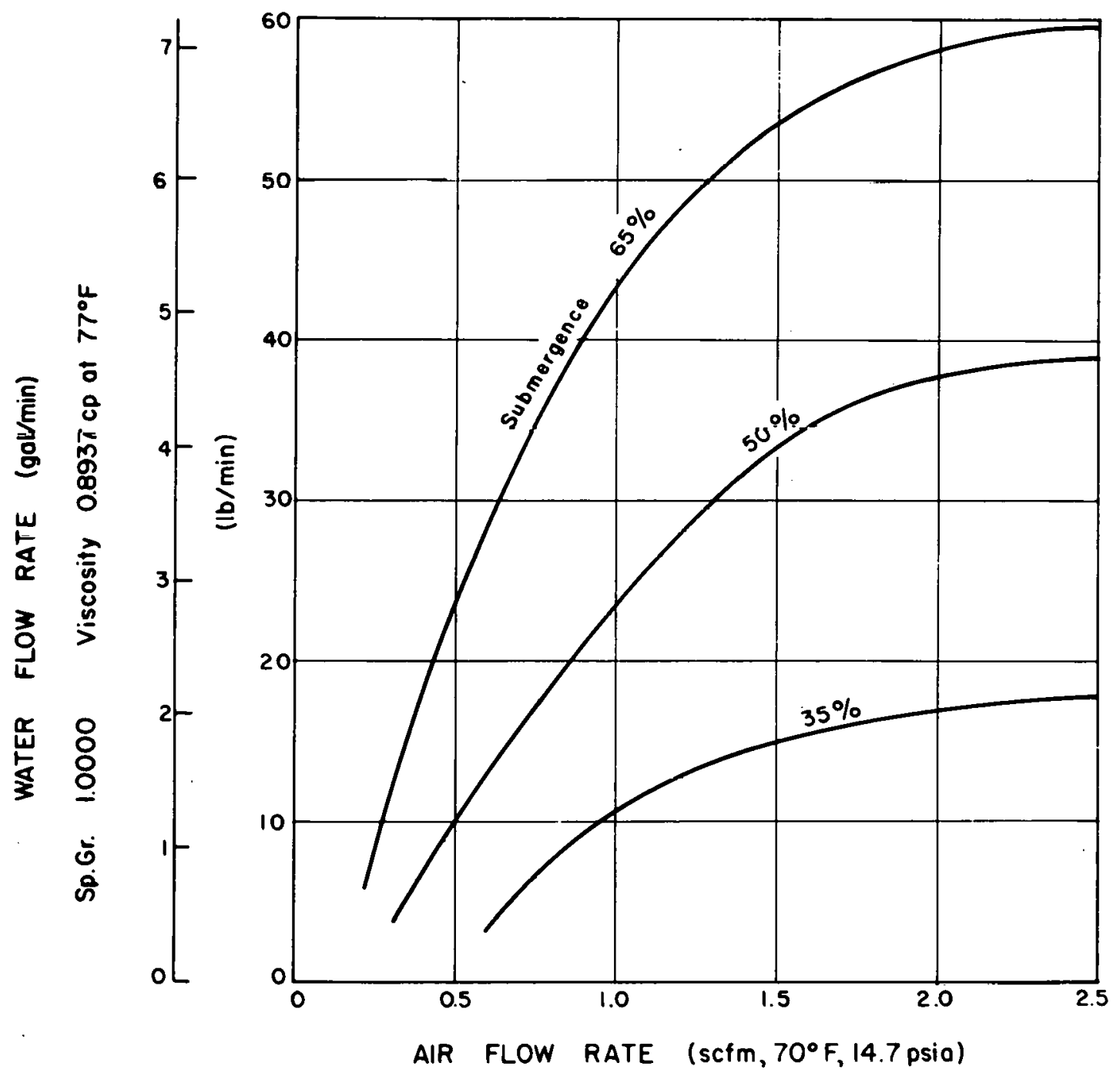

Fig. 7.11.11. Air Flow Rate vs. Water Flow Rate for a 1-in. Diam. Column Air Lift 
1. A. S. Foust et al, Principles of Unit Operations, John Wiley and Sons, Inc., 1964.

2. Literature Courtesy of Milton Roy Co., Philadelphia, Pa., Technical Paper Nu. 57.

3. Literature Courtesy of Milton Roy Co., Philadelphia, Pa., Bulletin No. 35.001 .

4. G. G. Brown and Associates, Unit Operations, John Wi.ley and Sons, 1950 .

5. Robert H. Perry and Cecil Ḧ. Chilton, Chemical Engineers' Handbook, 5th ed., McGraw-Hill Book Co., 1973.

6. Literature Courtesy of the Pump Division of Allis Chalmers Corp., Catalog 1959.

7. Literature Courtesy of Chempump Division of the Crane Co., Chempump Bulletins 1010 and 1100-5.

8 Literature Courtesy of the Penberthy Division, Houdaille Industries, Inc., Prophetstown, I11., Penberthy Catalog No. 512A.

9. Literature Courtesy of the Schutte and Koerting Co., Cornwells Heights, Bucks County, Pa., Bulletin 2A.

10. J. T. Long, Engineering for Nuclear Fuel Reprocessing, Gordon and Beach, 1967 .

11. G.W.T. Kearsley, Use of an Air Lift as a Metering Pump for Radioactive Solutions, Report ORNL-2175, 1956, p. 33. 


\subsection{GAS HANDLING EQUIPMENT}

The movement of air and gases within a radiochemical fuel reprocessing plant is achieved primarily with fans, rotary blowers, jets, vacuum pumps, and reciprocating compressors. Fans are used for the bulk movement of air when little or no compressing of the gases is required, as in the regulation of air movement to maintain radioactive areas at a slight negative pressure in relation to the surrounding environment. Rotary blowers, because they deliver a constant volume of air under varying pressure conditions, which a fan. will not do, are used in air monitoring instruments. They are also used to maintain a slight vacuum in laboratory hoods and small storage areas.

Jet ejectors are used for vacuum applications and are more suitable than reciprocating vacuum pumps for maintaining a steady, large-volume vacuum source. Vacuum pumps evacuate process vessels, transfer solutions, and maintain a vacuum supply for laboratory equipment. They are used also where the entrainment of droplets associated with the use of jets is detrimental to ventilation and off-gas systems.

Compressors provide the compressed air required for sampler jets, pneumatic instruments and valves, and laboratory equipment.

\subsubsection{Fans}

Fans are the most common devices for moving large volumes of air at pressures not exceeding 0.5 psig. ${ }^{1}$ They are classified as either radialflow or axial-flow. Radial-flow fans are commonly called centrifugal fans because the air or gases are discharged radially from the fan blades by centrifugal force. In axial-flow fans the air flows parallel to the fan shaft. Figure 7.12.1 shows a centrifugal $\mathrm{fan}^{2}$ and Fig. 7.12.2 an axial fan.

At the ORNL Fuel Reprocessing Pilot Plant, two electrically driven centrifugal fans with backward-curved blades discharge 40,000 cfm to the atmosphere, maintaining a negative pressure of 3 in. of water in the main ventilation duct. A steam-driven tubular-type axial-flow fan, rated at $40,000 \mathrm{cfm}$, functions as a backup unit in the event of an electrical power failure.

Centrifugal Fans - Centrifugal fans are classified according to the shape of the impeller blades: (1) those with straight radial blades, (2) those with the tip of the blades curved forward in the direction of rotation, and (3) those with the tip of the blades curved backward away from the direction of rotation. ${ }^{3}$ These are also characterized as moderate-speed, slow-speed, and high-speed types, respectively, although the speed ranges of the three types may be wide and overlapping. ${ }^{3}$ 
ORNL DWg 74-916,3

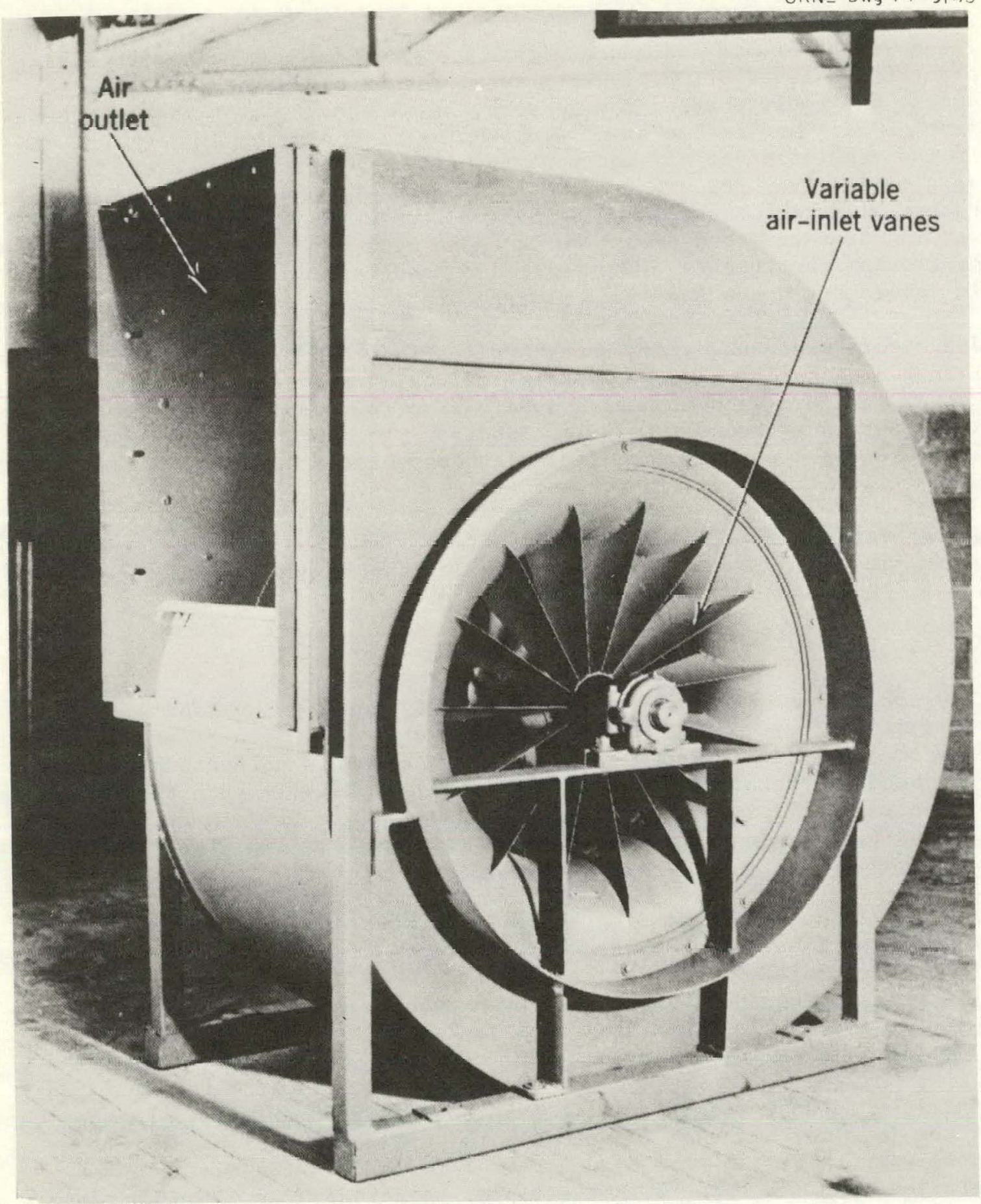

Fig. 7.12.1. Centrifugal fan. (Courtesy Buffalo Forge Co.) 
ORNL Dwg 74-9164

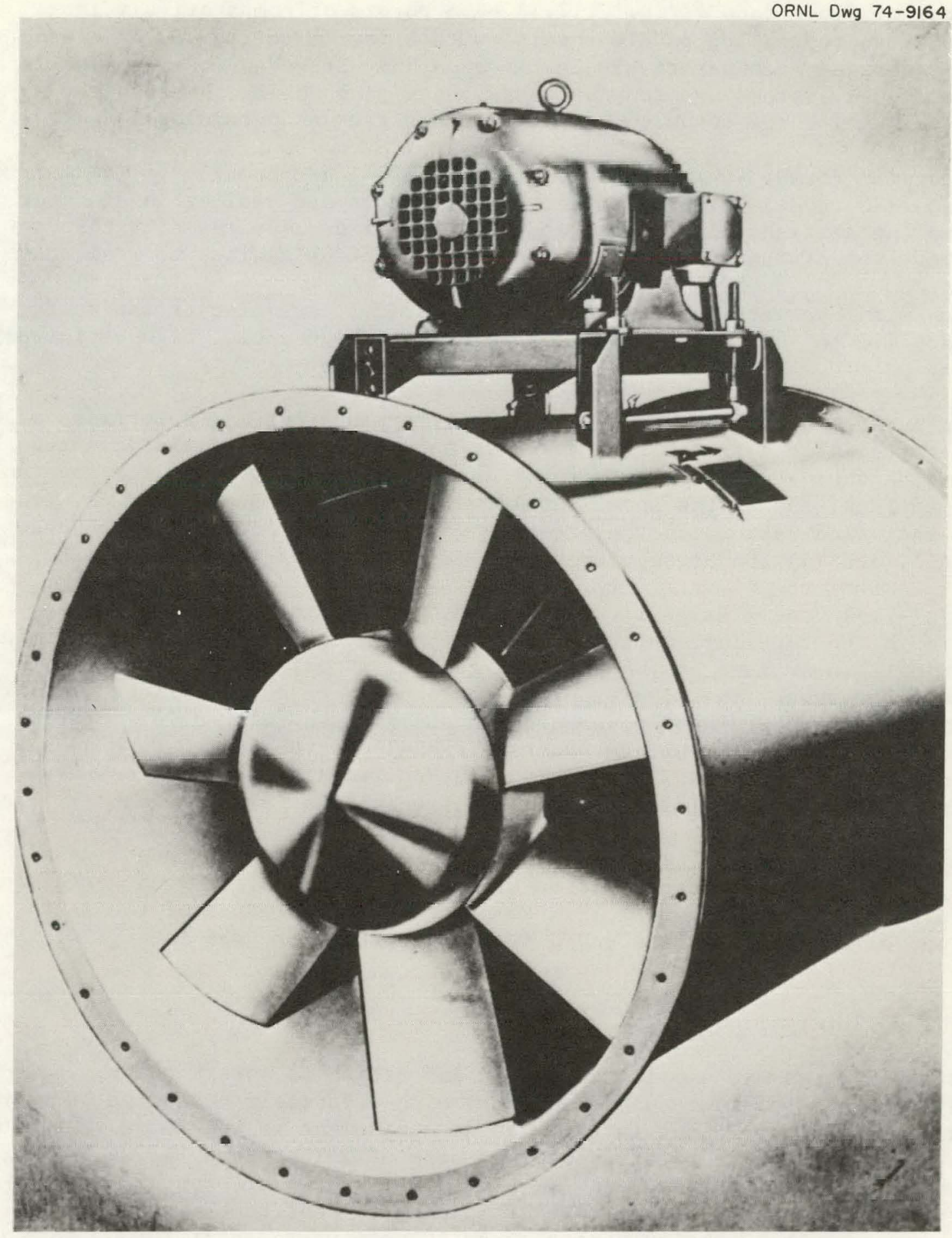

Fig. 7.12.2. Turbine Axial Fan 
Straight-blade fans ${ }^{4}$ (Fig. 7.12.3) have rotors of comparatively large diameter, resembling paddle wheels, with a few (5 to 12 ) radial blades, operating at a comparatively low speed. They are used most frequently in exhaust systems and to move gases containing solids, because the centrifugal force tends to keep the blades free of particles.

Fans with forward-curved blades ${ }^{4}$ (Fig. 7.12.4) are usually of the multiblade (20 to 64) "Sirocco" type. Their rotors are smalier in diameter than the straight-blade fans, and they have a greater capacity than any other type of fan of the same size when operating against no resistance. ${ }^{3}$

Fans with backward-curved blades ${ }^{4}$ (Fig. 7.12.5) are also of the multiblade (10 to 50 ) type. This is a relatively high-speed, high-efficiency fan.

Fan performance is best described by performance curves, sometimes called characteristic curves. Figure 7.12 .6 shows some characteristic curves for the three types of centrifugal lans.? These curves arc for constantspeed fans; and if the speed should vary, (1) the capacity varies directly as the speed ratio, (2) the pressure varies as the square of the speed ratio, and (3) the horsepower varies as the cube of the speed ratio.

Axial-Flow Fans - Axial-flow fans have air or gases flowing axially through the impeller, which revolves within a cylindrical housing or in a ring. These fans are made in two general types, disk-type and propeller-type. The disk-type fans have plain or curved blades similar to those of an ordinary household fan and are generally used in circulation or exhaust work without ducts. Propeller-type fans have blades similar to aeronautical designs and may be two-staged when necessary. Figure 7.12.7 is an illustration of a two-stage axial-flow fan."

Axial-flow fans usually have higher capacities than centrifugal fans and, like them, are dependent on blade configuration for good performance characteristics. Figure 7.12 .8 compares the performance of the three types of centrifugal fans and a two-stage propeller-type fan.

\subsection{2 .2 Rotary Blowers}

Rotary blowers are similar in design and action to rotary pumps. Such units have a constant-volume delivery with a variable discharge pressure range from $0 . b$ to about 15 psig and an equivalent vacuum range when used as exhausters. The rutary blower is morc cfficient than the reciprncating compressor at pressures below 10 psig, but above that pressure the compressor has the advantage. The efficiency is best at 3 or 4 psig pressure or vacuum. The capacity ranges ${ }^{4}$ from $10 \mathrm{scfm}$ up to about $10,000 \mathrm{scfm}$ in standard sizes, while special units have capacities up to 30,000 scfm. The capacity of these blowers can be varied only by changing the speed or by bypassing or wasting some of the blower's capacity. 5 


\section{$7-151$}

ORNL Dwg 74-9165
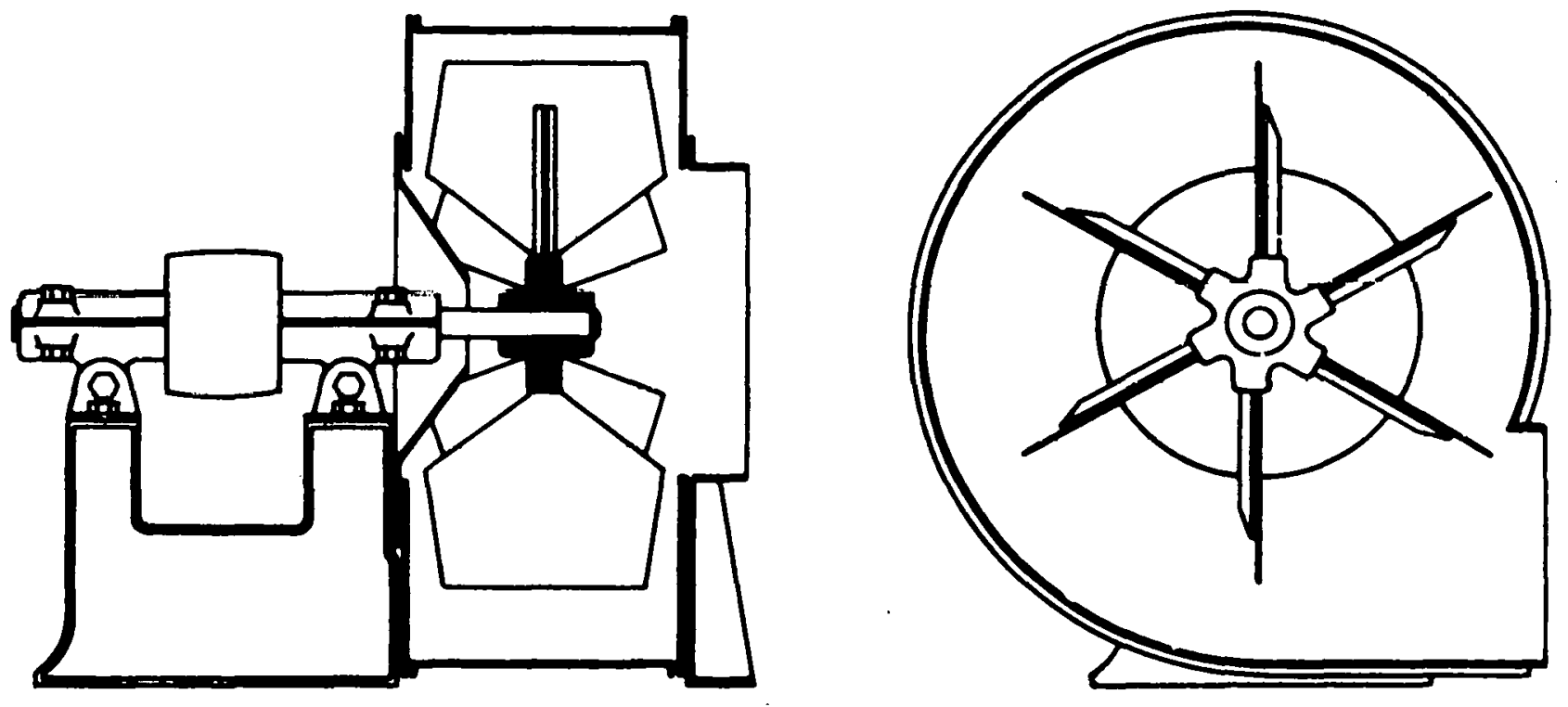

Fig. 7.12.3. Straight-Blade Fan 
ORNL Dwg 74-9166
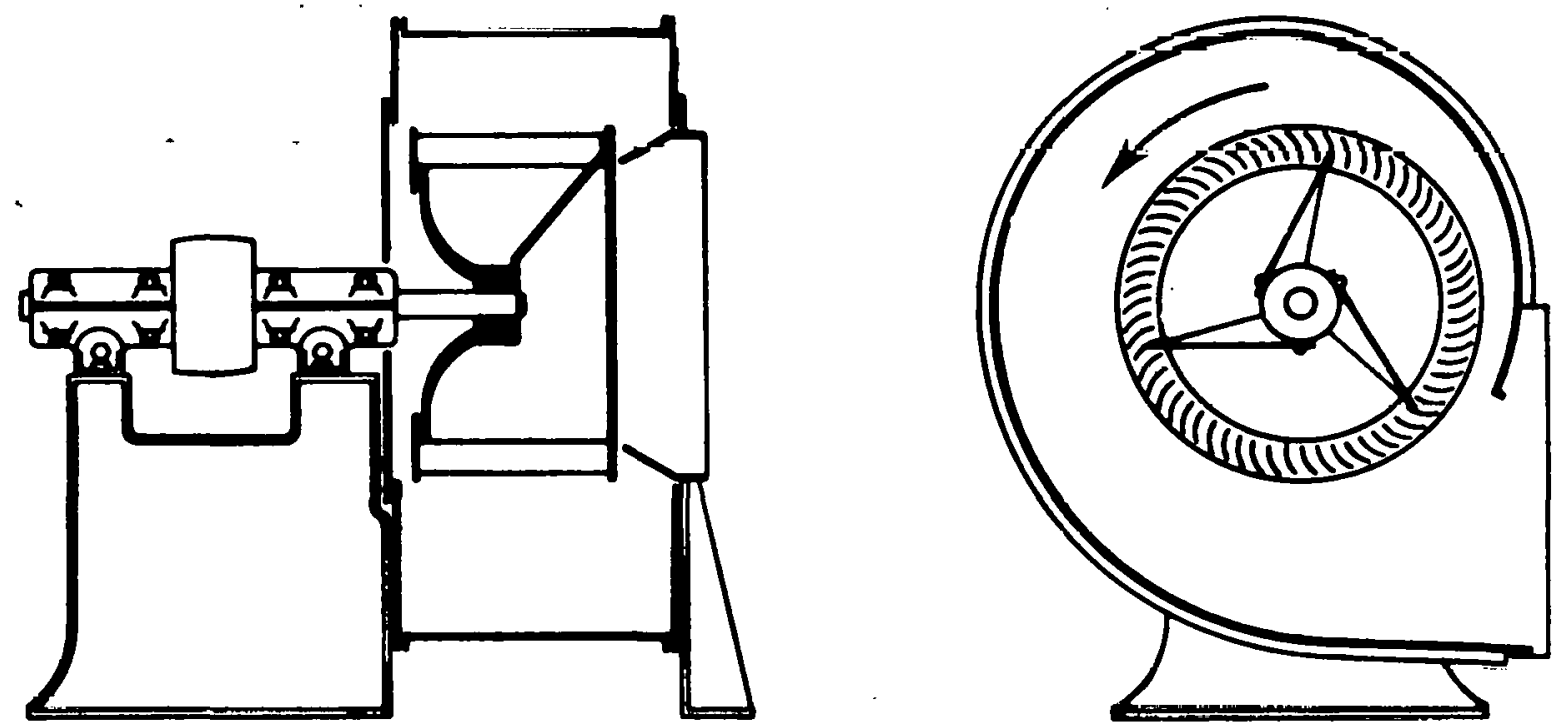

Fig. 7.1.2.4. Forward-Curved-Blade, or "Sirocco"-Type, Fan 
ORNL Dwg 74-9167
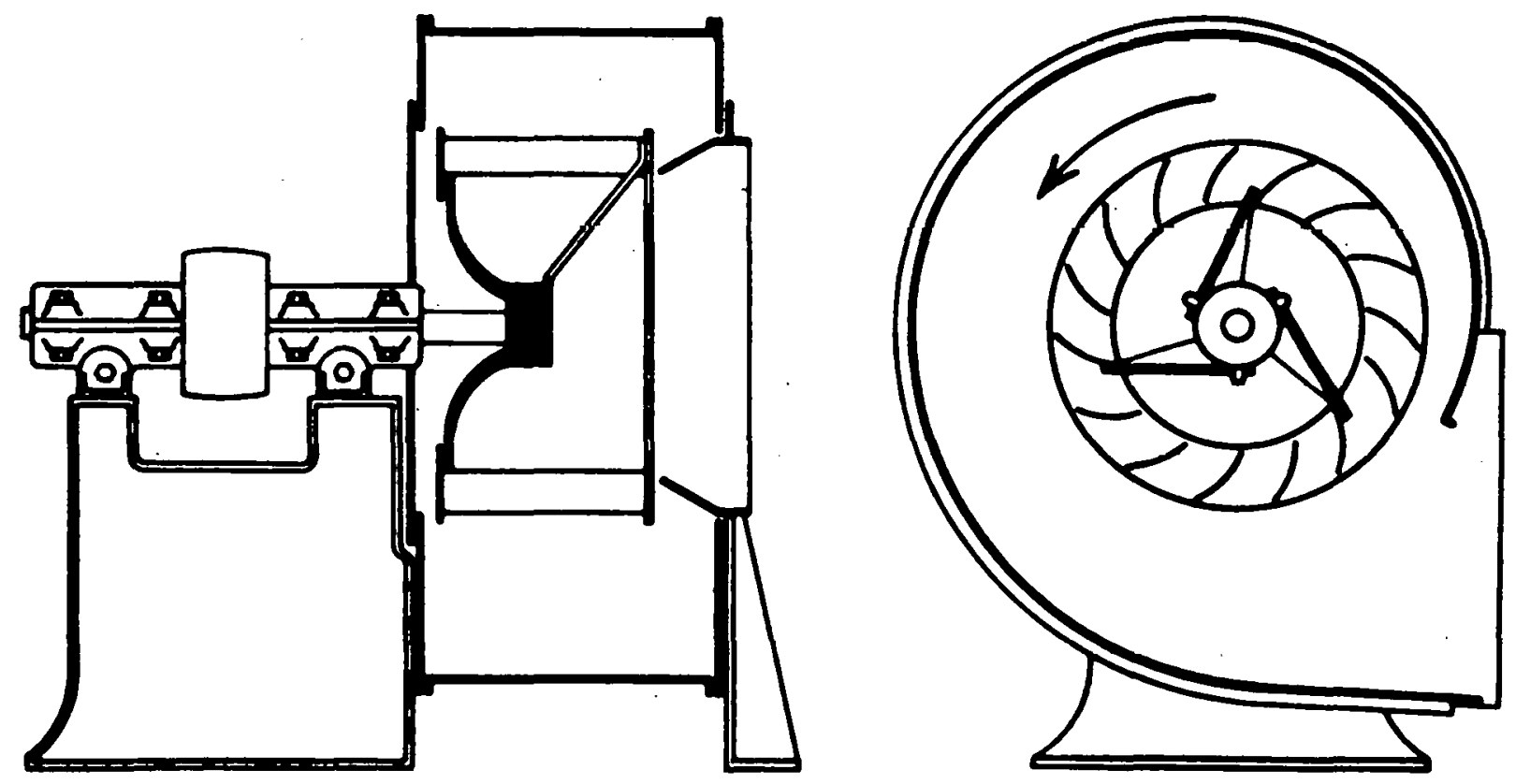

Fig. 7.12.5. Backward-Curved-Blade Fan 
ORNL DWg 74-9168

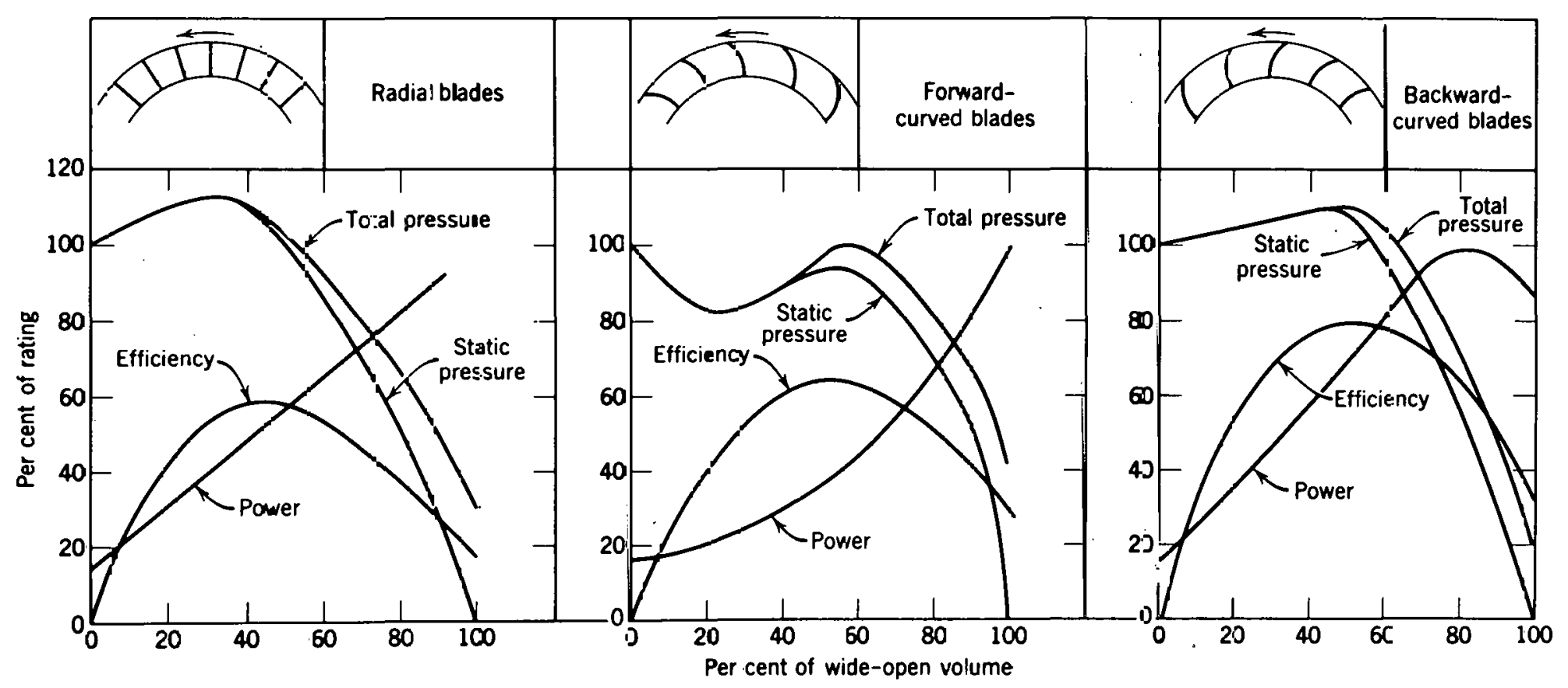

Fig. 7.12.6. Fan-Characteristic Curves 
ORNL Dwg 74-9169

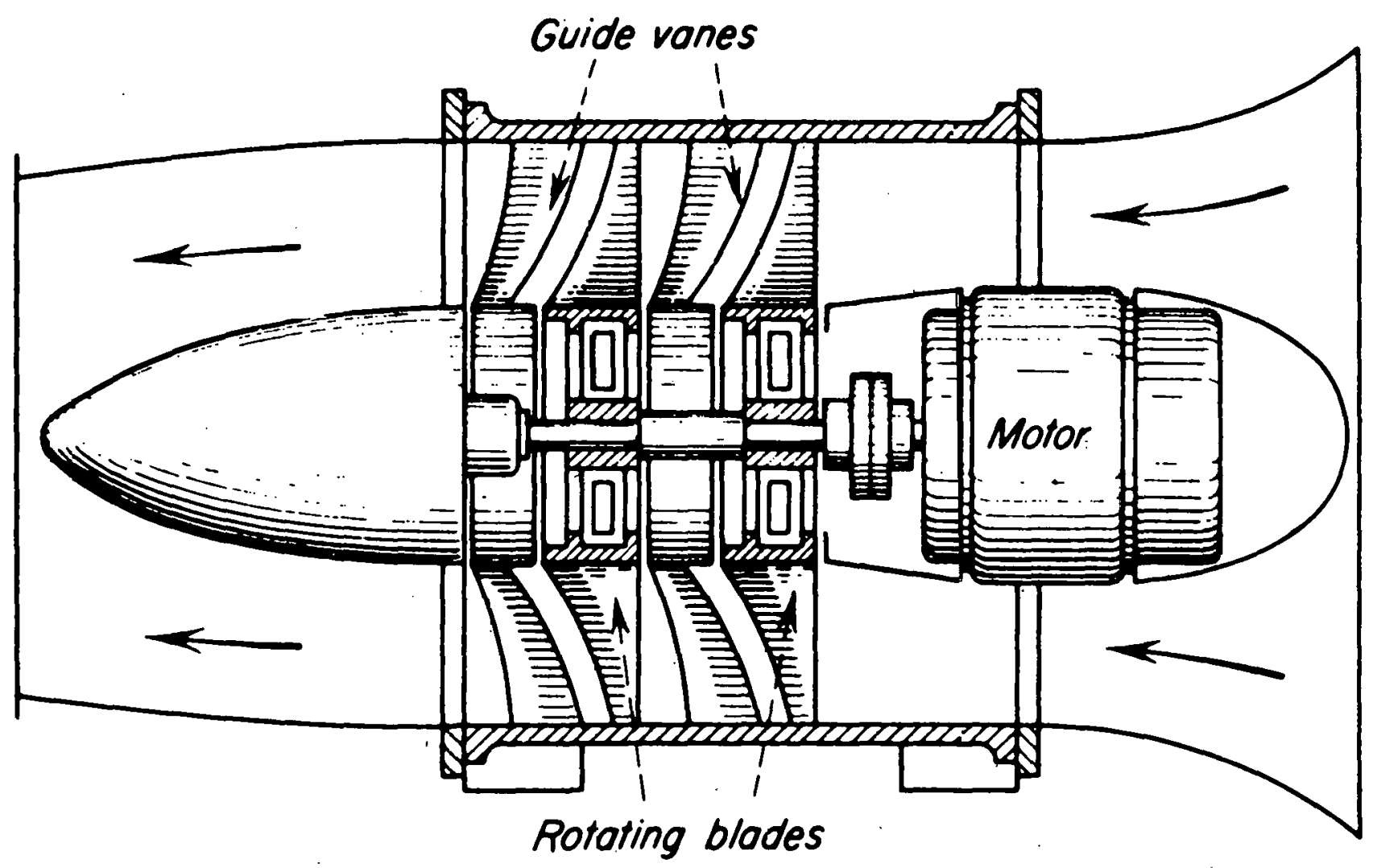

Fig. 7.12.7. A Two-Stage Axial-Flcw Fan 


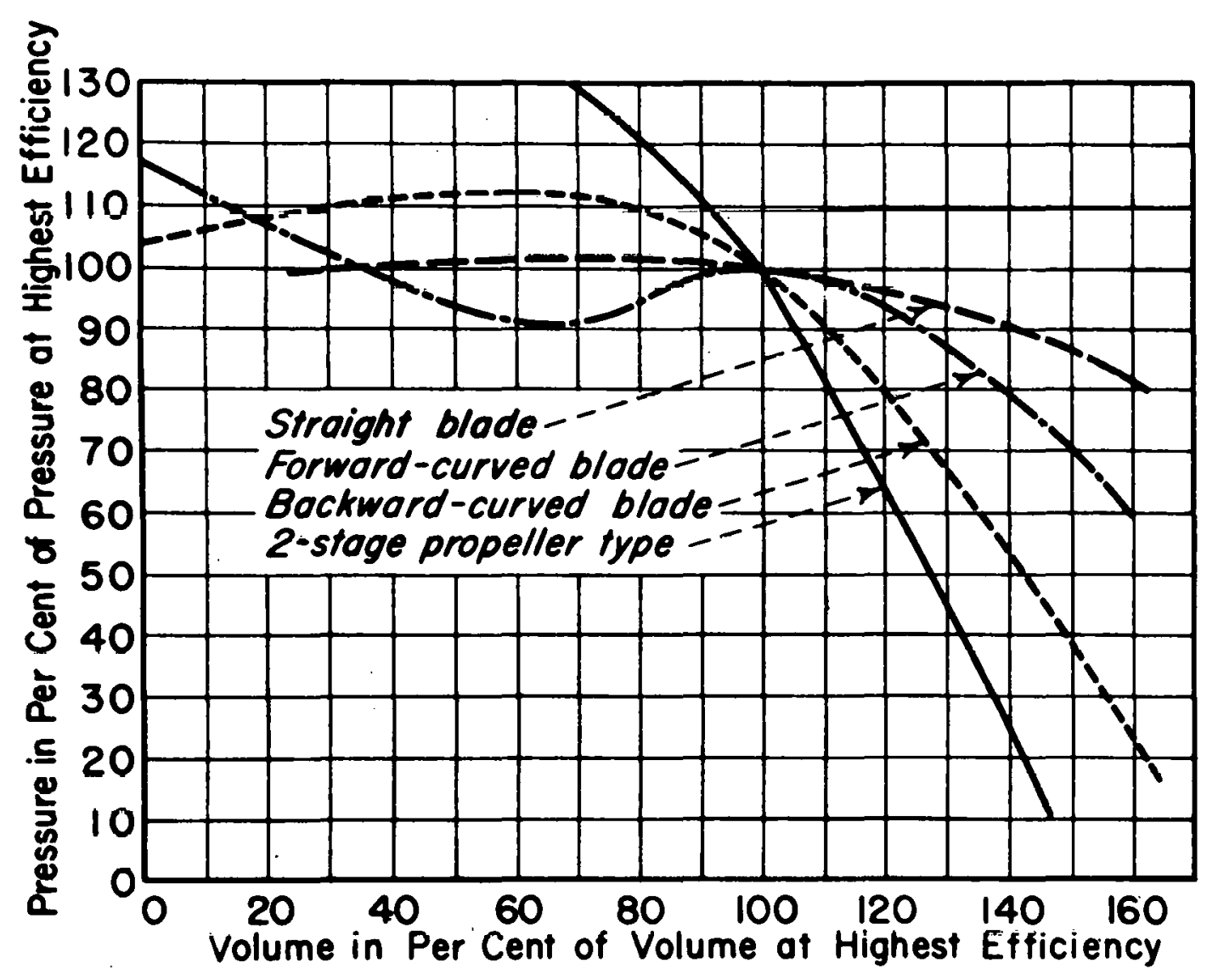

Fig. 7.12.8. Approximate Characteristics of Various Types of Fans 
Rotary blowers are classified as two-impeller type, sliding-vane type, and 1iquid-piston type. ${ }^{4}$

Two-Impeller Blower - This type of blower, illustrated in Fig. 7.12.9, 4 is better known as a lobe or cycloidal blower because of the shape of the impellers. These units have two impellers driven separately through external gearing, making it possible for the impellers to avoid contact with each other and the housing. The clearances are sufficient to reduce friction and wear, yet close enough to maintain minimum leakage from the discharge to the suction side. ${ }^{5}$

Sliding-Vane Blower - This type is illustrated in Fig. 7.12.10.5 The rotating circular disk has vanes sliding in slots that maintain sliding contact on the elliptically shaped housing. The vanes are thrown outward by centrifugal force. The space behind each vane enlarges and draws in the gases, then decreases and forces them out the discharge. The vanes receive nearly all the wear and are easily replaced. ${ }^{6}$

Liquid-Piston Blower - This type is illustrated in Fig. 7.12.11 is known best as a Nash Hytor blower. 5 The cylindrical rotor, with vanes around its periphery, rotates inside the elliptically shaped housing, in which a sufficient amount of water is placed to seal the impeller at its points of least clearance with the housing, which correspond to the minor axis of the ellipse. The rotating impeller also rotates the water, and centrifugal force keeps it against the housing. The liquid alternately advances toward and recedes from the center of the impeller, acting like a series of water pistons. As these recede, they suck air in from the inlet ports, and as they advance, they compress it into the outlet ports. I

The Nash Hytor blower is used as a vacuum pump on wet vacuum service. The two-impeller blower and the sliding-vane type are not satisfactory for handling gases containing dust or other abrasive material because of their close tolerances.

Maintenance and Troubleshooting - Fans and blowers should be inspected routinely whenever possible. Any change in the normal noise level could be indicative of possible trouble, and any necessary corrective action should be taken immediately to prevent serious damage to the equipment. The tension on belts should be checked and readjusted, if necessary. Belts should be inspected for excess wear and cracks, and if any one belt has evidence of wear or cracking, all belts should be replaced as a matter of preventive maintenance. Any particles sticking to the sheaves should be removed with a steel brush, and any foreign matter should be removed from fan blades and rotary impellers to prevent damage and upset of their delicate balance. All bearings and rubbing surfaces should be lubricated in accordance with the manufacturer's instructions. No adjustment should be made to the equipment without first consulting the manufacturer's operating manual. 
ORNL DWg 74-9171

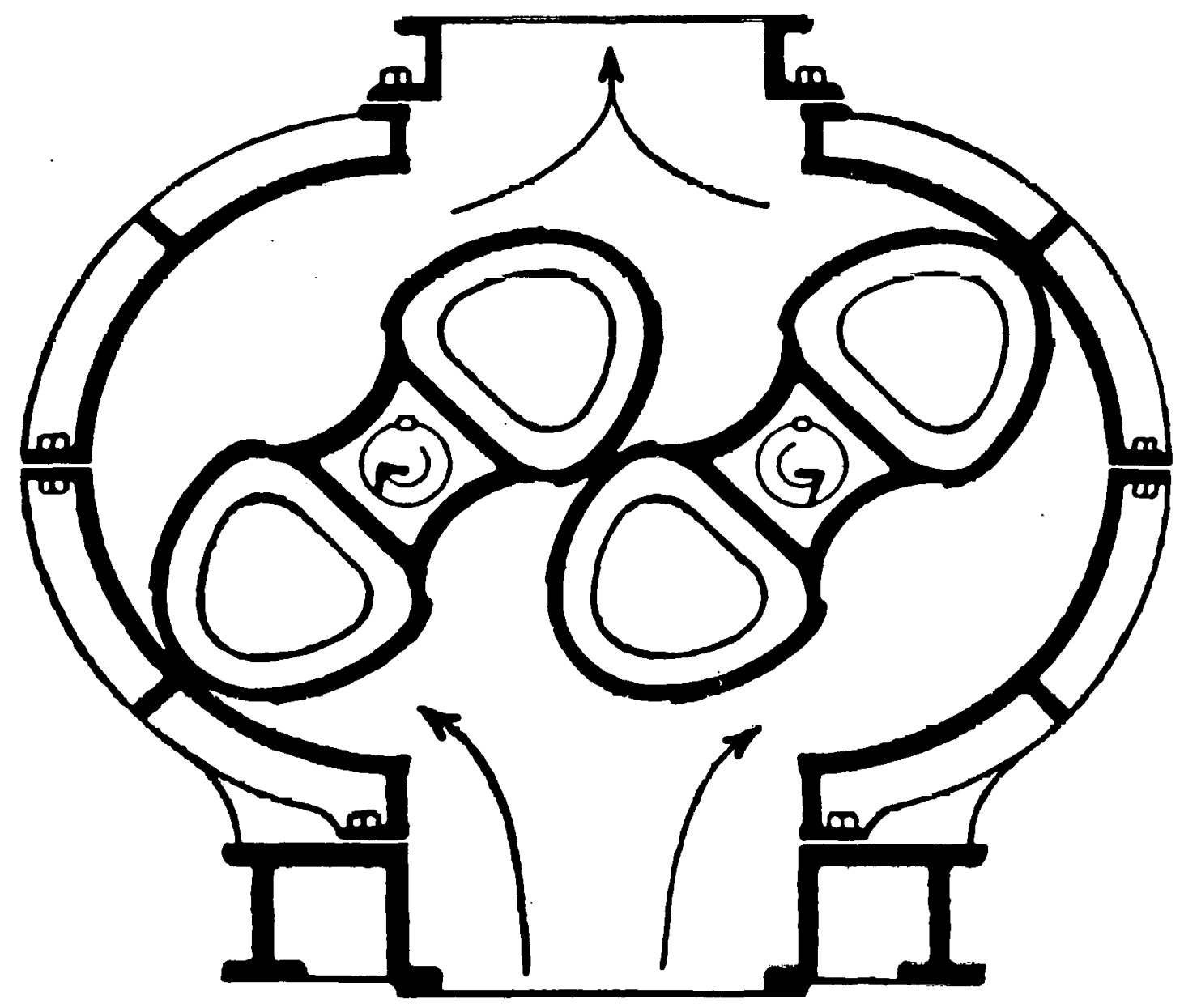

Fig. 7.12.9. Two-Impeller Type of Positive Rotary Blower 
ORNL Dwg 74-9/72

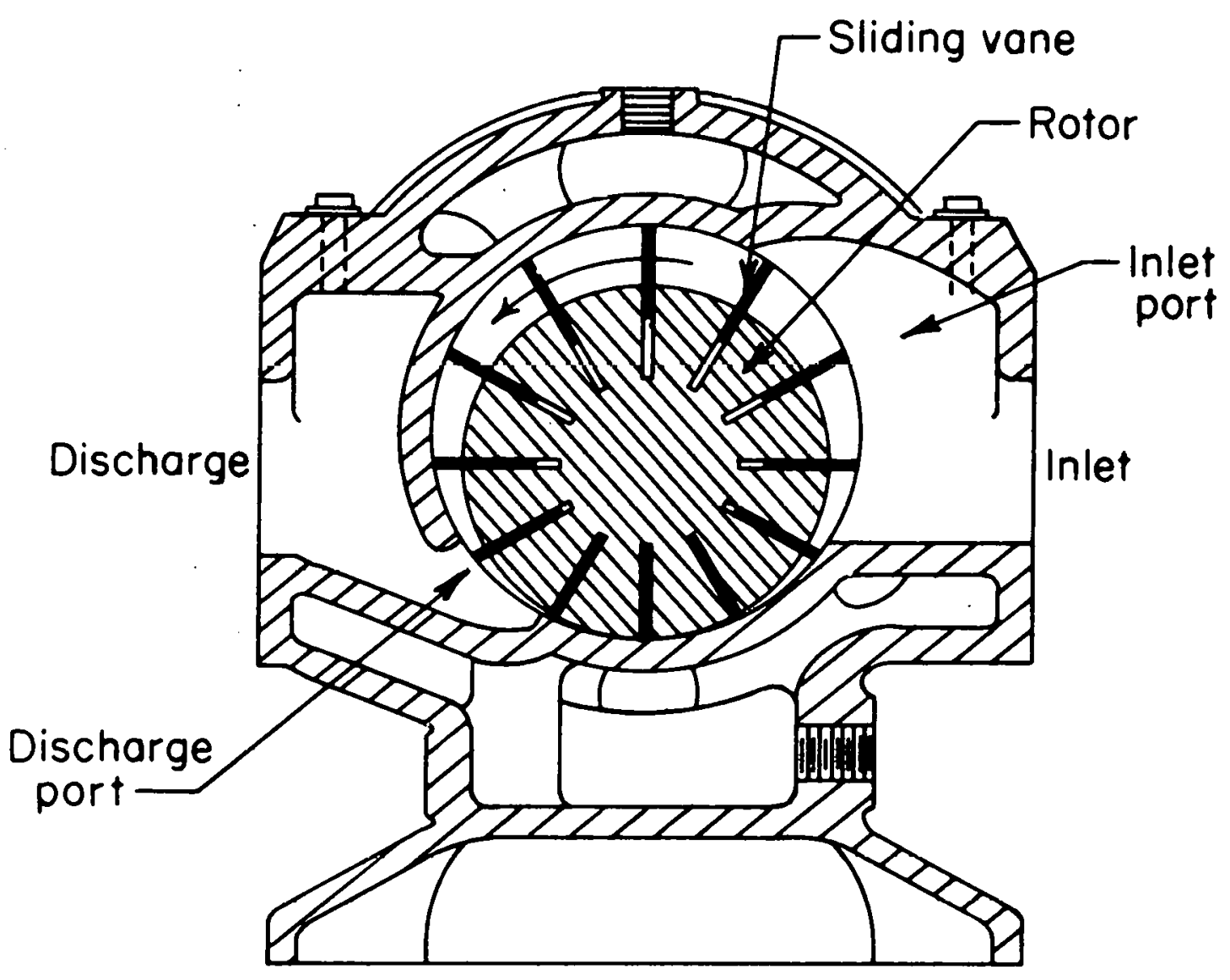

Fig. 7.12.10. Sliding-Vane Type of Rotary Blower 
ORNL DWg 74-9173

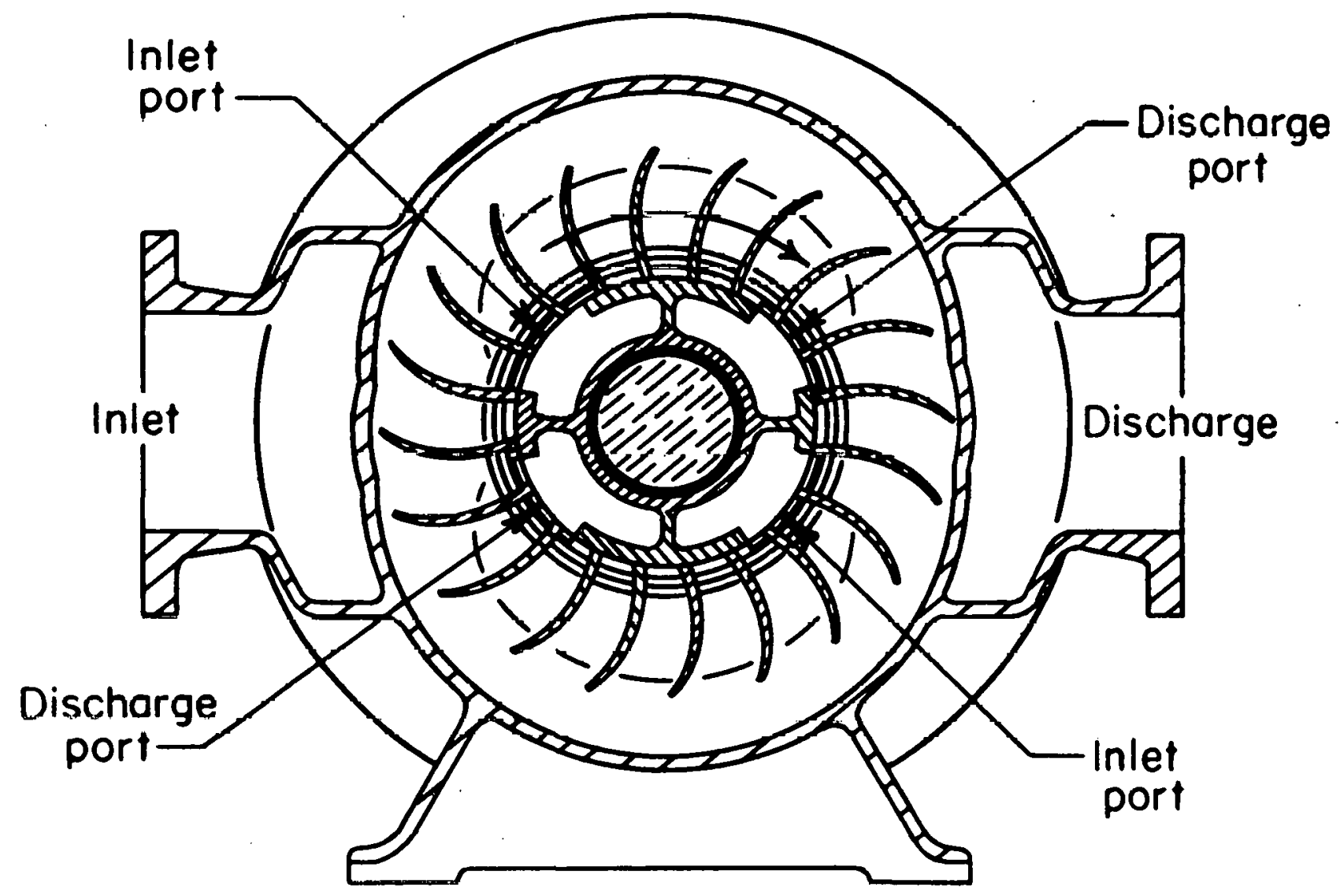

F1g. 7.12.11. Liquid-Piston Type of Rotary Blower 


\subsection{2 .3 Jets}

One of the most convenient devices for moving air and gases in a fuel reprocessing plant is the steam-motivated jet, sometimes called an ejector. Jets are small and inexpensive and have low maintenance costs because of the absence of moving parts. Jet ejectors are most useful in intermittent service, and they are reliable standby units for other types of vacuum systems.

Four different types of jets are used to move air and gases. Jet blowers are used to move large volumes of air against a differential pressure of a few inches of water. Exhausters and compressors are designed to produce moderately high vacuums using steam or compressed air as the motive force. Steam-jet vacuum pumps are designed for vacuums down to 1 micron of mercury absolute pressure. Their basic design and theory of operation are similar to those of the jets discussed in Section 7.11.2, except that air and vapors are entrained instead of a liquid.

Jet Blowers - Blowers are used in ventilation and circulation applications. Jet blowers, using steam or compressed air as the motive force, handle large volumes of air against a differential pressure of a few inches of water. The larger size of the type shown in Fig. 7.12.12 can discharge about $3000 \mathrm{cfm}$ of air against $15 \mathrm{in}$. of water when using 120-psig steam. The same jet can discharge 28,600 cfm against 1 in. of water using 120-psig steam. This type of blower is ideal for removing foul air and toxic or corrosive fumes from vessels and working areas to permit safe entry for inspection and maintenance.

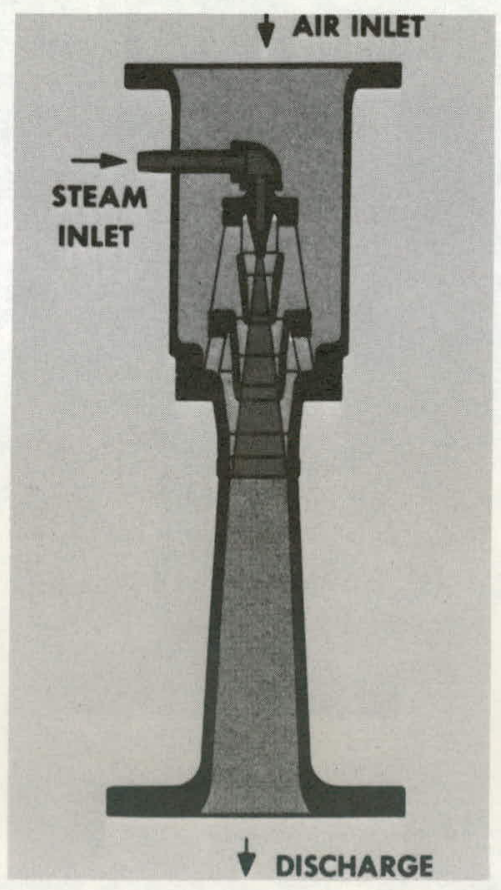

Fig. 7.12.12. Steam-jet Blower. Courtesy of the Schutte and Koerting Company. 
Jet Exhausters - Jets of this type develop a relatively high vacuum using steam or compressed air and have many uses in industrial plants. The exhauster (Fig. 7.12.13) ${ }^{8}$ is basically the same as other jets except that it has a spindle for regulating the steam flow into the nozzle, permitting the jet to function over a wide range of steam pressures. Using 100-psig steam, the larger-sized jet is capable of delivering approximately 1300 scfm against a pressure differential of 3 psig or can be throttled to $30 \mathrm{psig}$ to deliver about $600 \mathrm{scfm}$. The capability of throttling the steam pressure makes the exhauster a versatile gashandling device.

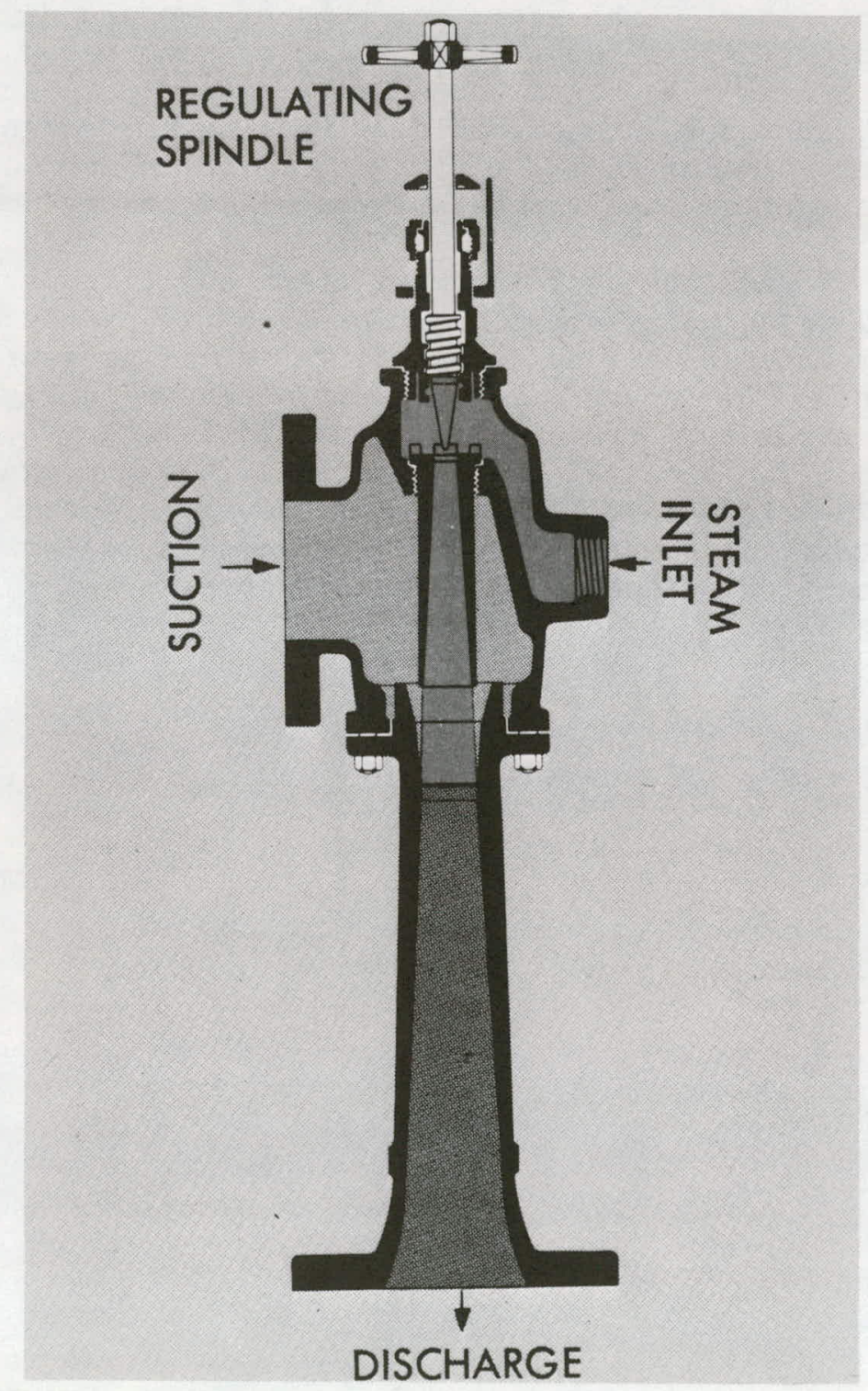

Fig. 7.12.13. Steam-Jet Exhauster. Courtesy of the Schutte and Koerting Company. 
Jet Compressors - Jet compressors and exhausters are constructed very much alike except for a slight difference in the diffuser section. The two types of compressors are the fixed-nozzle type (Fig. 7.12.14) and the spindle-controlled-nozzle type (Fig. 7.12.15). ${ }^{8}$ The fixed-nozzle jet compressor is suitable where no control is required or where the compressor is operated at a steady load. Spindle-controlled jet compressors are used where operating conditions may fluctuate or where some flexibility in nozzle orifice size is desirable.

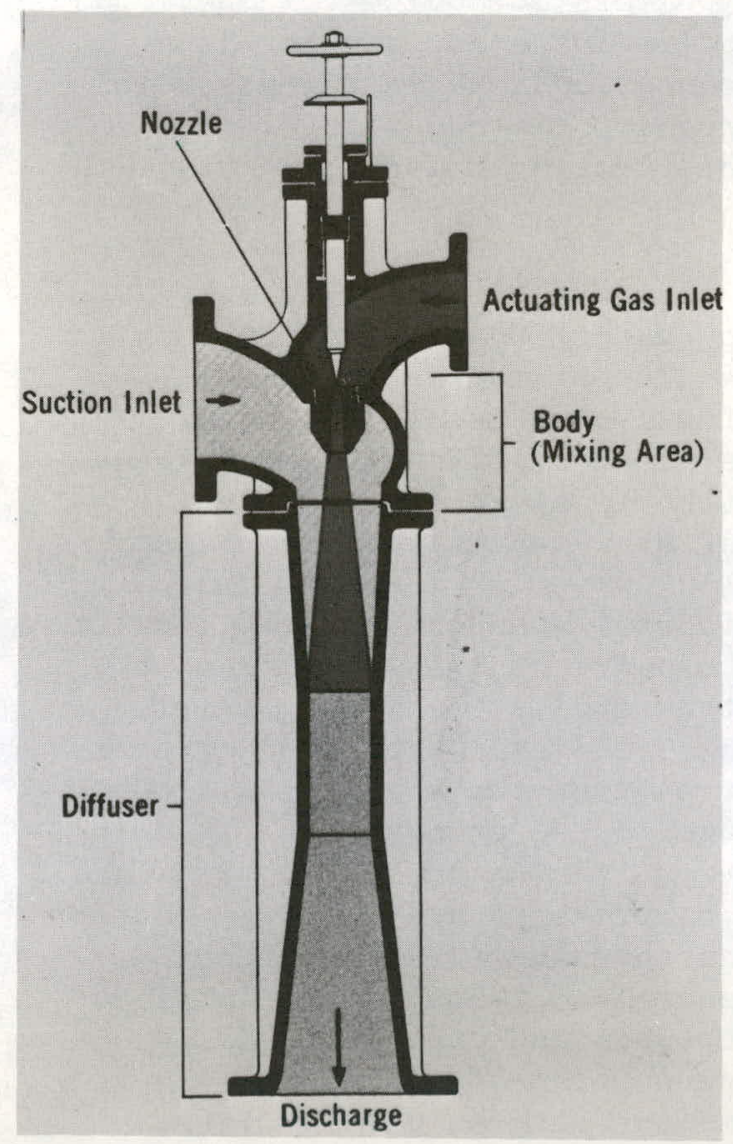

Fig. 7.12.14. Steam-Jet Compressor. Courtesy of the Schutte and Koerting Company.

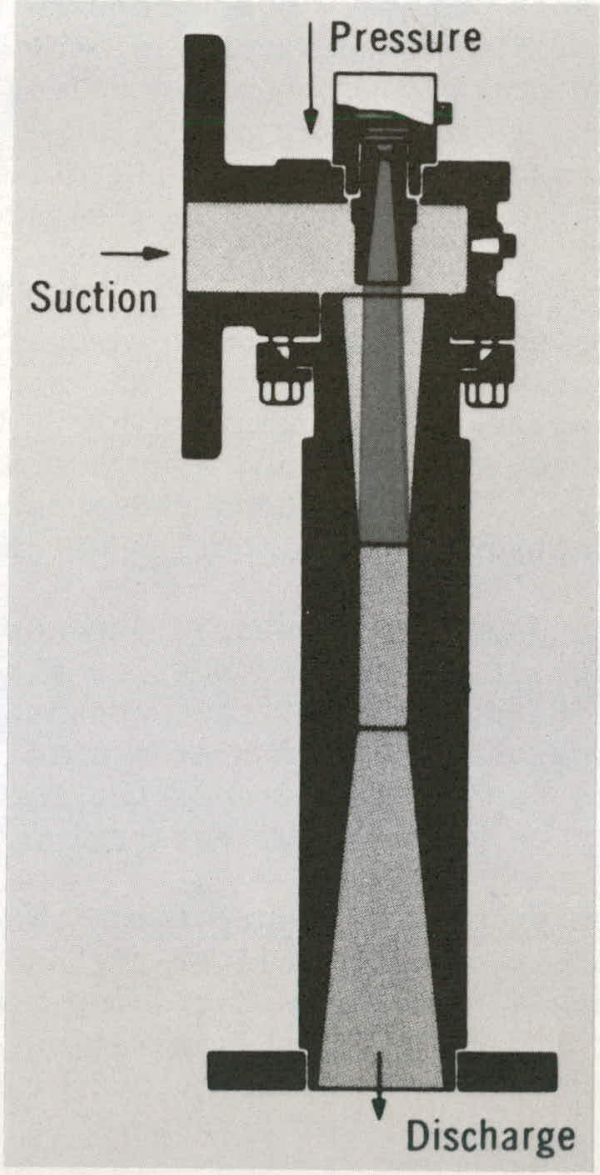

Fig. 7.12.15. Steam-Jet Compressor with Regulating Spindle. Courtesy of the Schutte and Koerting Company. 
Jet Vacuum Pumps - Steam-jet vacuum pumps, operating on the ejectorventuri principle, have been used successfully in industrial applications for many years. In fuel reprocessing plants, the vacuum jet is used to evacuate vessels to permit solution from another vessel to be sucked into the evacuated vessel.

Multistage steam-jet vacuum pumps are capable of producing absolute pressures as 1ow as 50 microns of mercury. Where large capacities at very low absolute pressures are desired, two or more multistage units may be placed in parallel service.

\subsection{2 .4 Compressanrs}

Compressed air is used extensively in radiochemical fuel processing plants for such operations as driving air pulsers for pulse columns, sparging process vessels, supplying the motive force for sampler jets, and operating pneumatic valves and instrumentation. Where atr pressure less than 30 psig and a large volume are required, a centrifugal compressor (turbo-blower) is often used:. Reciprocating compressors are used where higher pressures are needed.

Centrifugal Compressors - The centrifugal compressor is similar in design and operation to a centrifugal pump, except that the compressor handles a compressible gas and the pump handles a liquid that is practically noncompressible. Most centrifugal compressors operate above $3500 \mathrm{rpm}$, and they are almost always electrically or steam driven. Figure 7.12.16 shows the general shape of the housing and the relative position of the impeller within the housing of a centrifugal compressor. ${ }^{7}$

The pressure developed depends on the peripheral speed of the impeller tips, the type of impeller blade, and the density of the air or gas being compressed. The constant speed of the impeller assures a fairly constant pressure over a wide range of flows, and this type of compressor has the advantage over the reciprocating type that the nonpulsing flow can be shut off by throttling without damage to the compressor.

Reciprocating Compressors - Reciprocating compressors are the type most widely used to deliver air and gases against pressures in the higher ranges. In most processing plants, the general air supply is maintained at 100 psig for the operation of pneumatic tools and other such equipment requiring pressures in this range. A large portion of this supply is reduced to lower pressures to operate equipment such as sampler jets, air spargers, pulsed-column pulsers, and pneumatic valves and instrumentation. 
ORNL DWg 74-9174
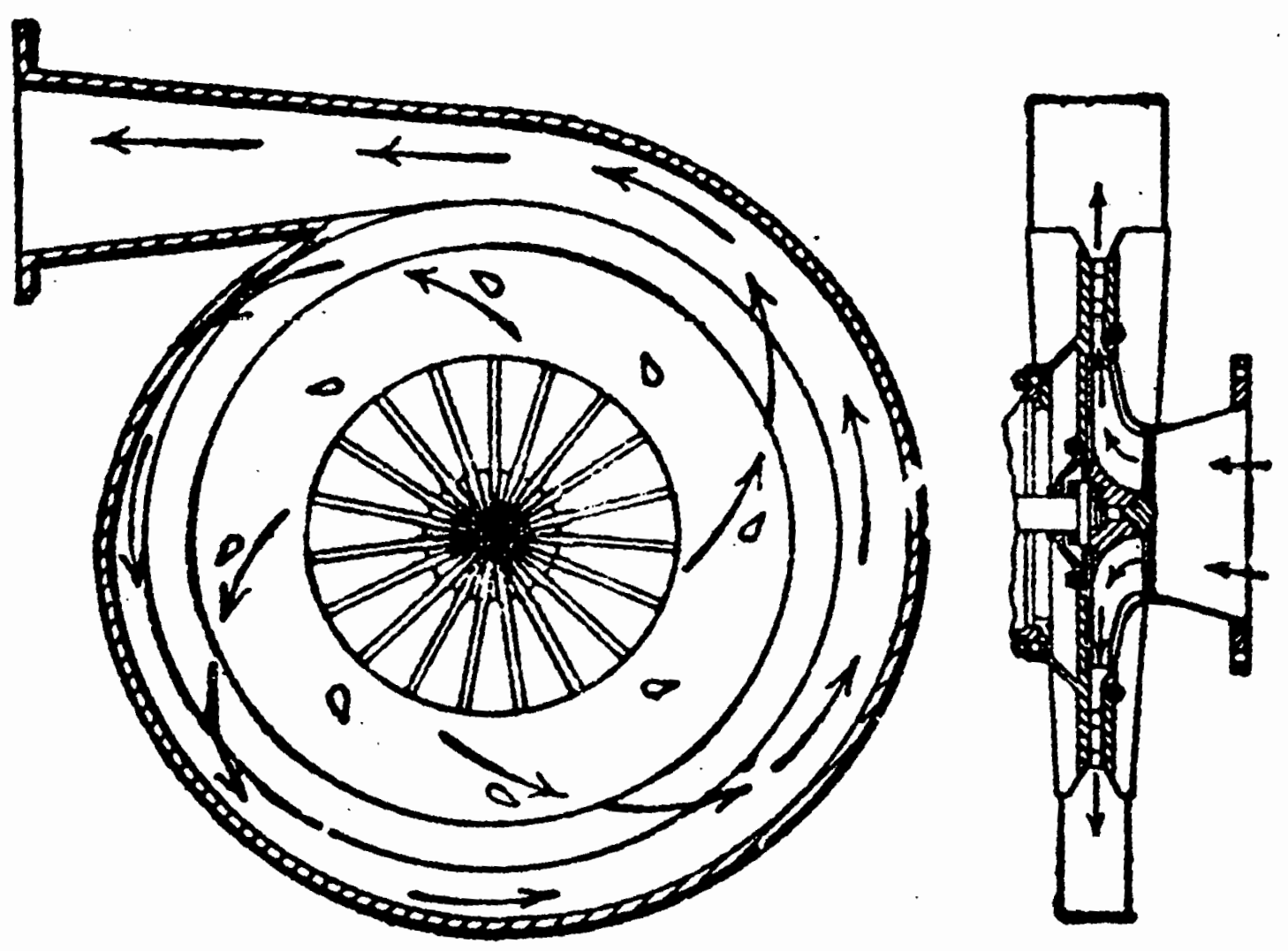

Fig. 7.12.16. Ingerso11-Rand Single-stage Compressor 
Reciprocating compressors are positive-displacement mechanisms and are equipped with relief valves placed ahead of any valve in the piping between the compressor and the receiver against the event that the high-pressure limit switch fails to function. The work done to compress a gas appears as heat and must be removed either by air-cooling or by water. The air-cooled type has fins on the cylinder walls with a fan blowing across them to remove the heat. The water-cooled type has water circulating in jackets surrounding the cylinders to carry away the heat. The air-cooled type is used where freezing is a possibility, and the water-cooled type should be used where the temperatures are high or where the heat from the compressor is objectionable.

An' air receiver is a necessity with reciprocating compressors. It damps the pulsations in the flow from the compressor, provides reserve storage capacity, and helps to cool the air and to condense part of its moisture. A typical arrangement of equipment in a reciprocating compressor installation that meets safety and convenience requirements is shown in Fig. $7.12 .1 \% .^{5}$

Maintenance and 'l'roubleshooting - The area around the compressor should be kept clean to prevent dust and particles from being sucked into the intake of the compressor. The intake normally has a filter to keep particles out, and the filter should be replaced regularly. Droplets of cylinder lubricating oil carried along in the air stream and condensed in the aftercooler accumualte with the moisture in the receiver and should be removed, since oil is flammable.

The compressor should not be permitted to overheat, and indications of high temperature should be investigated immediately. If the compressor is not equipped with temperature indicators, one can feel the cylinder walls or the valve covers to check the temperature. Un water-cooled compressors, an ample supply of cooling water should be circulated at all times.

A11 components in the compressor system should be equipped with safety relief valves, and these must be serviced and tested at regular intervals. A safety valve must be placed in the compressor discharge line (see Fig. 7.12.17) between the compressor and any stop valve that is placed in this line ahead of the air receiver.

One should never break an air line without first checking the line for flow and pressure. Compressed air, when released through a nozzle or an opening, travels at a high rate of speed and can cause sertous injury to operating and maintenance personnel. Workmen should be careful with air jets and should not play pranks with compressed air. Severe cases of internal injuries and even death have resulted when air jets were applied to one of the natural body openings. 5 


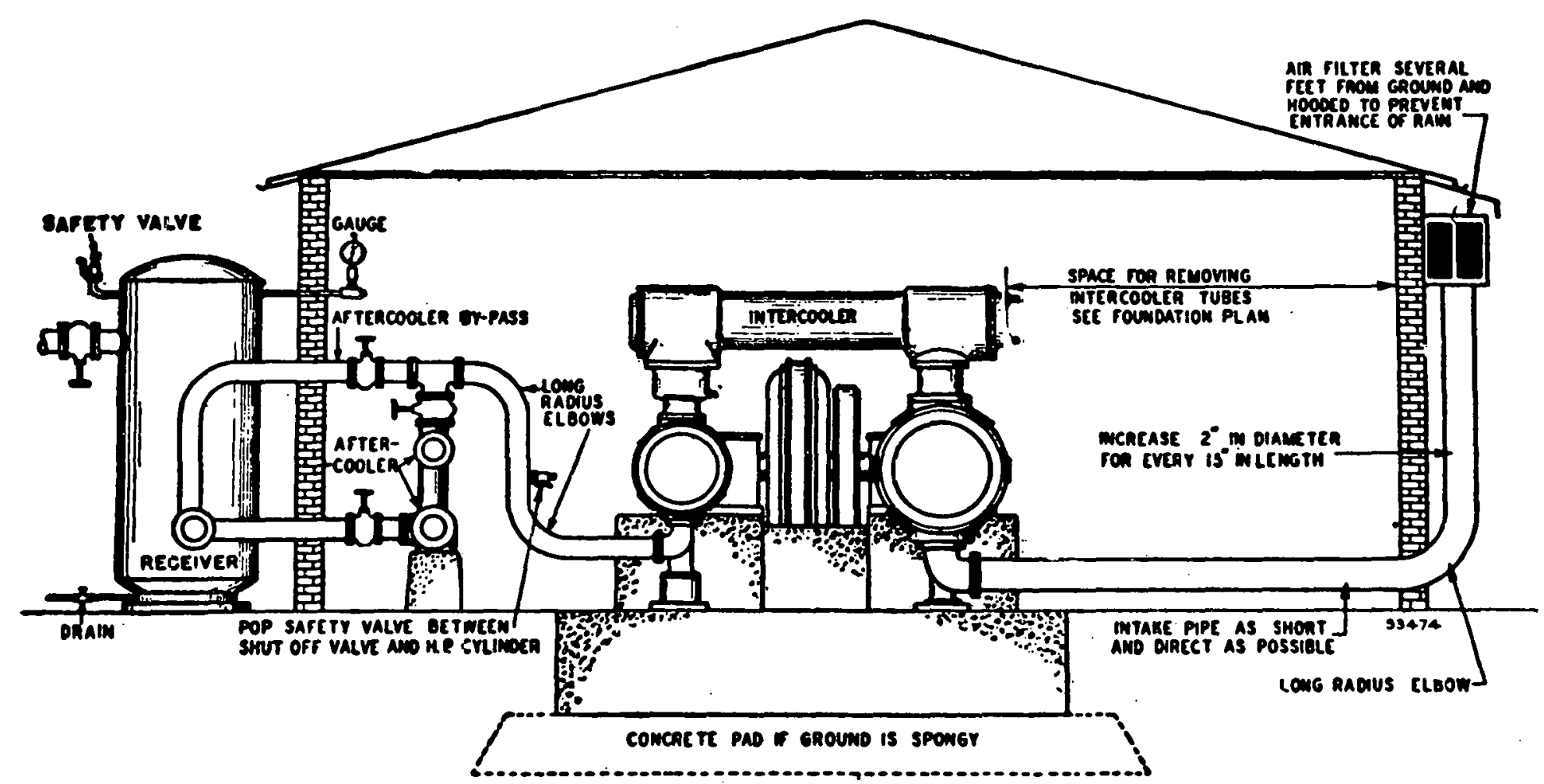

Fig. 7.12.17. Typical Arrangement of Equipmen= in a Reciprocating Compressor Installation 
Vacuum Pumps - Vacuum pumps are essentially the same as air compressors with the exception that they operate in a pressure range below atmospheric instead of above. Pressures of $0.5 \mathrm{in}$. of mercury are readily obtained with pumps of the rotary-piston type, the sliding-vane type, and the rotary-compressor type. The rotary-piston type is capable of producing pressures of $0.001 \mathrm{~mm}$ of mercury. The degree of vacuum required for a specific operation determines the type of pump to use. These pumps are similar in design, construction, and theory of operation to the compressors that have been discussed previously; the same general considerations for safety, maintenance, and troubleshooting apply to the use of vacuum pumps.

\section{REFERENCES FOR SECTION 7.12}

1. W. L. Badger, and W. L. McCabe, Elements of Chemical Engineering, 3d ed., McGraw-Hill.

2. A. S. Foust, and Associates, Principles of Unit Operations, John Wiley and Sons.

3. ASHRAE Guide and Data Book, American Society of Heating, Refrigeration, and Air-Conditioning Engineers, 1963, p. 653.

4. Robert H. Perry, and Cecil H. Chilton, Chemical Engineers' Handbook, 5th ed., McGraw-Hill Book Co., 1973.

5. William Staniar, P̈lant Engineering Handbook, McGraw-Hil1.

6. Brown and Associates, Unit Operations, John Wiley and Sons.

7. Lionel S. Marks, Mechanical Engineers' Handbook, 4th ed., McGrawHill, 1941.

8. Literature of the Schutte and Koerting Co., Cornwe11 Heights, Bucks County, Penn. 


\subsection{FLUIDIZED BEDS}

\subsubsection{Purpose and Uses in Fuel Processing}

The term "fluidized bed" is used to describe a bed of small solid particles that are kept in constant motion by a flow of gas or liquid upward through the bed. In the fluidized condition the solid particles behave somewhat as a liquid or fluid. In the fuel processing industry, fluidized beds are used mainly for operations that require gases to react with or to contact solids. Fluidized beds are also used for calcining (driving gases off) solutions, and for this they have several advantages over fixed beds, in which the solid particles remain stationary. The fluidized bed offers good heat transfer characteristics and relatively uniform temperature distribution, features that allow reaction rates to be maintained throughout the bed. Solids can be added to and discharged from the bed, permitting continuous operation. Representative solid samples can be withdrawn from the bed for process control.

Fluidized beds have been used extensively for the preparation of nuclear fuels and for calcination of radioactive waste from fuel processing plants. It is likely that in the future, most fuel reprocessing plants will have some process operations that are performed in fluidized beds. At the Midwest Fuel Recovery plant, operated by General Electric Company, fluidized beds were to be used to convert uranyl nitrate to uranium trioxide, to fluorinate the uranium trioxide to produce uranium hexafluoride, and also to convert high-level waste solutions to a solid form that is more suitable for storage. ${ }^{1}$

Other applications in which fluidized beds have been used for processing nuclear materials are listed below. In the large-scale production of uranium hexafluoride from ore concentrates, Allied Chemical ${ }^{2}, 3$ has used fluidized beds to reduce $\mathrm{U}_{3} \mathrm{O}_{8}$ to uranium dioxide, to hydrofluorinate the uranium dioxide to uranium tetrafluoride, and to fluorinate the uranium tetrafluoride to uranium hexafluoride. Mallinckrodt ${ }^{4}$ has used fluorized beds to convert uranyl nitrate to uranium trioxide, to reduce uranium trioxide to uranium dioxide, and to hydrofluorinate uranium dioxide to produce urantum tetrafluoride. At the Idaho Chemical Processing Plant, 5, 6 (ICPP) a fluidized bed has been used to convert high-level radioactive waste solutions to a solid form which can be stored more safely. Much of the early development work for nuclear fuel applications of fluidized beds was done at Argonne National Laboratory. 7-9

\subsection{3 .2 Description}

A typical fluidized-bed system is shown in Fig. 7.13.1. The bed material is contained in the lower section of the vessel, which may range in size from a few inches to several feet in diameter, depending on the quantity of material to be processed and whether or not this material presents a nuclear safety problem. A gas distributor is located below the bed to assure that the gas flows up through the bed uniformly. In the 
ORNL DWg 74-4943

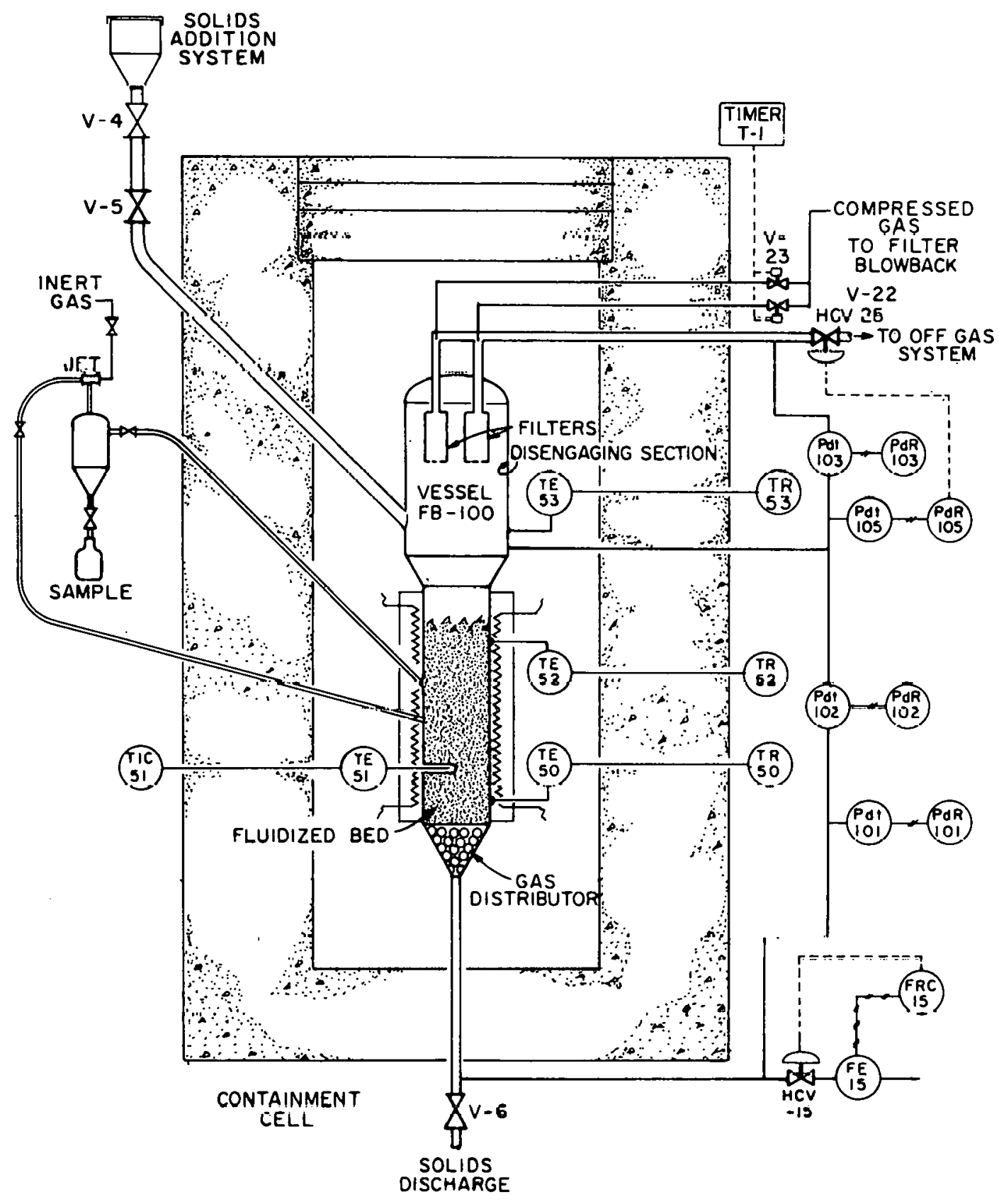

Fig. 7.13.1. Typical, Fluidized System 
Fig. 7.13.1 example the conical section at the bottom of the bed is filled with metal balls to distribute the gas. Porous metal plates or perforated plates are often used for this purpose.

The upper section of the vessel, called the disengaging section, is made larger in diameter than the fluidized section to allow fines (smaller particles) that are blown out of the bed to settle out of the gas stream and return to the bed.

Fines that do not settle out in the disengaging section are removed by the porous-metal filters located near the top of the vessel. Other devices such as cyclone separators are sometimes used instead of filters to remove particles from the off-gas stream. When filters are used, some method must be provided for periodically removing the particles that collect on the filter. In the example shown, a blow-back system is used in which a short blast of high-pressure gas is periodically introduced into the inside of the filter in the opposite direction to the normal gas flow to knock the dust from the filter and allow it to return to the fluidized bed. More than one filter is used so that when one filter is being blown back the off-gas from the vessel can flow normally through the others.

Lines are attached to the side and bottom of the vessel for adding material, for sampling, and for discharging the bed. Material may be manually added to the bed by gravity flow through lines that extend into operating areas, but in larger systems or systems in which highly radioactive material is handled, screw or pneumatic conveyors are used for charging and for discharging solids from the bed.

Samples may be withdrawn from the bed by applying vacuum to a line extending into the bed while the bed is fluidized. A typical system uses a jet to circulate solids from the bed to a sample point and then back into the bed. The system shown in Fig. 7.13.2 is similar to that used in the ICPP waste calcining facility.

The use of spray nozzles to introduce liquids into fluidized beds is discussed under Section 7.14.

\subsubsection{Instrumentation}

The basic instrumentation needed for the operation of a fluidized bed consists of temperature controllers and recorders and instruments to measure gas flow and pressure. Other instruments, such as gas analyzers and radiation monitors, are often used to provide additional information about the operation of the system. 
ORNL Dwg 74-4944

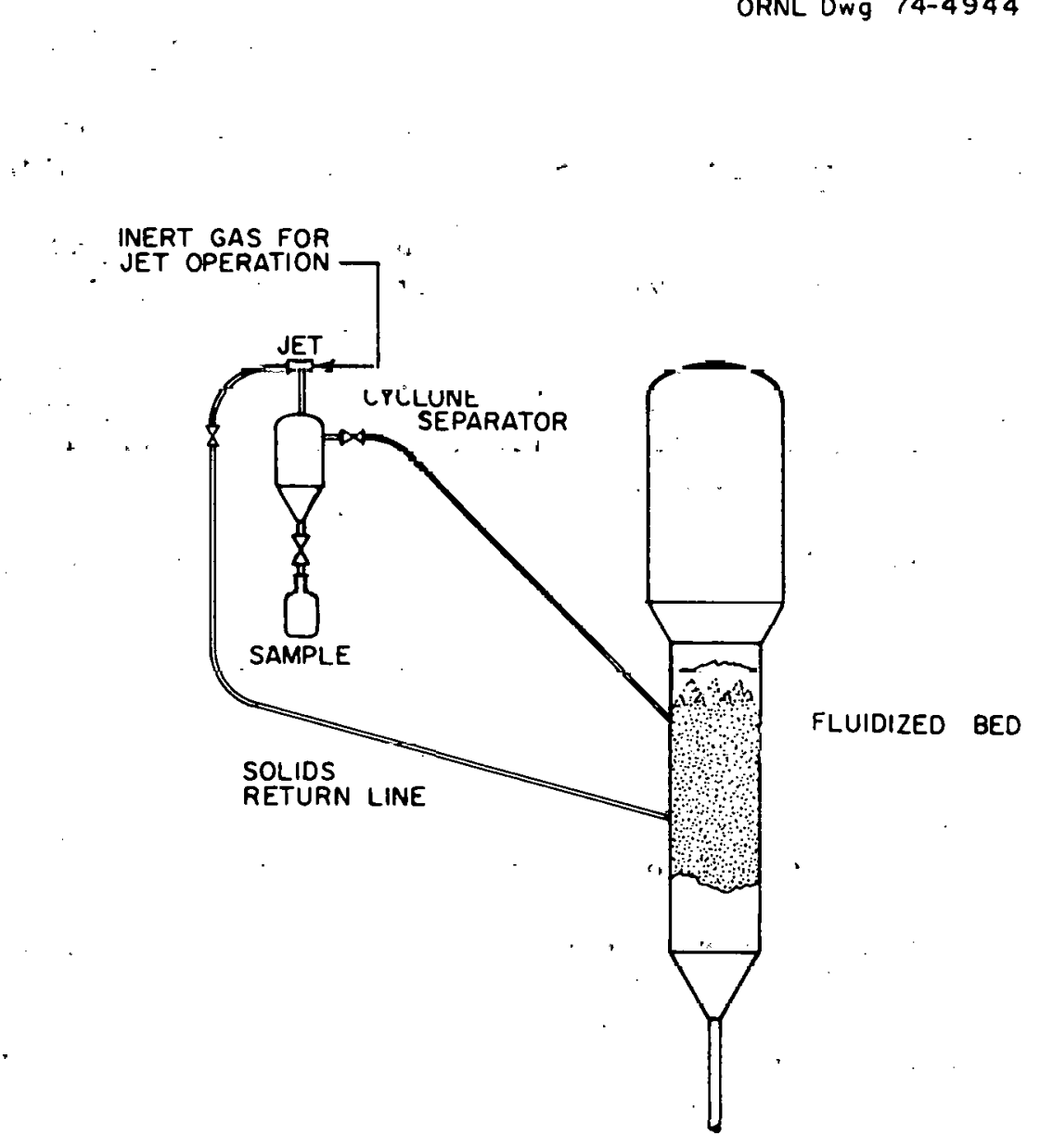

Fig. 7.13.2. Typical Fluidized Bed Sampling System 
Typical instrumentation used to control the operation of a fluidized bed is shown in Fig. 7.13.1. An orifice ( $\mathrm{FE}-15)$ is used to measure the flow rate of fluidizing gas to the bed. The pressure of the fluidizing gas before it enters the vessel is measured by pressure transmitter Pdt-101. Pressure differential transmitters Pdt-102 and Pdt-103 are used to measure the pressure drop across the fluidized bed and the filters, respectively. Pdt-105 measures the static pressure in the disengaging section of the bed and controls valve HCV-25 to maintain the pressure at the desired level. If feasible, the instruments are located outside of the containment area so that they are accessible for maintenance. Signals from the pressure and flow transmitters are sent (by either electrical or pneumatic lines) to indicators or recorders on the main panelboard.

In the example shown in Fig. 7.13.1, several thermocouples are attached to the exterior wall of the vessel at various points, and others are inserted into wells that extend into the vessel for temperature measurement. A temperature controller (TIC-51) which receives its temperature signal from thermocouple TE-51 is used to control the electric heaters to maintain the bed at the oporating temperature.

The solenoid valves ( $\mathrm{V}-22$ and $\mathrm{V}-23)$ that admit high-pressure gas for blowing back the filters are controlled by a timer ( $\mathrm{I}-1)$. Such a system has been used at Argonne National Laboratory. 10

The instrumentation may include safety interlocks to protect the equipment from damage or to prevent operational errors from occurring. For example, if in a particular system it were undesirable to heat the system unless the bed was fluidized, the heaters could be interlocked with the fluidizing gas flow instrument in such a way as to prevent the heater from becoming energized unless the flow of fluidizing gas was within the specified limits.

\subsubsection{Operating Variables and Methods of Control}

In the operation of a fluidized bed, as with most other systems, the operating limits for process variables are usually established before the system is put into routine service. Once the unit is in normal service it is the primary responsibility of the operating personnel to keep the process variables within the established limits; however, it is important that operating personnel understand the effect of operating variables on the process and to recognize possible operating difficulties before they become serious. A brief discussion of some of the variables associated with the operation of fluidized beds is given below.

Particle Size of Bed Material - It is important in the operation of a fluidized bed that the bed not be inadvertently allowed to become static. If the bed is not kept in a fluidized condition, overheating and caking could occur. For a given bed material, fluidization depends primarily on the particle size of the bed material and on the flow rate of the fluidizing gas. The initial bed material used usually consists 
of a range of particle sizes. The operating procedure may specify that particles be used that will pass through a certain mesh screen but will collect on a smaller mesh screen. For example, $-48+100$ mesh material consists of particles that pass through a 48-mesh screen but do not pass through a 100-mesh screen. During operation, however, the size of the particles in the bed material may change; smaller particles may be produced by the breaking up of larger particles, or particles may increase in size by reaction with material introduced into the bed. Excessive amounts of smaller or larger particles may be undesirable from the standpoint of bed operation, since these may cause filter plugging and difficulties in obtaining proper bed fluidization. Particle size distribution can be controlled by such means as addition and discharge of bed material and by controlling the operating conditions that affect particle size. The methods used depend to a large extent on the specific operation being performed.

Fluidizing-Gas Flow Rate - In determining the flow rate of gas necessary to fluidize a bed of particles it is helpful to observe the pressure drop across the bed as a function of the flow rate of the fluidizing gas (see Fig. 7.13.3). Initially the pressure drop across the bed increases steadily with an increase in gas flow until the bed begins to expand at point $B$, and at point $D$ the bed is completely fluidized. After the bed is fluidized there is only a relatively small increase in presssure drop as the flow rate of fluidizing gas is increased. After fluidization occurs, the pressure drop across the bed is approximately proportional to the weight of the bed material. Therefore, the pressure differential instrument (PdR-102 in Fig. 7.13.1) can be used to give an indication of the amount of material in the bed and thus permit the bed depth to be maintained within specified limits. A typical method of controlling the flow rate of fluidizing gas is shown in Fig. 7.13.1. Flow recordercontroller FRC-15 regulates the opening of control valve HCV-15 in the fluidizing-gas supply line to maintain gas flow at the rate at which the controller has been set.

Temperature - Temperature is an important variable in the operation of most fluidized beds. Proper temperature control is necessary to ensure that the proper reactions occur, to ensure efficient operation of the system, and to protect the system from damage. Excessive temperature could cause caking of the bed or damage to the vessel. Operation at temperatures below the acceptable limits could also cause bed caking and damage to the equipment, especially if a condensable vapor such as steam is present in the bed. The bed may require either heating or cooling or possibly both. Since most fluidized bed operations associated with fuel processing are run at elevated temperatures in order to achieve the desired reaction rate, heat is necessary to bring the system up to temperature. In systems where a large amount of heat is produced by the reaction taking place in the fluidized bed (as in the flunrination of uranium tetrafluoride to uranium hexafluoride), a heat removal system is required. Several methods have been used for heating and cooling fluidized beds. Electric heaters attached to the outside surfaces of the vessel or extending into the bed are often used. Molten metals or 
ORNL DWg. $74-4945$

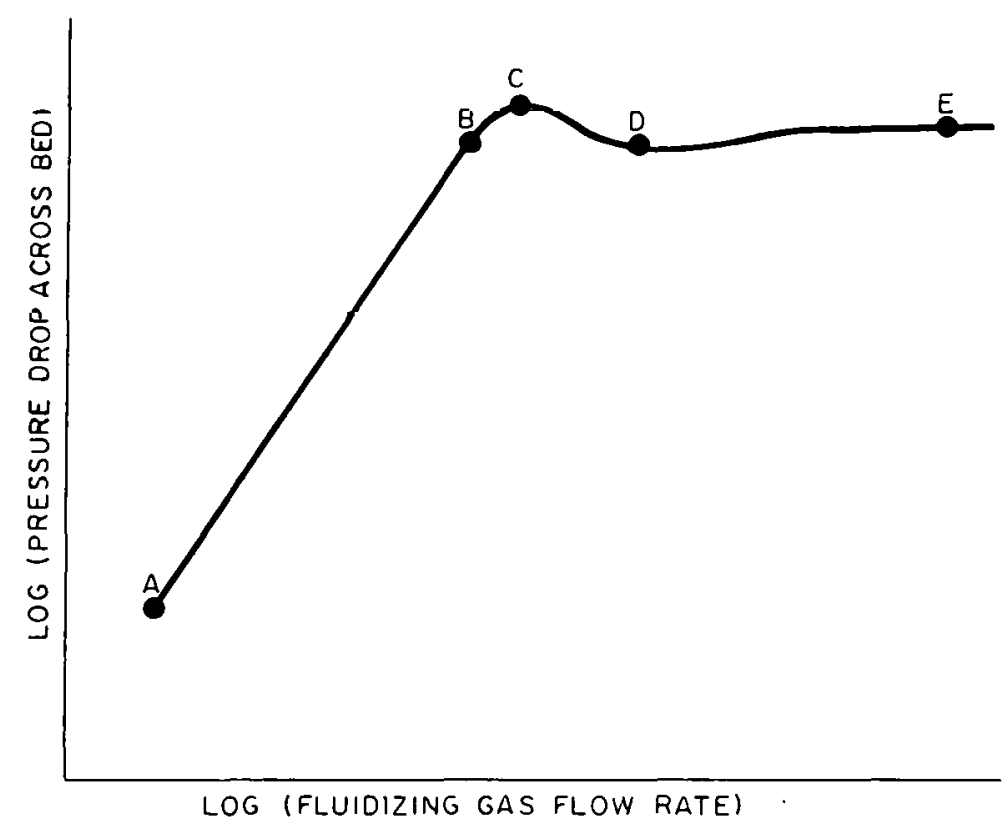

Fig. 7.13.3. Fluidized Bed Pressure Drop vs. Gas Flow 
salts can be circulated through tubes in the bed to provide heat. Cooling can be accomplished by circulating air, steam, a mist of air and water, or other coolants through tubes that are in contact with the bed.

Concentration of Reacting Material - The concentrations of the reacting materials are important variables in the operation of fluidized beds. In the gas phase the concentration of a reactant such as hydrogen fluoride or fluorine can be controlled by dilution with inert gases such as nitrogen or argon. The concentration of reacting material in the solid phase can be controlled by diluting it with inert material or with material that has already reacted. For example, in the fluorination of uranium tetrafluoride to uranium hexafluoride, an inert material such as fused alumina may be used as the bed material. If an excess of fluorine is used, the uranium tetrafluoride fed to the bed can be quickly fluorinated, and thus the concentration of uranium tetrafluoride in the bed can be kept low. In the reduction of uranium trioxide to uran1um dioxide, by having the bed material composed mafnly of uranium dioxide, the reaction rate can be controlled to quickly reduce the uranlum trioxide that is added, thus keeping the uranium tioxide concentration at a low level.

Depth of Bed Material - The bed-depth is'sanother important varlable in the operation of a fluidized-bed system. 'If the bed depthibecomes too small, the reaction efficiency may decrease and channeling may occur, the fluidizing gas passing through the bed in channels without properly contacting the solid particles in the bed. Another undesirable condition known as slugging is also related to bed depth. Slugging is a condition in which gas bubbles approximately the same diameter as the vessel pass up through the bed. In general, slugging is more likely to occur if the bed becomes excessively deep. The depth of bed material can be controlled by the addition and discharge of material from the bed. The pressure drop across the bed while 1 t is fluldized gives a good indication of bed depth.

Pressure - The pressure in the fluidization vessel is usually controlled to maintain the pressure in the disengaging section at the desired level. The operating pressure maintained in the vessel depends to a large extent on the specific system used. When practical, it is usually desirable to maintain the pressure in the upper section of the bed slightly below the pressure in the cell in which the vessel is located so that dust will not be blown out of the system during charging and sampling operations. However, when the bed is operated in conjunction with other equipment or for other reasons associated with the process, it may be necessary to operate at higher pressures. The pressure inside the vessel is normally controlled by regulating the pressure in the off-gas system. In a typical system the off-gas is maintained at a low pressure by the use of exhaust blowers or jets. A pressure controller is used to control the pressure inside the fluidized-bed vessel by regulating a control valve in the off-gas line from the vessel. 
REFERENCES FOR SECTION 7.13

1. General Electric Co., Design and Analysis, Midwest Fuel Recovery Plant, Docket No. 50-268, 1966.

2. W. C. Ruch, D. A. Peterson, E. A. Gaskil1, and H. G. Tepp, "Production of Pure Uranium Hexafluoride from Ore Concentrates," Chem. Eng. Progress Symposium Series 56, No. 28, 1960.

3. A. H. Sutton, J. C. Bishop, M. H. Cohen, and K. J. Stahman, "Reduction and Hydrofluorination of Uranium Concentrates by Fluid Bed Techniques," Chem. Eng. Progress Symposium Series 62, No. 65, 1966.

4. S. Simecek and W. T. Trask, The Integrated Fluid-Bed System, Report MCW-1478, Mallinckrodt Chemical Works Uranium Division, Weldon Spring: Mo.. June 10, 1963.

5. L. T. Lakey and J. R. Bower, ICPP Waste Calcining Facility Safety Analysis, Report IDO-14620, National Reactor Testing Station, 1963.

6. J. A. Buckham, A. L. Ayers, and J. A. McBride, "Fluidized Bed Calcination of High-Level Radioactive Waste in a Plant-Scale Facility," Chem. Eng. Progress Symposium Series 62, No. 65, 1966.

7. Argonne National Laboratory, Chemical Engineering Division Sumary Report October, November, and December 1954, Report ANL-5388.

8. W. J. Mecham, J. D. Gabor, and A. A. Jonke, "Pilot Plant Studies of a Direct Fluorination Process Applied to Uranium Dioxide Reactor Fuels," Chem, Eng. Prog. Symposium Series 60, No. 47, 1964.

9. A. A. Jonke, M. J. Steindler, and N. M. Levitz, "Development of Fluoride Volatility Reprocessing Methods for Plutonium-Containing Fuels," Chem. Eng. Prog. Symposium Ser1es 63, No. 80, 1967.

10. G. J. Vogel, E. L. Carls, and W. J. Mecham, Engineering Development of Fluid-Bed Fluoride Volatility Processes, Part 5. Description of a Pilot-Scale Facility for Uranium Dioxide-PLutonium Dioxide Processing Studies, Report ANL-6901, 1964. 


\subsection{CALCINERS}

Calciners are mechanical devices for heating solids to elevated temperatures to change their chemical and physical properties, usually by driving off vapors and gases to leave a powdery solid. They are used for operations such as drying and solidification of solutions.

\subsubsection{Use in Fuel Processing}

Two major uses of calciners in nuclear fuel processing are for the denitration of uranyl nitrate to produce uranium trioxide and for the conversion of high-activity liquid waste solutions to a solid form that is more suitable for storage than liquids are.

The denitration of uranyl nitrate to produce uranium trioxide and the conversion of high-activity nitrate waste solutions to a solid form involve similar steps. The solutions are first concentrated by boiling to remove excess water. The concentrated solution is then fed to the calciner, which is operated at an elevated temperature. As the solution enters the hot calclner, the remaining water is evaporated, and the nitrate is decomposed to produce an oxide.

Several types of calciners have been used for denitration of uranyl nitrate and for waste calcination. Batch-operated stirred vessels, 1 stirred troughs, ${ }^{1}$ and fluidized beds ${ }^{2},{ }^{3}$ have been used for denitration. Pot calciners, ${ }^{4}$ spray calciners, ${ }^{4}$ and fluidized beds ${ }^{3}, 5$ have been used for waste calcination. Sincc fluidized-bed calciners are commonly used for both denitration and waste calcination, they will be described in more detail to illustrate the typical waste in which calciners operate.

\subsubsection{Description of a Fluidized-Bed Calciner}

The fluidized-bed calciner is very similar in design and operation to the typical fluidized-bed reactor described in Section 7.13, with the exception that some method must be provided for introducing the feed solution. Figure 7.14.1 is a schematic diagram of a typical fluidizedbed calciner. The bed material is located in the lower section of the vessel. Fluidizing gas is introduced at the bottom of the vessel. The fluidized bed is heated by circulating molten metal (NaK) through tubes located in the bed. A cyclone separator is located above the vessel for removing small particles from the off-gas stream. A common method of introducing liquid into a fluidized-bed calciner is through a spray nozzle. Figure 7.14.2 shows a typical spray nozzle of the type used at the Idaho Chemical Processing Plant for waste calcination. ${ }^{5}$ The feed solution enters one side of the nozzle and flows through an opening in the center of the nozzle. Compressed gas enters the opposite side of the nozzle and discharges through an annular opening around the feed opening to atomize the feed stream. The nozzle is equipped with an air-operated plunger for cleaning the feed-solution opening in the event that it becomes plugged. 


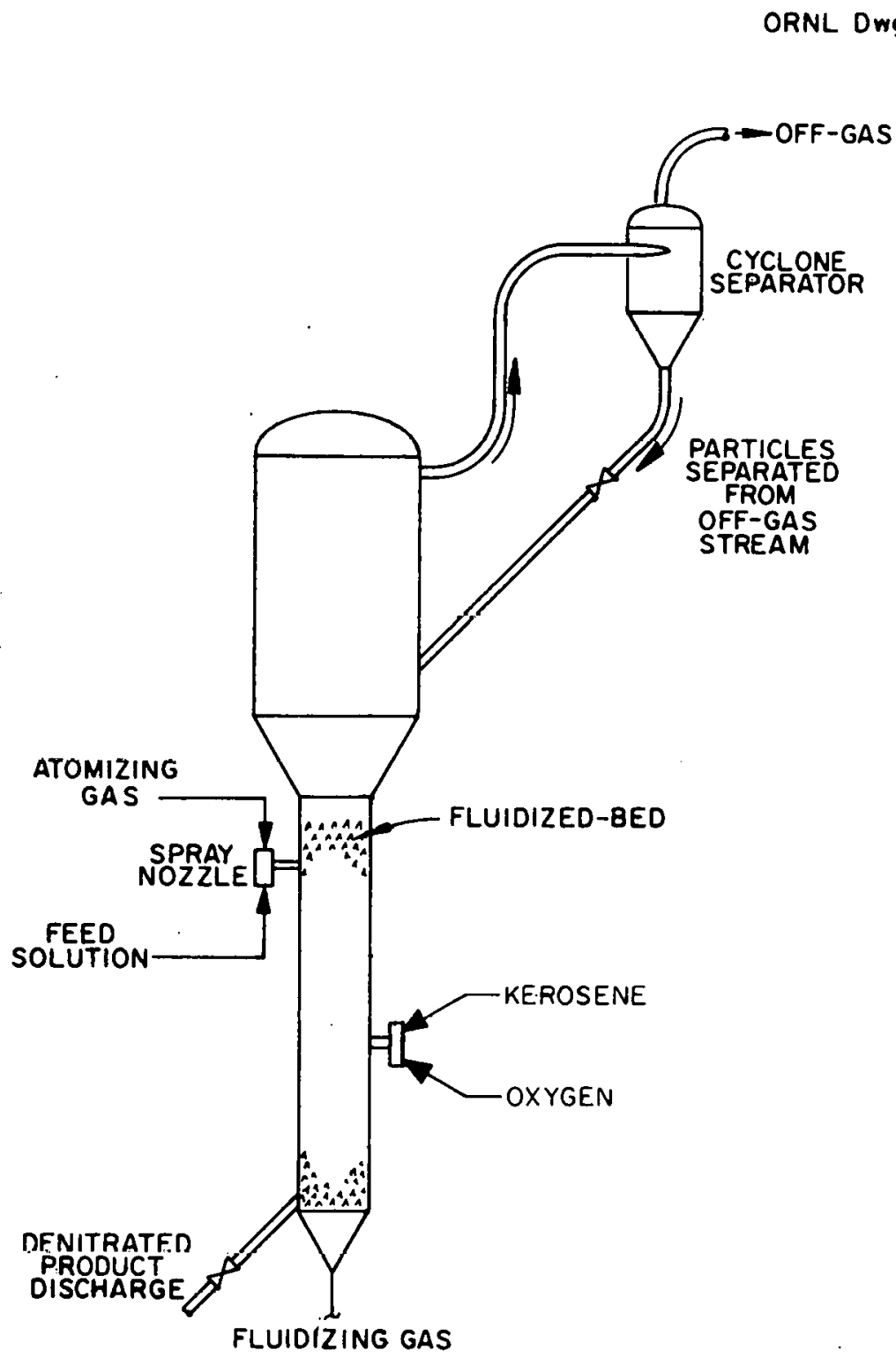

Fig. 7:14.1. Schematic Diagram of a Fluidized-Bed Calciner 


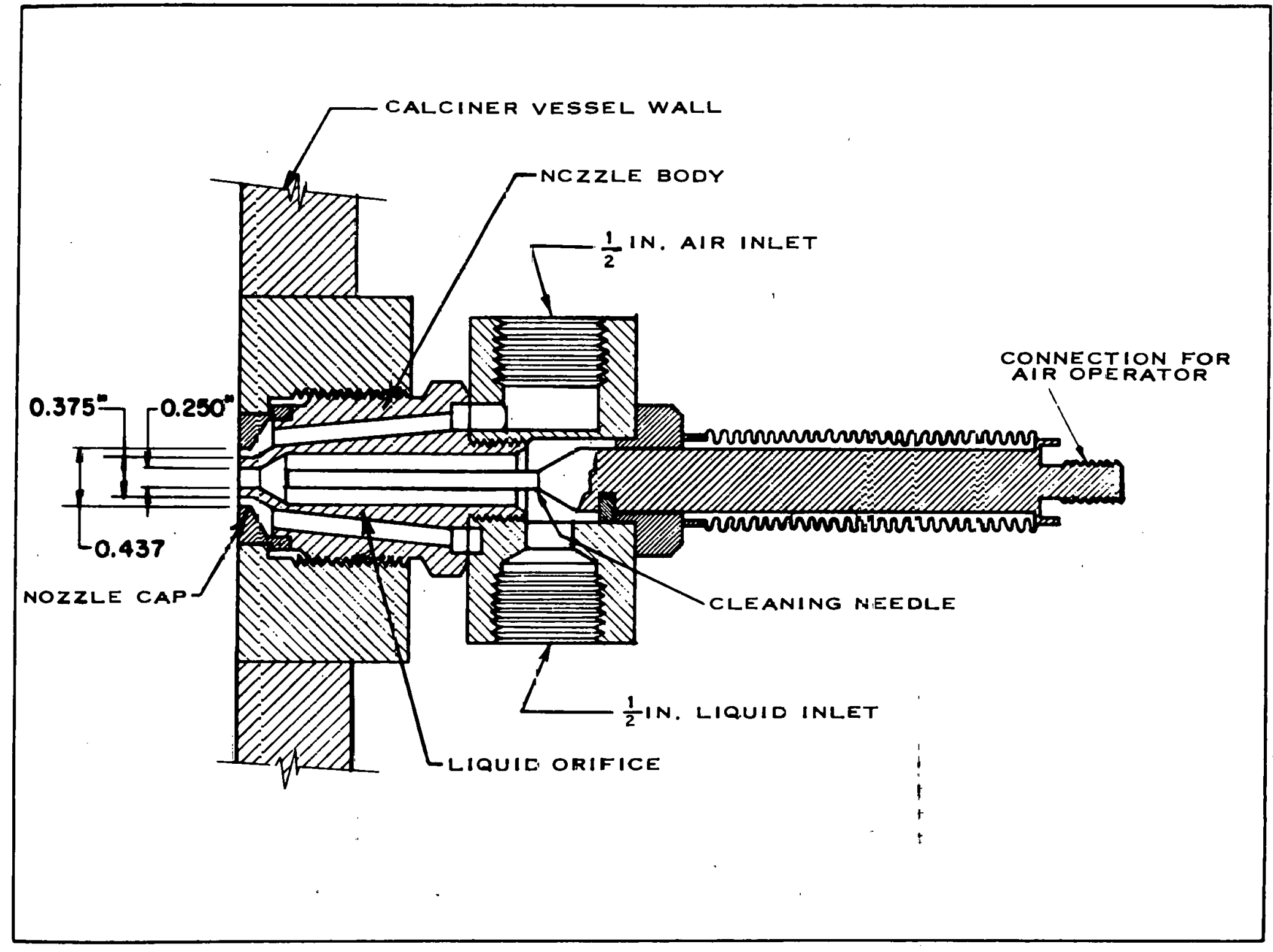

Fig. 7.14.2. Spray Nozzle Used to Introduce Feed Solutior. Into a Fluidized-Bed Calciner 
The feed nozzle is located in the side wall of the fluidized-bed vessel in a position where it will be covered by the bed material at all times to prevent solids from being deposited on the vessel walls. The solids produced by evaporation and decomposition of the feed solution coat the surfaces of the fluidized particles of bed material and cause them to increase in size.

Brief descriptions of calciners that have been used commercially in the fuel reprocessing industry are given below. The waste calciner designed for the Midwest Fuel Recovery Plant ${ }^{3}$ was about 6 in. in diameter with a larger diameter disengaging section which contains sintered-metal filters for removing particles from the off-gas stream. The unit was electrically heated and had provision for forced-air cooling. Steam was used as the fluidizing gas and for atomizing the feed solution. The calciner was to be used to convert high-activity waste solution to a solid waste that could be sealed in steel cans for storage.

The Midwest Fuel Recovery Plant also has a fluidized-bed calciner for conversion of uranyl nitrate solution to uranium trioxide. The calciner was electrically heated and fluidized with steam. It was similar to smaller-scale units operated at Weldon Sprint ${ }^{2}$ and at Argonne National Laboratory. 6

At the Idaho Chemical Processing Plant, a 4-ft-diam fluidized-bed calciner is used for solidification of liquid waste. 5 The calciner contents are maintained at about $400^{\circ} \mathrm{C}$ by combustion of fuel oil located in the fluidized bed. Preheated air is used as the fluidizing gas. A cyclone separator, a spray-quench tower, a scrubber, silica gel absorbers, and high-efficiency filters are used to separate entrained particles and volatile fission products from the off-gas stream.

\subsubsection{Instrumentation}

The usual instrumentation for the operation of a fluidized bed, which was discussed in Section 7.8.3, is needed for the operation of fluidizedbed calciners. Additional instrumentation is needed for the fluidizedbed calciner for introducing the feed solution and to protect the system from improper operation. Instrumentation unique to the operation of the fluidized-bed calciner is described below.

A typical system for introducing feed into the fluidized-bed calciner is shown in Fig. 7.14.3. An air lift is used to transfer the feed solution to a heat pot, where it flows by gravity into the feed nozzle. More feed solution is transferred to the head pot by the air lift than is fed to the calciner. The excess overflows from the head pot back to the storage tank. The rate at which liquid is fed to the spray nozzle is measured by a flowmeter in the feed line. The signal from the flowmeter is transmitted to a flow recorder-controller which regulates a control valve to maintain a set flow through the valve. The air supply to the spray nozzle contains a pressure regulator and a flow controller for adjusting the air 


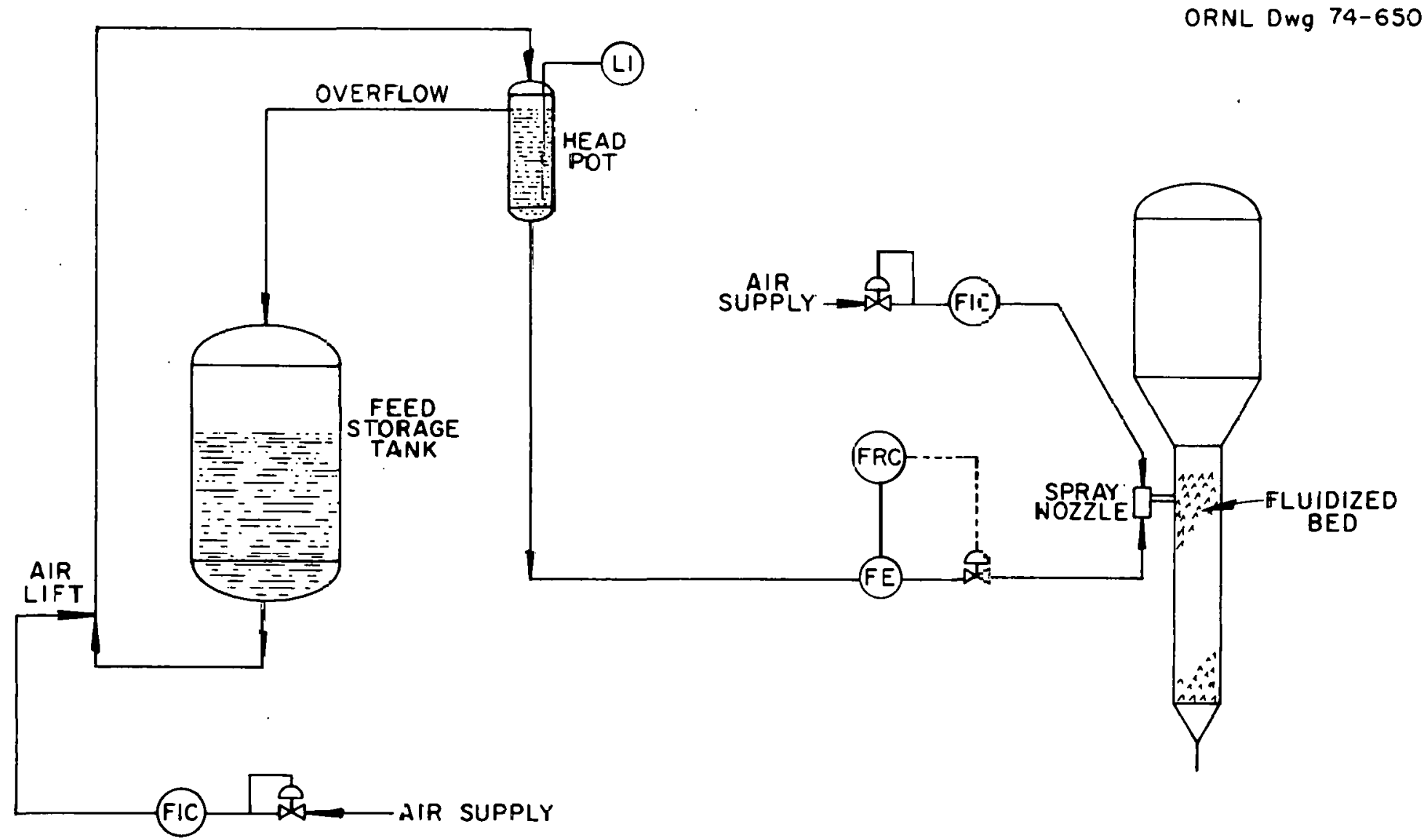

Fig. 7.14.3. Typicai Feed System for a Fluidizéি-Bed Calciner 
flow to the nozzle. The feed storage vessel, head pot, and other lines are traced with electric heaters to maintain the feed system at an elevated temperature to prevent freezing and precipitation of solids from the feed solution. Provisions are made for flushing the feed nozzle with demineralized water when the feed flow is stopped. This prevents plugging of the nozzle.

Examples of interlocks that are sometimes used on the calciner feed system are (1) interlocks that will not allow feed to flow to the waste nozzle unless the calciner is fluidized and at operating temperature and (2) an interlock that causes the feed line and nozzle to be automatically flushed with demineralized water each time the feed flow is stopped.

\subsubsection{Operating Variables and Common Difficulties}

Some of the important operating variables that can be controlled in the operation of a fluidized bed calciner are listed below:

1. Temperature

2. Fluidizing gas flow rate

3. Feed flow rate

4. Feed concentration and composition

5. Flow rate of atomizing gas to feed nozzle

6. Bed depth

Conditions are selected to give a product that has the desired chemical and physical properties. Since the bed particles increase in size by deposition during operation, conditions must be selected that will maintain the desired particle size distribution in the bed. High-velocity atomizing air has been used to break up bed material to control particle size. The effect of the various operating variables on the properties and particle size of the material produced are interrelated and depend on the spectflc system used.

Typical operating difficulties that may be encountered in the operation of fluidized-bed calciners are plugging of the feed nozzle, caking of the bed material, and problems in controlling the particle size of the bed material. Provisions are made for remotely cleaning out the feed nozzle if plugging should occur. Control of bed caking and of the particle size of bed material is achieved by carefully operating within specified limits that have been found to give satisfactory results. 
1. C. D. Harrington and A. E. Ruehle, Uranium Production Technology, D. Van Nostrand Company, Inc., Princeton, N.J., 1959.

2. S. Simecek and W. T. Trask, The Integrated Fluid-Bed System, Report MCW-1478, Mallinckrodt Chemical Works, Uranium Division, Weldon Spring, Mo., 1963.

3. General Electric Company, Design and Analysis, Midwest Fuel Recovery PZant, Docket No. 50-268, 1966.

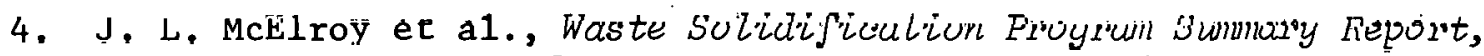
vol. TT, Fvaluatinn nf WSFP. High Level. Waste Solidification Processes, Report BNWL-1667, 1972.

5. L. T. Lakey and J. R. Bower, ICPP Waste Calcining Facility Safety Analysis, Report IDO-14620, National Reactor Testing Station, 1963.

6. Argonne National Laboratory, Chemical Engineering Division Summary Report October, November, and December 1954, Report ANL-5388. 


\subsection{WASTE HANDLING SYSTEMS}

Radioactive wastes in gaseous, liquid, or solid forms are generated in essentially all operations associated with nuclear energy facilities, beginning with the mining of ore, through feed material production, reactor operation, chemical reprocessing of reactor fuels, and a wide variety of uses in medicine, agriculture, and industry. Because of the chemical and radioactive nature of these wastes, including, in specific cases, long effective life, ability to damage human tissue, and potential danger as environmental contaminants, the safe handling and disposal of these wastes are integral and important aspects of nuclear operations.

The goal of waste management must be to dispose of wastes as safely and as economically as is practicable. The first emphasis must be on health and safety because of the insidious hazard which radioactivity poses. Not only must the safety of the general public be considered, but also that of the people who work as a part of the waste management system. While safety is most important, economy is so basic that it must be considered as a close second in importance, since no operation can continue long if its costs cannot be justified. Practicability must be included, since it strongly influences both safety and economy. All these factors must be taken into account in the planning and operation of a waste management system. ${ }^{1}$

Since there is no practical process for destroying the radioactivity of nuclear wastes, there are basically only two things that can be done with them:

1. The radioactive materials may be permanently confined or isolated within restricted areas away from people and their resources. This is the concept of concentrate and contain, which is usually applied to high-activity-level liquid and solid wastes.

2. On the other hand, the radioactivity may be reduced to safe levels by dilution in nature. This is the concept of dilute and disperse, which is often applied to low-activity-level liquid and gaseous waste.

These concepts are widely used in nonnuclear industrial waste handling. An example of the first concept is the use of trash for landfill a type of contaimment. An example of the second concept is the release of smoke, noxious gases, and other products of combustion into the atmosphere for dilution. The nuclear Industry applies these concepts by concentrating and containing fuel reprocessing wastes, evaporator residues, incinerator ash, etc., in tanks and by diluting and dispersing low-level radioactive liquids into surface waterways and radioactive gases into the atmosphere from tall stacks.

A combination of these two concepts, called partial containment consists of discharging a waste to nature in such a way that, although control is lost, the rate at which hazardous materials return to the part of the biosphere used by man is so slow that no damage will occur. An 
example of this concept is the discharge of waste into a natural geological formation where the ion-exchange properties of the soil plus the time required for the liquid to reach the water table and then get back to man is so long that the waste will have decayed before it reaches man. This example also illustrates the technique of delay and decay, which is especially applicable to very short-lived radioisotopes that can be held in tanks or ponds until most of their radioactivity has disappeared.

While it would be desirable to discharge no radioactivity to the environment, it is impractical to make a waste concentration process so effective that $100 \%$ cleanup can be accomplished. Thus, it is necessary to select some realistic disposal level which can be maintained at a reasonable cost. The factor of cost enters because in most processes for removing radioactive contaminants from waste, the cost of processing increases directly with the degree of removal required. To achieve a discharge level approaching zero radioactivity would be extremely expensive. As the discharge level is permitted to increase, the cost of processing tends to diminish rapidly; however, a point is reached where real or imagined injury to the surroundings and its inhabitants occurs. If this should happen, the costs of restoring the environment and of medical treatment of the victims, in addition to damages awarded as a result of lawsuits, would become highly important, and the cost would increase markedly. Moreover, restoration of the environment might be impossible, and productive areas might be lost for an indefinite time.

Note the use of the term "imagined injury." Because the public is particularly apprehensive about the menace of radioactivity in its drinking water and in the air it breathes, limits of radioactive discharge must be kept low enough to provide a public reassurance factor to avoid imagined injury.

The radioactive content of wastes that come from reprocessing reactor fuel represents more than $99.9 \%$ of the total produced by the nuclear industry. When spent fuel is dissolved, all the fission products go into solution, are liberated as gases or aerosols, or are collected as solid waste. Figure 7.15 .1 shows the flow of radioactive materials in a typical fuel reprocessing plant. The major radloaclive elements of roncern to waste management are listed in Table 7.15.1, the upper portion of the table showing the fission-product elements and the lower portion the actinides. The table also shows the radioactivity levels of these elements (in curies*) at various times from 90 days to 1,000 years after the fuel originally containing them was removed from a typical reactor operated at $30 \mathrm{MW}$ per metric ton of uranium and irradiating the fuel for 33,000 MW-days/metric ton. After aging a few months, wastes from different types of fuel do not show much difference in their radioactive constituents, although the chemical nature of the waste depends on the reprocessing method used. In American reprocessing plants, about $2 \mathrm{~m}^{3}$ (530 gal) of high-activity waste $\left(10^{6} \mathrm{Ci} / \mathrm{m}^{3}=10^{3} \mathrm{Ci} / 1 \mathrm{iter}\right.$ or about

* See definition in Section 6.1.1. 


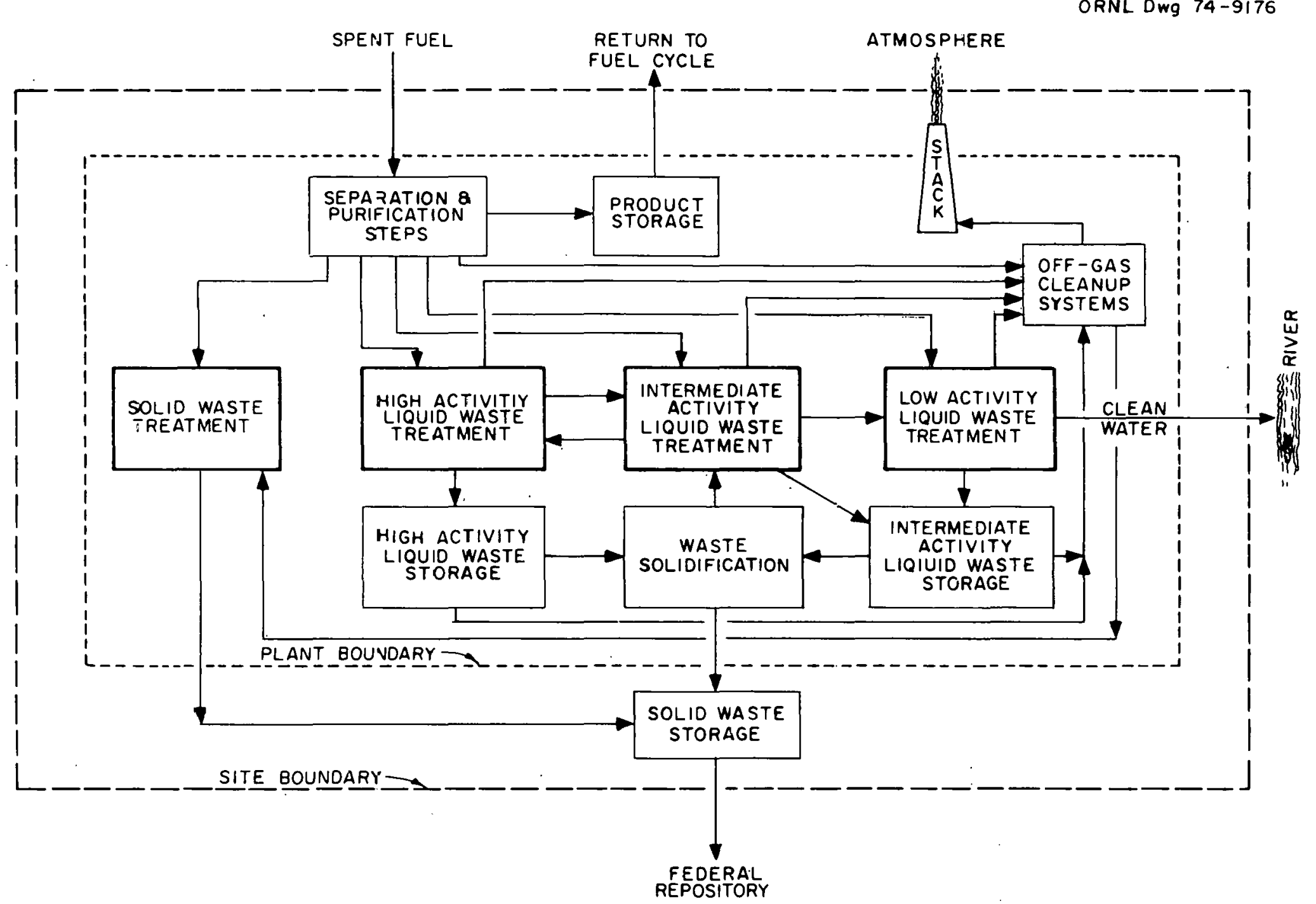

Fig. 7.15.1. Flow of Radioactive Material in a Typical Fuel Reprocessing Plant 
Table 7.15.1. Calculated Radioactivity (Total) Present in Spent Typical Reference LWR Fuel and in the Wastes Generated by the Reprocessing of This Fuel*

Power $=30.00 \mathrm{MW} / \mathrm{MT}$, Burnup $=33000 . \mathrm{MWd} / \mathrm{MT}$, Flux $=2.91 \times 10^{13}$ neutrons $/ \mathrm{sec} / \mathrm{cm}^{2}$

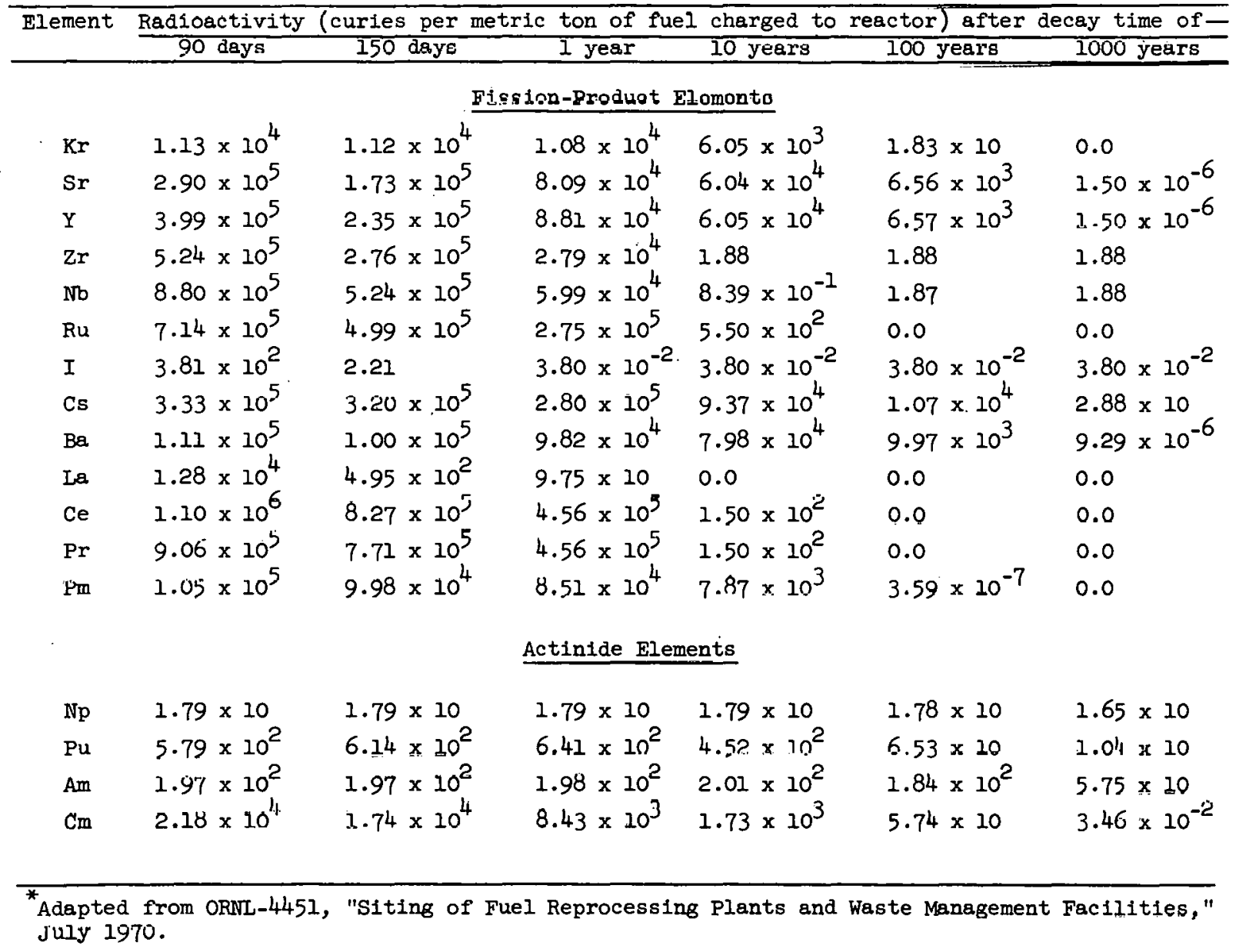


4,000 Ci/gal) are produced for every metric ton of uranium processed. This volume is usually concentrated to between 100 and 300 gal for temporary (five years maximum) storage before solidification by calcining.

It has been estimated that by 1980 the nuclear power industry in the United States will have produced $10,000 \mathrm{~m}^{3}$ (about 2,600,000 gal) of waste containing $10^{10} \mathrm{Ci}$, of which about $8 \%$ will be strontium-90. Although this is a huge volume, it is well within the limits of present technology, since several times this much high-activity waste is already stored in nearly 200 tanks in the United States. Tank storage is considered a temporary expedient, and techniques for solidification into glasses or other forms and ultimate storage in deep geological formations are being developed.

Intermediate-activity wastes (in the range of a curie per liter) arise from washing of solvent used in the extraction process, equipment decontamination, spills and leaks, regenerants from ion exchangers, and chemical decladding of fuel elements. These wastes are usually evaporated; the concentrate is stored temporarily in tanks before being solidified, and the condensate is sent to low-activity waste (see Fig. 7.15.1).

Low-activity wastes (in the range of a microcurie per liter) are frequently more troublesome to manage than high-activity waste, because their volumes are too large for tank storage. Approximately $20,000,000 \mathrm{~m}^{3}$ $(5,300,000,000 \mathrm{gal})$ of such wastes are produced each year in the United States alone. At nuclear sites remote from public water supplies, much of this waste can be discharged into the ground, but other sites must employ various treatment methods to reduce the radioactive content of waste discharged to the environment. The sources of low-activity wastes are laundry and decontamination-center effluents, cooling water that has the possibility of being contaminated, and wash water from cleanup operations.

Reprocessing of fuel produces radioactive gaseous waste in the form of volatile and gaseous fission products -- bromines, iodines, xenons, and kryptons, which are liberated when fuel elements are dissolved. Ruthenium, although not normally regarded as gaseous, is volatilized in some dissolving procedures.

Solid wastes consist of outworn equipment, unserviceable clothing and respirators, exhausted filters and gas-purification media, waste ionexchange resin, and even whole buildings. Glasses, ceramics, slags, and other colids used for nltimate disposal of high-level wastes; sludges and scavenging media resulting from treatment of low-level wastes; and cladding material from mechanical decladding of fuel elements must be included also. 


\subsubsection{Liquid Waste Systems}

Waste management policy for high-activity liquid wastes is specified in the Code of Federal Regulations, Title 10, Part 50 (10 CFR 50), Appendix F. The handling of low-activity liquid wastes is governed by state and Federal (10 CFR 20) laws for water quality control.

Intermediate-activity liquid wastes are treated to produce low-activity liquid waste streams and concentrates or solids. The concentrates and solids are managed and disposed of by the same procedure used for highactivity wastes. Three barriers are used to confine radioactive materials in reprocessing plants: the first consists of the process vessels, the interconnecting piping, and the highly efficient vessel off-gas train; the second is the thick concrete cell wall designed to provide shielding against radiation; and the third is an industrial building which surrounds all penetrations in the cell walls and doors. The cells are kept under slight negative pressure and the building under a slightly higher pressure but lower than atmospheric pressure in order to force air to move from less radioactive areas to areas of higher activity and on to the ventilation treatment system before release to the atmosphere. Liquid wastes from reprocessing operations are managed in facilities similarly provided with three barriers of confinement -the tanks, concrete vaults, and a building, plus treatment of off-gases from waste treatment and storage facilities as shown in Fig. 7.15.1.

Chemically, high-activity liquid wastes from variations of the PUREX solvent-extraction process for recovering light water reactor fuel are nitrates of sodium, iron, and fission products, with smaller concentrations of other constituents such as chromium and nickel. In some processing schemes, sulfates can be present in significant quantities.

In the past, wastes were stored containing as much as $6 M$ free nitric dcid, dentrrated to less than $1 M$ free nitric acid, or made alkaline with caustic with or without prior denitration. However, beralse the addition of large quantities of inert materials, such as caustic, increases the volume of the waste and makes other problems in the storing of liquid and in solidifying it, and because recent Federal regulations require that high-activity liquid wastes be solidified for ultimate disposal, most such wastes will hereafter be stored in the acidic state. The acid or nitrate concentration may be adjusted to sontrol oor ruvion rates or oxidizing potential during processing or storage of the wastes.

Each 1000 MWd (megawatt-day) of thermal nuclear energy yields approximately $0.9 \mathrm{~kg}$ of nongaseous fission products plus $0.04 \mathrm{~kg}$ of transuranium and transplutonium elements (americium, curium, neptunium, etc.) and plutonium (as a waste loss). High-activity wastes contain essentially all of the intensely radioactive nonvolatile fission products in the irradiated fuel. The primary fission products of concern in waste management are a mixture of more than 37 elements having atomic numbers ranging from 30 to 64 . Most of these are radioactive, and more than 300 different isotopes have been observed. However, the number of radioactively important nuclides is about a dozen, as shown in Table 7.15.1. 
Strontium-90, with a 28-year half-life, is a principal contributor to the long-term activity of the waste and is the most serious hazard in the fission product spectrum, reaching man through his consumption of dairy products and foods of plant origin (milk being the largest source). Strontium moves with calcium and is incorporated into bone, where, because of its long half-life, it remains as an internal source of radiation. Cesium-137 has a 26.6-year half-life and is another significant long-term fission product, remaining as a principal radioactive isotope in waste for a long time. It has a biological half-life of 70 to 140 days in the human. The first critical organ is muscle, then kidney, spleen, liver, and bone in that order.

Parasitic capture of neutrons by fissionable materials or by the fertile isotopes uranium-238 and thorium-232 also produces significant amounts of radioactive materials that end up in the liquid wastes. Neutrons from the fission of plutonium-239, uranium-235, and uranium-233 are captured to produce other heavy elements shown in the lower part of Table 7.15.1.

The usual limit for release of radioactive liquid waste to the environment is established at 0.1 times the maximum permissible concentration in drinking water $\left(\mathrm{MPC}_{\mathrm{w}}\right)$ of the most hazardous radionuclides present in the waste to make allowances for possible error in monitoring their escape to surrounding and subterranean areas. A similar allowance for atmospheric releases is used for gaseous and semivolatile radionuclides with the exception of iodine, which requires special and more stringent control because its meteorological, botanical, and biological behavior causes more hazard to man. Therefore, iodine release should be minimized and controlled to less than $0.01 \%$ of its MPC in air or water.

7.15.1.1 High- and Intermediate-Activity Liquid Waste Handling Systems Most high-activity waste from the reprocessing of nuclear fuel originates as the aqueous raffinate from the first-cycle solvent-extraction step (see Section 7.6). In some reprocessing plants, aqueous raffinate from subsequent extraction cycles may be included in high-activity waste also, but these streams are usually several orders of magnitude less radioactive and are more often handled as intermediate-activity waste along with wastes from other sources. The high-activity wastes create the most challenging problems in waste management because of the intense radioactivity $(100 \mu \mathrm{Ci} / \mathrm{m} 1$ to thousands of curies per liter of liquid and, if they are made alkaline, 70 to thousands of curies per kilogram of solids). Furthermore, substantial amounts of heat are generated in them from radioactive decay, which will raise the temperature to the boiling point if cooling is not provided; and the long-lived fission products in them need hundreds of years to decay to safe levels (see Table 7.15.1). During all this time, these wastes must be carefully managed to minimize the potential hazard they present to man and his environment. 
An area some distance away from the main reprocessing plant is usually provided for storage of concentrated high-activity wastes. The concentrators may be located either in the main reprocessing plant or in the waste management area, but it is desirable to minimize the distance that concentrated high-activity waste must be moved, both because of the potential hazard from leaks and because of shielding and pumping problems. Evaporation (see Section 7.7) is the preferred method for concentrating high- and intermedlate-activity wastes, because of 1 is relatively high decontamination factors and the convenience it offers for recovery of nitric acid from the wastes (Section 7.7.7).

Because of the high radiation levels associated with high-activity wastes, treatment and storage facilities are usually located underground to minimize shielding requirements. Nonetheless, cells or vaults with concrete walls and roofs several feet thick are necessary to contaln such equipment. The floors and walls may also be lined with stainless steel to protect the concrete from acidic attack resulting from leakage of waste. A system of sumps equipped with liquid level measuring devices and alarms must be provided to warn of liquid waste leaking from treatment or storage vessels. The tanks, pipes, jets, pumps, and other equipment in contact with acid waste must be made of corrosion-resistant material, usually stainless steel.

High-activity wastes are usually stored in cylindrical tanks that vary in size from plant to plant. The older reprocessing plants use tanks 75 to $85 \mathrm{ft}$ in diameter and 20 to $32 \mathrm{ft}$ high, which can hold about $1,000,000 \mathrm{gal}$ of alkaline waste each. These tanks are made of reinforced concrete lined with carbon steel or are themselves made of carbon 3 teel, mounted in steel saucers to catch leakage, and housed in cuncrete vaults to carry the weight of the 7 to $10 \mathrm{ft}$ of earth above them that provides radiation shielding. ${ }^{2}$ Newer reprocessing plants use smaller tanks (40 to $54 \mathrm{ft}$ in diameter and about $20 \mathrm{ft}$ high) that hold from 150,000 to 300,000 gal of acidic waste each. Several tanks may be housed in a single vault, or each tank may be in a vault to itself. Since a spare tank must be provided to receive the contents of any tank found to be leaking, high-activity waste storage tanks are usually installed as multiple units.

\section{Waste Storage Tank Auxiliary Equipment}

To provide safe interim storage for high-activity liquid waste, the tanks containing the waste must be equipped with the following:

1. A system to reject the radioactive decay heat generated by the waste. This is usually a series of cooling coils arranged in segments, each of which can be isolated in the event one of them springs a leak. A reflux condenser should also be located in the off-gas piping that vents one or more storage tanks. The objective in removing decay heat is to lower the temperature of the waste to about $140^{\circ} \mathrm{F}$ in order to (a) reduce corrosion of the metal surfaces 
of the tanks and other equipment and (b) prevent loss of water by evaporation from the stored waste, resulting in precipitation of dissolved solids. The heat reject system must also include provisions for emergency cooling in the event of failure in the water or power supplies.

2. A system to provide sufficient air flow through the tanks to maintain the hydrogen content of each tank's atmosphere below the explosive limit. Hydrogen is evolved by radiolytic decomposition of water in the highly radioactive waste.

3. An agitation system to minimize the settling of solids. This is usually a series of air-lift circulators suspended through nozzles in the tank top and extending to within a few inches of the tank bottom. Air is usually used to provide supplemental sweeping of hydrogen from the tank and to avoid using mechanical agitators, which would require lubrication and maintenance. Solids settling in the tanks tend to cause hot spots, which can damage the tanks and cause plugs in instrument dip lines.

4. An instrumentation system to provide redundant liquid-level and specific gravity indicators, measurement of the pressure of the tank atmosphere, and multiple temperature sensing points.

5. An off-gas system provided with reflux condensers to return evaporated water to the waste tanks, filters and iodine scrubbers to prevent discharge of radioactive materials to the atmosphere, sampling devices to permit testing of the efficiency of the system, and pressure-vacuum relief valves to protect the waste storage tanks and the off-gas system from pressure surges.

6. A system of sumps provided with liquid level indicators in the tank vaults to detect when a tank is leaking.

7. A system of jets and discharge lines to permit further processing of the waste and to allow a leaking tank to be emptied to a spare tank.

8. Sampling devices to allow accountability measuring and other data about the liquid contents to be taken and off-gas samplers to permit measurement of hydrogen evolution and other data on each tank's atmosphere.

The intermediate-activity tanks require the same auxiliary equipment except for cooling and high air flow to remove hydrogen. 
Solidification of High-activity Liquid Wastes

All high-activity liquid wastes will eventually be processed to a solid form for ultimate disposal. Several methods for waste solidification have been tested. Some are now ready, and others will be ready for industrial application within the next few years. These methods, listed graphically in Fig. 7.15.2, are spray calcination, pot calcination, fluidized-bed calcination (Sect. 7.14), and phosphate glass formation. The best final method has not been decided; a trade-off between solubility and physical properties is still in question. Any of these methods may be acceptable from operational and safety standpoints.

All processes for solidifylng high-activity liquid wastes generate additional waste streams that contain intermediate levels of radioactivity. These are the vapor or condensate streams from the solldifler, which have been decontaminated by factors of 10 to 1000. Further decontamination requirements for these effluents are comparable with those for effluents from the high-activity liquid waste. These elflueril streams would logically and readily be recycled to the existing high-activity liquid waste concentration and processing equipment, requiring unly a modest increase in capacity (on the order of 10\%) of that portion of the reprocessing plant.

7.15.1.2 Low-Activity Liquid Waste System - In addition to the highactivity 1iquid wastes from fuel processing plants, large volumes of liquid wastes containing low concentrations of radioactive materials are produced during these operations. For most of these wastes, it is practical to reduce their radioactivity to levels within the established standards for release to the environment by treatment methods such as flocculation and precipitation, ion exchange, evaporation, or retention to allow for the decay of radionuclides.

The low-activity liquid wastes from fuel processing are not greatly different, chemically, from natural waters. They contain only very small amounts of inert chemicals and radionuclides in addition to the chemicals that contribute to natural hardness. The radionuclides of greatest routine importance in these wastes are strontium-90, cesium-137, ruthenium-106, and trilium; however, under unusual circumstances of accidental contamination, other fission products, as well as cobalt-60, uranium, plutonium, and thorium, may also be present.

Low-activity liquid wastes originate from radioactive fuel reprocessing operations in streams such as the condensate from evaporation operations and from nonprocess liquid waste such as drainage from the plant laundry, analytical laboratories, and equipment decontamination work and from safety showers and floor drains in the contamination zones. These wastes are very large in volume. Evaporator condensates alone may average $10,000 \mathrm{gal}$ per metric ton of fuel processed, and the total generation from all sources within a plant may average several hundred thousand gallons per day. Because of their great volumes and low concentrations of radionuclides, these wastes have been suitable for environmental disposal. 

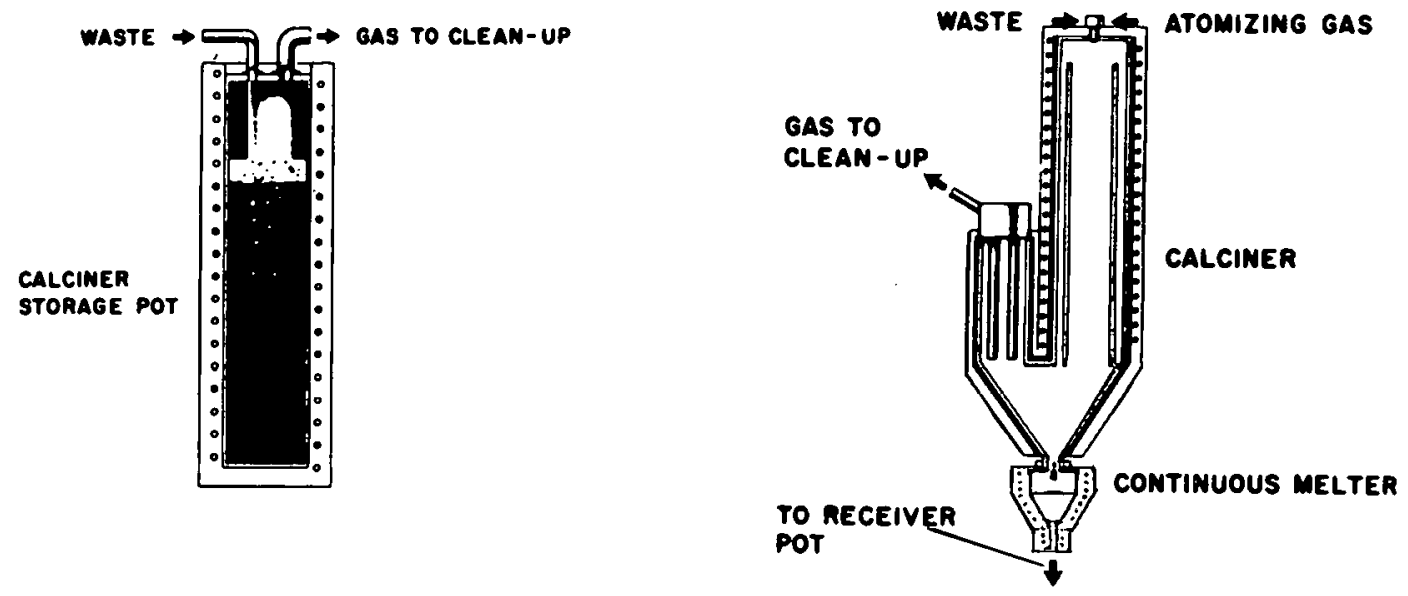

a - Pot Solidification

b - Spray Soliditication
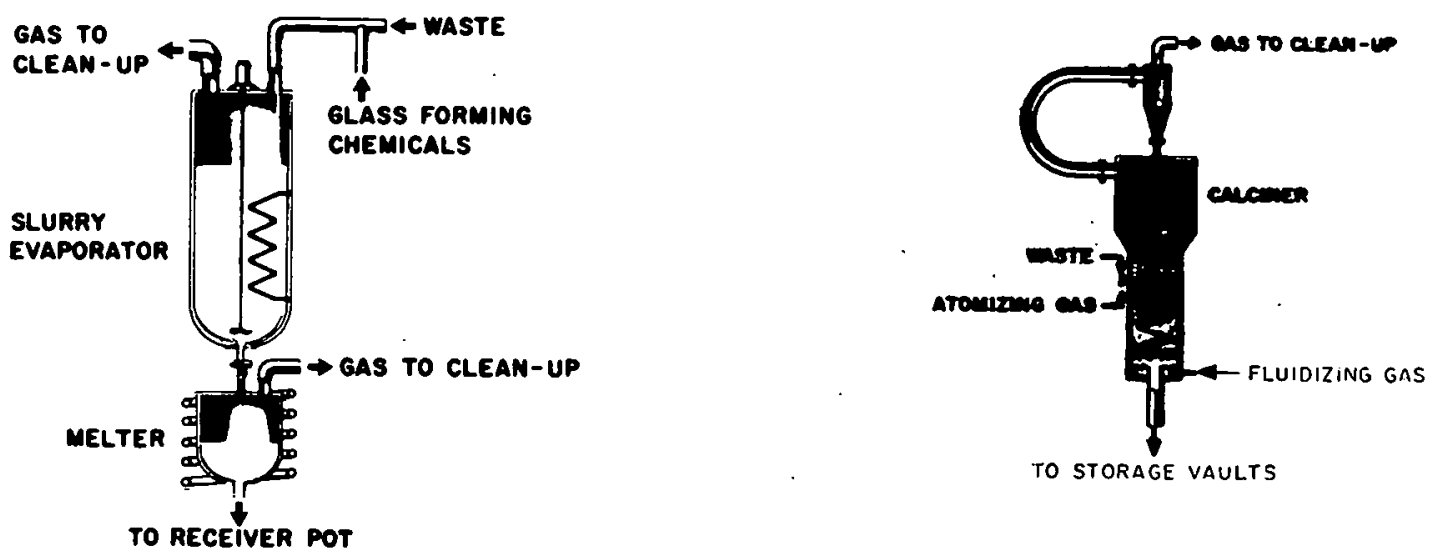

TO STORAGE VAULTS

c - Phosphate Glass Solidification

d - Fluidized Bed Solidification

Fig. 7.15.2. Primary Solidification Techniques in the United States (Drawing by Courtesy of Battelle-Northwest Laboratory) 
At ERDA production sites, where processing plants are located on large tracts of land, ground disposal via seepage basins, cribs, trenches, etc., has been practiced. In these cases, the sorptive capacity of the soils is such that the majority of the isotopes are retained and, in turn, contamination of the groundwater is reduced. Each year during the past several years, almost $1,000,000,000$ gal of low-activity waste, containing an average of 35 to 415 kilocuries of radionuclides, has been safety discharged in this manner. In Europe, such wastes receive appropriate treatment for decay or decontamination and are then released to the sea or to rivers.

The trend, however, is toward relatively less dependence on the environmental disposal of radioactive wastes. This reflects an awareness of the projected greatly increased production and application of radioisotopes and of the realization that the pressures of an expanding population and nuclear industry will make it difficult for remoteness to provide the necessary safety factor between the point of waste discharge and the polnt of population exposure. Present regulations (10 CFR 20) encourage a minimum of dependence on environmental dispersion and contain a standard clause requiring reduction of the radioactivity in effluents to $10 \%$ ( $0.01 \%$ for iodine) of the continuous occupational MPC before the effluents are discharged to unrestricted area; however, amendment of licenses to permit higher limits is possible if the licensee makes a "reasonable effort" to minimize radioactive discharges and if the resulting exposure of individuals in nearby areas is not likely to exceed $10 \%$ of the continuous occupational MPC.

Evaporation, ion exchange, and coprecipitation and coagulation processes are most frequently used for removing radionuclides from low-activitylevel wastes; the choice of treatment depends on factors such as the degree of decontamination required, the volume of waste to be treated, and the considerations of cost that pertain at the installation in question. Although evaporation generally yields the highest decontamination factors (ratios of the activity in the feed to that in condensates of $10^{4}$ to $10^{5}$ are routinely obtained), the cost is in the range of several cents per gallon. Single-stage coprecipitation processes typically remove from 60 to $90 \%$ of the radioactivity at a cost in the range of $\$ 1.00$ per thousand gallons. Ion exchange with either natural minerals or organic resins is frequently used in conjunction with precipitation for additional decontamination at extra cost. In addition to partially decontaminated waste water (which can be released to surface waters), each process produces a sludge, a slurry, or a solution containing the separated isotopes. This material is usually packaged and may have to be shipped off site for burial. Attention has been given to incorporating the precipitation sludges, organic wastes, the ion-exchange regenerants, the ion-exchange media, and ashes from the incineration of combustible waste materials into low-solubility solid bodies for disposal by burial. In addition, a method based on the hydraulic fracturing of shale has been developed for disposing of liquid wastes. 


\subsubsection{Gaseous Waste Systems (see also Sect. 7.16)}

The primary sources of release of gaseous radioactive fission products from a fuel reprocessing plant occur in the dissolution, digesting, and evaporation processes. Practically all the tritium in irradiated fuel elements is released to the environment during the processing of spent fuel. This release is in the form of HTO, either as tritiated water or as tritiated water vapor. Essentially all the noble gases krypton-85 and xenon-133 are released from the fuel during the mechanical processing and dissolution steps. About 90 to $99 \%$ of both krypton and xenon can be retained by means of processes that use sorption, fluorocarbon scrubbing, or membranes to remove them from the gaseous waste before it is discharged. The amounts of these radioactive gases and vapors that may be released to the environment are controlled by state and Federal (OSHA) government agencies.

Airborne wastes containing radioactive contamination can be divided into two categories: (1) volatile and gaseous radioactive elements and compounds and (2) aerosols containing radioactive liquid or solid mist and droplets. The volatiles comprise the largest portion of the radioactivity in airborne releases from fuel reprocessing plants, because aerosols are more effectively removed from the contaminated air stream.

Ventilation air for process buildings is supplied from the atmosphere by fans which pump the outside air through roughing filters and then through heating and cooling coils to condition the air prior to its entry to the offices and uncontaminated work areas of the facility. From these areas, air flows through roughing filters in the inlet ducts supplying air to the hot processing cells. A pressure differential is maintained in a gradual gradient between the hot cells and outside. A negative pressure relative to the ambient atmospheric pressure is maintained in the hot cells.

Process or hot off-gas originates when cell air or purge air or gas becomes contaminated by contact with process materials as the gas is drawn into the vessel off-gas system. Process off-gas is treated separately to remove or reduce the level of contamination and is then directed to the cell ventilation system to receive further filtration prior to disposal to the environment. Treatment of off-gas from process equipment varies significantly depending on the gas and its history and composition.

Process off-gas systems also collect, treat, and dispose of contaminated air from operations such as fuel-element disassembly, cropping, and shearing work conducted in open equipment inside the process cel1. The process off-gas system may also serve high-level waste storage tanks and other containers in which gases, volatiles, or aerosols containing radioactivity may arise. 
The principal methods used to treat gaseous effluents are (1) delay for radioactive decay, (2) charcoal absorbers to retain iodine, (3) charcoal beds to delay the release of noble gases, (4) high-efficiency (HEPA) filters to remove particulate materials, and (5) cryogenic distillation or selective adsorption for the removal of the noble gases. The latter method may provide for long-term storage of the noble gases (a minimum of 30 years). The airborne activity confinement system for the dissolver off-gas system is designed to collect halogens and particulates that are present in the dissolver off-gas.

Administrative controls and stack and environmental monitoring programs are maintained to ensure the continued effectiveness of operating procedures and to detect any trends requiring corrective action. Atmospheric contamination and fallout in the general environment are usually monitored by the following: (1) Airborne particulates and radioiodine contamination are evaluated from samples collected by passing air continuously through filter paper backed up by cartridges containing activated charcoal. (2) fiallout is monitored by means of gummed-paper fallout trays. (3) Rainout is measured from samples of rainfall collected at the air monitoring station sites. (4) Samples of milk produced nearby are collected and analyzed for iodine-131 and strontium-90.

\subsubsection{Solid Wastes}

Solid wastes of widely diverse nature and contaminated to varying degrees with many different forms of radioactive materials are generated in fuel reprocessing operations. The sources of radioactivity in these wastes are fission products, induced radionuclides such as those in reactor fuel cladding, and alpha-active transuranium elements, principally plutonium.

Solid radioactive wastes are essentially dry or contain sorbed fluids in sufficiently small amounts to be immobile in the soil, if the wastes are buried. Solid wastes are further classified by handling requirements that are determined by size, weight, and radiation intensity. Typical waste packages includes boxes (made of cardboard, wood, concrete, or steel), steel drums, scrap metal, dirt, absorbent paper, various filter media and frames, all types of glassware, powder, wire, depleted uranium, major equipment pieces, solidified high-level retrievable waste, solids from mechanical dejacketing of fuel, and waste solidified and encapsulated for burial or storage under water.

\subsubsection{Definition of Terms}

1. Solid Radioactive Waste - In general, radioactive waste material that does not flow perceptibly is considered as solid radioactive waste. Solid radioactive waste may include contaminated or irradiated waste material such as paper, laboratory glassware, scrap metals and lumber, discarded clothing, equipment, etc. 
2. Transferable Contamination - Unconfined surface contamination that can be easily rubbed off the surface to which it clings or can be otherwise easily removed and transferred to other locations.

3. Routine Solid Radioactive Waste - Solid radioactive waste, deposited in either an approved hot can or a specially marked auto truck dump container, where the radiation reading at contact with the outer surface of the receptacle does not exceed (a) $200 \mathrm{mrad} / \mathrm{hr}$ for the hot can or (b) $400 \mathrm{mrad} / \mathrm{hr}$ for the dump container.

4. Nonroutine Solid Radioactive Waste - Solid radioactive waste segregated in hot cans with exterior surface readings in excess of $200 \mathrm{mrad} / \mathrm{hr}$ or in specially marked auto truck dump containers with exterior surface readings greater than $400 \mathrm{mrad} / \mathrm{hr}$; other solid radioactive wastes that cannot be reasonably contained in hot cans or specially marked dump containers; and radioactive, toxic, pyrophoric, explosive, or other material requiring special disposal arrangements and instructions.

7.15.3.2 Management of Solid Wastes - Policies and criteria for handling radioactive solid waste are established and regulated by the Nuclear Regulatory Commission (NRC) acting under the authority of the Atomic Energy Act. Specific regulations for disposal of high-activity solid wastes are specified in $10 \mathrm{CFR}$ 50, Appendix F. Other solid radioactive wastes may be buried on land not owned and controlled by the Federal government in near-surface burial locations approved by the NRC. Since early 1970, it has been an AEC (now NRC) requirement that all solid wastes containing significant amounts of transuranium nuclides be segragated, contained, and stored retrievably.

Most solid wastes must be collected, treated, and disposed of on a routine basis; but during periods of shutdown, decontamination, or other abnorma1 conditions, special arrangements may be necessary to handle large or bulky solid items, such as contaminated damaged vessels and other major equipment pieces or even parts of buildings. As indicated in sect. 7.15.1.1, the routine solid radioactive waste is collected in hot cans or other containers for transfer to the waste treatment building. Cardboard boxes may be used for slightly contaminated wastes such as wiping tissues, rubber gloves, and contaminated clothes. Steel drums are usually used for. grossiy contaminated rags and small pieces of hardware. The drums may be shielded or transported in shielded containers. Large pieces may be placed in wooden, concrete, or steel boxes, depending on size, weight, and radioactivity. Exposure dose rates from packages of this size may require remote handling during the filling, transport, and burial operations.

Solid wastes containing significant amounts of transuranium nuclides are to be segregated from other radioactive solid wastes. Combustible and noncombustible transuranium-contaminated wastes should be packaged separately and stored in locations apart from other radioactive solid wastes so that the packages can be readily retrieved in an intact, 
contamination-free condition for 20 years. The packages should be suitably labeled so that the wastes they contain can be identified by cross-reference to permanent records.

Treatment of solid wastes may consist of compaction or baling of paper and other crushable material. Incineration of combustible material may be practiced, but the handling of radioactive off gas from incinerators is difticult, and there is always danger of igniting the filters in the off-gas system of the incinerator. The ash, along with ion-exchange resin and evaporator sludges, may be encapsulated in cement or asphaltic material for safer burial.

Land burial of solid waste will probably continue in the future. Careful selection of burial sites is required, for waste confinement, for land conservation, and for preservation of water and air quality. Special vaults or other confinement facilities may be required. Containers of low-level solid wastes are disposed of in open trenches. An ideal trench is $10 \mathrm{ft}$ wide, $14 \mathrm{ft}$ deep, and up to $150 \mathrm{ft}$ long. Excavated material is placed adjacent to the trench to simplify backfilling. Although excavation may occur in advance of burial, backfill operations take place immediately after the placement of the waste in the open trenches. The ends of the trenches are usually marked with reinforced concrete posts and/or corrugated steel pipe to serve as reference points for monitoring trench conditions and for surveys.

Long-term disposal and retrievable storage are features common to practically all high-level solid waste management methods being practiced at this time. It is recognized that methods have not been found which provide for the ultimate in perpetual storage that will be needed to accommodate the radioactive wastes produced in this world's expanding nuclear economy. Methods that show promise in this category include disposal in salt mines, storage in deep underground caverns or in manmade and engineered vaults, and disposal in the ocean deeps.

\section{REFERENCES FOR. SECTTON 7.1.5}

1. I.A.E.A. Safety Series No. 24, "Basic Factors for the Treatment and Disposal of Radioactive Wastes," International Atomic Energy Agency, Vienna, 1967.

2. "Treatment and Storage of High-Level Radioactive Wastes," Proceedings of a Symposium, Vienna, October 1962, I.A.E.A. (published 1963). 


\subsection{VENTILATION SYSTEMS}

The functions of ventilation systems in a fuel reprocessing plant are (1) to supply a continuous sweep of clean fresh air to normally occupied zones in the plant and (2) to control airborne radioactive materials to meet the criterion of the Code of Federal Regulations, Title 10, Part 20 (10 CFR 20), that "radioactivity in gaseous effluents shall be reduced to levels which are as low as practicable before being released to the environs." These functions are achieved by dividing the ventilation systems into a series of supply and exhaust subsystems which are described in this section as (1) building ventilation, (2) cell ventilation, (3) process off-gases, (4) high-level and intermediate-level waste off-gas, (5) high-level and intermediate-level waste building ventilation, (6) iodine recovery building ventilation, and (7) miscellaneous ventilation. These systems utilize roughing filters, scrubbers, adsorption beds, and high-efficiency particulate air (HEPA) filters to remove radioactive materials and, finally, tall stacks for dispersing the cleaned air to the atmosphere. A flow diagram of a typical ventilation oyotem is shown in Fig. 7.16.1.

\subsubsection{Building Ventilation Systems}

The building ventilation system provides clean, conditioned fresh air for the laboratories and operating areas of the process buildings. The air is routed from areas of low contamination potential to areas of higher contamination potential. Interlocks are provided between these areas to maintain a slight pressure differential that prevents air flow backward to a lower contamination area.' Contamination within the laboratories is controlled by providing a minimum inward air flow of 150 linear feet per minute face velocity for each hood and glove box opening.

Air exhausted from the laboratory hoods, glove boxes, and the fuel receiving and storage areas is passed through a water scrubber to remove mists and particulate matter. The air is then combined with the building ventilation air and routed through a roughing filter, then through HEPA filters and out the stack. Glove box exhaust will normally receive an additional filtration step through HEPA filters prior to treatment by the water scrubbers.

The differential pressure is measured across the air locks, between areas, and across hoods, glove boxes, and all filter trains.

If this differential decreases below preset limits, an alarm sounds in the immediate area and in the control room. At the same time, additional ventilation air is automatically supplied to restore the desired differential. 


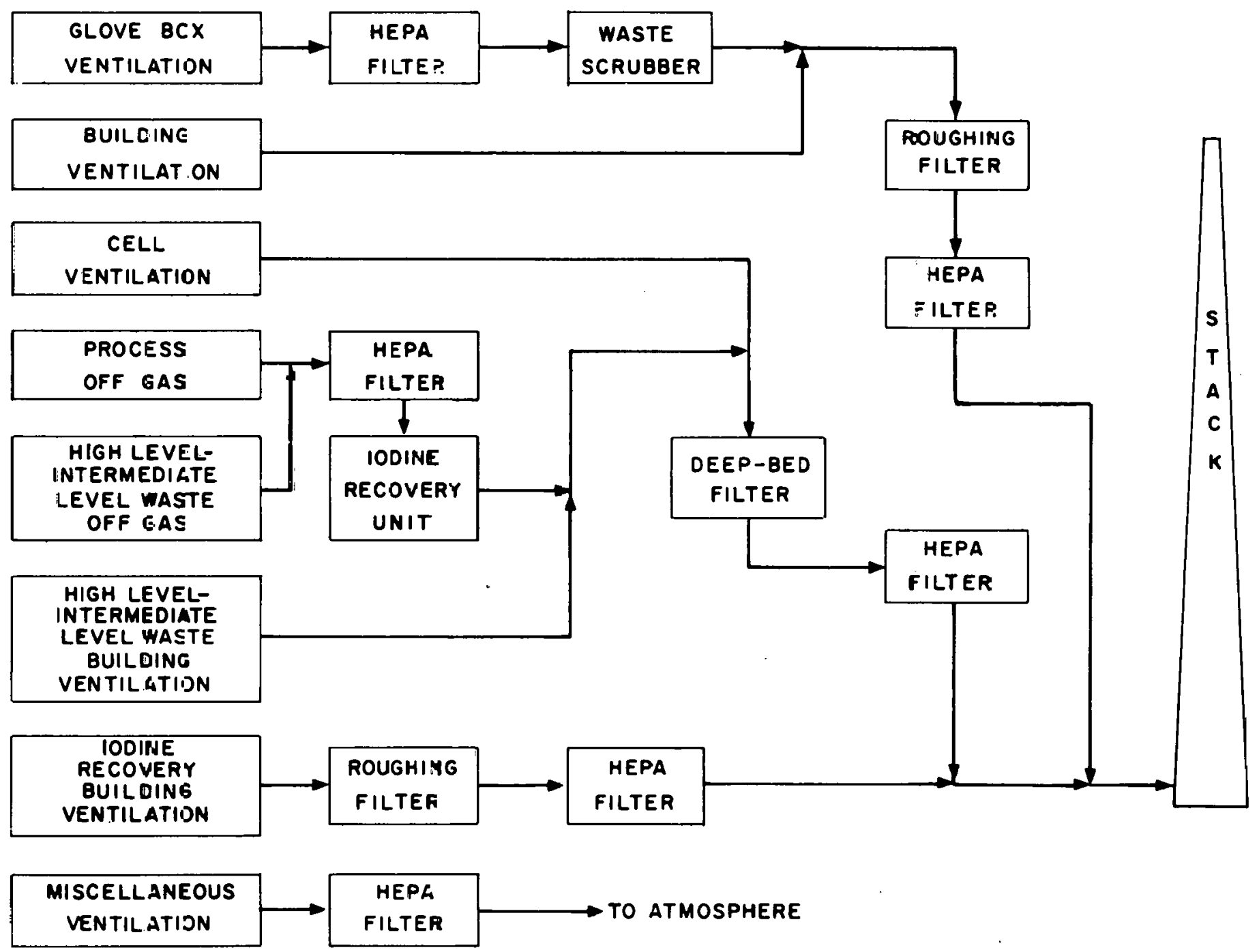

Fig. 7.16.1. Ventilation Systems 


\subsubsection{Cell Ventilation}

The cell ventilation system provides the primary control of radioactive contamination generated by processing and maintenance activities in the process, mechanical, and extraction cells and provides the secondary control for the process and storage vessels.

Normally, supply air for the cell ventilation system comes from the building ventilation system. If the pressure differential between the supply and the exhaust falls below a preset level, all supply air is routed through an absolute filter to prolong the life of the exhaust filters by removing inert matter. The exhaust air from the cell ventilation is routed through multiple roughing filters and then through HEPA filters before release to the environs by way of the stack. Safety interlocks activate and alarms sound when conditions warrant attention.

\subsubsection{Process Off-Gas and High-Levcl and InLetuediace-Level Waste off-Gas}

The process off-gas system maintains a negative pressure on the process vessels with respect to the surrounding cells. This system isolates the radioactive gases and particulates evolved in the dissolvers, process vessels, and the storage tanks for concentrated waste. These gas streams are first cooled and then treated b.y HEPA filters, iodine adsorbers, deep-bed filters, and a second HEPA train before being discharged to the atmosphere through the stack.

The instrumentation included for this ventilation system is composed of recorders for temperature, density, and liquid level. These instruments alarm in the control room whenever conditions reach a predetermined point.

\subsubsection{High-Level and Intermediate-Level Waste Building Ventilation}

The high-level and intermediate-level waste building ventilation system minimizes the airborne contamination in the routinely occupied operating aisles and areas of the process, storage, and support buildings of the high-level waste storage facility. Airborne activity is generated during normal operations and during periods of maintenance. The inlet air for this facilitity is filtered and conditioned for personnel comfort; a portion of the exhaust air from the cleaner areas is recycled for further use.

The air path in the storage building is again from areas of low contamination potential to a higher-potential area. Upon leaving the area of highest potential, the exhaust air is combined with the ventilation air from the cell ventilation system (Section 7.16.2) for treatment. Pressure differential indicators with alarms are supplied across the filter trains and air-lock passageways. 


\subsubsection{Iodine and Acid Recovery Building Ventilation}

The iodine and acid recovery building ventilation system prevents airborne contamination in routinely occupied operating areas of the iodine and acid recovery building. All inlet air is filtered and conditioned for personnel comfort. The sources of airborne contamination consist of redispersed radioactive material and material from maintenance activities and from the cells and equipmont in the huilding,

The exhaust air is routed through a roughing filter and then through a HEPA filter prior to release out the stack. Passage of ventilation air from the clean areas to the iodine cells is controlled by a system that consists of a pressure differential indicator operating a butterfly valve. During normal operation, air flows through a filter into the cel1. If the pressure ditterential belween the coll and the riean area falls below the set point, the valve cluses to isolate the cell from the clean operating aisle.

The differential pressure is measured across each filter holder in the building ventilation system. Each filter holder also has a local low-pressure alarm which sounds a trouble annunciation in the control room. The differential pressure across each bank of filters is recorded in the control room with a high differential pressure alarm.

\subsubsection{Miscellaneous Ventilation Systems}

Other ventilation systems serve such areas as the laundry building, the low-level storage building; and ventilators on chemical mix tanks. These systems normally release the air to the atmosphere, not through the stack, since the activity levels are within $10 \mathrm{CFR} 20$ limits. The air is processed by roughing filters and then through HEPA filters and can be recycled during the winter months. The differential pressure is measured across each filter bank. There are panel annunciators for high differential pressure and low differential pressure across the absolute filter banks. In addition, a pressure differential recorder is provided in each absolute filter bank. 


\section{PROCESS CONTROL}

Process control is often classed as a unit operation, and a most important one; for without reliable control methods, manual or automatic, process industries could not operate. The fuel reprocessing industry in particular depends on the remote measurement and control of process variables. Instrumentation and analysis have come to be an integral part of reprocessing.

Sampling is the very important first step in analyses. The object of taking samples is to learn the composition and characteristics of a bulk item from the results of examining samples taken from it. To achleve this objective, each sample that is analyzed must be representative of the bulk item at the time the sample is taken. The bulk material, therefore, must be homogeneous, and the sample must not be altered during the withdrawal or in handling, transporting, storage, or subsequent steps prior to inspection or analysis.

In fuel reprocessing, process instruments are those which measure specific parameters in a manufacturing process. For example, if steam were manufactured in a coal-fired plant, it would be desirable to know the water level in the boilers, the steam pressure, and other important operating variables. The instruments used to measure and/or maintain control of a process would be called process instruments.

In this section the principal methods of measuring the parameters of interest in such areas as coolant loops, waste systems, containment, primary and secondary process streams, and radiation control systems will be discussed. Much process information is read out either locally, or remotely in the control room, or both, on electrical or pneumatic indicators or recorders. In the case of the liquid level, the local instrument may be a sight glass, and the remote indicator may be a light and/or an alarm actuated by some other type of monitor.

The sensing clcment, often ralled just a sensor, is the instrument that does the monitoring of a parameter and can be equipped to furnish a signal for remote recording or readout. The transmitter is generally a force-balance type operating on plant air and producing a small airpressure signal proportional to the pressure in the monitored stream. The air-pressure signal is conveyed to a recorder, indicator, switches, and/or controller as required. The switches may operate interlocks, alarms, and operating lights. The controller actuates a device (generally a control valve) to modulate the process system to maintain the control desired.

\subsection{BASIC INSTRUMENTATION}

Instruments are provided in a process to (1) furnlsh information on process conditions to operating personnel, (2) control process variables, and (3) warn operating personnel when hazardous conditions develop. In 
a reprocessing plant this information is usually displayed on a graphic panel-board in a central control room.

The graphic panel is an ordered arrangement of recording, controlling, and indicating instruments and switches mounted on symbolic representations of primary pieces of process equipment and piping aligned like a flowsheet so that process operations can be easily followed from beginning to end. Farh rontrol point, valve, swilch, ludlcator, and recorder is located on or as near as possible to the symbol for the actual process point. Conventional flowsheet symbols for pieces of equipment assist in visualizing the process. For ease in differentiating and for better representing the process, colored lines usually represent piping. Since several instruments are often necessary for each piece of equipment, minature instruments are used.

Basic instruments fall into two general classes, (1) those that merely indicate and (2) those that indicate and autnmatically control. Most instruments are used for control purposes, but not all are automatic, and some are employed primarily as a guide for manual control. Recording instruments are used where a record of operating variables may be of use and may be helpful for material or energy balances. A typical circuit for remote control and display (as in the control room) of process variables is shown in Fig. 8.1.1.

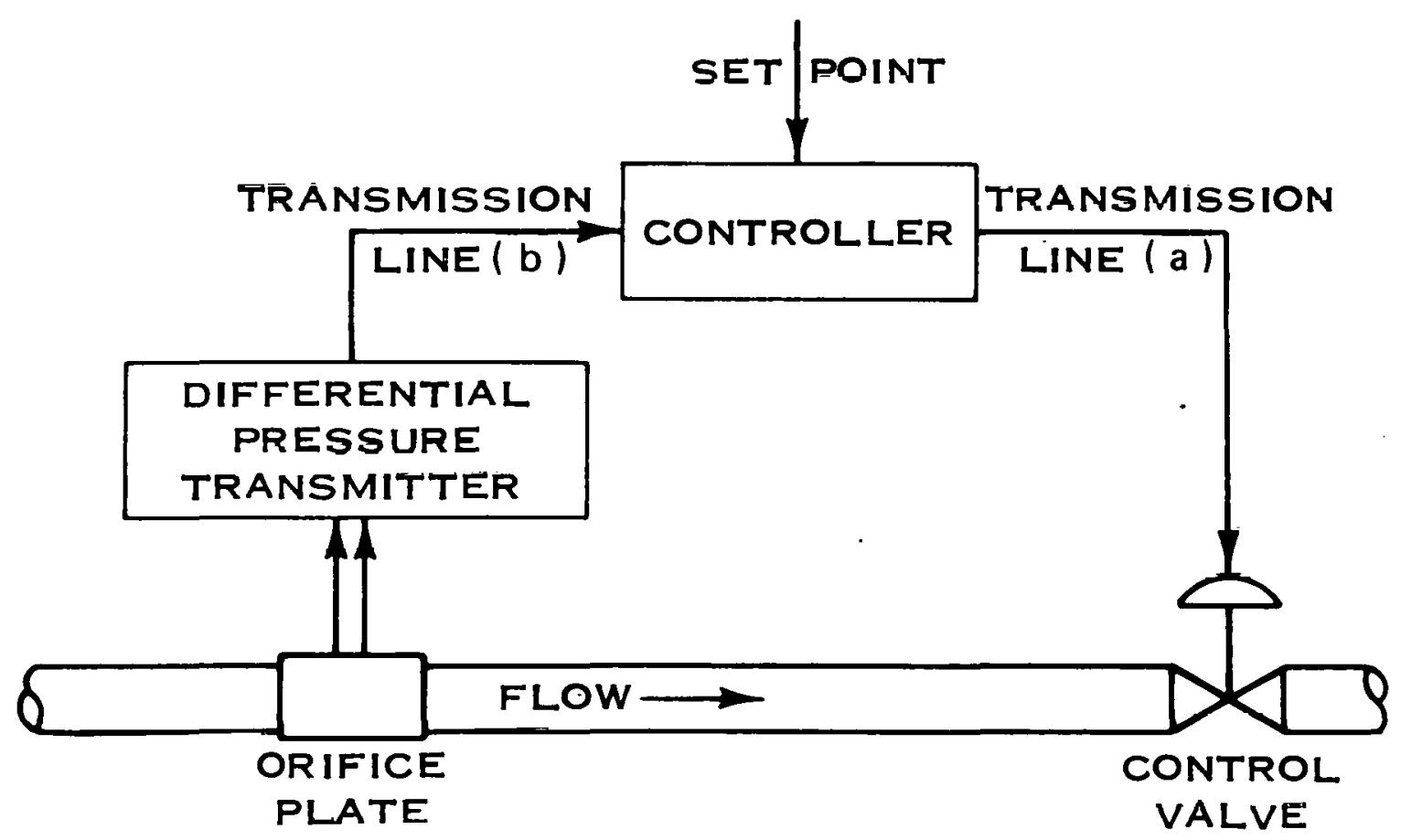

Fig. 8.1.1. Block Diagram of a Process Instrument Channel (From Chemical Engineers' Handbook, Fifth Edition, by Robert H. Perry/ Cecil H. Chilton, Copyright 1973, 1963 by McGraw-Hill, Inc.) 
To monitor and control all the different process variables requires a number of instruments, and sometimes two or three instruments may be needed to cover the entire range of one variable. Among the variables that require measurement and control in the nuclear reprocessing industry are temperature, pressure, fluid flow, liquid level, density, $\mathrm{pH}$ and concentrations of various solutions, interface location, radioactivity level, and motor speed. Descriptions of the instruments necessary to sense, record, and control these variables are given in this section.

\subsubsection{Definition of Terms}

Temperature - The degree (intensity) of hotness or coldness measured on a definite scale. It is the result of molecular activity. The higher temperature of a hot body indicates that the movement of the molecules in it is greater than in a cold body.

Pressure Force divided by arca. The force (pull) of gravity on an object resting on an area of the earth's surface is its weight. Thus, if the object weighs 200 pounds and rests on 2 square inches of the earth's surface, it is exerting a pressure of 100 pounds per square inch (lb/in. ${ }^{2}$ ) on the earth.

Density - The weight of material per unit of volume, usually measured in pounds per cubic foot $\left(1 \mathrm{~b} / \mathrm{ft}^{3}\right)$ or grams per cubic centimeter $(\mathrm{g} / \mathrm{cc})$.

Specific Gravity - The ratio of a meterial's density to the density of water at $4^{\circ} \mathrm{C}\left(39^{\circ} \mathrm{F}\right)$. In the metric system, density and specific gravity have the same numerical value.

Interface - A surface that forms the common boundary between two layers of liquids having different densities - observed especially in solvent extraction.

Conductivity (electrical) - The property of a material to transmit electric current. Frequently expressed in mhos (reciprocal ohms).

\subsubsection{Temperature Measurement}

Heat flows from a body that is at a higher temperature toward one that is at a lower temperature. Heat is transferred in three ways: conduction, convection, and radiation. Conduction transfers heat from one part of a body to another part of the same body or from one body to another body in physical contact with it, without appreciable displacement of the particles of the body. Convection transfers heat from one point to another within a fluid (gas or liquid) by the mixing of one portion of the fluid with another. Radiation transfers heat from one body to another, not in contact with it, by means of wave motion through space. 
Instruments to measure temperature operate on either physical or electrical phenomena. Examples of the first type are liquid-in-glass thermometers, bimetallic thermometers, pressurized-fluid expansion thermometers, vapor pressure thermometers, and the use of melting points of substances.

Mecury-filled glass thermometers have a usable range of $-31^{\circ}$ to $400^{\circ} \mathrm{C}$ $\left(-22^{\circ}\right.$ to $\left.752^{\circ} \mathrm{F}\right)$. For temperatures lower than the freezing point of mercury, other liquids may be used. Their overall usefulness in the nuclear field is limited because they are fragile and not readily automated to give remote signals.

Bimetallic thermometers depend on the different thermal expansions of two dissimilar metals. As the temperature of the bimetal changes, the different expansions cause the system to deflect toward the metal with the lower coefficient of expansion. 'This motion may mechanically operate an indicating device or may be electrified to operate a control device.

Expansion-type thermometers utilize the expansion of a liquid or gas as temperature increases. The sensor can be a Bourdon tube, a spiral of tubing, or a bellows (Fig. 8.1.2). The rise in temperature generates an increase in pressure within the sensor, and this tends to uncoil or straighten the tube or expand the bellows. This motion is proportional to the rise in temperature. Long lengths of capillary tubing may be used between the bulb (transmitter) and the sensor if ambient temperature variations along the tube are compensated for.
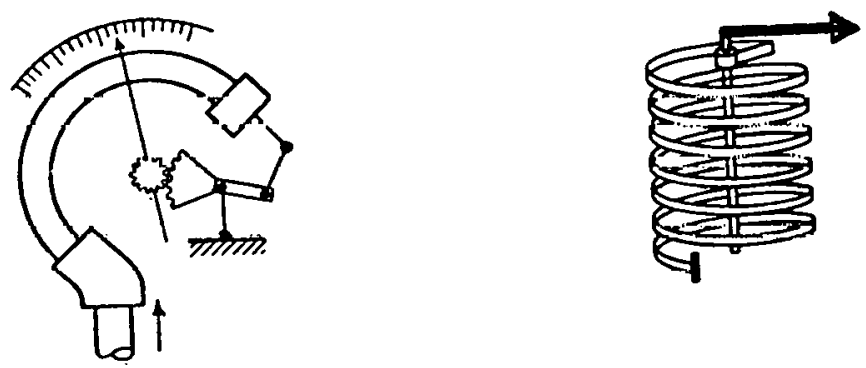

Fig. 8.1.2. Types of Temperature Sensing Devices (From Chemical ingineers' Handbook, Third Edition, by John H. Perry, Copyright 1934, 1941, 1950 by McGraw-Hill Book Co., Inc.) 
The melting points of various pure metals can be observed to measure the specific temperature of a furnace, but this method has limited application and is normally confined to the standardization of optical temperature measuring devices.

Examples of temperature measuring instruments based on electrical phenomena are (1) thermocouples, (2) resistance thermometers, and (3) radiation pyrometers.

A thermocouple (Fig. 8.1.3) consists basically of a pair of wires of two dissimilar alloys ( $A$ and $B$ ) fused together at one end $\left(T_{2}\right)$, which is referred to as the hot junction. Another identical fused couple $\left(\mathrm{T}_{1}\right)$, normally located in the readout instrument, acts as a cold junction. At each junction an electrical potential is developed which is proportional to the temperature at the junction. Since the voltages (emf) developed at the junctions are of opposite polarity, there will be a net emf that can be detected with an instrument calibrated to read directly in temperature units. Such an instrument may be a millivoltmator or a millivolt recorder.

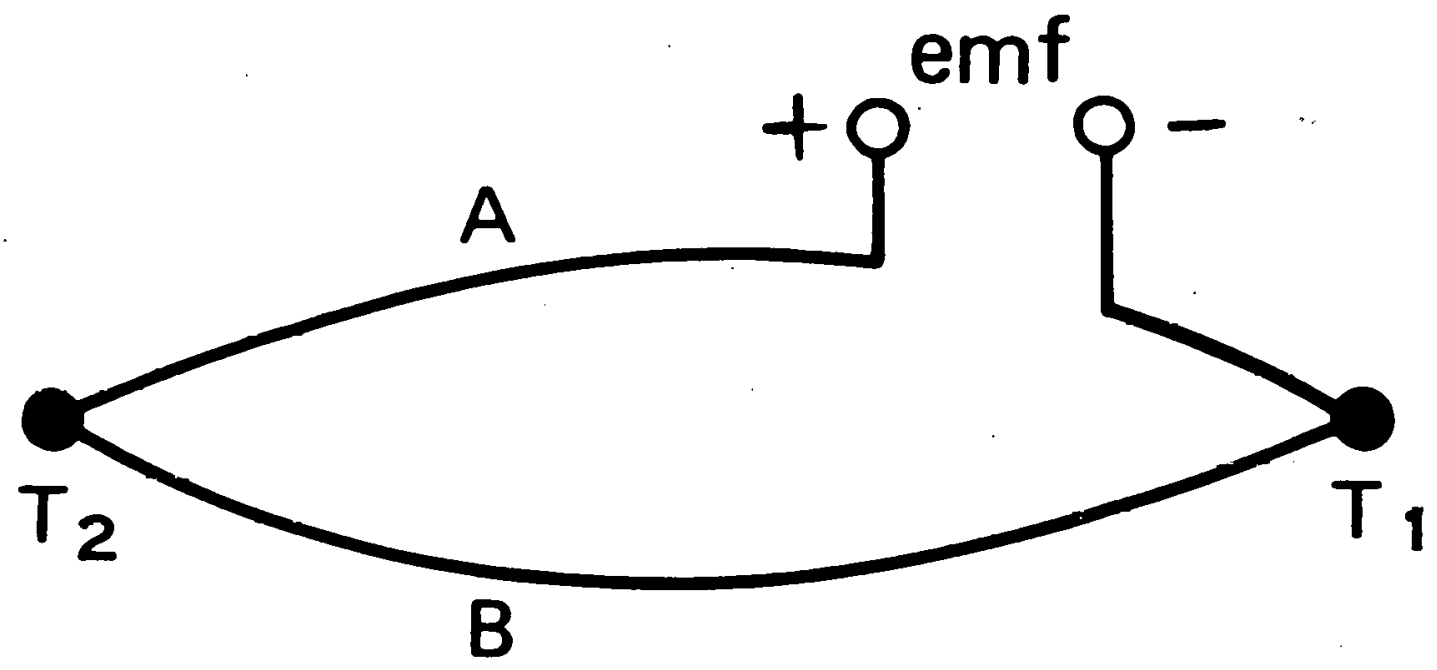

\section{( b )}

Fig. 8.1.3. Simple Thermocouple Circuit (From Chemical Engineers' Handbook, Fifth Edition, by Robert H. Perry/Cecil H. Chilton, Copyright 1973, 1963 by McGraw-Hill, Inc.) 
A wide range of temperatures can be monitored by the proper choice of thermocouples: (1) copper-constantan, $-150^{\circ}$ to $+320^{\circ} \mathrm{C}\left(-238^{\circ}\right.$ to $\left.608^{\circ} \mathrm{F}\right)$, (2) iron-constantan, $0^{\circ}$ to $870^{\circ} \mathrm{C}\left(32^{\circ}\right.$ to $\left.1598^{\circ} \mathrm{F}\right)$, (3) Chromel-Alumel, $0^{\circ}$ to $1150^{\circ} \mathrm{C}\left(32^{\circ}\right.$ to $\left.2102^{\circ} \mathrm{F}\right)$, (4) platinum vs platinum-rhodium, $700^{\circ}$ to $1600^{\circ} \mathrm{C}\left(1292^{\circ}\right.$ to $\left.2912^{\circ} \mathrm{F}\right)$.

Another instrument which produces an electrical signal variation that is linear over a wide temperature range is the resistance thermometer. When a wire is heated, its resistance increases. In a resistance thermometer a heated wire is connected into a circuit (called a bridge circuit) which compares its resistance with a fixed resistance. Unlike the thermocouple, this device does not generate a voltage; therefore, a battery is needed to provide an electric current for measurcment of the resistance. The degree of unbalance in the bridge circuit caused by the changing resistance as the wire is heated is linear with the temperature change and is detected by a galvanometer.

Temperatures above the upper limits of thermocouples may be delermined by measuring the radiation emanating from a hot object. Two types of instruments are based on the measurement of radiation: the optical pyrometer and the radiation pyrumeter. These instruments are useful over the range from $50^{\circ}$ to $3000^{\circ} \mathrm{C}$.

The optical pyrometer (Fig. 8.1.4) measures the wavelength of the light given off by a hot object. 'lo accomplish this, voltage supplied to an incandescent filament is increased until the filament optically appears to be radiating at the same temperature as the hot object. The voltage to the lamp is measured and calibrated in degrees of temperature.

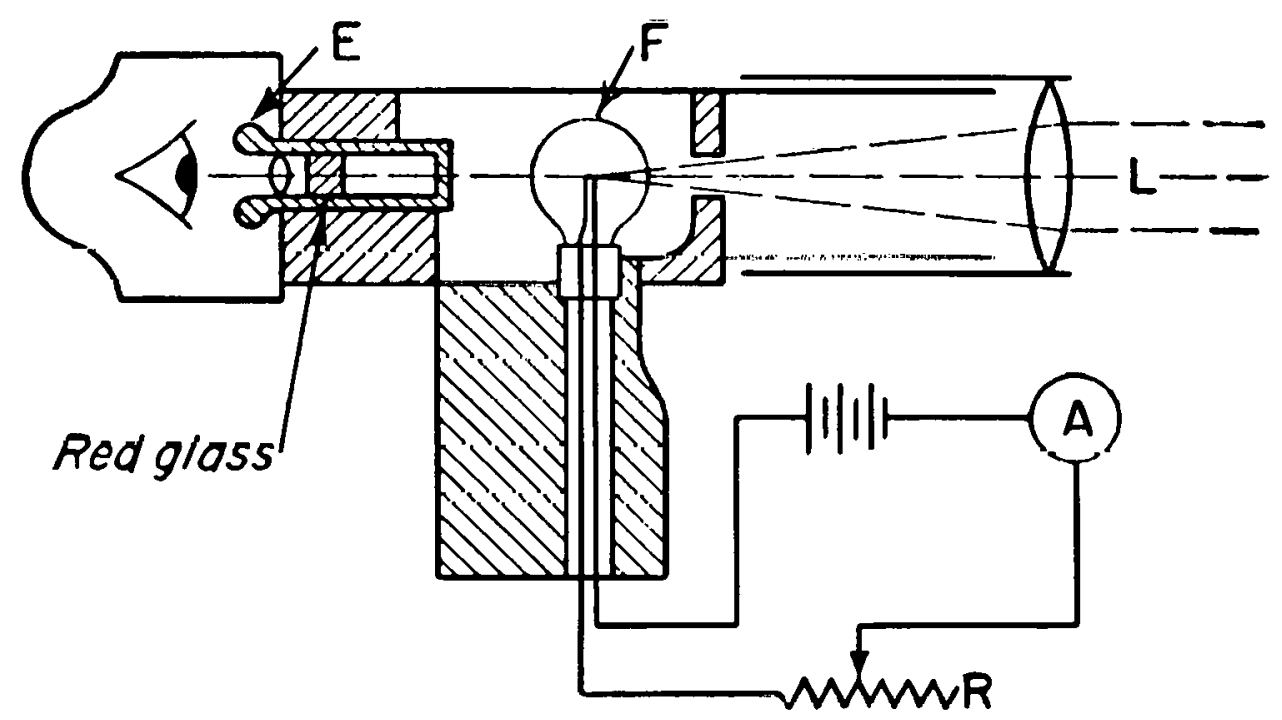

Fig. 8.1.4. Optical Pyrometer - Disappearing Filament Type (From Chemical Engineers' Handbook, Third Edition, by John H. Perry, Copyright 1934, 1941, 1950 by McGraw-Hil1 Book Co., Inc.) 
The radiation pyrometer has an advantage over the optical pyrometer in that visual comparison by the human eye is eliminated. The radiation pyrometer measures the total intensity of radiation. The radiation from the hot body is focused on the junction of a thermocouple, and the potential of the thermocouple indicates the intensity of the radiation reaching it (Fig. 8.1.5).

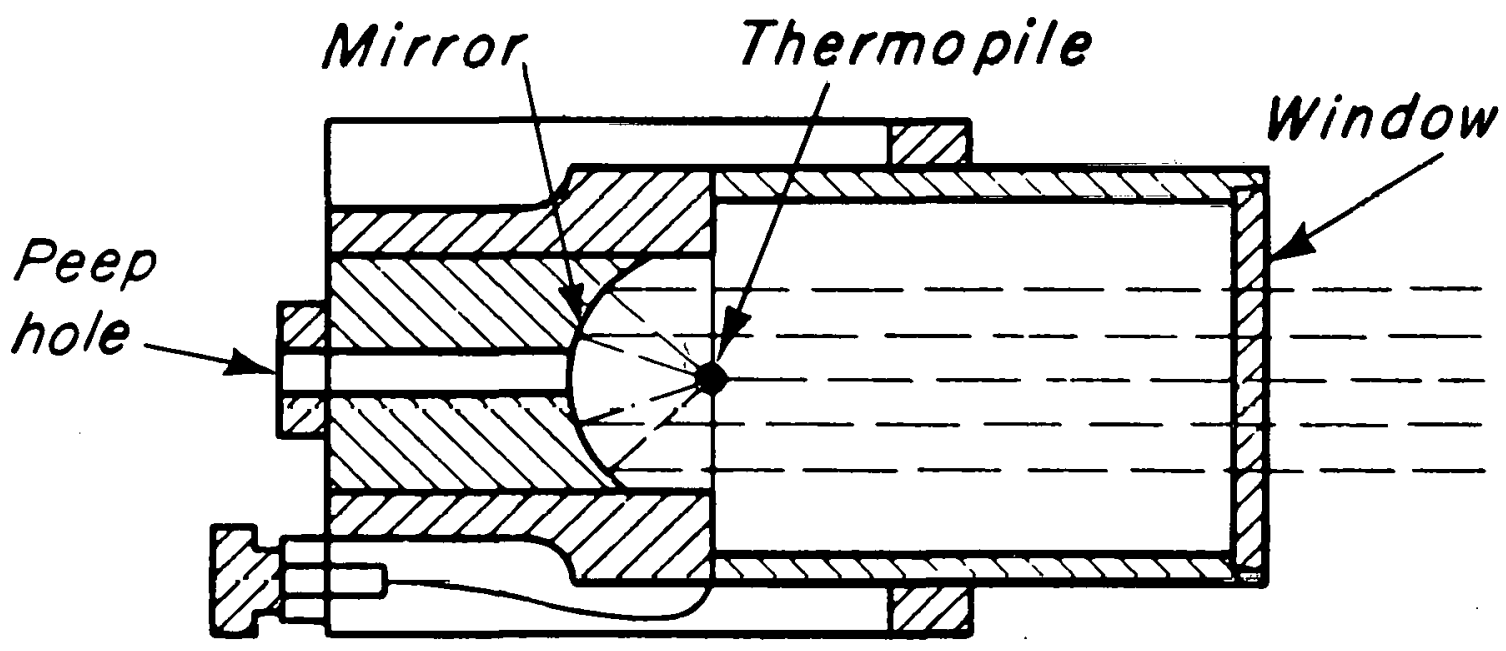

Fig. 8.1.5. Leeds and Northrup Radiation Pyrometer (From Chemical E'ngineers' Handbook, Third Edition, by John H. Perry, Copyright 1934, 1941, 1950 by McGraw-Hill Book Co., Inc.)

\subsubsection{Pressure Measurement}

Pressure is force per unit area. Usually it is measured directly by balancing it against a known force, which may be the weight of a liquid column, the tension of a spring, a weighted piston, a spring-loaded diaphragm, or any other component capable of being distorted quantatively when pressure is applied. Examples of these are (1) manometers, (2) bourdon tube gages, (3) spiral tubing elements, (4) slack diaphragms, and (5) bellows.

A common pressure-measuring instrument is the manometer, a device that uses the height of a column of fluid (mercury, water, glycerin, oil, etc.) as a measure of the pressure in a vessel or system compared with that of the atmosphere. Figure 8.1 .6 shows the basic types of manometers.

The Bourdon tube and spiral (helix) elements are discussed in Section 8.1.2. The most common instruments using these sensors are simple and compound gages. 
ORNL DWG. 76-1693

ATMOSPHERIC

PRESSURE

MANUAL ADJUSTED PRESSURE REGULATOR

GAGE UNDER TEST

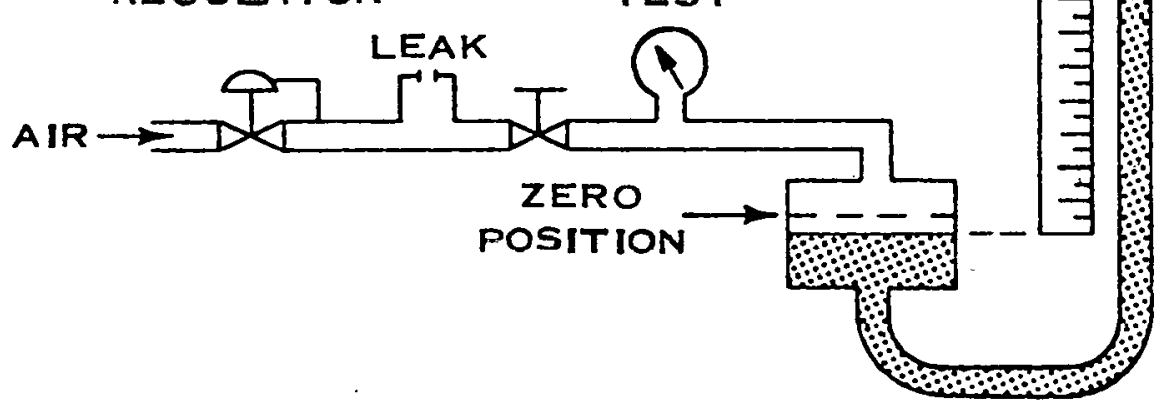

Fig. 8.1.6. Mercury-Column Pressure-Gauge Test Stand Using WellType Manometer (From Chemical E'ngineers' Handbook, Fifth Edition by Robert H. Perry/Cecil H. Chilton, Copyright 1973, 1963 by McGraw-Hill, Inc.)

Diaphragm and bellows-type sensing elements are frequently used for measuring low or differential pressures as in ventilation draft gages (Fig. 8.1.7). Electrical devices may be attached to the diaphragm bellows to provide a certain electrical change for each unit change in pressure.

Many of the pressure sensors described above may be used in conjunction with pressure transmitters or transducers to provide a signal to a receiving station. These devices allow a wide range of pressures to be monitored from a long distance away. Pressure transmitters operate on plant compressed air or dry "instrument air." Their output signals vary from 3 to 18 psig. When calibrated, they translate the actual pressures in the process vessels or piping into readings on a recording or indicating instrument.

\subsubsection{Liquid Leve1 Measurement}

There are two basic methods of measuring liquid level in a tank: direct and indirect. Direct methods include sight glasses, gage sticks, floattype gages, and buoyancy-type displacers. Fig. 8.1.8 illustrates these instruments. 


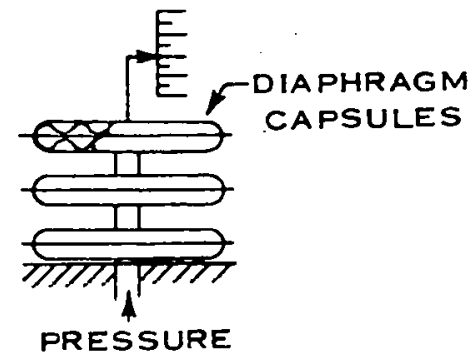

(a)

ORNL-DWG 76-1692

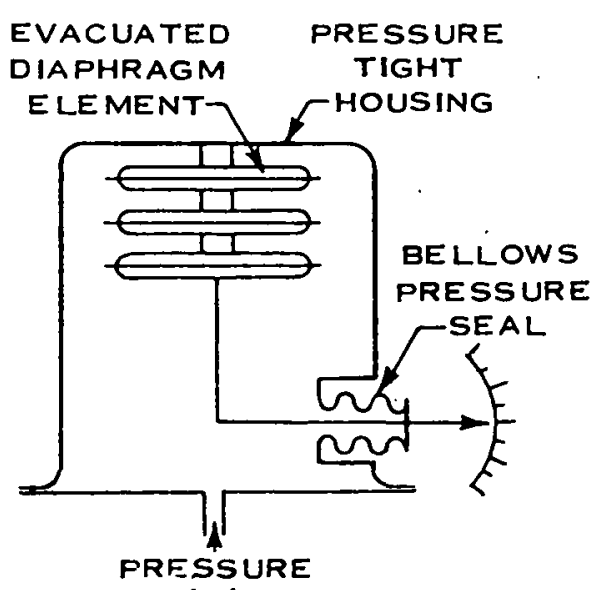

(b)

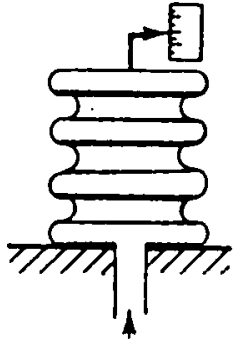

PRESSURE

(c)

Fig. 8.1.7. Pressure-Measuring Elements (a) Gage Pressule, (b) Aboolute Flessurè, (c) Bellows Pressure (From Chemical Engineers' Handbook, Fifth Edition by Robert H. Perry/Cecil H. Chilton, Copyright 1973, 1963 by McGraw-Hill, Inc.)

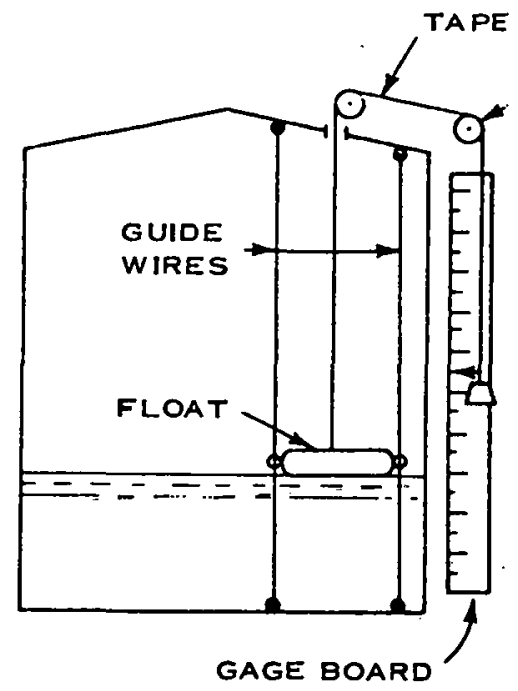

(a)

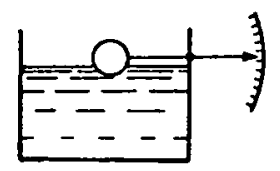

(b)

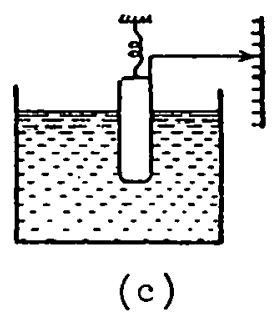

(c)

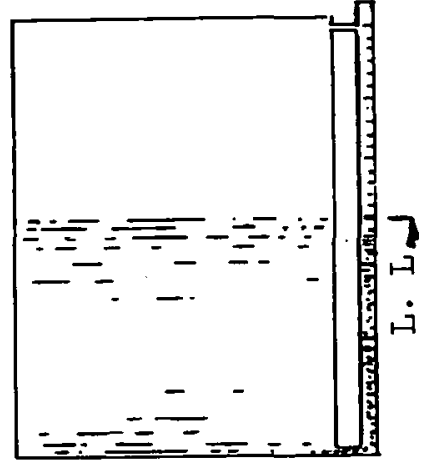

(d)

Fig. 8.1.8. Types of Level Measurement Devices (a) Gage Stick, (b) Flnat Indicator, (c) Buoyancy-Type Level Indicator, (d) S1ght Glass (From Cherrical Engineers' Handbook, Third and Fifth Editions, by John H. Perry and Robert H. Perry/Cecil H. Chilton, Copyright 1934, 1941, 1950, 1963, 1973 by McGraw-Hill Book Co., Inc.) 
Indirect methods for measuring liquid level utilize variables that change with changes in liquid leve1, such as hydrostatic pressure, differential pressure, differential temperature, and electrical signals. The device employed by most of the reprocessing industry is the bublertype hydrostatic pressure meter. This meter measures the pressure necessary to force air down and out the lower end of a pipe extending vertically into the liquid in a vessel to the desired reference point (Fig. 8.1.9). A closed bell. with a flexible diaphragm may also be used to determine the hydrostatic pressure cullesponding to the liquid in a vessel (Fig. 8.1.10).

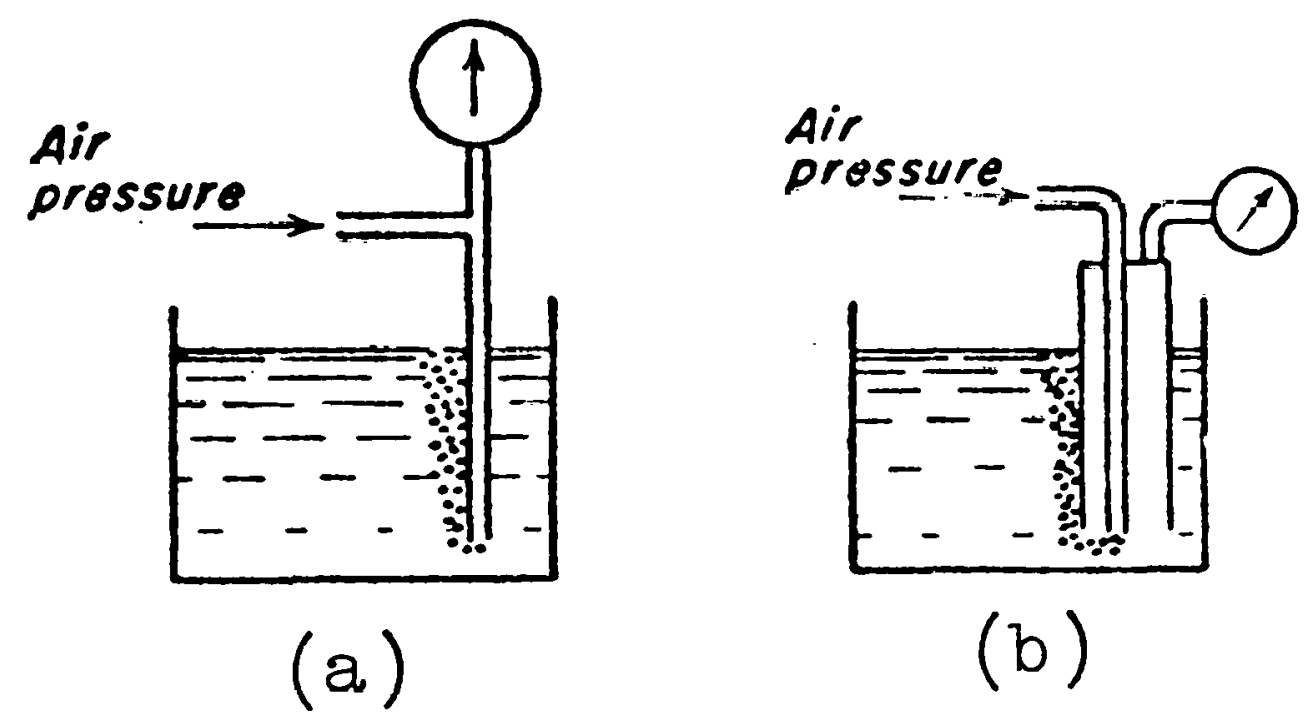

Fig. 8.1.9. Types of Leve1 Measurement Levlces (a) Bubbler-Type Liquid-Level Meter, (b) Bubbler-Type Meter for Corrosion Fluids (From Chemical Engineer's' Ilundbook, Third Edition, by John H. Perry, Copyright 1934, 1941, 1950 by McGraw-H111 Book Co., Inc.)

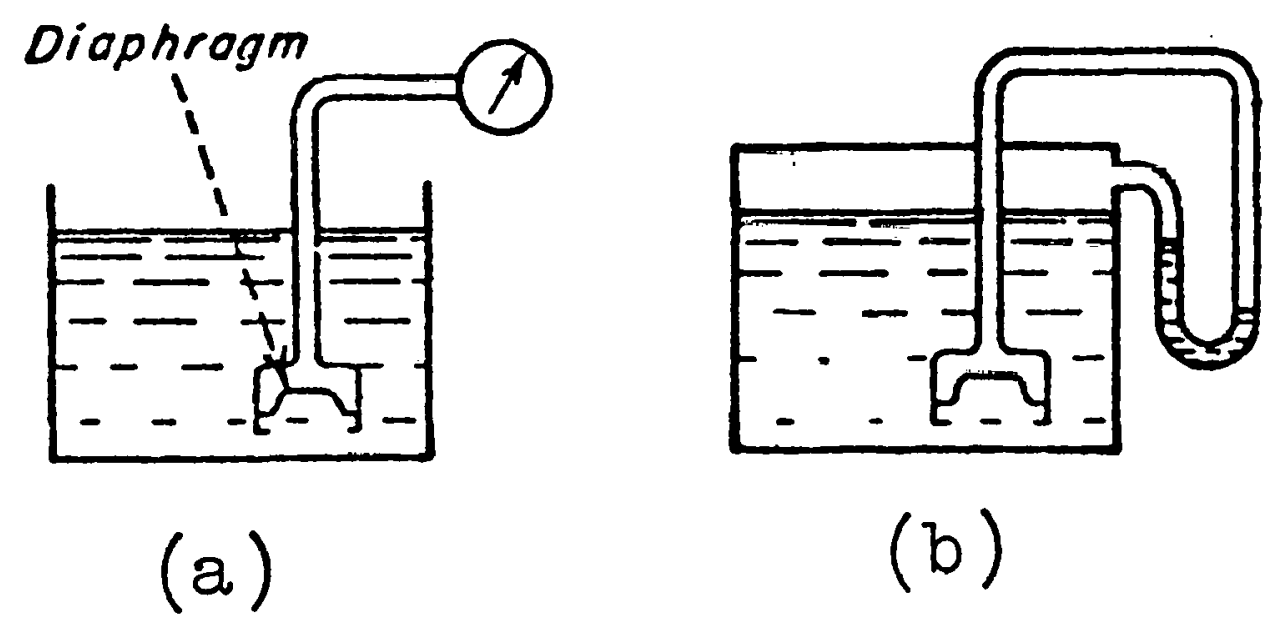

Fig. 8.1.10. Types of Level Measurement Devices (a) Diaphragm-Type Liquid-Level Meter, (b) Diaphragm-Type Meter on Closed Vessel (From Chemical E'ngineers' Handbook, Third Edition, by John H. Perry, Copyright 1934, 1941, 1950 by McGraw-Hill Book Co., Inc.) 
In a closed system under pressure, a differential-pressure manometer can be used to give a reading proportional to the liquid level (Fig. $8.1 .11)$.
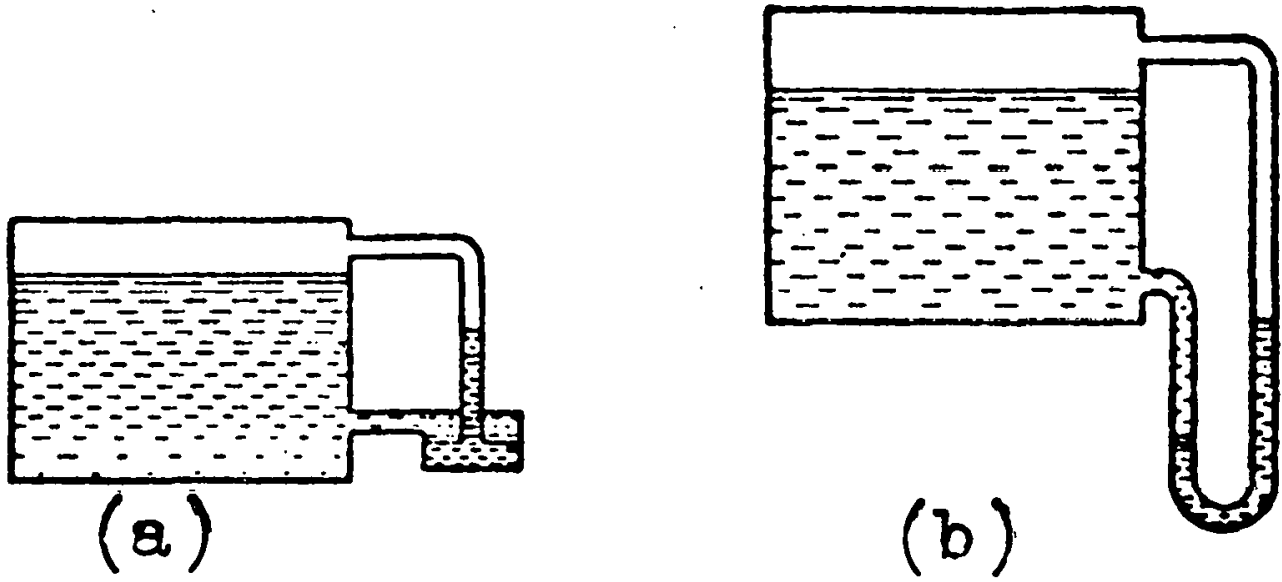

Fig. 8.1.11. Types of Level-Measurement Devices (a) DifferentialPressure Manometer-Type Level Meter, (b) Manometer-Type Liquid-Level Meter (From Chemical Engineers' Handbook, Third Edition, by John H. Perry, Copyright 1934, 1941, 1950 by McGraw-Hill Book Co., Inc.)

A differential temperature method utilized in steam generation may also be applied. The changes in the length of a tube connected to the top and bottom of a boiler drum measure the liquid-steam interface level (Fig. 8.1.12). The length of this tube varies as the average temperature of the tube.

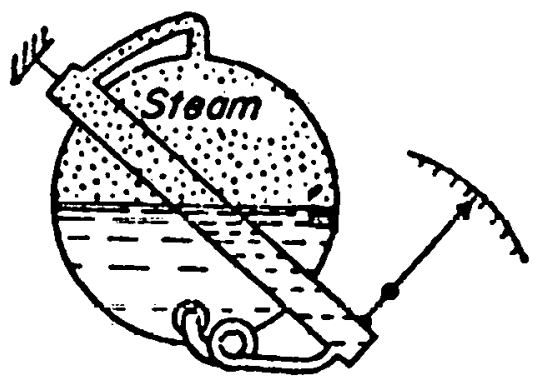

Fig. 8.1.12. Type of Leve1-Measurement Device DifferentialTemperature Method of Boil Water Level (From Chemical Engineers' Handbook, Third Edition, by John H. Perry, Copyright 1934, 1941, 1950 by McGraw-Hill Book Co., Inc.) 
Electrical methods of level detection utilize conductivity of solutions (Fig. 8.1.13a), capacitance between two plates (Fig. 8.1.13b), or currents generated by photocells (Fig. 8.1.13c).

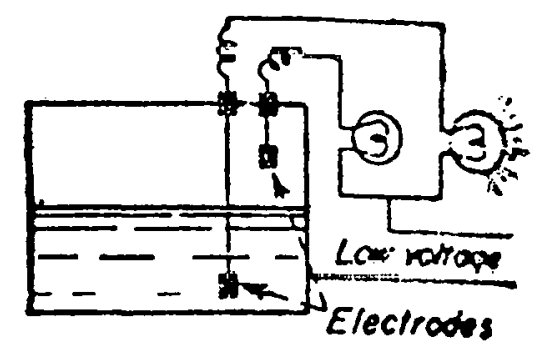

(a) Electrode-Type Liquid-Level Meter

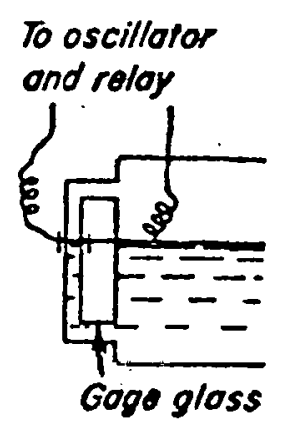

(b) Capacitance Levelel Meter

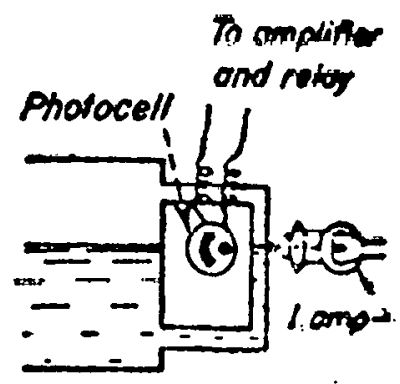

(c) Photocell Level Meter

Fig. 8.1.13. Types of Electrical Liquid-Leve1 Measurement Devices (From Chemical E'ngineers' Hondbook, Third Edition, by John H. Perry, Copyright 1934, 1941, 1950 by McGraw-Hill Book Co., Inc.) 


\subsubsection{Flow Measurement}

Fluid flow is one of the most important variables in the nuclear reprocessing industry and may be measured by either direct or indirect means. The direct methods divide the flowing fluid into definite unit volumes that are totaled automatically, while the indirect methods measure the instantaneous rate of flow.

Some of the more common direct measurement instruments are: (1) rotatingimpeller meters, (2) gear-pump meters, and (3) the piston-displacement meter. Fig. 8.1.14 shows these types of instruments.

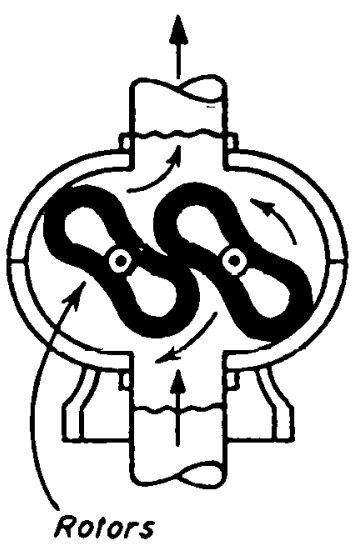

(a)

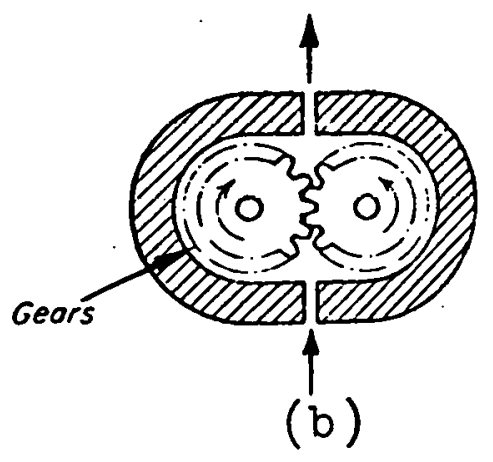

(b)

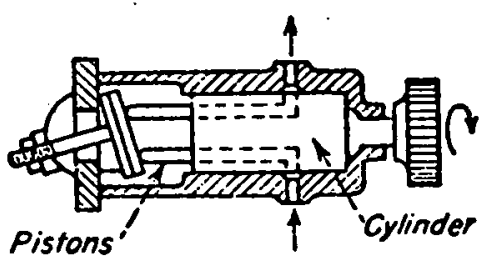

(c)

Fig. 8.1.14. Types of Flow Measurement Devices (a) RotatingImpeller Type Meter, (b) Gear-Pump-Type Meter, (c) Constant-Displacement Pump (From Chemical Engineers' Handbook, Third Edition, by John H. Perry, Copyright 1934, 1941, 1950 by McGraw-Hill Book Co., Inc.)

Indirect measurement of flow is based either on determining the pressure drop across a restriction in the flow by directly measuring the velocity head caused by the flow or on measuring an area that varies with flow while the pressure drop across a restriction in the flow remains constant.

Generally, flowmeters consist of a flow restriction that produces a differential pressure (pressure drop) and some means to measure and translate this difference to a readout station. The restriction may be an orifice plate, a venturi tube, a nozzle, or a variable orifice such as that provided by the float in a rotameter. The formula to calculate the flow is 


$$
F=c \sqrt{\Delta \bar{P}}
$$

$$
\text { where } \begin{aligned}
F & =\text { flow rate } \\
P & =\text { differential pressure, } \\
C & =\text { constant for specific flow media. }
\end{aligned}
$$

Fig. 8.1.15 illustrates these types of instruments.
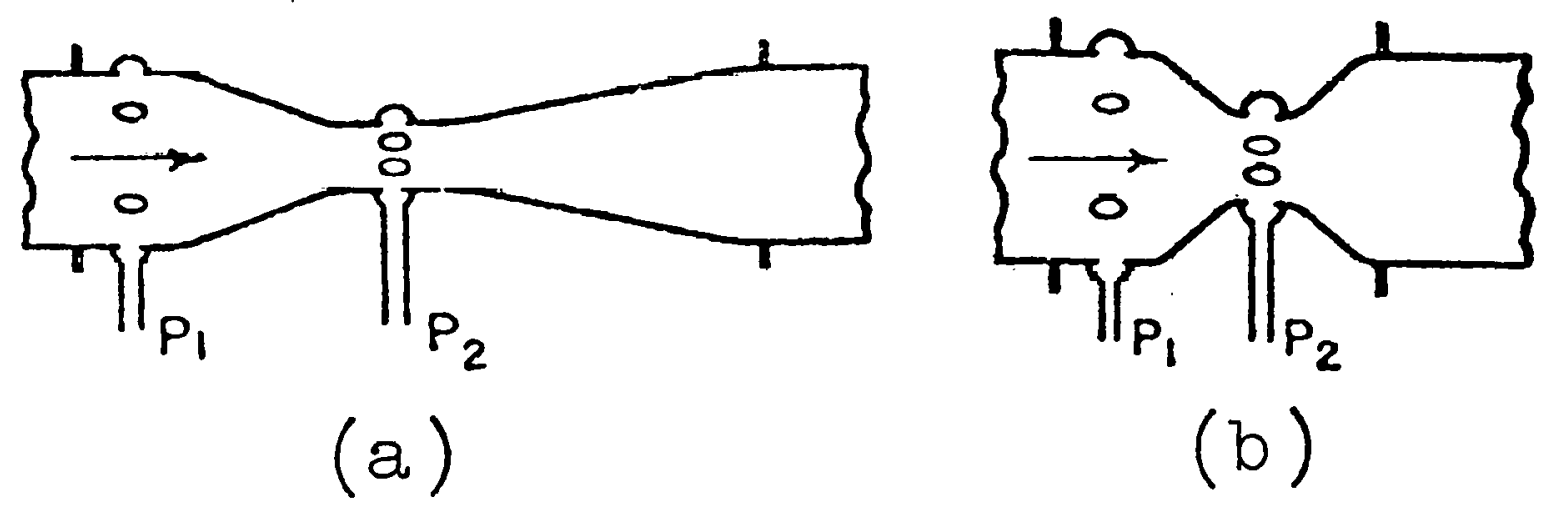

Fig. 8.1.15. Types of Flow-Measurement Devices (a) Venturi Tube, (b) Venturi Nozzle (From Chemical Engineers' Handbook, Third Edition, by John H. Perry, Copyright 1934, 1941, 1950 by McGraw-Hill Book Co., Inc.)

The rotameter is a variable-area meter; i.e., the area (orifice cross section) is varied around the float as the tloat moves up or down in a tube with sloping walls. The float moves upward until the force exerted by the moving tluid equals the weight of the float. Remule readout is possible with the rotameter.

\subsubsection{Density and Specific Gravity Measurement}

Density is a function of the composition of a material at a given temperature and pressure. For nonideal solutions and gases, empirical calibration will give the relationship between density and composition. The density or specific gravity of a material may be measured by (1) differential pressure, (2) displacement, (3) direcl miss measurement, (4) weight of fixed volume, and (5) viscous-drag techniques.

In the differential pressure method, liquid density is measured by the differential pressure needed to force air through two pipes immersed to different depths in the liquid (Fig. 8.1.16). The differential pressure $\Delta \mathrm{h}$ is proportional to the density of the liquid. 


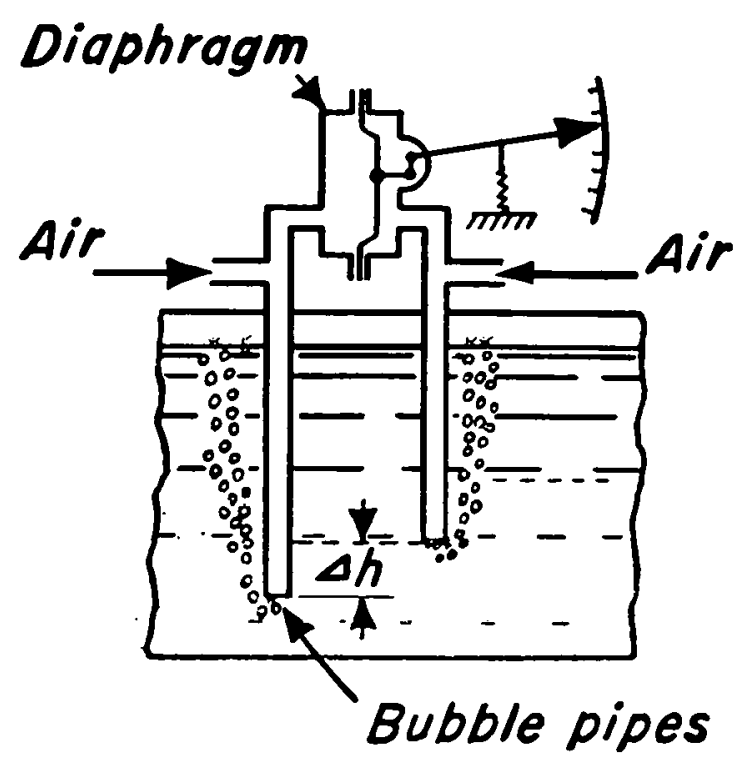

Fig. 8.1.16. Differential-Pressure Density Meter (From Chemical Lrigirteen's' Hurkbouk, Ih1rd Ed1c1on, by John H. Perry, Copỹright 1934, 1941, 1950 by McGraw-Hill Book Co., Inc.)

Displacement methods for measuring density include the use of hydrometers and displacement floats. A hydrometer is a constant-weight, variable-immersion device that when partially immersed in a liquid displaces a quantity of the liquid that equals the hydrometer's weight. Thus the degree of immersion is a measure of the density of the liquid. It is usually indicated by marks on the stem, which sticks above the surface of the liquid in which the hydrometer floats.

The displacement-float method measures the position of a float attached to a chain (Fig. 8.1.17). The position of the float varies with the weight of chain that can be supported by the buoyant force acting on the float, thus indicating the density of the liquid supporting the float and chain.

The direct mass principle is utilized by a device that electrically forces a U-tube to vibrate while the material whose density is being measured is circulated through the tube (Fig. 8.1.18). The amplitude of vibration decreases as the density increases and is measured to indicate changes in density.

Force-balance mechanisms measure the weight of a fixed-volume chamber or tube attached to a sample container (Fig. 8.1.19).

The viscous-drag device consists of a pair of vane-type impellers, one motor-driven and the other stationary. The torque imposed on the stationary impeller by the drag or resistance of the fluid is a measure of the fluid density. The torque generated by a standard gas mixture on identical impellers rotating in the opposite direction gives a differential torque that is calibrated for density (Fig. 8.1.20). 


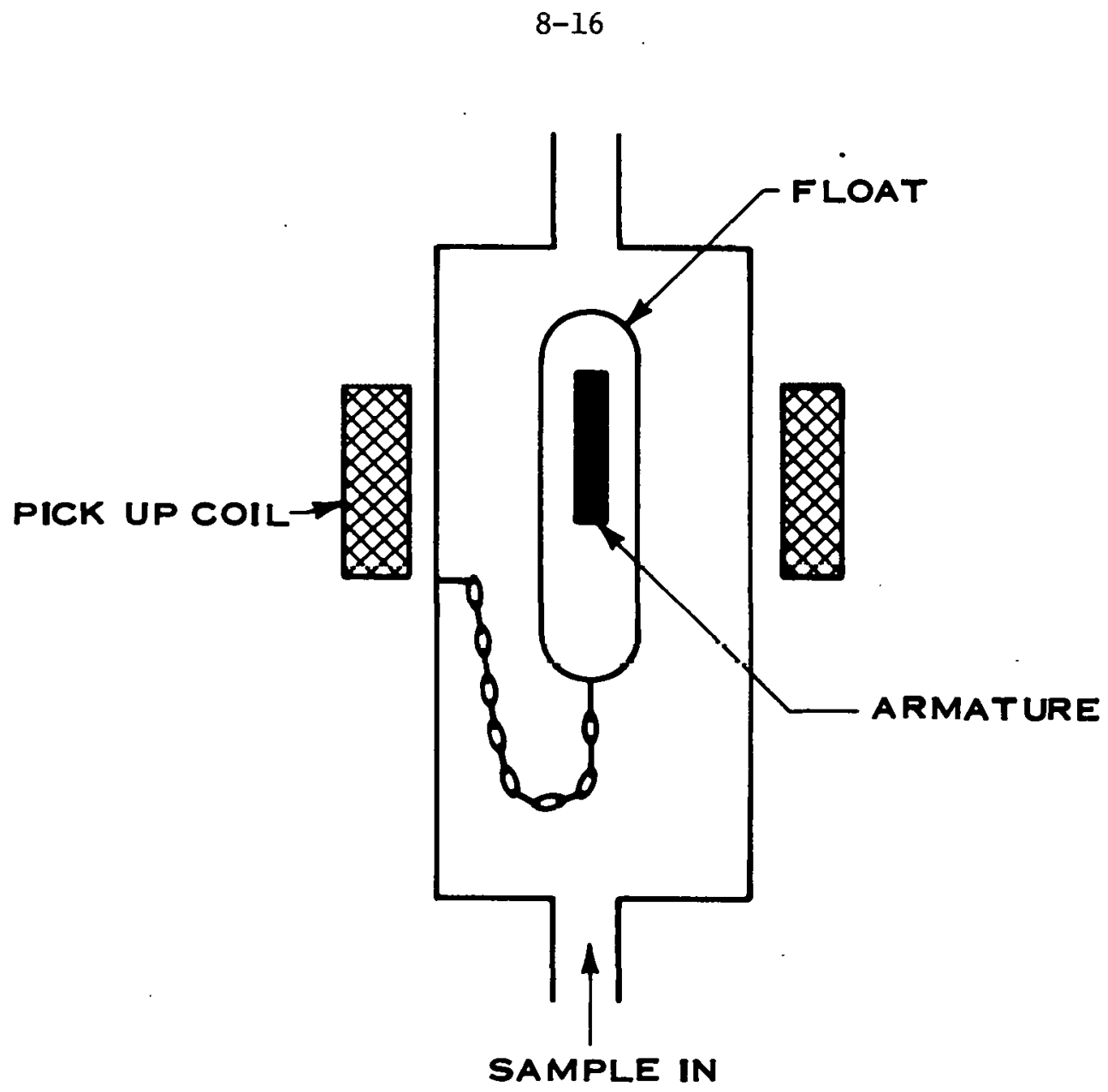

Fig. 8.1.17. Chain-Balanced Density Meter (From Chemical E'ngineers' Hondbook, Fifth Edition by Robert H. Perry/Cecil H. Chilton, Copyright 1973, 1963 by McGraw-Hill, Inc.)

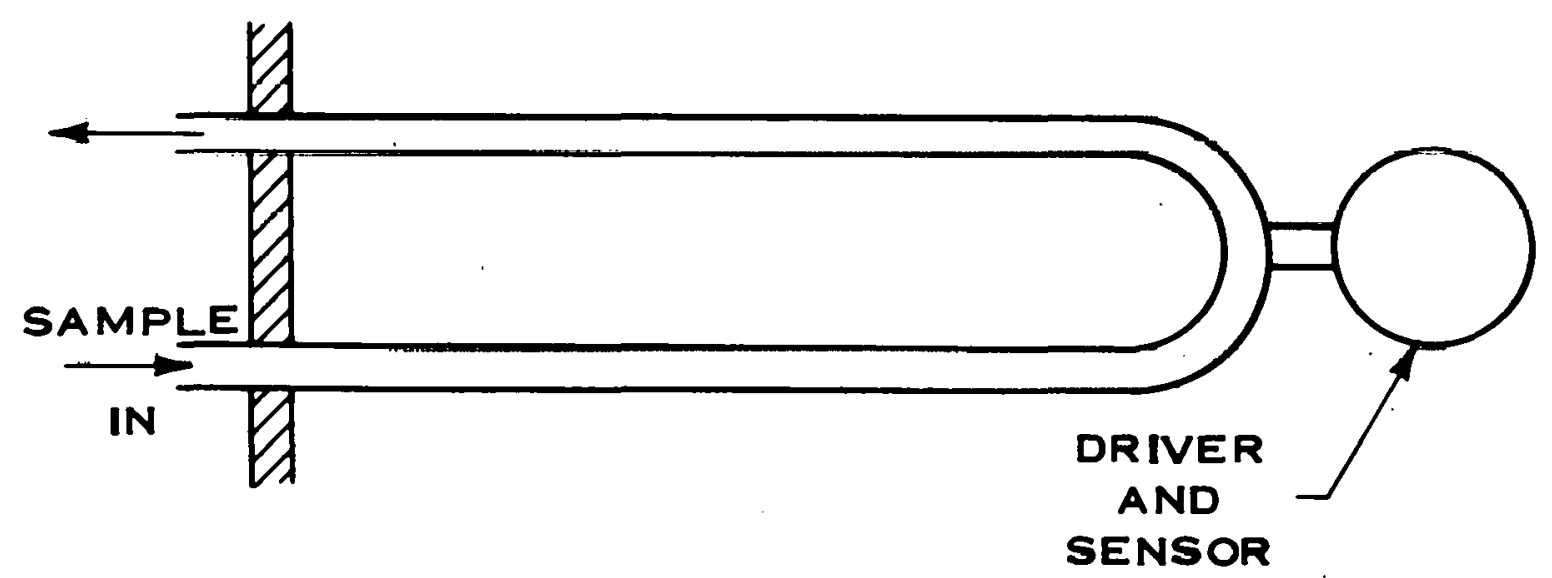

Fig. 8.1.18. Vibrating U-Tube Density Meter (From Chemical E'ngineers' Handbook, Fifth Edition by Robert H. Perry/Cecil H. Chilton, Copyright 1973, 1963 by McGraw-Hill, Inc.) 
$8-17$

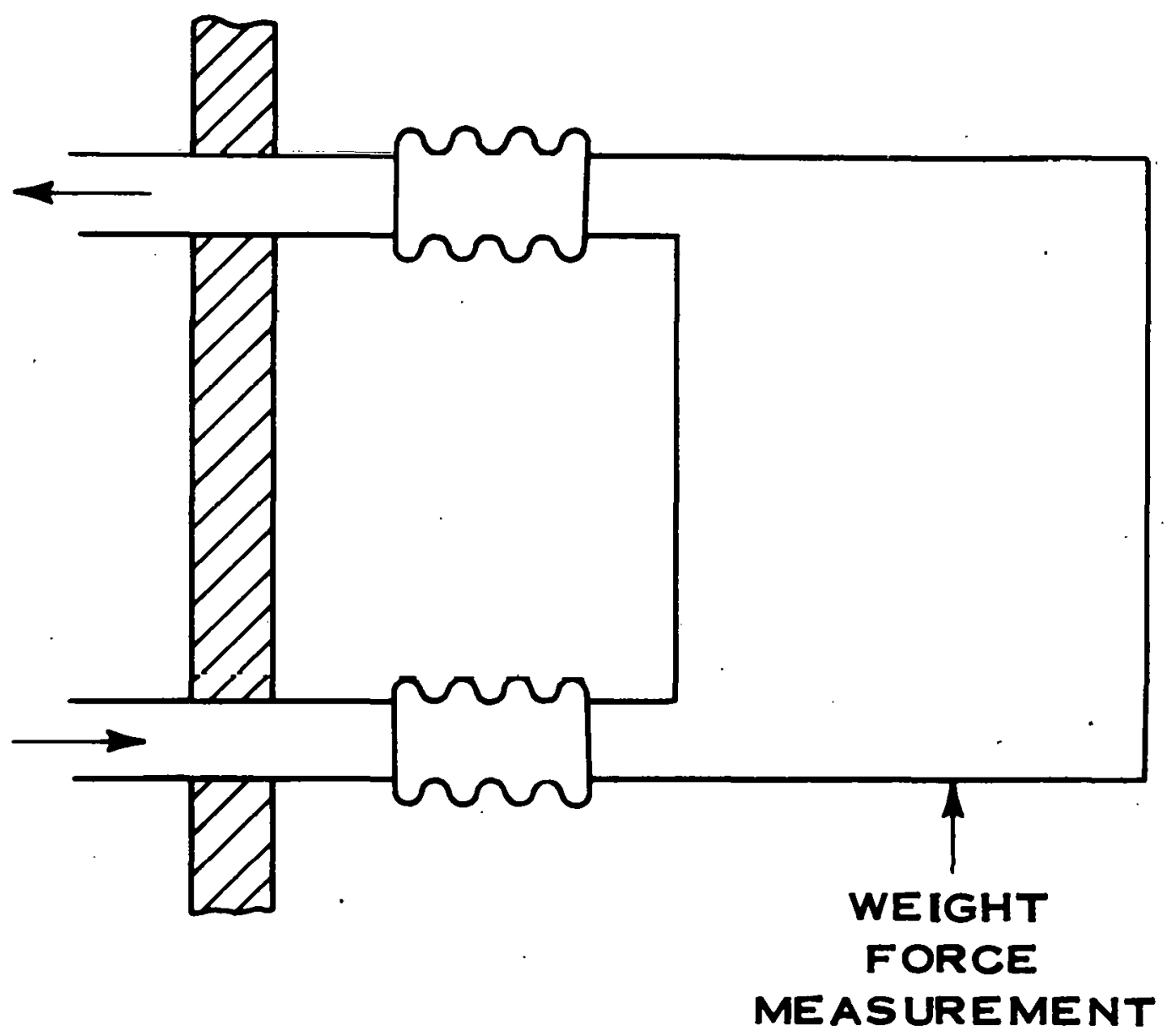

Fig. 8.1.19. Continuous-Weighing Determination of Fluid Density (From Chemical Engineers' Handbook, Fifth Edition by Robert H. Perry/ Cecil H. Chiton, Copyright 1973, 1963 by McGraw-Hill, Inc.)

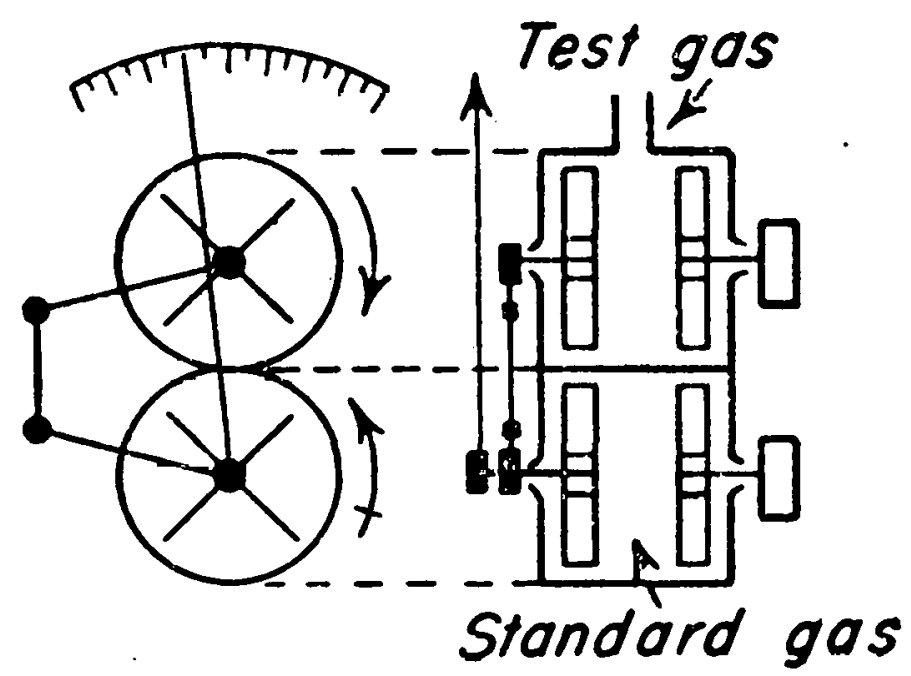

Fig. 8.1.20. Viscous-Drag-Type Gas Density Meter (From Chemical Engineers' Handbook, Third Edition, by John H. Perry, Copyright 1934, 1941, 1950 by McGraw-Hill Book Co., Inc.) 


\subsubsection{Interface Location}

The location of the interface between the heavy and light liquids in solvent-extraction processes may be identified by using a bubble-typc instrument similar to that described in Section 8.1.6. The dip tubes are arranged so that one tube terminates in the light liquid and the other terminates in the mixed or the heavy phase. The differential pressure across the ends of the tubes reveals the interface position, and the instrument signal can be used to control the position by controlling the rate at which the heavy phase is drawn from the extraction vessel.

\subsubsection{Instruments for Measuring Chemical Composition}

A number of composition analyzers have been designed for radiochemical applications. Among those more commonly used are $\mathrm{pH}$ meters, conductivity meters, and moisture analyzers.

The hydrogen ion concentration in a solution (frequently expressed as $\mathrm{pH}$ ) is a measure of the effective acidity or alkalinity of the solution and is an important factor in the process chemistry. The pH scale is calibrated from 0 to 14 , with pure water reading 7.0 (neutra1). The correlation between hydrogen ion concentration, $\mathrm{pH}, \mathrm{pOH}$, and hydroxyl ion concentration is shown in Fig. 8.1.21. The signal received from the $\mathrm{pH}$-sensing instrument may be used to regulate the acidity or alkalinity of process solutions by controlling valves or pumps that admit chemicals to the process.

\begin{tabular}{|l|l|l|l|l|l|l|l|l|l|l|l|l|l|l|l|}
\hline$\left[\mathrm{H}^{+}\right]$ & $10^{0}$ & $10^{-1}$ & $10^{-2}$ & $10^{-3}$ & $10^{-4}$ & $10^{-9}$ & $10^{-6}$ & $10^{-7}$ & $10^{-8}$ & $10^{-9}$ & $10^{-10}$ & $10^{-11}$ & $10^{-12}$ & $10^{-13}$ & $10^{-14}$ \\
\hline $\mathrm{PH}$ & 0 & 1 & 2 & 3 & 4 & 5 & 6 & 7 & 8 & 9 & 10 & 11 & 12 & 13 & 14 \\
\hline $\mathrm{POH}$ & 14 & 13 & 12 & 11 & 10 & 9 & 8 & 7 & 6 & 5 & 4 & 3 & 2 & 1 & 0 \\
\hline$\left[\mathrm{OH}^{-}\right]$ & $10^{-14}$ & $10^{-13}$ & $10^{-12}$ & $10^{-11}$ & $10^{-10}$ & $10^{-8}$ & $10^{-8}$ & $10^{-7}$ & $10^{-6}$ & $10^{-5}$ & $10^{-4}$ & $10^{-3}$ & $10^{-2}$ & $10^{-1}$ & $10^{0}$ \\
\hline
\end{tabular}

FIg. 8.1.21. Hydrogen- and Hydroxyl-Iun-Concentracton Chart (From Chemical Engineers' Handbook, Thrid Edition, by John H. Perry, Copyright 1973, 1963 by McGraw-Hill Book Co., Inc.) 
While $\mathrm{pH}$ is a measure of the effective acid concentration, the electrical conductivity (the reciprocal of the specific resistance) of a solution is a measure of the total ionic concentration. To measure the specific resistance, two inert electrodes are positioned in the solution (close together for high-resistance solutions and farther apart for more conductive solutions), and the electrical resistance is determined by means of a Wheatstone bridge circuit, as shown in Fig. 8.1.22.

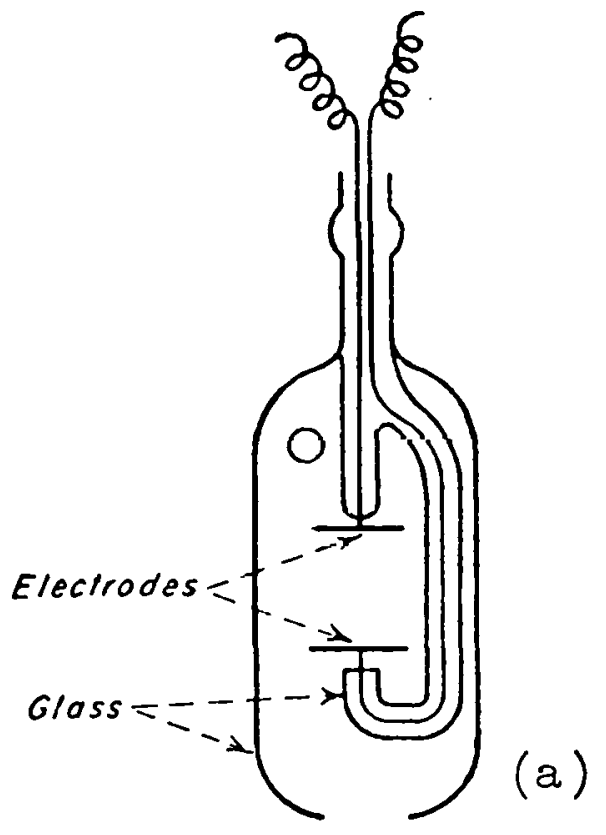

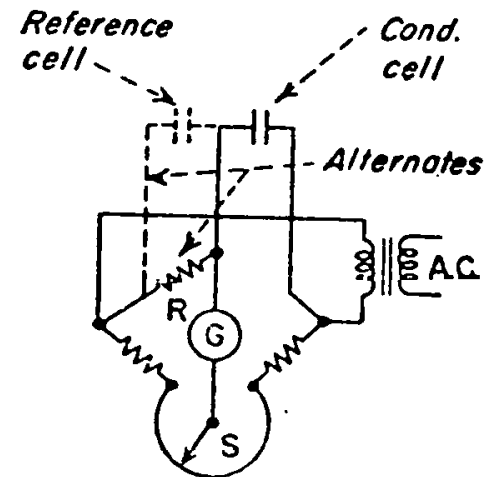

(b)

Fig. 8.1.22. (a) Conductivity Cell for Measuring Liquid Resistance, (b) Wheatstone Bridge Circuit for Use with Conductivity Cell (From Chemical E'ngineers' Handbook, Third Edition, by John H. Perry, Copyright 1934, 1941, 1950 by McGraw-Hill Book Co., Inc.)

Electrical conductivity may also be used to determine the moisture content of colid (granular) materials wlien the denstcy is known. 'lhe instrument must be calibrated using a material of known moisture content and having electrical properties identical to those of the sample.

\subsubsection{Motor Speed Control}

Rotational and translational motions of various pieces of process equipment often require measurement and control. Rotational speed is usually measured with a tachometer. Translational motion may be measured by the use of photocells to count the number of times a part of the equipment passes between a light source and the detector. 
Some tachometers coupled directly to a motor shaft contain a small dc magneto that generates a voltage proportional to the speed of rotation. The sensing unit consists of a voltmeter calibrated in revolutions per minute (rmp) and can be located some distance away.

Another type of tachometer familiar to all is the automobile speedometer, which operates on the principle of magnetic drag. A rotating disk in the speedometer imparts a force proportional to the square of the speed and causes a spring-loaded needle to deflect, thus indicating miles per hour.

Indirectly coupled tachometers, such as the stroboscope, are frequently used when direct connections to the motor shaft are undesirable. The strohoscope measures rotational speed by electronically matching the speed of the shaft with the flashing of a light. When the speeds are matched, the rotating shaft appears to be motionless. The signal can be remotely indicated in the control room.

\subsubsection{Radiation Detection Instruments}

Radiation detection instruments are used to monitor not only personnel but also cell or glove box areas and process streams. Radiation monitors normally measure the gamma energy emanating from fission products. In-cell monitors are adequate for detecting when a tank of radioactive material is full or empty; but the precise control necessary to perform separations in the nuclear processing industry requires in-line monitors or sampling and analysis. In-cell monitors can detect the position of specific bands of radioactive nuclides on ion-exchange colums to inform the operator when colum breakthrough will occur or, conversely, when radionuclides have been eluled.

\subsubsection{Interpretation of Data}

All the instruments in the world would be useless if correct interpretations were not applied to the data displayed. For an experienced operator who knows his prucess, a sudden change or a gradual change without reason may indicate a number of significant conditions. The inexperienced operator may fail to notice changes or may not take the proper corrective measures.

This points out the 1mportance of a training program to include information on interpretation of results and to enhance this program with on-the-job training under the guidance of an experienced, licensed nuclear reprocessing operator. 


\subsection{SAMPLING}

In a fuel reprocessing facility one encounters the need to sample (1) bulk materials such as aqueous uranium or plutonium solutions, both as pure material and as scrap solutions; (2) uranium and plutonium oxides as individual powders, pellets, or microspheres and similarity as mixtures of the oxides; (3) cylinders containing uranium hexafluoride (liquid and gas); and (4) bulk waste materials, such as liquids or solids containing traces of uranium and plutonium. In this section we examine a few details of sampling typical items.

Facilities for reprocessing irradiated fuel usually consist of (1) a fuel receiving and storage area; (2) a head-end processing system to separate inert material from the bulk fuel and to convert the fuel into a form suitable for purification by chemical processes; (3) a purification system; (4) a purified product isolation, conversion, and packaging system; and (5) a waste emission and disposal system.

IIl Llıe fuel recelving and scorage àrea óf existing plants, spent tuel assemblies from water-moderated power reactors are unloaded from shipping casks and stored in basins filled with water, which must be sampled for impurities and evidence of leaking fuel elements. (As spent fuels from other types of reactors appears, such as HTGR and LMFBR, different types of storage systems will be designed and installed which probably will not include water-filled basins as storage areas.)

In the head-end processing system, aqueous liquid samples, occasional solid (cladding) samples, and gaseous samples from the dissolver offgas system must be taken. The aqueous samples generated in this system are of extreme importance, since plant input measurements are based on the analytical results obtained from them. Consequently, much care must be exercised in ensuring that the bulk dissolver solution is homogeneous; equally important is an inspection of the sample for homogeneity, noting the presence of separate phases, solids, etc. This inspection is also of considerable importance to the process engineer, since it may signal the necessity for corrective action in the dissolution procedure or in dissolver control and operation to deal with the accumulation of finely divided undissolved solids there. Large errors in estimating plant input can accrue as a result of such accumulations and their effect on volume measurements.

The purification system, at least in part, currently consists of one or more cycles of solvent extraction along with the associated process tanks, evaporators, and solvent purification system(s). As a rule, the entering and exiting streams are single-phase liquids (either all aqueous or all organic), but the opportunity for heterogeneous mixtures of two phases is present in many points in the process. Knowledge of this, aside from the chemical content, is important to the process engineer for process control and nuclear safety. As a rule, when a heterogeneous sample appears, the fact that it is not homogeneous frequently is the only information about it that warrants a firm 
conclusion, since the ratio of the phases is not known with certainty. Also, analysts in most laboratories are, as a matter of policy, trained to centrifuge all samples before beginning an analysis and to conduct analyses only on clear, homogeneous solutions. Thus, visual inspection of samples from the solvent-extraction and the evaporator systems is extremely important to avoid analytical results leading to erroneous conclusions about current system performance, as well as to obtain the earliest possible indication of equipment malfunction.

In the purification system we first encounter a need to know the composition of a flowing process stream. This information is important in obtaining an instantaneous indication of the performance of subsystems or of individual equipment items during normal operation; it also indicates the approach to equilibrium operation during startup or shutdown or during a period of abnormal operation such as that following an upset. Samples from a fllowing streatm usually are withdrawn at desired intervals by diverting a portion of the stream through the sampling device for a prescribed period (usually 10 to 15 minutes) and finally trapping the desired quantity (see Sect. 8.2.2) in a bottle, which is later transferred to the analytical facility for analysis; this method is used where the flow of the process stream is large. For streams of small flow it is possible to divert the entire stream to a small collection pot for prescribed intervals (emptying the pot several times to flush it) and either to collect the final lot as a sample or to remove a sample from it. This second method permits the effect of any striation (banding) to be observed and if the stream was two-phased, the phase ratio to be shown.

In some reprocessing facilities, the purification process may include, in addition to the solvent-extraction system already mentioned, an ionexchange system for further purification and concentration of the plutonium nitrate product and a volatility-type system ${ }^{1}$ for further purification of the uranium (especially if enriched in uranium-235). Samples originating in the ion-exchange system will occur as aqueous nitrate solutions (solid samples of spent ion-exchange resin are discussed in the section below dealing with waste disposal). Samples may be withdrawn from the volatility system as eutectic mixtures of metallic fluorides, liquid or gaseous hydrogen fluor1de, liquid or gaseous uranium hexafluoride, aqueous scrubber solutions, calciner product $\left(\mathrm{U}_{3} \mathrm{O}_{8}\right.$ powder or pellets) and wastes, and aqueous waste or recycle streams. In general, except for the eutectic salt samples (the withdrawal of which is described in Ref. 1), the samples required in this process are handled similarly to those in other processes described above.

The finished uranium product from the solvent-extraction system in some reprocessing plants may be converted to a dry oxide either by calcination in air or precipitation with ammonia (as gas or hydroxide) followed by calcination in air, and then packaged for shipment. Aside from the liquid waste and recycle solutions, which are generated and handled as already described above in the section on the solvent-extraction system, 
or containers of bulk solids must be sampled by one of the methods described in Section 8.2.2.

It is expected that the shipment of aqueous plutonium nitrate solutions will soon be discontinued. ${ }^{2}$ Instead, the purified nitrate solution will be converted to dry oxide by precipitating the plutonium with oxalic acid and calcining the hydrous oxalate. The waste and recycle streams from the operation will be liquid, and samples of these will be handled as already described. The solid oxide samples will be taken and handled with all care for reasons of safety as described in Section 8.2 .2 .

Waste emission from spent-fuel reprocessing facilities include liquids, solids, and gases. Current trends in the Nuclear Regulatory Commission (NRC) and the Environmental Protection Agency (EPA) indicate that solidification of all highly radioactive liquid wastes will probably soon be required prior to storage. Economic pressure dictates converting all low-level waste to the smallest practical volume by compaction or a burn-leach method that recycles the uranium and plutonium for recovery. By whatever path, both solid and liquid samples will be required for control of the process and to ensure compliance with regulations developed by the regulatory agencies. Certainly, sampling of all gaseous effluent streams will be required. Continuous monitoring of the gaseous streams will also be required; this will involve continuous air monitors (usually operated by health physics personnel) and analysis of the fallout trays. However, the withdrawal of gaseous samples from the off-gas system (dissolver) for determination and control of tritium, krypton-85, and iodine-131 may become routine. These will also be discussed in the following sections.

\subsubsection{Basic Requirements of Sampling}

The objective of a sampling program is to infer the characteristics and composition of a bulk item from the results of examinations of samples taken from it. In order to make such an inference valid, certain requircments must be met, as follows:

1. The composition and characteristics of the samples and the bulk item must be identical.

2. The bulk item must be homogeneous throughout.

3. The composition and characteristics of the sample must not be altered during the withdrawal or in subsequent handling privi lu analysis.

\subsubsection{Methods of Sampling and Sampling Devices}

As already indicated above, we can anticipate a need to sample materials existing in the form of solids, liquids, and gases. 'l'he sampling 
procedures to be followed differ in minor detail and in application but in every case must include a provision for meeting the requirements shown in Section 8.2.1. A discussion of sampling methods and procedures that are recognized and acceptable throughout the nuclear industry is given in Ref. 3.

Solids - Samples of solid materials will include those taken from metal plates, tubing, ductwork, and occasionally from equipment already installed. These samples are usually taken for metallurgical examination for acceptance or rejection of purchased items or for evidence, in the case of installed equipment, of performance, such as resistance (or lack of it) to corrosion or mechanical failure. Since the need for samples of this type usually occurs mostly in the construction and early shakedown phases of facility operation, we will not go into much detail here. Suffice it to say that the fundamental requirements of sampling mentioned above still apply. Consequently, when dealing with samples of this nature, a carefully planned procedure and sampling plan must be developed before embarking on the actual withdrawal of the sample.

Powders, Crystals, and Pellets - The nature, the value, and the lot size of solids falling into this category will govern the sampling procedures and methods to be employed. For very valuable materials, such as enriched uranium oxide or plutonium oxide, each container might be sampled according to the procedure given in Ref. 1, where several small samples of roughly equal volume (or weight) are taken at designated depths and at specified locations in the cross-sectional area of each container. These small samples may be analyzed individually and the results averaged, or all of the samples from a single container may be combined and thoroughly blended, for example in a V-blender, and several samples may then be removed from the blended composite, whtch represents the contents of the single contaluer of material originally sampled. Occasionally a grinding step is included as part of the blending operation.

An alternative method that can be used where the material sampled is less valuable (normal uranium oxide, thorium oxide, bulk reagents, etc.) involves obtaining representative samples from an entire lot comprising many containers. In this case, small approxlmatuly equal quantitico of the material may be withdrawn from a few of the containers chosen at random and composited and blended. Several small samples may then be withdrawn from the composite and analyzed. The results of the analysis are then applied to the whole lot.

Liquids - Most of the samples that occur in fuel reprocessing facilities will be withdrawn from process liquids. To meet the requirements for representative samples, the process fluids are made homogeneous by thorough mixing, which is for the most part accomplished by means of sparging with air or other inert gas. Mechanical agitators could be used in certain applications to achieve the same result.

The air flow rate that must be used for sparging in a vessel containing liquid to be rendered homogeneous depends somewhat on the diameter of 
the vessel, the depth of the liquid, the arrangement of the spargers in the vessel, and the geometry of the vessel internals. For a method of determining the flow rate in vertical cylindrical tanks, the reader is directed to Ref. 4. One is cautioned, however, that vessels of unusual geometry (slab tanks, horizontal cylinders, annular tanks, etc.). are often encountered in both fuel reprocessing and fabrication facilities. In these special vessels, which often include complex internals, the required mixing procedure that ensures homogeneity over the range of operating conditions must be developed individually. Such a procedure specifies both the air flow rate and the minimum time to sparge the vessel to achieve the desired degree of homogeneity.

In a fuel reprocessing facility all the process fluids other than the reagent streams are radioactive and are located in heavy-walled structures (cells). All operations are conducted remotely. Each vessel is equipped with a sampling line, which terminates at sampling devices (Ref. 1) assembled in sampling stations; each station may include several sample points. The sampling station, of course, is heavily shielded and is located inside the primary containment shell.

The sampling devices (a typical one of which is shown in Fig. 8.2.1) provide means of continuously lifting a stream of the process fluid to the sampler, of passing relatively large, with respect to the line holdup, volumes of process fluid through the line and the sample bottle to flush any residual material out of the system, and, finally, of trapping the desired predetermined volume of fluid in the sample bottle.

Fuel fabrication facilities for uranium-233 and plutonium fuels, as a rule, have fewer occasions to handle highly radioactive fluids requiring heavy shielding, and most vessels require only containment to restrict dispersal of alpha contamination. Accordingly, such vessels are often located in alpha-tight enclosures, but the vessels are readily accessible to direct sampling with spigot-type samplers, however, in these, care must be taken to flush the spigots and associated piping (usually smali) before withdrawing the sample into the sample bottle.

Occasionally - for example, in the volatility process - it may be necessary to sample a molten salt at operating temperature $\left(400-500^{\circ} \mathrm{C}\right)$. This is a difficult problem because of the high temperature of the process, the high intensity of radiation from the fission products in the molten salt, and the fact that some of the fission-product fluorides are volatile. This requires a very elaborate heated sampler system that includes sample-bottle heater, heated piping, and a means of circulating the liquid salt through the bottle. In pilot plant demonstrations ${ }^{1}$ the procedure was to lower a copper cup (used only once) from above by means of a windlass and cable through a tube attached to the vessel and allow it to fill. After filling, the cup was lifted from the liquid and allowed to cool and solidify, after which it would be transferred to a clean container. The sealed container, which was clean on the outside, was then placed in the shielded carrier for transport to the analytical laboratory. 


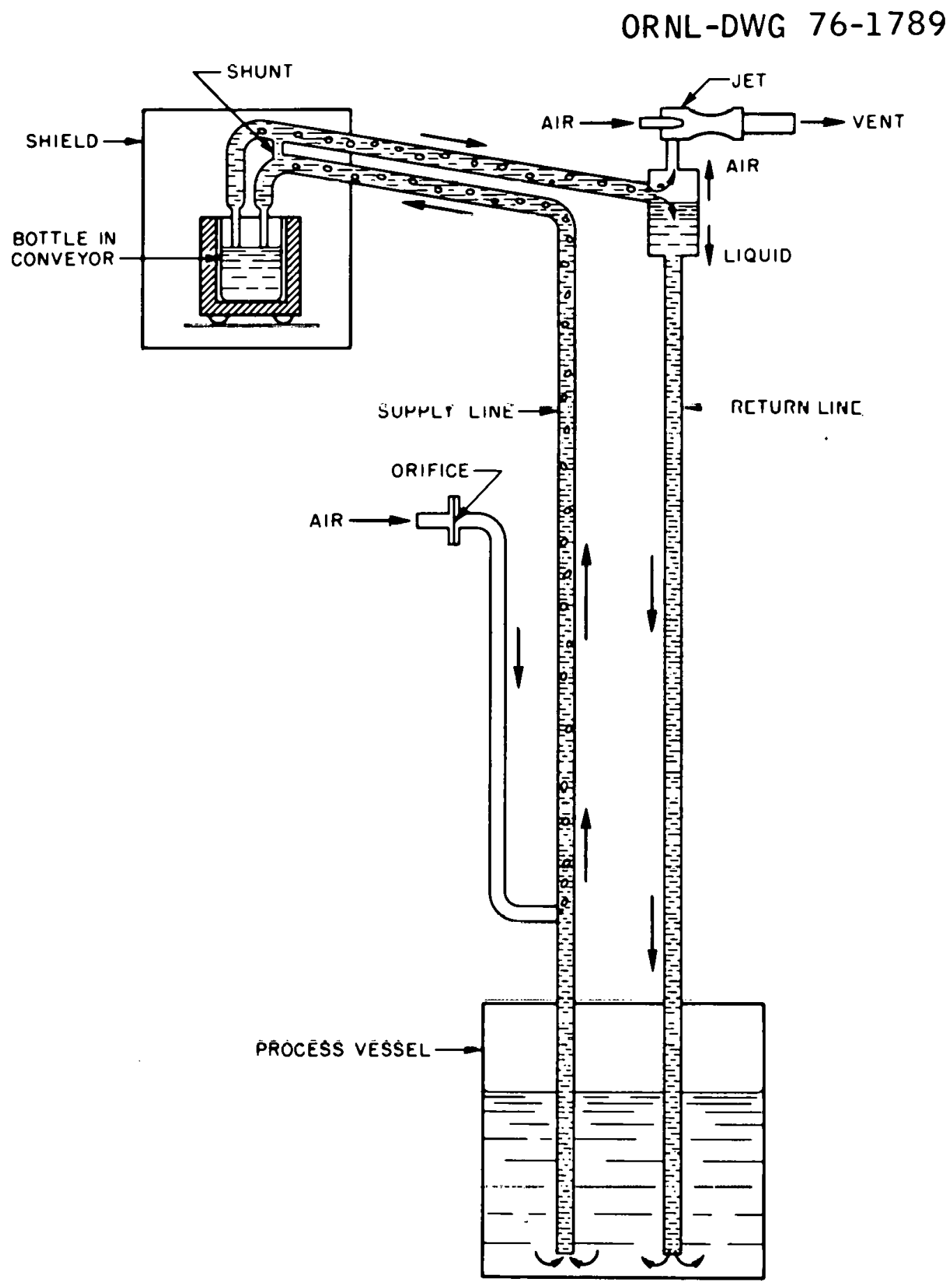

Fig. 8.2.1. Remotely Operated Sampling System for Highly Radioactive Solutions 
Gaseous samples may be withdrawn from cylinders, piping, or ducts. Here, we will differentiate between continuous air monitors, commonly used for health physics purposes, and samples to be examined for chemical composition. One type of gas sampling device features passing a side stream of the bulk gas through a gas burette sufficiently to flush out residual air and then closing both valves, one located at each end, to trap a sample.

A second type of gas sampling device consists of an evacuated cylinder or bulb; once attached to the bulk gas source, the valve is opened, allowing the bulk gas to flow into it. The valve is then closed, the bulb disconnected, and the sample delivered for inspection.

\subsubsection{Records of Sampling}

Material to be examined, characterized, or qualified must be identified as a lot, batch, run, ingot, etc. Inferences as to its characteristics, based on examinations, analyses, tests, or other measurements performed on samples withdrawn from the lot, batch, etc., must be traceable and directly related to it. This is accomplished through detailed accurate sampling records in which the identity of the bulk material lot (batch, ingot, etc.) is assigned an identifying code number, which is recorded in a sample log. Simultaneously, the identifying markings on the sample(s) are also entered in the sample log along with the date, time, run, batch, etc., that are pertinent to the sample.

The sample identifying markings may take the form of a serial number, which is recorded in the sample $10 \mathrm{~g}$ along with its source, etc., thereby establishing its traceability, or it may consist of a code number (an alphanumeric number) which permits identifying its source, the type of material sampled, etc., at a glance without reference to a key or to the sample log. However, the markings in either case must be recorded in the sample $10 \mathrm{~g}$.

The sample log is the primary record of all samples and will include as a minimum the following information:

1. identity of the sample (marking, etc.),

2. identity of the material sampled (batch, tank, ingot, run),

3. date and time of sampling,

4. determinations requested of the analyzer and signature of of the person conducting the sampling operation,

5. measurements that define the size of lot sample.

Other information often included consists of:

1. volume or weight of the sample, 
2. analytical results of interest to operating personnel in process control,

3. disposition of the material sampled,

4. action taken based on results of analyses.

Responsibility - Operating personnel are responsible for maintaining the sample log and entering such information as is required at the time a sample is withdrawn from the system (or process). It is also their responsibility to record such measurements, identifications, and analytical data as are of interest for process control.

Data other than those necessary for process control are acquired by personnel responsible for quality control, who maintain records in the form of tables used to support the quality control program.

\subsubsection{Transportation of Samples}

Samples must be transferred to inspection areas, which may be, and often are, remote from the processing area. It is assumed (and is necessary) that the primary container of the sample is such that no leakage of the contents occurs. Precautions are usually taken for safety reasons to minimize the consequences of leakage from the primary container, should it occur, and to contain contamination present on the exterior of the primary container.

Radiation shields may be requilrèd for samples of radioactive materlal that are to be transported. These may range from small capped lead cylinders (called pigs) for moderately radioactive materials to complex, specially designed, heavily shielded casks for very highly radioactive materials. Such complex casks require detailed procedures for loading, transporting, and unloading.

Once the sample(s) have been prepared for transport, the assembly is inspected for compliance with safety regulations (as to contents, radiation, and external contamination) by health physics personnel; it may be moved to the laboratory where the inspections (analyses) are to be conducted.

The movement of the assembly between the process areas and inspection areas is conducted according to specified procedures which are designed to ensure preservation of the integrity of the sample and the safety of the operation. These may vary from the handling of routine samples according to a standard operating procedure, described in detail in the Operating Procedure Manual, to a special written procedure according to check sheets that were developed specifically for a nonroutine sample. These will always have been extensively reviewed and approved by various groups of specialists charged with responsibility for the safety of the program, personnel, and organization. 


\subsubsection{Replicates}

In order to obtain confidence that the inferences drawn from the inspection of samples withdrawn from bulk material are truly representative, multiple samples, called replicates, are taken. As a result, conclusions can also be drawn from the inspection data as to the homogeneity of the bulk material sampled (and to the necessity for further mixing and resampling), the probability of contamination of one or more of the samples after withdrawal, the precision and accuracy of the measurement, and the probability that the observed data occur within a specified range. As more replicates are examined, the probability increases that the characteristics and composition observed in the samples include the true magnitude of those of the bulk material.

\section{REFERENCES FOR SECTION 8}

1. W. H. Carr et al., Molten Salt Fluoride Volatility Pilot Plant: Recovery of Enriched Uranizon from Alunium Clad Fuel Elements, ORNL-4574 (April 1971).

2. Code of Federal. Regulations, Title 10, Part 71.42.

3. R. J. Jones, Selected Measurement Methods for Plutonium and Uranium in the Nuclear Fuel Cycle, Chap. 3 (1963), Superintendent of Documents, U.S. Government Printing Office, Washington, D.C.

4. J. E. Harrel, Mixing and Sampling Enmiched U-235 Fluids in CyZindrical Storage Container, Y-1561 (Jan. 17, 1967). 


\section{UTILITY SYSTEMS}

The utility systems described in this section are the systems used to supply services such as water, steam, compressed air, and electricity necessary for the operation of the process. The processing plant operator normally has less contact with the auxiliary systems than with the main processing equipment, since much of the auxiliary equipment operates automatically and needs only periodic maintenance and inspection to ensure that it is operating properly. Sometimes special crews are assigned the job of overseeing the operation of the utility equipment. However, since this equipment is important in both the normal and emergency operation of the plant, all process operators should have a basic understanding of the utility systems and how they are related to the main process. Some typical utility systems used in reprocessing plants are described below.

\section{Y.I WAILEK SYS'LEMS}

Water is used extensively in fuel reprocessing plants. Its uses may be grouped into three categories: domestic, plant safety, and plant operations. Domestic uses include water for consumption by personnel and for sanitation. Plant safety requirements include a reliable water supply for fire control systems and safety showers. Many essential plant operations require the use of water as an integral part of their functions, for example:

1. steam generation,

2. direct cooling of compressors, pumps, and other support equipment,

3. indirect cooling of process solutions and gases by condensers and heat exchangers,

4. makeup and adjustment of process solutions, and

5. flushing and rinsing of process lines and vessels.

With few exceptions, raw water is not suitable for any of the uses listed under the three general headings. Natural raw water contains various quantities of both organic and inorganic substances which are present as insoluble particulates, dissolved salts (ions), and dissolved gases. These substances can cause personal illness and can damage equipment, inhibit heat transfer, and contaminate process and product fluids. Consequently, it is imperative that raw water receive adequate treatment (purification) before its use in the reprocessing plant. The treatment (or extent of purification) the water receives depends on its intended use in the plant. 
Water treatment facilities and techniques vary from plant to plant; however, most plants generate only three basic grades of water, namely, process, potable, and demineralized (or deionized). Each of these grades of water is discussed below.

\section{1 .1 Process Water}

Process water is generated by the treatment of raw water. Typical purification steps for process water production are as follows:

1. Raw water is pumped from the source (wells, lakes, or rivers) through a coarse filter, usually a screen, to a central treatment plant.

2. If the concentration of dissolved mineral salts is too high (i.e., if the water is very hard), a lime-soda process (or a variation of this) is used to reduce the calcium, magnesium, and iron concentrations to an acceptable leve1, and the water is passed through a sand filter. When the water does not require treatment for hardness, it is merely passed through a fine filter (usually a cartridge type) to remove particulate contaminants down to a diameter of 0.0002 in.

3. The filtered water is chlorinated by infecting e1ther chlorine gas or a chlorine compound to control organic contaminants.

4. The treated water ie pumped to a central holding tank to aupply the primary. water distribution trunk lines. The holding tank is usually set atop a tower to develop a water pressure head of approximately 50 psig.

In addition to serving as starting water for the potable and demineralized water treatment units, process water is used to supply the fire control system and for direct cooling of equipment such as boiler feedwater pumps, air compressors, hydraulic units, and some condensers and heat exchangers. Generally, the heat absorbed by the process cooling water is dissipated to the atmosphere by means of cooling towers, spray ponds, and/or blower devices. Salt buildup in the cooling tower is prevented by adding a small amount of acid to the cooling water.

\section{1 .2 Potable Water}

Potable water is usually prepared by passing the process water through a second set of filter and cartridges and rechlorinating. Potable water is used almost exclusively for personal consumption and for sanitation purposes. 


\subsubsection{Demineralized (Deionized) Water}

The quality (purity) of water used for many processing operations is a critical factor. Process water is not suitable for such uses as chemical makeup or adjustment of solutions that require high purity, because it contains residual ions and dissolved gases, even after the lime-soda and filtering treatments. The cations (positive ions) present include calcium, magnesium, sodium, and iron, which are in equilibrium with anions (negative ions) such as carbonate, bicarbonate, hydroxyl, sulfate, and chloride. The common dissolved gases are oxygen, carbon dioxide, ammonia, hydrogen sulfide, and chlorine. The presence of these ions and gases in process water leads to contamination of the high-purity water.

To remove these potentially harmful dissolved salts and gases, the water is passed through distillation or ion-exchange equipment coupled with degasification and/or deaeration units. Distilled water is obtained (essentially) by collecting the condensate of boiled process water. Properly operated distillation and deaeration equipment is capable of producing water which contains as little as 0.5-0.7 ppm (parts per million) of residual reactive contaminants. (Note: 0.5-0.7 $\mathrm{ppm}^{1}$ is equivalent to $0.00005-0.00007$ percent.) While the quality of distilled water is good enough for its use as boiler feedwater and process water, economic factors favor the use of ion-exchange units for production of high-purity water in most reprocessing plants.

The basis of the ion-exchange purification technique lies in the unique property of certain materials to preferentially exchange one type of ions for another of like charge. The ion-exchange operation is usually accomplished by passing process water through a vessel (column) packed with one of the special ion-exchange materials. Initially, a natural mineral known as zeolite was used in exchange columns to soften water by replacing the calcium and magnesium ions in the water with sodium ions from the zeolite. When the zeolite no longer functioned satisfactorily, it was regenerated by backflushing the column with a sodium chloride solution, which caused replacement of the calcium and magnesium with sodium. In equation form, these two processes are:

$$
\begin{array}{ll}
\text { softening: } & \mathrm{Na}_{2} \mathrm{Ze}+\mathrm{Ca}^{2+} \rightarrow \mathrm{CaZe}+2 \mathrm{Na}^{+} ; \\
\text {regenerating: } & \mathrm{CaZe}+2 \mathrm{NaCl} \rightarrow \mathrm{CaCl}_{2}+\mathrm{Na}_{2} \mathrm{Ze} .
\end{array}
$$

Both natural and synthetic zeolites are currently used to soften water, but this water is not of sufficient purity to serve as process water since only the calcium and magnesium are removed.

Most reprocessing plants rely on commercially developed demineralizing units for a supply of water for ion exchange, solvent extraction, and spend-fuel storage pools. These demineralizing units employ sophisticated ion-exchange materials, called resins, to deionize the water. Resins are cross-linked polymer networks to which ionized and ionizable 
radicals are appended. There are two basic types of resins, whose names are derived from their functions. Cation-exchange resins replace positively charged ions with hydrogen ions $\left(\mathrm{H}^{+}\right)$, while anion-exchange resins substitute alkali ions (e.g., $\mathrm{OH}^{-}$) for other negatively charged ions in solutions.

A typical procedure for the generation of high-purity water using the resin-bed ion-exchange technique is as follows:

1. Process water is passed through an activated charcoal filter to remove chlorine.

2. The filtered water is fed through a column containing the cation-exchange resin.

3. The acidic effluent is degassed lu remuve free calbun dinxide.

4. The degassed water is passed through a column containing the anion-exchange resin.

Water produced by this procedure is neutral and contains few ionized solids. Its electrical conductivity lies in the range from $10 \times 10^{-6}$ to $50 \times 10^{-5}$ mhos. ${ }^{2}$ (Note: The quality of high-purity water is frequently expressed in terms of its ability to conduct electricity. The conductivity decreases as the water purity increases.) When the water quality drops to a predetermined point, the two ion-exchange resins are regenerated separately. Acid is backflushed through the cation-exchange column, and the anion-exchange column is backwashed with the appropriate alkali solution. The backflushing time necessary to regenerate the ion-exchange columns depends on the quantity and type of resin used and the degree of decontamination desired.

Recently, a modified version of the double-column demineralizer system has come into prominence. The modified system employs a single ionexchange column in which both basic resin types are intimately mixed. The mixed-bed deionizing units offer several advantages over the conventional double-column systems. These advantages include a lower initial cost, reduced process and control problems, and the capability of generating higher quality water.

The procedure for generation of high-purity water using the mixed-bed deionization unit is the same as that for the double-column system except that the degassing operation is performed as the final step, since the ion-exchange column contains both cation and anion resins. Regeneration of a mixed-bed deionizer is usually accomplished by either of two methods. Both methods begin by backflushing the ion-exchange column with water to separate the cation and anion resins. Because of density and/or size differences, the cation resin accumulates in the lower portion of the column, while the anion resin is shifted to the top portion of the resin bed. Depending on the design of the equipment, 
the resins are then regenerated either sequentially or simultaneously. Sequential regeneration is performed by first contacting the anion resin with an alkali solution, which is rinsed through the cation resin below, then treating the cation resin with acid introduced at the bottom of the anion resin bed. Simultaneous regeneration is accomplished by concurrently feeding an alkali solution into the top of the anion resin bed and an acid solution into the bottom of the cation resin bed, and drawing off both effluents at the interface of the two beds. The quality of water produced by mixed-bed deionizing systems lies in the range from $3 \times 10^{-6}$ to $20 \times 10^{-6}$ mhos. The time required for resin-bed regeneration is dependent on whether the operation is performed sequentially or simultaneously and on the factors previously stated for double-column systems.

\section{1 .4 Nuclear Safety Aspects}

To preclude the possibility of releasing radioactively contaminated water to the environment, reprocessing plants rely heavily on the use of closed water systems. Closed systems are normally required when steam or cooling water is separated from radioactive material by only a single barrier (e.g., a vessel wall). The heat absorbed by cooling water in a closed system is dissipated to the atmosphere indirectly via heat exchangers and the utility-water central cooling device (e.g., a cooling tower). The cooled cooling water is then recirculated to the head end of the primary cooling loop. The use of closed systems establishes a double assurance against the accidental release of contaminated cooling water.

\subsection{STEAM}

Steam is used in fuel reprocessing plants to heat buildings and process equipment; for operation of jets for the transfer of process fluids; for the operation of steam-driven turbines to drive pumps, generators, and other equipment; as a fluidizing gas for the operation of fluidizedbed process vessels; and for many other applications. If steam is used to power emergency equipment during an electrical power failure, a highly reliable steam generation system is required.

Steam is normally produced by vaporizing water in a standard commercial boiler unit that burns gas, oil, or other fuels. Condensate from equipment such as heaters is normally collected and pumped back to the steam generator for reuse. Steam used for the operation of jets to transfer process fluids and as fluidizing gas in process vessels and for similar operations cannot be returned to the steam generator; therefore, makeup water must be supplied to the steam generation system. The water used must be pumped and treated to prevent corrosion or scale buildup in the steam generation system. Since steam used in contact with process vessels could become contaminated with radioactive material if a leak developed, special precautions are used to detect any such 
leakage and to confine the radioactivity to a controlled area. The steam condensate from process equipment is usually monitored for radioactivity before it is returned to the steam generator. If a high radiation level is detected, the condensate is diverted to the waste system or to a purification system, and makeup water is added to replace the water that has been diverted. Other methods are also used to reduce the possibility of a release of radioactivity from the process through the steam system. These include keeping the steam pressure higher than the pressure inside process vessels, so that if any leaks developed, steam would leak into the process vessel instead of process fluid leaking into the steam. A separate closed-cycle system is used to supply steam to process vessels at the Midwest Fuel Recovery Plant. 3 In this system, low-pressure steam for the process vessels is produced in a heat exchanger using steam supplied from the plant steam system. The steam condensate from process equipment returns to the heat exchanger. Thus, the steam system used for the process equipment is isolated from the plant steam system.

\section{3 COMPRESSED AIR}

Compressed air is used in fuel processing plants for such purposes as operating jets and air lifts, pulsing extraction colums, fluidizing beds of solid particles, sparging vessels, purging pipe lines, operating pneumatic valves, instruments, and tools, and to provide air for breathing. Since compressed air is normally used for the operation of valves and instruments that control the process, it is important to have compressed air available for use while the process is in operation and also when the system is in standby. Backup systems which can be operated from the emergency power supply are normally provided to supply compressed air in the event of a power failure or failure of the primary compressor.

A typical compressed-air system uses two or more electrically driven compressors. Steam-driven compressors may also be used to provide protection against loss of air in the event of an electric power failure. The air from the compressors is passed through coolers to remove the heat generated during compression and to remove water condensed from the air. Filters and chemical traps are used to remove oil and other impurities from the air. Air accumulation tanks are installed in the air supply lines to smooth out surges and to store enough air to supply the system needs for a short time in the event a malfunction develops.

Pneumatic instruments and certain other applications in the process (such as purges in the uranium hexafluoride system) require dry air for proper operation. The air supply for these applications may be further dried by passing it through beds of silica gel or molecular sieves. These beds must be periodically regenerated. This is accomplished by heating the beds while they are being purged with air to remove the moisture. Two beds are used so that one unit can be kept in service while the other is being regenerated. 


\subsection{VACUUM}

Vacuum is used in fuel processing plants for transferring solutions, removing air or other noncondensable gases from process vessels, withdrawing samples from the process, maintaining a negative pressure in process vessels, and many other applications.

Jets and rotary vacuum pumps (described in Section 7.12) are commonly used to provide vacuum. Separate jets or pumps are of ten provided for each individual operation instead of using a centralized system. When rotary vacuum pumps are used, it may be necessary to install chemical traps and filters ahead of the vacuum pumps to protect the pumps from corrosive or radioactive material. The process technician should be familiar with the specific vacuum system in use in the plant where he is employed.

\subsection{ELECTRICAL SYSTEMS}

The main electrical system for operating motors, heaters, instruments, lighting, and other electrical equipment is normally supplied by highvoltage transmission lines that extend from commercial power generation stations. At the plant site, transformers are used to reduce the voltage to a value suitable for operation of the equipment. For example, the voltage may be initially reduced to 440 Volts for distribution throughout the plant. Additional transformers may be connected to the 440-V distribution system to provide $220-\mathrm{V}$ and $110-\mathrm{V}$ systems. Switchgear is provided for turning circuits on and off and for protecting circuits against overload. Switchgear is provided for the main distribution circuits, as well as for circuits that supply power to the individual pieces of equipment. It is important that operating personnel be familiar with the electrical distribution system and location of the switchgear.

For safety reasons it is necessary for certain equipment to be kept in operation at all times. Emergency power must be provided to such equipment for use in the event of failure of the normal power supply. A typical emergency electrical system consists of a diesel-powered generator that is automatically started by batteries if a failure of the normal power supply occurs. Steam-driven generators or steam-turbine drives for fans, pumps, and other equipment units may also be used to provide emergency power. Batteries are often used to provide emergency power for small equipment. It is usually not practical to provide emergency power for all the equipment necessary for the operation of the plant; therefore only essential equipment such as ventilation fans, off-gas blowers, process instrumentation, electrically operated solenoid valves, lights, radiation monitoring equipment, and other equipment necessary to maintain the plant in a safe standby condition is provided with emergency power. If a power failure occurs, it may be necessary to manually switch some equipment to emergency power and to make sure that other equipment has started automatically on emergency power. 


$$
9-8
$$

Standard procedures are normally provided for use in putting the plant in standby condition in the event of a power failure and also for returning the plant to normal operation after power has been restored.

\subsection{COMMUNICATIONS SYSTEMS}

It is important that operating personnel be familiar with the communications systems used. The communication system includes not only the intercom and telephone systems used for communicating between individuals but also the emergency systems such as evacuation alarms, fire alarms, emergency public address system, and other systems used to warn personnel of impending danger. Operating personnel should know how to make use of the systems and the action to be taken if an emergency alarn is sounded.

REFERENCES FOR SECTION 9

1. R. M. E. Diamant, Applied Chemistry for Engineers, Pitman Publishing Corporation, New York, N.Y., 1972.

2. ASTM Committee D-19 on Water, Manual on Water, American Society for Testing and Materials, Philadelphia, Pa., 1969.

3. General Electric Company, Design and Analysis, Midwest Fuel Recovery Plant, Docket 50 268, 1966. 
ORNL/TM- 5324

(Second Volume of ORNL/TM-5323)

INTERNAL DISTRIBUTION

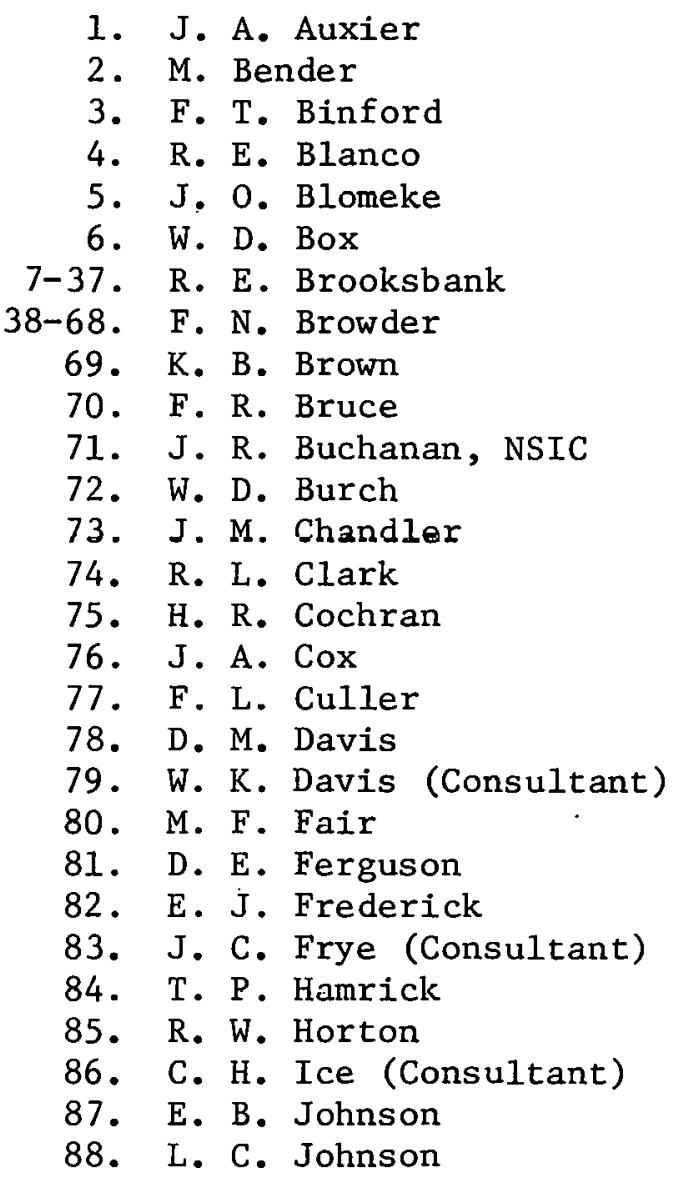

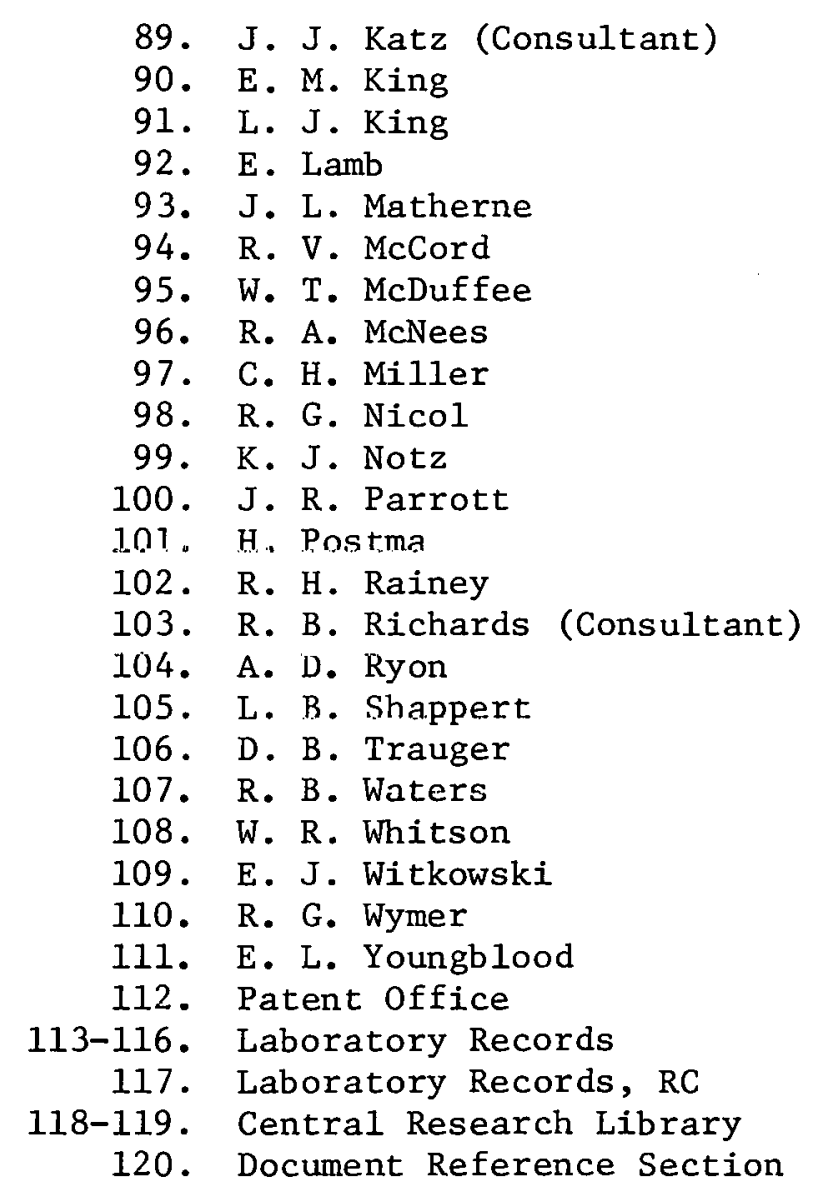

EXTERNAL DISTRIBUTION

U.S. Energy Research and Development Administration, Washington, D.C. 20545

121. Assistant Administrator for Environment and Safety

122-141. Division of Operational Safety, Attention: Chief, Process Facilities Safety Branch

142-143. Nuclear Fuel Cycle and Production Division

144. Division of Reactor Research and Development, Attention: Fuel Reprocessing Branch

145. Library at 20 Mass. Ave., D.C.

146. Library at Germantown, MD

147. E. K. Loop, Division of Operational Safety, Process Facilities Safety Branch

148. B. P. Brown, Division of Operational Safety, Overview Staff

149. E. J. Vallario, Division of Operational Safecy, Standards Group 
150-176. ERDA; Technical Information Center, Oak Ridge, TN 37830

ERDA, Albuquerque Operations Office, P.0. Box 5400, Albuquerque, NM 87115

177. J. R. Roeder, Director of Operational Safety Division

178. J. F. Burke, Assistant Manager, Office of Operations

179. Los Alamos Area Office, Attention: Chief, Technical Programs Branch

ERDA, Chicago Operations Office, 9800 South Cass Ave., Argonne, IL 60439

180. A. E. Mravea, Director, Reactor Programs Division

181. R. M. Moser, Director, Safety Division

ERDA, Idaho Operations Office, 550 Second St., Idaho Falls, ID 83401

182-183. K. K. Kennedy, Director, Production and Materials Division

184. R. J. Beers, Director, Operational Safety Division

ERDA, Oak Ridge Operations Office, P.0. Box E, Oak Ridge, TN 37830

185. Rescarch and Technical Support Division

186-188. R. L. Egli, Director, Reactor Division

189. W. H. Travis, Director, Safety and Environmental Control Division

ERDA, Richland Operations office, P.O. Box 550, Richland, WA 99352

190. R. L. Ferguson, Director, FFTF Program Office

191. 0. J. Elgert, Director, Office of Assistant Manager for Programs

192. Director, Safety Division

ERDA, San Francisco Operations Office, 1333 Broadway, Wells Fargo Bldg., Oakland, CA 94612

193. R. L. Westbÿ, Director, Safety and Nuclear Materials Division

194. Robert DeWitt, Assistant Virector, Uffice of Program Coordination and Management

195-196. J. Radcliffe, Program Coordinator, P.M.R.S., Box 81325, San Diego, CA 92138

ERDA, Savannah River Operations Office, P.0. Box A, Aiken, SC 29810

19/. W. D. Sandberg, Direclui, Techinical Productlon Division

198-199. W. A. Reese, Director, Safety and Environmental Division

U.S. Nuclear Regulatory Commission, Washington, DC 20555

office of Administration

200. Library, Attention: R. E. Devine

Office of Standards Development

201. C. M. Nilsen

202. R. E. L. Stanford 
Office of Nuclear Material Safety and Safeguards

203. Lawrence F. Wirfs, Chief, Material Control Licensing Branch, SG

204. L. C. Rouse, Acting Assistant Director, Fuel Safety and Licensing Branch, FCMS

205. Robert M. Bernero, Chief, Fuel Reprocessing and Recycle Branch, FCMS

206. A. T. Clark, Fuel Reprocessing and Recycle Branch, FCMS

207. R. B. Chitwood, Chief, Facility Environmental Assessment Branch, FCMS

208. W. T. Crow, Acting Chief, Fuel Processing and Fabrication Branch, FCMS

Office of Inspection and Enforcement

209. G. H. Bidinger

U.S. NRC, Chief, Fuel Facility and Material Safety Branch

210. Region I, 631 Park Ave., King of Prussia, PA 19406

211. Region II, 230 Peachtree St., N.W., Suite 818, Atlanta, GA 30303

212. Region III, 799 Roosevelt Rd., Glen Ellyn, IL 60137

213. Region IV, 611 Ryan Plaza Dr., Suite 1000, Arlington, TX 76012

214. Region V, 1990 N. California Blvd., Suite 202, Walnut Creek, CA 94596

Allied Chemical Corp., Idaho Chemical Programs-Operations Office, 550 Second Street, Idaho Falls, ID 83401

215. G. F. Offutt, Fuel Processing, C.P.P. Production

216. L. G. Pearson, Training Group, Operational and Environmental Safety

Los Alamos Scientific Lab., P.0. Box 1663, Los Alamos, NM 87545

217. R. D. Baker, C.M.B. Division

218. R. J. Bard, C.M.B. -8 Division

219. W. J. Maraman, C.M.B.-8 Division

220. Roy Reider, Safety Director

221. Don Rose

Atlantic Richfield Hanford Co., P.0. Box 250, Richland, WA 99352

222. George Burton, Jr., Vice President, Research and Engineering

223. J. E. Seeds, Manager, Training and Development Department

224. C. W. Malody, Manager, Production and Waste Processing Department

Argonne National Lab., 900 South Cass Ave., Chicago, IL 60439

225. M. J. Steindler, Section Head, Fuel Reprocessing, Chemical Engineering Division

226. D. S. Webster, Deputy Director, Chemical Engineering Division

227. Brian R. Frost, Director, Materials Science Division

228. H. J. Moe, Occupational Health and Safety 
Allied General Nuclear Services (AGNS), P.0. Box 847, Barnwell, SC 29812

229-230. A. L. Ayers, Director, Plant Support Division

231-232. P. E. Ebel, Supervisor of Training Programs

233. R. I. Newman, Vice President for Environmental Affairs

234. W. H. Carr, Licensing Engineer for Environmental Affairs

Nuclear Fuel Services, Inc. (NFS)

235. B. E. Knight, Production Manager, Box 124, West Valley, NY 14171

236. J. P. Duckworth, Waste Systems Project Manager, Box 124, West Valley, NY 14171

237. W. H. Lewis, Vice President, Engineering and Construction, 6000 Executive Blvd., Suite 600, Rockville, MD 20852

238. J. R. Clark, Manager Licensing, 6000 Executive Blvd., Sulte B̃oO, Rockville, MD 20852

General Electric Co., Morris, IL 60409

239. Charles Dietz, Manager, BWR Training Center, Rt. 1, Box 220

240. E. E. Voiland, Manager, Morris Operation, Rt. 1, Box 219B

Exxon Nuclear Co., Inc.

241. S. J. Beard, Manager Reprocessing Engineering, 777-106th Ave., N.E. C-0077, Bellevue, WA 98004

242. H. C. Rathvon, Manager Mechanical Division Engineering, 777-106th Ave., N.E. C-0077, Bellevue, WA 98004

243. S. G. Smolen, Manager Reprocessing Plant Operations, c/o Bechte1, Inc. (525/23), P.0. Box 3965, San Francisco, CA 94119

244. G. L. Ritter, Manager Reprocessing Process Engineering, Research and Technology Center, 2955 Geo. Wash. Way, Rich1and, WA 99352

E. I. duPont de Nemours \& Co., Savannah River Plant, Aiken, SC 29801

245-254. S. W. O'Rear, Technical Information Service

255-256. A. J. Hill, Separations Engineering Division

257. E. I. duPont de Nemours and Co., Attention: Document Custodian, ERDA Division, Wilmington, DE 19898

Rockwell International, Atomics International Division, Rocky Flats

Plant, P.0. Box 464, Golden, CO 80401

258. E. Vejvoda, Director, Chemical Operations

259. R. E. Hoppe, Jr., Manager of Training

260. S. E. Hagum, Training Division

261. C. O. Reiser, Arizona State University, Tempe, AZ 85281

262. Forrest J. Remich, Nuclear Engineering Department, Pennsylvania State University, State College, PA 16201

263. Marion C. Boyd, Jr., Nuclear Technology Department, Tri-County Technical College, P.0. Box 87, Pendleton, SC 29670 
264. William I. Fox, Nuclear Engineering Technology Department, Trident Technical College, 7000 Rivers Ave., N. Charleston, SC 29405

265. Brian K. Hajek, Nuclear Reactor Laboratory, Ohio State University; 1298 Kinnear Rd., Columbus, OH 43212

266. Robert J. Brown, Texas State Technical Institute, 401 Richland Dr., Waco, TX 76710

267. Tek Chand, Administrator, Aiken Technical Education Center, 908 McKenzie Dr., N. Augusta, SC 29841

268. Robert J. Neel, Midlands Technical College, 316 Beltline Blvd., Columbia, SC 29250

269. Ra1ph K. Wahlen, N Plant Training Manager, United Nuclear Industries, P.0. Box 490, Richland, WA 99352

270. S. Harkness, Dept. 466-5, Nuclear Power Systems, Combustion Engineering Co., Windsor, CT 06095

271. Wayne Niemuth, Exxon Nuclear Co., Richland, WA 99352

272. Grant La Pier, Nuclear Materials Division, Babcock \& Wilcox Co., 609 N. Warren Ave., Apollo, PA 15613

273. S. Seshadri, M/C 682, General Electric Co., 175 Curtner Ave., San Jose, CA 95152

274. G. R. Kilp, Manager, Materials Design, Westinghouse Electric Corp., Power Systems, Nuclear Fuel Division, Box 355, Pittsburgh, PA 15230

275. Division Head, Technical Information Division, Brookhaven National Laboratory, Upton, NY 11973 